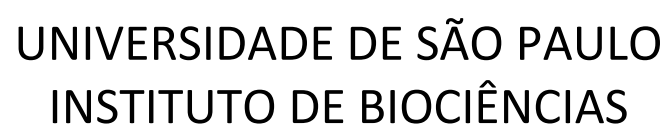

NATALIA DA MATA LUCHETTI

Diversidade, taxonomia e especificidade de solitárias (Platyhelminthes: Cestoda) parasitas de papaformigas (Aves: Passeriformes: Thamnophilidae) no sul da Amazônia brasileira

\begin{abstract}
Diversity, taxonomy and specificity of tapeworms (Platyhelminthes: Cestoda) inhabiting antbirds (Aves: Passeriformes: Thamnophilidae) in southern Brazilian Amazon
\end{abstract}




\title{
Diversidade, taxonomia e especificidade de solitárias (Platyhelminthes: Cestoda) parasitas de papa-formigas (Aves: Passeriformes: Thamnophilidae) no sul da Amazônia brasileira
}

\begin{abstract}
Diversity, taxonomy and specificity of tapeworms (Platyhelminthes: Cestoda) inhabiting antbirds (Aves: Passeriformes: Thamnophilidae) in southern Brazilian Amazon
\end{abstract}

\author{
Tese apresentada ao Instituto de \\ Biociências da Universidade de São \\ Paulo para obtenção do título de \\ Doutora em Ciências Biológicas \\ Área de Concentração: Zoologia \\ Orientador: Prof. Dr. Luís Fábio \\ Silveira
}

São Paulo 
Autorizo a reprodução e divulgação total ou parcial deste trabalho, por qualquer meio convencional ou eletrônico, para fins de estudo e pesquisa, desde que citada a fonte.

Luchetti, Natalia da Mata.

Diversidade, taxonomia e especificidade de solitárias (Platyhelminthes: Cestoda) parasitas de papa-formigas (Aves: Passeriformes: Thamnophilidae) no sul da Amazônia brasileira / Natalia da Mata Luchetti; orientador Luís Fábio Silveira. - São Paulo, 2017.

$234 \mathrm{fls}$

Tese (Doutorado) - Universidade de São Paulo, 2017

Palavras chave: 1. Eucestoda. 2. Cyclophyllidea. 3. Impedimento taxonômico. 4. Relação parasita-hospedeiro. 
LUCHETTI, N. M. Diversidade, taxonomia e especificidade de solitárias (Platyhelminthes: Cestoda) parasitas de papa-formigas (Aves: Passeriformes: Thamnophilidae) no sul da Amazônia brasileira. Tese apresentada ao Instituto de Biociências da Universidade de São Paulo para obtenção do título de Doutora em Ciências Biológicas, área de concentração Zoologia.

Aprovado em:

Banca examinadora

Prof. Dr.

Instituição:

Julgamento:

Assinatura:

Prof. Dr.

Instituição

Julgamento:

Assinatura:

Prof. Dr.

Instituição:

Julgamento:

Assinatura:
Prof. Dr.

Instituição:

Julgamento:

Assinatura:

Prof. Dr

Instituição:

Julgamento:

Assinatura: 


\section{AGRADECIMENTOS}

Ao meu orientador, Dr. Luís Fábio Silveira, por seu apoio e orientação nos cinco anos de elaboração e execução deste doutorado. A confiança depositada em mim para desenvolver um projeto que não estava integrado em sua linha de pesquisa e no qual ele era ciente de sua limitação para me auxiliar nunca poderá ser expressa em palavras. Sou enormemente grata sua acolhida e sua amizade, pelo incentivo quando nos deparamos com contratempos, por construir este trabalho junto comigo e por compreender em diversos momentos minhas dificuldades em ser uma helmintóloga iniciante em ornitologia. Foi, e sempre será, uma honra ser sua aluna.

Ao meu co-orientador, Dr. Boyko Georgiev, da Academia de Ciências da Bulgária, pela generosidade em compartilhar o seu conhecimento sobre cestódeos de aves comigo, quase sempre à distância, pela disposição em vir ao Brasil e me mostrar como proceder em campo e por responder muitas dúvidas. Seu auxílio foi imprescindível na compreensão do material coletado neste trabalho e seu entusiasmo e interesse em dar continuidade ao que começamos a construir neste projeto é um enorme incentivo para levarmos essa pesquisa adiante. Благодаря.

Ao Programa de Pós-Graduação do Departamento de Zoologia do Instituto de Biociências pelo suporte recebido para o desenvolvimento deste projeto e participações em eventos científicos.

À Coordenação de Aperfeiçoamento de Pessoal de Nível Superior (CAPES) pela concessão da bolsa de estudos para o desenvolvimento deste projeto.

A todos os biólogos que me auxiliaram no trabalho de campo para a coleta das aves, pois ao longo de três anos e durante treze campanhas, muitas pessoas estiveram presentes nas viagens para amostragem de cestódeos, aprendendo sobre estes parasitas e me ensinando sobre as aves. A experiência de muitos foi enormemente importante para o sucesso deste trabalho. Agradeço pelos ensinamentos e companhia a Alan Cerqueira, André Grassi, Ariane Gouvea, Bianca Matinata, Bruno Rennó, Carlos Garske, Caroline Nascimento, Cláudio Nucitelli, Cristiane Apolinário, Denise Martins, Diego Evangelista, Dorinny Lisboa, Elinete Batista, Elivânia Reis, Érika Machado, Estela Brandi, Fábio Schunck, Felipe Arantes, Fernanda Bocalini, Fernando Flores, Gabriela Decker, Gláucia Del-Rio, Glauko Correa, 
Gregório Menezes, Gustavo Bravo, Ivã Barbosa, Jeremy Dickens, José Jacomelli, Karlla Barbosa, Kleber Rodrigues, Leonardo Miranda, Marcel Lemos, Marcelo Barbosa, Marcelo Barreiros, Marcelo Félix, Marina Somenzari, Nina Marcondes, Paulo Oliveira Jr., Rafael Marcondes, Rebeca Funke, Samuel Oliveira, Sergio Bolívar, Silvia Carvalho, Vitor Piacentini e Vitor Torga.

Aos auxiliares de campo em todas as amostragens em Rondônia e no Pará que acompanharam o meu trabalho de campo. Não é possível listar todos que estiveram presentes em tantas campanhas, mas alguns serão sempre lembrados por toda a ajuda recebida.

À Sandra Favorito, pelo auxílio e logística nas viagens a Porto Velho (RO) e Altamira (PA).

À Adriana Akemi pelo apoio e logística na viagem a Machadinho d'Oeste (RO).

Ao Wilson Lemos de Morais Neto da Agropecuária Fartura pelo apoio e logística nas viagens a Santana do Araguaia (PA).

Aos Dr. Jean Mariaux e Dra. Anna Phillips pelo auxílio na primeira viagem de coleta de aves na qual participei e aprendi os procedimentos de coleta de helmintos e por estarem sempre dispostos a discutir sobre os cestódeos de aves e colaborar com o andamento da minha pesquisa.

Ao Dr. Fernando Marques, do Laboratório de Helmintologia Evolutiva IB/USP, pela generosidade em permitir que eu utilizasse as instalações de seu laboratório no desenvolvimento de meu doutorado e por intermediar o primeiro contato com meu coorientador. Agradeço também pelas discussões sobre cestódeos sempre que possível.

Aos Dr. Gustavo Bravo, Dr. Miguel Rodrigues e Dr. Silvio Nihei pela participação em meu exame de qualificação para o doutorado, com valiosos conselhos para o aprimoramento de meu projeto.

Aos técnicos do Laboratório de Histologia do Departamento de Zoologia IB/USP Ênio Mattos e Phillip Lenktaitis pelo auxílio para obtenção dos dados de Microscopia Eletrônica de Varredura e pela amizade durante todos estes anos.

Aos secretários da Seção de Pós-Graduação do IB/USP, Érika Takamoto, Gilmar Neves, Lilian Parpinelli e Patrícia Almeida, por todo o apoio nestes mais de 5 anos de convivência. As secretárias do Departamento de Zoologia IB/USP, Franciany Dias e Maria Lúcia Vieira, pelo auxílio em diversos momentos burocráticos. 
Aos colegas da Seção de Aves do MZUSP, pela acolhida a uma "estranha no ninho" e apoio em todos os momentos que lá estive. São muitas as pessoas com as quais convivi, mas o carinho é especial à Anna Ferraroni, Bianca Matinata, Diego Evangelista, Fernanda Bocalini, Gustavo Bravo, Marcelo Félix, Patrícia Mancini, Rafael Marcondes, Sérgio Bolívar e Vagner Cavarzere. Agradeço também à Marina Lima, do Laboratório de Taxidermia do MZUSP, por sua constante gentileza e atenção em sanar as minhas dúvidas para não inviabilizar os espécimes que dissequei em campo.

Aos colegas do Laboratório Helmintologia Evolutiva IB/USP, pela companhia, Bruna Trevisan, Juliana Primon, Murillo Rodrigues, Yuri Golfetti.

Ao meu irmão Ricardo, minha cunhada Katy e meu sobrinho Hector, pelo apoio incondicional e palavras de carinho e incentivo sempre que o caminho pareceu difícil, mesmo com a distância física entre nós.

Aos meus tios Cecília, Norma e Agnaldo, pelo suporte e acolhida em todas as horas, compreendendo há anos meu interesse em biologia e as escolhas que fiz por ele. À minha mãe Ana e minha irmã Daniela, pelo apoio no início deste projeto.

Aos amigos que participaram desta jornada, seja desde o início ou os que surgiram durante o caminho, meu mais sincero obrigada. André Nishikawa, Bianca Matinata, Bruna Locardi, Camila Martin, Camila Mini, Carla Machado, Hingrid Yara, Júlia Pereira, Marina Somenzari, Patrícia Mancini, Verônica Bueno, Vivian Altebarmakian. Em especial à Bruna e Carla, pela acolhida excepcional em sua casa em um momento em que as soluções eram poucas para tantas questões.

A todos que contribuíram com minha formação acadêmica, permitindo que eu alcançasse um objetivo que parecia tão distante há 13 anos, quando entrei pela primeira vez em um laboratório para "fazer pesquisa". Muito obrigada. 
"Já acabou a época dos estudiosos de gabinete, que aí ficavam esperando que lhes fosse levado o material, bem ou mal colhido, para ser estudado. Em helmintologia, como em qualquer outro ramo da zoologia, o pesquisador tem que ir ao campo e observar, em seu meio natural, o material de estudo."

Lauro Travassos

Introdução ao Estudo da Helmintologia, 1950 


\section{RESUMO}

LUCHETTI, N. M. Diversidade, taxonomia e especificidade de solitárias (Platyhelminthes: Cestoda) parasitas de papa-formigas (Aves: Passeriformes: Thamnophilidae) no sul da Amazônia brasileira. 2017. 234 f. Tese (Doutorado). Instituto de Biociências, Universidade de São Paulo, 2017.

O conhecimento sobre cestódeos parasitas de aves na região Neotropical é bastante escasso, sendo baseado em materiais coletados nos séculos XVII e XVIII. No Brasil, a diversidade reportada para estes helmintos é baixa e não é compatível com a grande diversidade de aves registrada no país. Buscou-se inventariar a riqueza e a diversidade de cestódeos parasitas de aves da família Thamnophilidae no sul da região Amazônica brasileira, nos seus principais interflúvios e centros de endemismo, afim de caracterizar a fauna de cestódeos e verificar sua distribuição em relação à observada para os hospedeiros. Ao todo foram amostrados 487 tamnofilídeos pertencentes a 81 táxons, distribuídos nos principais interflúvios e centros de endemismo ao sul da Amazônia brasileira, no levantamento mais extenso do ponto de vista geográfico e temporal já realizado para Aves na América do Sul. As técnicas tradicionais de coleta e amostragem de cestódeos foram aperfeiçoadas levando-se em conta as especificidades de clima e logística características da região amazônica, resultando na coleta de aproximadamente 1.500 indivíduos de cestódeos das famílias Dilepididae, Hymenolepididae, Paruterinidae e Metadilepididae, pertencentes à Ordem Cyclophyllidea. Os parasitas encontrados podem representar 83 novas espécies, além de novos gêneros em todas as famílias de cestódeos amostradas. As chaves de identificação disponíveis para estes grupos não são suficientes para permitir a identificação dos táxons encontrados parasitando os Thamnophilidae. A consideração da especificidade parasita-hospedeiro para a identificação dos helmintos obtidos é um impedimento no refino taxonômico para este grupo, pois não há cestódeos descritos formalmente parasitando a família Thamnophilidae e é necessária uma ampla revisão das chaves de identificação disponíveis. A técnica de Microscopia Eletrônica de Varredura foi utilizada pela primeira vez para caracterizar os táxons da família Dilepididae, mostrando-se informativa na distinção dos morfotipos. A relação de especificidade parasita-hospedeiro não foi verificada na maioria dos casos, sendo o mais frequente uma relação ecológica entre hábitos alimentares dos hospedeiros e as diferentes famílias de parasitas. Verificou-se que os grandes rios amazônicos não atuam como barreiras para os parasitas, sendo encontrados os mesmos morfotipos em táxons de aves distintos e separados pelos rios. A influência das relações ecológicas entre os hospedeiros parece ser um fator mais relevante na distribuição dos parasitas, pois diferentes populações de aves em um mesmo interflúvio apresentaram uma comunidade de cestódeos distinta. A diversidade de cestódeos ainda é extremamente subestimada na região Neotropical, e este impedimento taxonômico dificulta a realização de análises mais aprofundadas, sendo fundamental que a taxonomia esteja mais bem resolvida para os membros desta Classe. Este estudo foi pioneiro na caracterização dos cestódeos parasitas de Thamnophilidae e abre uma nova e promissora linha de pesquisa nesta área em nada explorada. 


\begin{abstract}
LUCHETTI, N. M. Diversity, taxonomy and specificity of tapeworms (Platyhelminthes: Cestoda) inhabiting antbirds (Aves: Passeriformes: Thamnophilidae) in southern Brazilian Amazon. 2017. 234 f. Tese (Doutorado). Instituto de Biociências, Universidade de São Paulo, 2017.

The information about tapeworms inhabiting Neotropical birds is scarce, based on samples collected from XVII and XVIII centuries. In Brazil, these helminths diversity is low and not consistent with the high birds diversity. In this study, we examined the abundance and diversity of tapeworms inhabiting antbirds of family Thamnophilidae in southern Brazilian Amazon, in areas of endemism between the major rivers, to report the tapeworm fauna and its distribution regarding the hosts distribution. As result, we sampled 487 antbirds of 81 taxa, along the major interfluvial areas and areas of endemism is southern Brazilian Amazon, in the more extensive survey of parasites in South American birds. The traditional protocols for sampling cestodes were improved based on climate conditions and organization of Amazon area, resulting in a sample about to 1500 Cyclophyllidean cestodes belonging to families Dilepididae, Hymenolepididae, Paruterinidae e Metadilepididae. The specimens collected may represent 83 new species, besides new genera for all the families. The keys for Cyclophyllideans tapeworms are not useful for Thamnophilidae parasites, demanding revision for considering the host-parasite specificity and no parasites described inhabiting antbirds. For the first time Scanning Electronic Microscopy is used to discriminate Dilepididae species successfully. The host-parasite specificity for Thamnophilidean tapeworms is low and the parasite diversity is more influenced by the host foraging habits. The major Amazonic rivers are not physiographic barriers for cestodes distribution and the same parasites morphotype were reported in different host from both sides of a river. The ecological relationships between the hosts in a same area can influence their parasite diversity, with distinct birds populations in the same area parasited by different cestodes. The Neotropical tapeworm diversity is underestimated and this interferes in broader studies for host-parasites relationships, demanding taxonomic revision for these parasites class. This is the first survey for Thamnophilidae tapeworms and suggests a new and promising unknown line of research.
\end{abstract}




\section{SUMÁRIO}

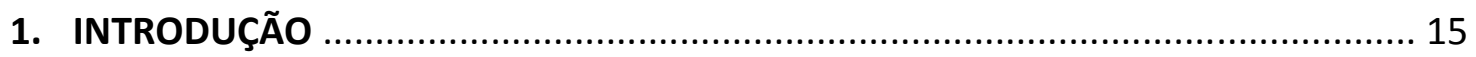

1.1 Histórico dos estudos de cestódeos parasitas de aves ........................................... 16

1.2 Histórico e estado da arte dos estudos de cestódeos de aves no Brasil .................... 21

1.3 Diversidade de cestódeos em aves ...................................................................... 25

1.4 Hospedeiros: família Thamnophilidae (Passeriformes) …………………………...... 31

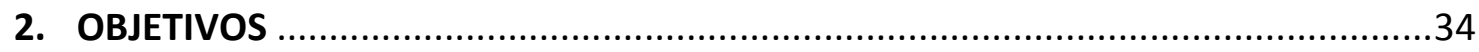

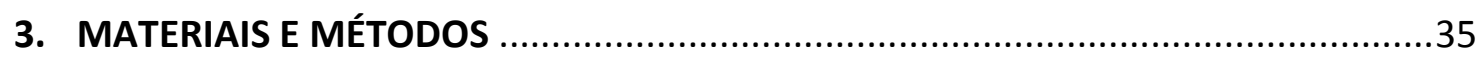

3.1 Amostragem e coleta dos hospedeiros ………………..........................................35

3.2 Processamento do material biológico em campo .......................................................36

3.3 Processamento do material biológico em laboratório ..................................................36

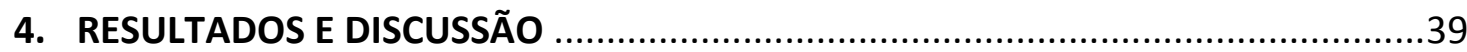

4.1 Processamento do material biológico em campo ………………………………......39

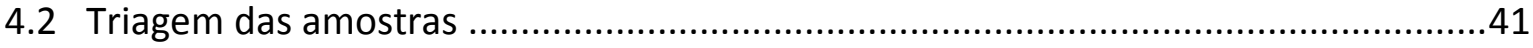

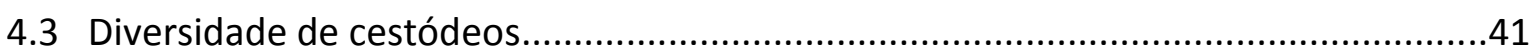

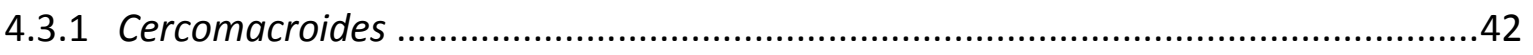

4.3.1.1 Cercomacroides nigrecens ochrogyna ..............................................................42

4.3.1.2 Cercomacroides serva hypomelaena .................................................................43

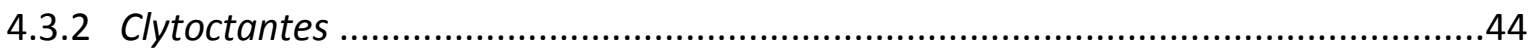

4.3.2.1 Clytoctantes atrogularis ...................................................................................

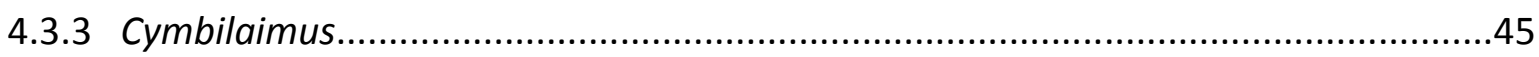

4.3.3.1 Cymbilaimus lineatus intermedius ..............................................................45

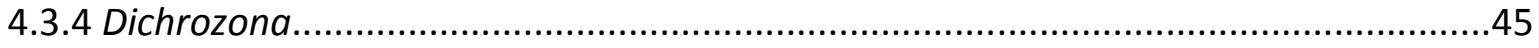

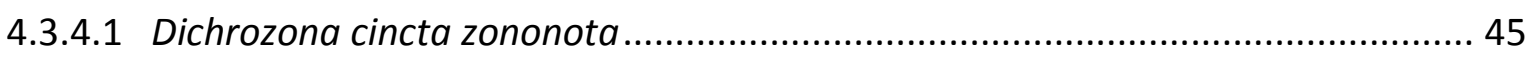

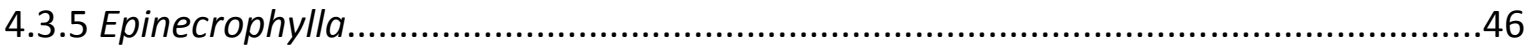

4.3.5.1 Epinecrophylla amazonica...........................................................................46

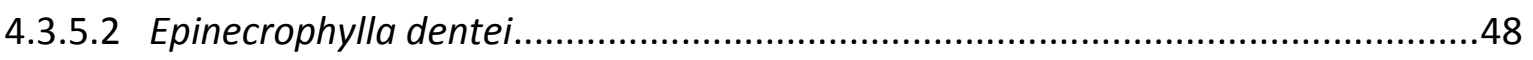

4.3.5.3 Epinecrophylla leucophtalma leucophtalma...................................................50 


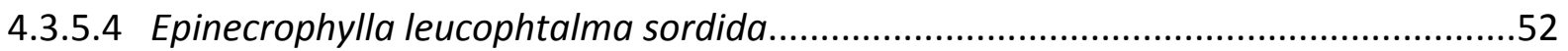

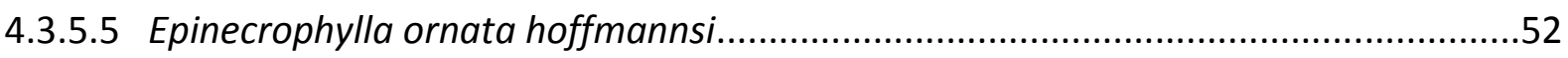

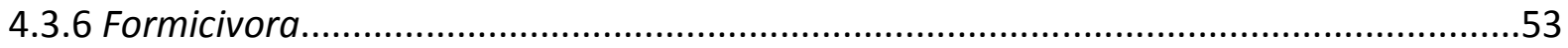

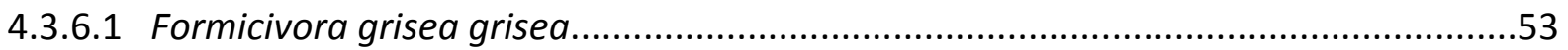

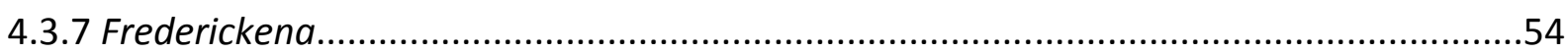

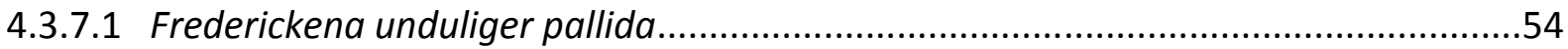

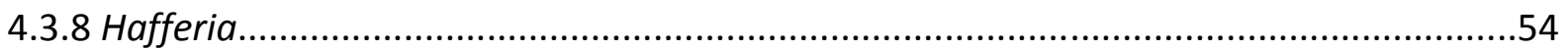

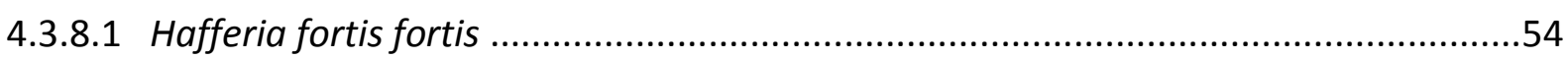

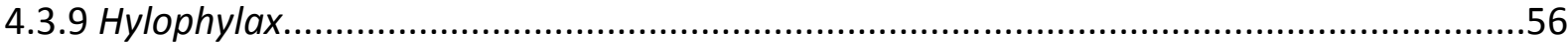

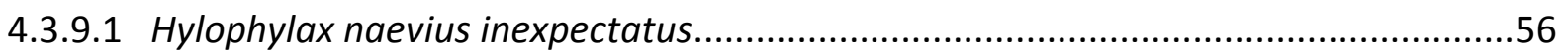

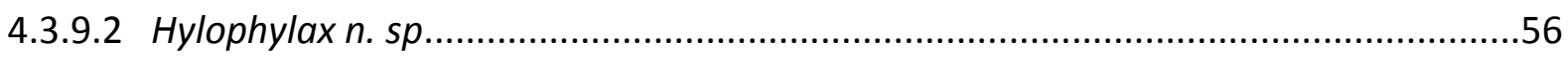

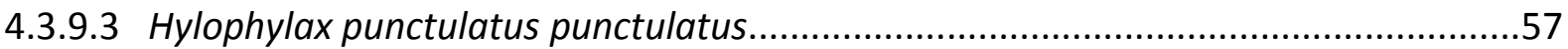

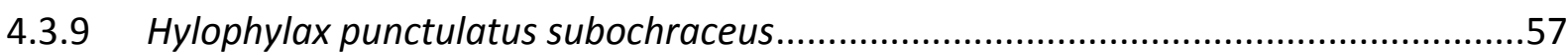

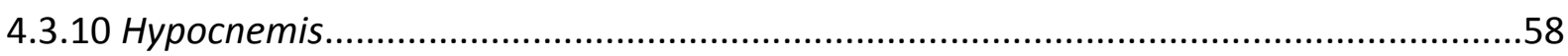

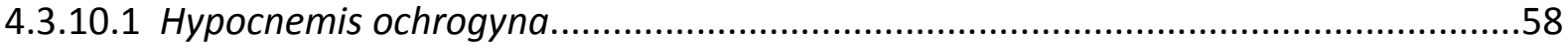

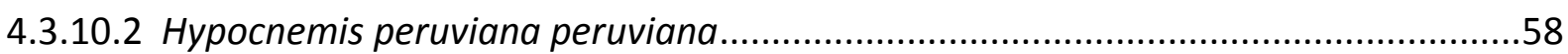

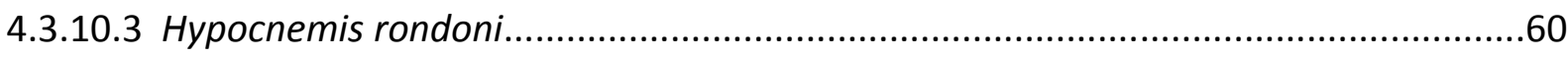

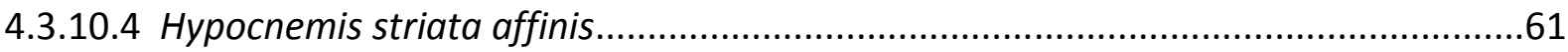

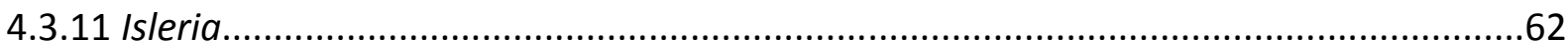

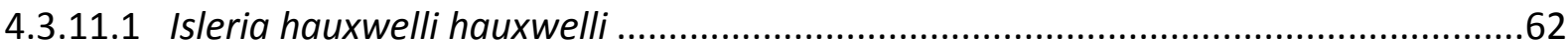

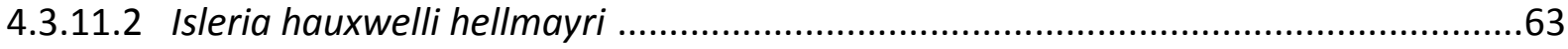

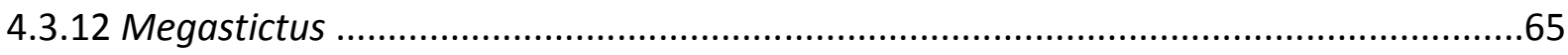

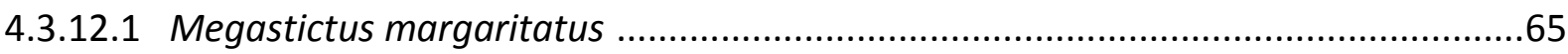

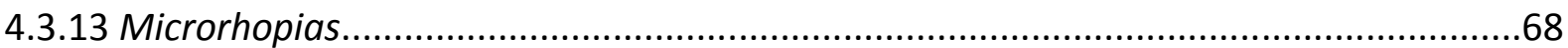

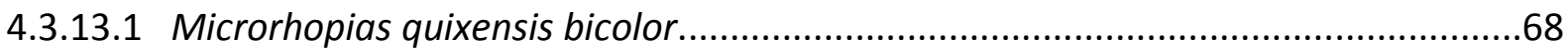

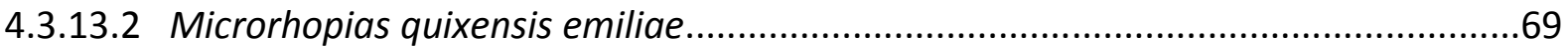

4.3.13.3 Microrhopias quixensis intercedens....................................................................70

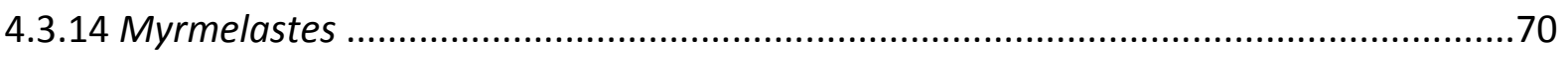

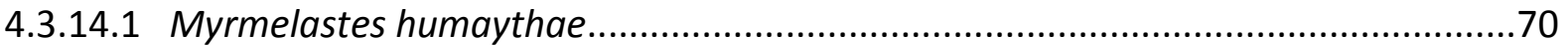

4.3.14.2 Myrmelastes rufifacies ....................................................................................

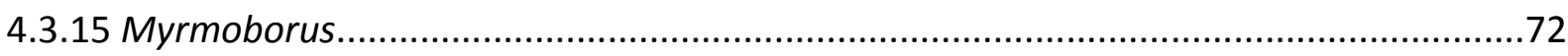

4.3.15.1 Myrmoborus leucophrys leucophrys..................................................................72 


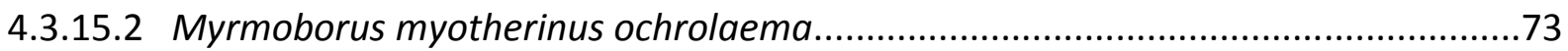

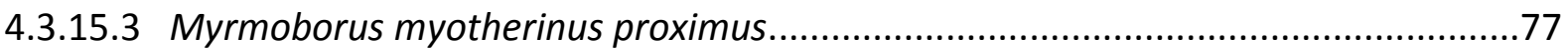

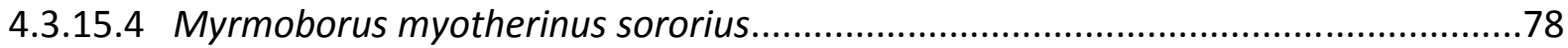

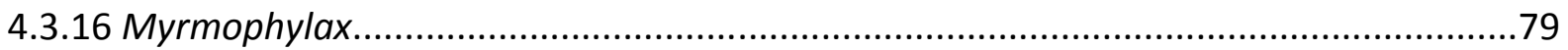

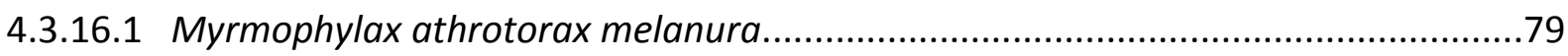

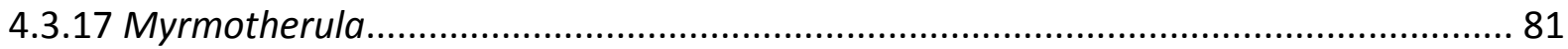

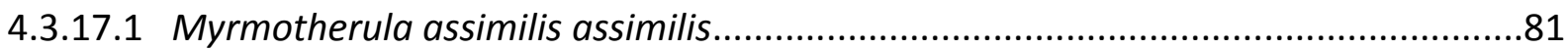

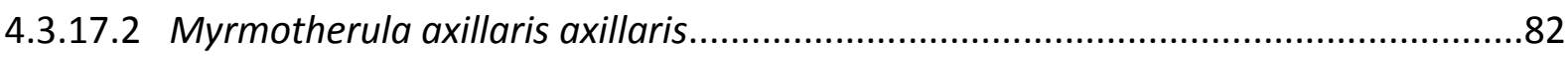

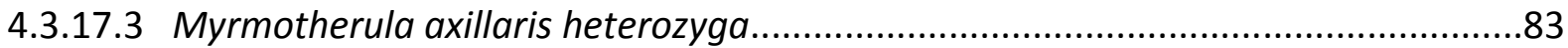

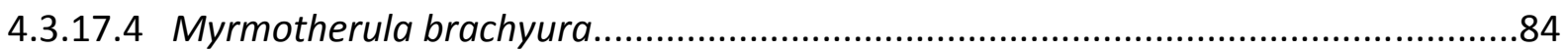

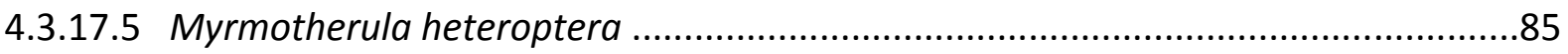

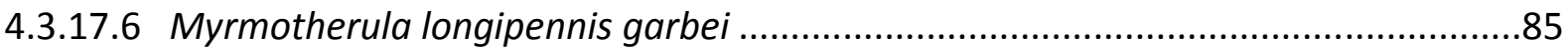

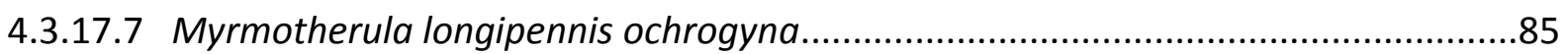

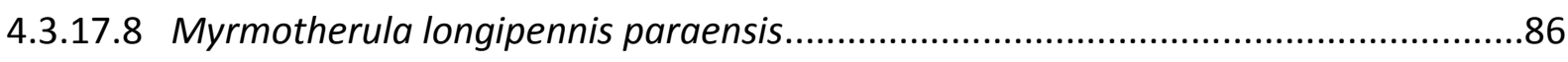

4.3.17.9 Myrmotherula menetriesii menetriesii....................................................................86

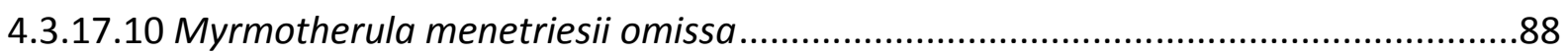

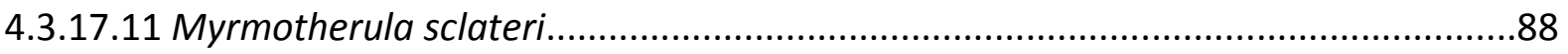

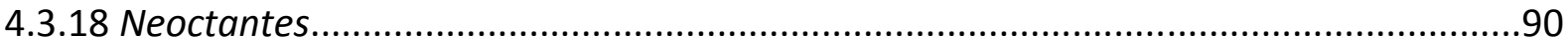

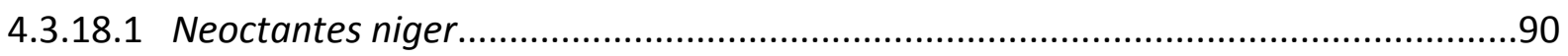

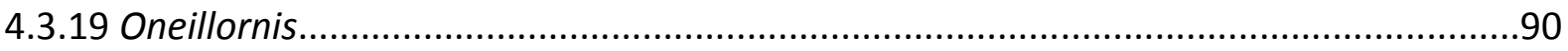

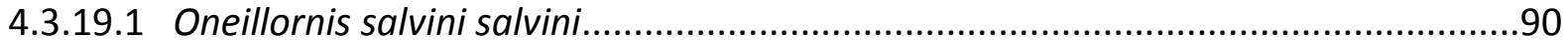

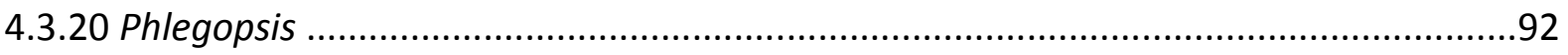

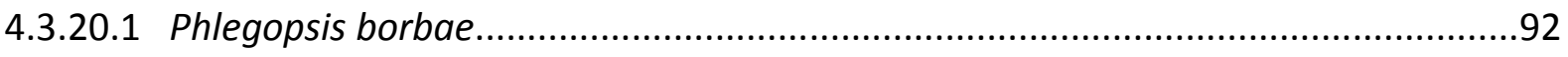

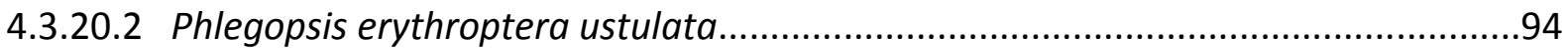

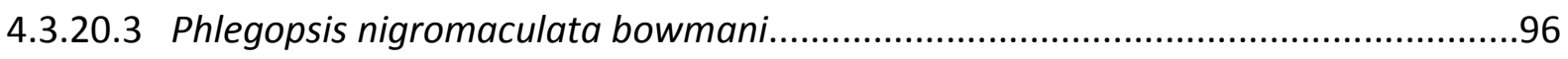

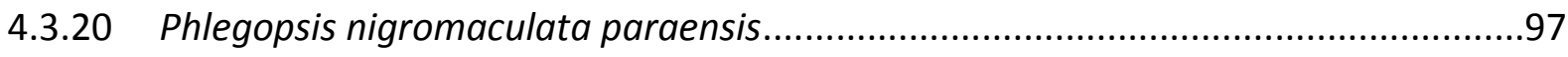

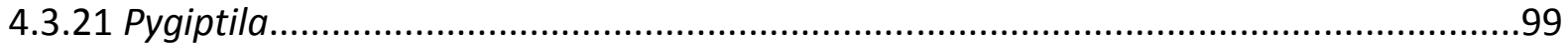

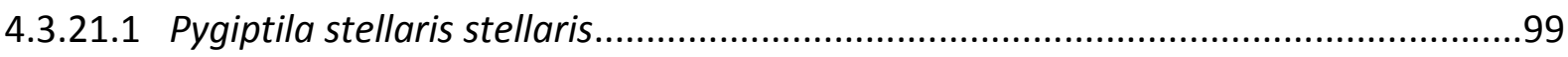

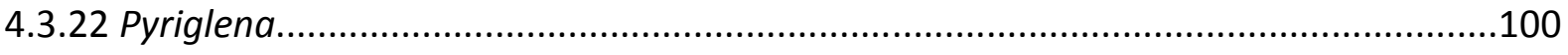

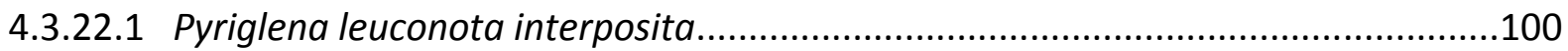

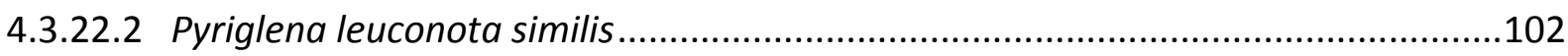

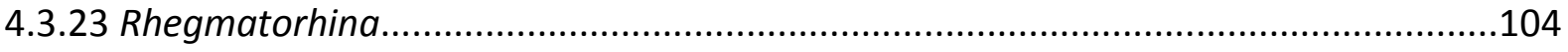




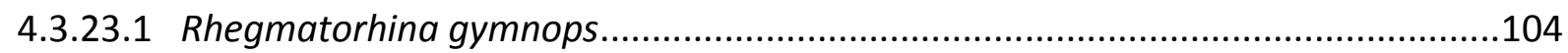

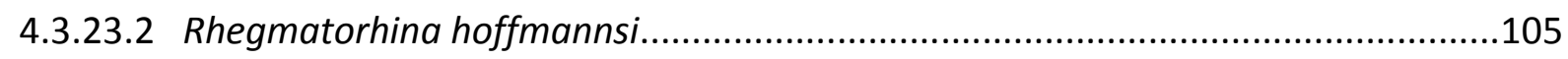

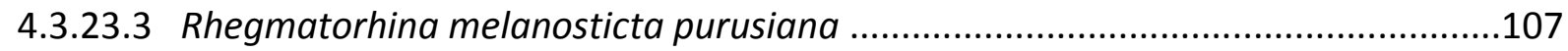

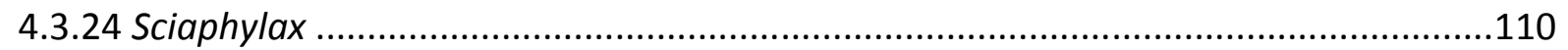

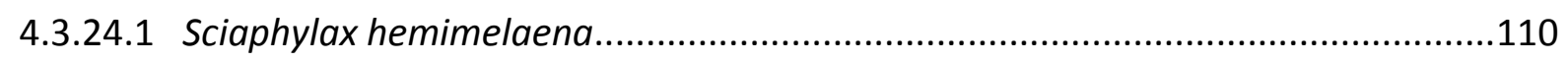

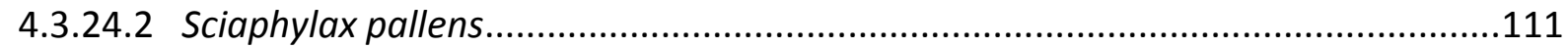

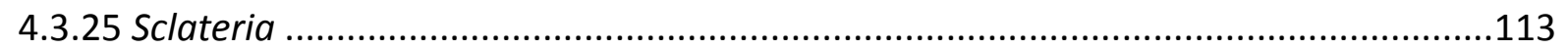

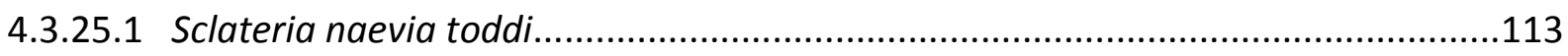

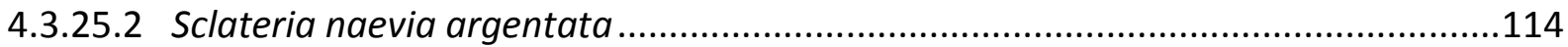

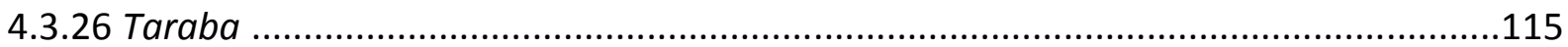

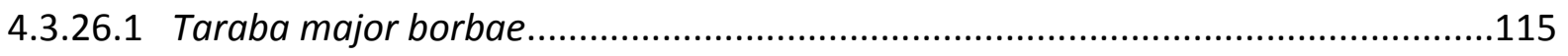

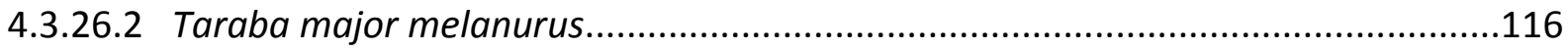

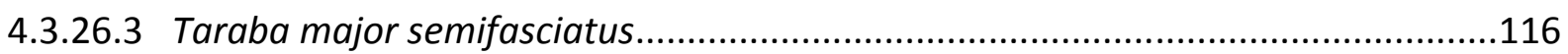

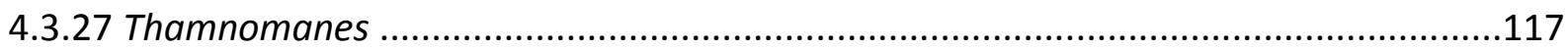

4.3.27.1 Thamnomanes ardesiacus ardesiacus...............................................................117

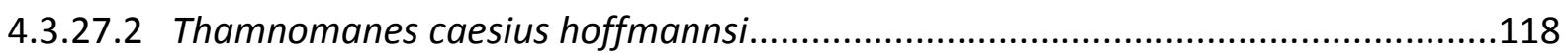

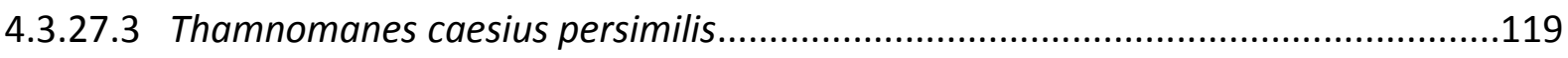

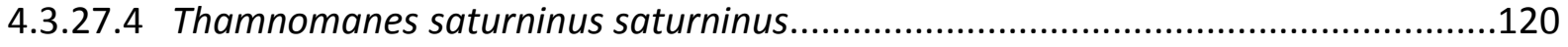

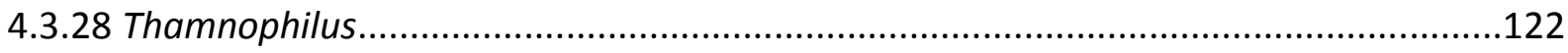

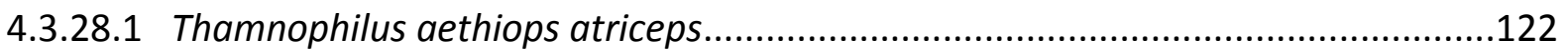

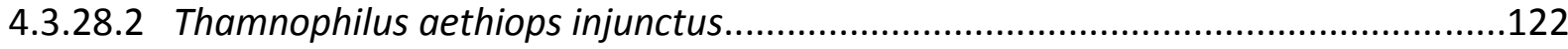

4.3.28.3 Thamnophilus aethiops punctuliger................................................................123

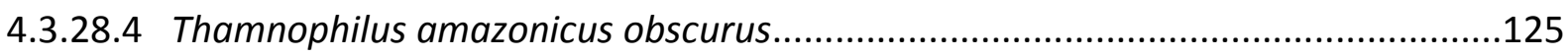

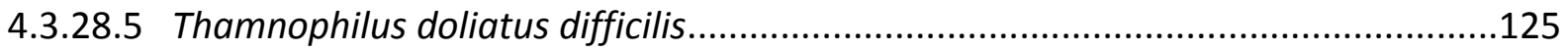

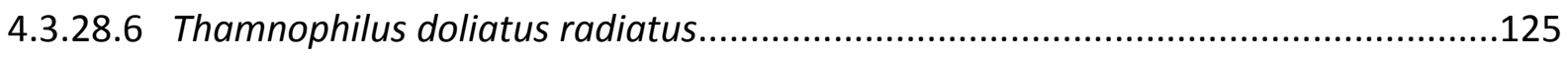

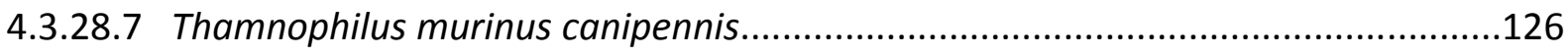

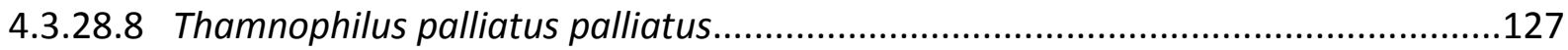

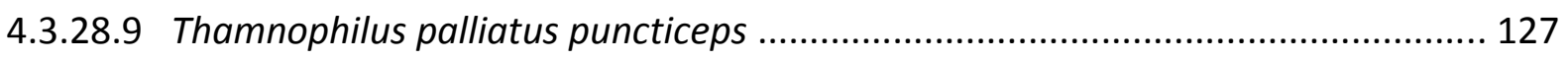

4.3.28.10 Thamnophilus schistaceus schistaceus..........................................................128

4.3.28.11 Thamnophilus stictocephalus stictocephalus....................................................128

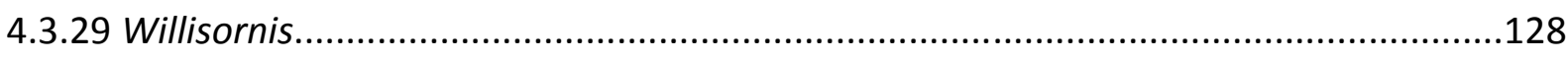

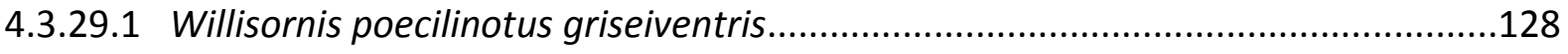




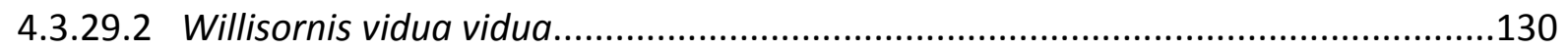

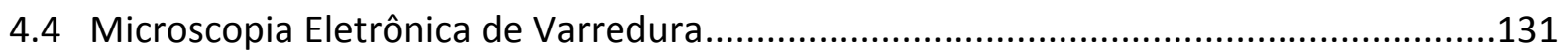

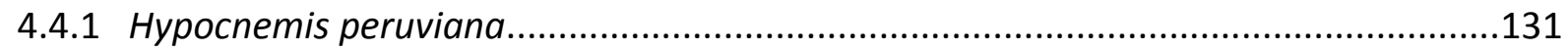

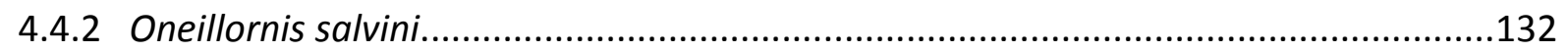

4.4.3 Phlegopsis nigromaculata bowmani.................................................................132

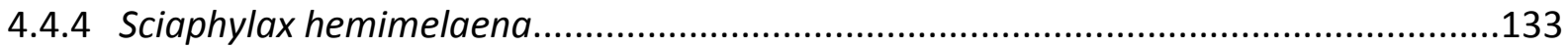

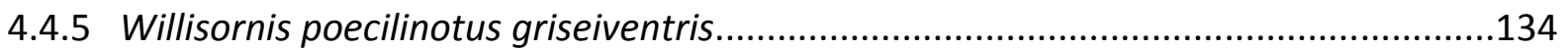

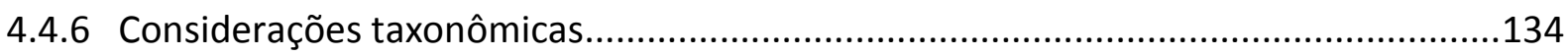

4.5 Distribuição de cestódeos: áreas amostradas e condições climáticas...........................139

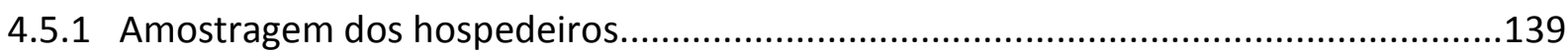

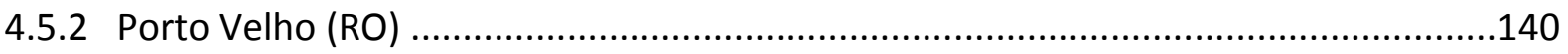

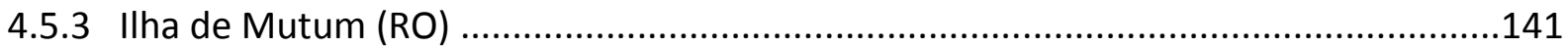

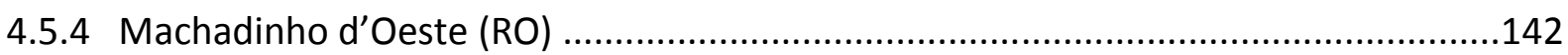

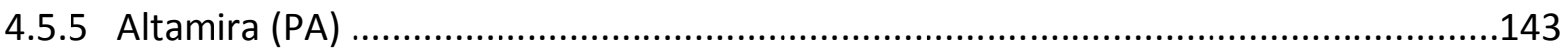

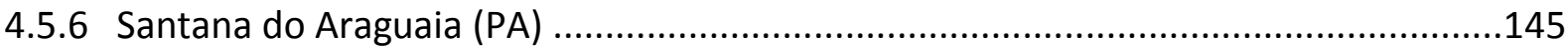

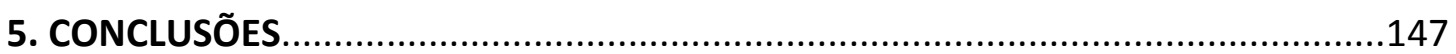

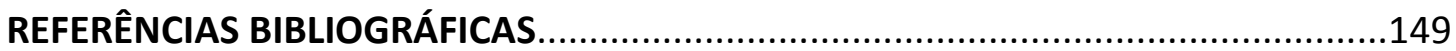

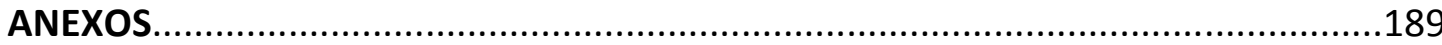




\section{INTRODUÇÃO}

O conhecimento acerca de parasitas é bastante antigo, com registros de helmintos parasitas no homem em papiros oriundos do Egito Antigo, próximos a 1.500 a.C. (BUSH et al., 2001). As referências a estes organismos acompanham a literatura mundial através dos tempos, principalmente pela importância médica que muitos grupos apresentam (BUSH et al., 2001; EDLER, 2011). Esta relação entre parasitas e enfermidades frequentemente resulta em uma visão negativa desta associação ecológica, porém o conceito de parasitismo pode apresentar diversas interpretações de acordo com o autor que o utiliza (ver ZELMER, 1998). Uma definição de parasita comumente aceita é aquela em que um organismo vive em outro organismo - o hospedeiro - nutrindo-se, mostrando alguma adaptação morfológica a este e causando-lhe algum tipo de prejuízo sem levar à sua morte (POULIN, 2007). O parasitismo entre metazoários evoluiu independentemente ao menos 60 vezes durante a diversificação deste grupo (POULIN; MORAND, 2000), podendo ser observado em diversos táxons que o integram e apresentando características distintas em relação à sua morfologia, estratégias de reprodução e dispersão e habitats.

Entre os grupos de metazoários em que o parasitismo é conhecido, estão representantes dos filos Acanthocephala, Nematoda, Mollusca, Anellida, Arthropoda e Platyhelminthes, cada qual com características intrínsecas a este modo de vida (POULIN; MORAND, 2000). Para os platelmintos, o parasitismo é observado nos integrantes do subfilo Neodermata, caracterizados por possuir uma epiderme sincicial não ciliada, a neoderme. Os neodermados constituem um grupo monofilético bem estabelecido tanto morfológica quanto molecularmente (LITTLEWOOD; ROHDE; CLOUGH, 1999; LITTLEWOOD et al., 1999) e todos os seus membros são parasitas obrigatórios no estágio adulto pertencentes às classes Monogenea, Trematoda e Cestoda, apresentando diferentes características morfológicas adaptadas a este modo de vida, como a presença de órgãos adesivos e alterações nos órgãos para absorção de nutrientes (ver CAIRA; LITTLEWOOD, 2013). A máxima especialização ao parasitismo nos neodermados é observada na classe Cestoda, com a ausência total de órgãos digestórios e absorção de nutrientes ocorrendo exclusivamente pelo tegumento (HALTON, 1997).

Os cestódeos, popularmente conhecidos como solitárias, são helmintos cuja forma adulta parasita o intestino e, ocasionalmente, a cavidade abdominal de vertebrados 
(YAMAGUTI, 1959), tendo seus estágios larvais ocorrendo em diversos grupos de invertebrados e vertebrados (LITTLEWOOD; BRAY; WAESCHENBACH, 2015). Há mais cerca de 4600 espécies de solitárias válidas, alocadas em aproximadamente 870 gêneros em 72 famílias (LITTLEWOOD; BRAY; WAESCHENBACH, 2015), e levantamentos recentes vem ampliando este número, sendo publicados mais de 180 novas espécies e 47 novos gêneros nos últimos 8 anos (CAIRA; JENSEN; BARBEAU, 2012). Por outro lado, a ausência de amostragem direcionada para cestódeos em grupos de possíveis hospedeiros indica que a diversidade do grupo ainda é subestimada (CAIRA; LITTLEWOOD, 2013). Entre os grupos de hospedeiros que necessitam aumento no esforço amostral voltado para a pesquisa de cestódeos, estão os membros da classe Aves, pois para as cerca de 10.000 espécies de aves conhecidas no mundo (DEL HOYO et al., 2010), são conhecidas pouco mais de 1.700 espécies de cestódeos (YAMAGUTI, 1959; SCHMIDT, 1986). Este é um número incipiente se considerado que quase todas as espécies de vertebrados examinados em busca de endoparasitas apresentaram uma ou mais espécies de cestódeos (SCHMIDT, 1986). O estudo direcionado para solitárias parasitas de aves é relativamente recente, com início no século $X X$, após publicações de espécimes coletados eventualmente. Como resultado, o conhecimento na área é restrito geograficamente e não abrange todas as famílias de possíveis hospedeiros, principalmente quando se tratam de táxons Neotropicais, como, por exemplo, os representantes da família Thamnophilidae.

\subsection{Histórico dos estudos de cestódeos parasitas de aves}

Os primeiros registros de parasitas de aves foram feitos a partir de observações fortuitas em aves domesticadas (ver RAUSCH, 1983) e o início dos estudos de helmintos voltados para parasitas de aves ocorreu na Europa no final do século XVIII. O primeiro trabalho significativo reunindo descrições de várias espécies de cestódeos foi publicado por Goeze, baseado principalmente em hospedeiros da fauna europeia como Milvus sp. e Corvus corone (GOEZE, 1782). Os registros das espécies nesta publicação foram feitos brevemente e sem ilustrações, e alguns táxons não possuem espécimes designados para séries tipo e depositados em coleções de referência (LOSS-FRANK, 1980), sendo revistos por diversos autores, inclusive na obra Entozoorum Synopsis, de Rudolphi (1819). O material analisado por Rudolphi foi reunido em grande parte nos Museus de Berlim e de Viena, a partir de 
expedições de naturalistas ao redor do mundo e ainda compõem a base do que sabemos hoje sobre alguns grupos de cestódeos parasitas de aves. Este volume, junto com os trabalhos de Dujardin $(1845)$ e Diesing $(1850,1854)$, sintetizam o avanço da pesquisa na área de helmintos em aves na primeira metade do século XIX, em sua maioria contemplando apenas espécies europeias. Durante a segunda metade do século, as maiores contribuições para o conhecimento dos cestódeos de aves foram publicadas por Krabbe (1869), com descrições de dezenas de espécies, a maioria de aves provenientes da Europa e também de hospedeiros provenientes de outras partes do mundo e mantidos em cativeiro, como Cygnus atratus (KRABBE, 1869), e por Railliet, com descrições de espécies parasitas como as de Columba livia (RAILLIET, 1892a), revisões de espécies (RAILLIET; LUCET, 1892) e a revisão da classificação dos cestódeos parasitas de aves (RAILLIET, 1892b).

As primeiras décadas do século XX foram marcadas por um enorme avanço na pesquisa referente aos cestódeos parasitas de aves. As publicações de Fuhrmann (1904, 1906a, 1906b, 1907a, 1908a, 1908b, 1908c, 1911, 1913, 1918, 1920a, 1920b, 1927, 1932, 1936) com descrições de espécies e revisões dos trabalhos publicados no século XIX, trouxeram refino a taxonomia do grupo e a sua classificação (FUHRMANN, 1907b). Os trabalhos de Fuhrmann basearam-se em espécimes provenientes de museus europeus, de colaboradores ao redor do mundo e de coletas próprias, inclusive na América do Sul e tiveram continuidade com seus pupilos, como Baer (e.g. BAER, 1925, 1928, 1937, 1940, 1955, BAER; BONA, 1960). A fauna de cestódeos africanos, antes conhecida por espécimes provenientes de hospedeiros levados a zoológicos europeus (RAUSCH, 1983), recebeu contribuições da Swedish Zoological Expedition to Egypt and the White Nile, ocorrida em 1901 (FUHRMANN, 1909) e de uma coleção sul-africana doada a Fuhrmann pelo Laboratório de Pesquisas Veterinárias de Pretória (BAER, 1924; JOYEUX; BAER, 1928). No mesmo período, outras publicações de Railliet e colaboradores também contribuíram para a taxonomia (RAILLIET; HENRY, 1912) e classificação do grupo (RAILLIET, 1916), incluindo revisões de espécies (RAILLIET; HENRY, 1909) e dados sobre cestódeos de aves domésticas (RAILLIET, 1921).

A primeira metade do século XX também marcou o desenvolvimento da pesquisa sobre as solitárias de aves em centros de pesquisas além da Europa ocidental. Southwell publicou trabalhos sobre taxonomia e classificação de cestódeos na Índia, (e.g. SOUTHWELL, 1911, 1926, 1929), com destaque para duas publicações acerca de parasitas de aves nessa 
região (SOUTHWELL, 1922; SOUTHWELL; HILMY, 1929). Ainda na Ásia, a fauna de cestódeos parasitas de aves do Japão foi descrita por Yamaguti (1935, 1940, 1956), além do volume sobre cestódeos da monografia Systema Helminthum (YAMAGUTI, 1959), com revisão sobre todos os helmintos conhecidos parasitando vertebrados. Na América do Norte, as linhas de pesquisas de helmintos eram focadas em helmintos de peixes e não houve o estabelecimento de investigações voltadas aos cestódeos parasitas de aves, sendo que Ranson (1909) e Mayhew (1925) publicaram seus estudos sobre o material recebido de colaboradores por Ward na Universidade do Nebraska e Linton (1927) descreveu cestódeos de aves marinhas coletados eventualmente por Edwards, um ictiólogo de Massachusets. $\mathrm{Na}$ Austrália também não há registro de uma linha de pesquisa exclusiva para parasitas de aves neste período, tendo somente o estudo de Johnston e Clarke (1948) acerca de cestódeos de pelicanos publicado.

O aprofundamento do conhecimento na área, entretanto, deu-se no leste europeu com a formação da Escola Helmintológica Soviética, pelo russo Skryabin. Fundador do conceito moderno de helmintologia devido ao refinamento de seus trabalhos (RYSAVY, 1979), Skryabin publicou seu primeiro estudo sobre parasitas de aves baseado em cestódeos reunidos por Fuhrmann, incluindo uma espécie brasileira, coletada em Pyrrhura sp. (SKRYABIN, 1914). A partir de 1919, Skryabin liderou mais de 400 expedições em busca de helmintos com a organização da "The Union Helminthological Expeditions" na antiga União das Repúblicas Socialistas Soviéticas (RYSAVY, 1979; RAUSCH, 1983), resultando em material para dezenas de publicações nas décadas seguintes (e.g. MATEVOSYAN, 1953, 1968, 1969; SKRYABIN; MATEVOSYAN, 1942; 1945; SPASSKAYA, 1954, 1959, 1964, 1966; SPASSKAYA; SPASSKII, 1971, 1973, 1977, 1978). Para as solitárias de aves, além das descrições de espécies, estes trabalhos também revisaram a literatura de autores como Rudolphi, Diesing, Fuhrmann e Baer, porém, por terem sido publicados em sua maioria na língua russa, o alcance destes estudos foi restrito até há cerca de três décadas (ver SCHMIDT, 1986; KHALIL; JONES; BRAY, 1994).

Devido à importância que Skryabin dava ao treinamento de novos helmintólogos e suporte na pesquisa de colaboradores, as pesquisas na área desenvolveram-se enormemente nos países soviéticos como Bulgária, Hungria, Polônia, Romênia e na atual República Checa (ROSICKÝ, 1967; RYSAVY, 1979) e resultaram que a fauna de helmintos do leste europeu fosse uma das estudadas com mais refinamento taxonômico e abrangência 
geográfica até os dias atuais. Em 1951, Skryabin e Spassky deram início a publicação da série Osnovy Tsestodologii (Essentials ou Fundamental of Cestodology, como geralmente é traduzida para a língua inglesa), a partir da percepção de Skryabin da necessidade de trabalhos que detalhassem os grupos de cestódeos (ŚAWIDERSKI; GEORGIEV, 2008). A série foi publicada no idioma russo e todos os 14 volumes abrangeram revisões de cestódeos de todo o mundo, escritos ou editados por autoridades em taxonomia como Spasskii (1951), Matevosyan (1963, 1969), Abuladze (1964), Freze (1965), Artyukh (1966), Protasova (1977), Chertkova e Kosupko (1978), Temirova e Skryabin (1978), Ryzhikov e Tolkacheva (1981), Delyamure, Skryabin e Serdyukov (1985), Protasova e Roytman (1995) e Bondarenko e Kontrimavichus (2006b), sendo o último volume publicado em 2006 (KHALIL; JONES; BRAY, 1994; ŚWIDERSKI; GEORGIEV, 2008; HAUKISALMI, 2015).

A partir da década de 1960, estudos acerca das solitárias de aves abrangeram diversas partes do mundo. A pesquisa na África teve contribuições de cientistas europeus, com as publicações de Jones $(1980,1982)$ e Jones e Khalil $(1980,1992)$ para cestódeos parasitando aves como psitacídeos, flamingos (Phoeniconaias minor) e aves-de-crocodilo (Pluvianus aegyptius) em áreas do Quênia e do Sudão e as de Mariaux para a fauna da Costa do Marfim para diversos táxons endêmicos, como membros da família Malaconotidae (MARIAUX, 1991a, 1991b; MARIAUX; VAUCHER, 1989; MARIAUX; BONA; VAUCHER, 1992). Na América do Norte, Rausch publicou sobre da fauna local (RAUSCH, 1970) e, apesar do foco de sua linha de pesquisa não ser somente cestódeos e aves, sua revisão sobre o histórico dos estudos de helmintos em aves (RAUSCH, 1983) é referência até os dias atuais. Embora sua pesquisa não se limitasse a estes hospedeiros, Ahern e Schmidt (1976) descreveram 4 novas espécies de cestódeos parasitas de Recurvirostra americana, ave sobre a qual Burt e Burt (1984) também estudaram solitárias. Schmidt também colaborou com o conhecimento da fauna australiana, descrevendo 3 novas espécies de solitárias para Lobibyx novaehollandae (SCHMIDT, 1972) e com a fauna israelense, com a descrição de um novo gênero, Cloacotaniella, parasitando o maçarico Tringa totanus (SCHMIDT; BAUERLE; WERTHEIM, 1988). Na Índia, descrições e revisões de helmintos foram publicadas para aves como Columba livia, Passer domesticus (CAPOOR; SRIVASTAVA, 1966, 1967, 1975), Sturnus contra (DIXIT; CAPOOR, 1988) e para aves do gênero Vanellus (SHINDE, 1968, 1972).

A pesquisa no continente europeu manteve-se ativa na segunda metade do século $X X$, porém não concentrou-se apenas na fauna local; além das contribuições de Jones, Khalil 
e Mariaux, Bona trabalhou em revisões para espécimes da família Dilepididae em aves (BONA, 1975, 1978) e descrições de espécies a partir de espécimes depositados em museus (BONA; MAFFI, 1984a, 1987), também publicando descrições de espécies parasitas de picapaus (Picidae), cucos (Cuculidae) e surucuás (Trogonidae) neotropicais provenientes da Argentina (BONA, 1994; BONA; MAFFI, 1984b; BONA; BOSCO; MAFFI, 1986). A Escola Soviética também contribuiu com o conhecimento na região Neotropical, com as descrições de solitárias em aves de Cuba como podicipediformes, pelicaniformes e ciconiiformes (RYSAVY, 1966; RYSAVY; MACKO, 1973). Nos anos 1990, especialistas em todos os grupos de Cestoda se reuniram e publicaram uma chave de identificação abrangendo todas as famílias conhecidas até então (KHALIL; JONES; BRAY, 1994), com revisões da literatura e considerações sistemáticas sobre todos os táxons, sendo esta chave geral a mais recente publicada e referência taxonômica para algumas ordens, como os Cyclophyllidea, até os dias atuais.

A partir dos anos 2000, os grupos de pesquisa do Museu de História Natural de Genebra e da Academia de Ciências da Bulgária consolidaram-se como referências no estudo de cestódeos em aves. Na Suíça, as principais publicações foram de Vaucher e Mariaux e seus colaboradores, com trabalhos sobre taxonomia e sistemática e contribuições nos primeiros trabalhos e desenvolvimento da pesquisa com dados moleculares para este grupo e cestódeos em geral (MARIAUX, 1996; HOBERG et al., 1997; MARIAUX, 1998; ZEHNDER; MARIAUX, 1999; GEORGIEV; VAUCHER, 2000, 2001, 2003, 2004; HOBERG; MARIAUX; BROOKS, 2001; OLSON et al., 2001; BONDARENKO; KONTRIMAVICHUS; VAUCHER; 2002). Em Sofia, a pesquisa liderada por Georgiev e Vasileva e seus colaboradores baseou-se em taxonomia, levantamentos de fauna e ciclos de vida dos parasitas, com novas coletas de diversos táxons de aves no país e em regiões próximas como a Ucrânia (GEORGIEV; GENOV, 1998; VASILEVA; GEORGIEV; GENOV, 1998, 1999, 2000; VASILEVA; GEORGIEV, 1999, 2005; GEORGIEV; VASILEVA, 2001; GEORGIEV et al., 2002, 2004; VASILEVA; GIBSON; BRAY, 2003a, 2003b, 2003c; GEORGIEV; GARDNER, 2004; LITERÁK et al., 2004; NIKOLOV et al., 2005; GEORGIEV; GIBSON, 2006; KOMISAROVAS; GEORGIEV, 2007; KORNIENKO et al., 2008; NIKOLOV; GEORGIEV, 2008; VASILEVA; SKIRNISSON; GEORGIEV, 2008; KORNYUSHIN et al., 2009; GULYAEV; VASILEVA; KONYAEV, 2010; MARINOVA; VASILEVA; GEORGIEV, 2013; SÁNCHEZ et al., 2013; GEORGIEV et al., 2014; MARINOVA; GEORGIEV; VASILEVA, 2015). Além das publicações próprias, os dois grupos mantêm colaboração mútua, com diversos 
trabalhos publicados em conjunto (e.g. VASILEVA et al., 2004; GEORGIEV; MARIAUX, 2007; KOMISAROVAS; GEORGIEV; MARIAUX, 2007).

Em 2008, com o início do projeto "A Survey of the Tapeworms (Cestoda: Platyhelminthes) from Vertebrate Bowels of the Earth", a colaboração entre pesquisadores de 21 países para o levantamento e expansão do conhecimento sobre cestódeos no mundo estabeleceu-se efetivamente (CAIRA; JENSEN; BARBEAU, 2012), cabendo a Mariaux e Georgiev a coordenação do componente referente aos parasitas de aves. Inseridos neste projeto de levantamento mundial, Mariaux, Georgiev e seus colaboradores realizaram coletas em diferentes partes do mundo como África (Gabão), América do Sul (Brasil, Chile) e Ásia (China, Irã e Malásia) (CAIRA; JENSEN; BARBEAU, 2012), buscando material para estudos morfológicos e moleculares em localidades nas quais o conhecimento nesta área de pesquisa era inexistente ou apresentava lacunas. Os dados já publicados destas amostragens resultaram na descrição de 3 gêneros, 5 novas espécies, redescrições de 2 espécies e registros de 2 outras espécies em novas localidades (HALAJIAN et al., 2011; PHILLIPS; MARIAUX; GEORGIEV, 2012; DIMITROVA; MARIAUX; GEORGIEV, 2013; WIDMER; GEORGIEV; MARIAUX, 2013; PHILLIPS et al., 2014), ainda restando material coletado para futuros estudos e indicando que o conhecimento dos parasitas de aves ainda é exíguo e necessita de atenção e maiores esforços para ser compreendido.

\subsection{Histórico e estado da arte dos estudos de cestódeos de aves no Brasil}

O início do século XIX marcou os primeiros registros de atividades sobre helmintos coletados no Brasil. Exceto por uma breve menção de Marcgrave sobre parasitas de tamanduá e iguana (MARCGRAVE, 1648), não há referência sobre helmintos brasileiros até 1819 (TRAVASSOS, 1965; REGO, 1982), quando Rudolphi publicou seus estudos sobre o material coletado por von Olfers e Sellow, além daquele coligido por Natterer (RUDOLPHI, 1819; TRAVASSOS, 1965). Os helmintos coletados por von Olfers e Sellow foram enviados para Berlim juntamente com diversas amostras animais, vegetais e minerais (PACHECO; WHITNEY, 2001) e não há registros de uma nova remessa, indicando que a coleta foi feita ocasionalmente, certamente durante a preparação dos espécimes hospedeiros. Os espécimes descritos que foram coletados por Natterer, ao contrário, foram apenas os primeiros enviados a Viena, e resultantes de seu trabalho como membro da "Missão 
Austríaca" no Brasil.

A “Missão Austríaca" (1817-1836) foi uma expedição de exploração naturalista organizada pelo governo austríaco por ocasião do casamento da Arquiduquesa Leopoldina da Áustria com D. Pedro, herdeiro do trono de Portugal, Brasil e Algarves, em 1817. Johann Natterer trabalhava no Gabinete de História Natural de Francisco I, Imperador da Áustria, e lá conviveu com Karl von Schreibers, médico diretor do Gabinete, que o instruiu a buscar vermes intestinais e os preservar em álcool quando preparasse os animais para a taxidermia (RIEDL-DORN, 1999). A experiência de Natterer na preparação de espécimes, aliada ao período de 18 anos que permaneceu no Brasil, resultou na coleta de 1.729 vidros com helmintos enviados a Viena (GOELDI, 1895), recebidos pelo helmintólogo Karl Diesing e descritos, em parte, em dois volumes na obra Systema Helminthum (1850). Os trabalhos de Rudolphi e Diesing foram pioneiros nas descrições de cestódeos parasitas de aves do Brasil, totalizando 37 espécies (TRAVASSOS, 1965).

A maior parte das espécies de cestódeos parasitas de aves brasileiras conhecidas atualmente foi descrita por Fuhrmann, que estudou espécimes brasileiros depositados nas coleções dos museus de história natural de Berlim e Viena, além de amostras enviadas por outros pesquisadores, como Adolpho Lutz e Ernst Bresslau (FUHRMANN, 1907, 1927; BAER, 1946; REGO, 1982). Entre redescrições de espécies publicadas por Rudolphi e Diesing e descrições de novos táxons, foram publicadas 90 espécies (FUHRMANN, 1904, 1906a, 1906b, 1907a, 1908a, 1908b, 1908c, 1927, 1932), das quais 73 são válidas hoje (CAIRA; JENSEN; BARBEAU, 2012). As descrições de Fuhrmann apresentam refino taxonômico para os parasitas, porém os dados disponíveis para localidades e hospedeiros de algumas amostras não são acurados. Os espécimes provenientes dos museus de Berlim e de Viena estão, em sua maioria, com a localidade de coleta identificada apenas como Brasil (e.g. FUHRMANN, 1908a, 1908b, 1908c); há descrições que apresentam o estado da federação onde o material foi coletado, mas não citam quaisquer outras referências espaciais (e.g. FUHRMANN, 1906). As identificações dos hospedeiros amostrados não são precisas para todas as descrições, existindo pontos de interrogação do próprio autor nas citações: Biuterina campanulata (Fuhrmann, 1908b), por exemplo, é descrita parasitando quatro espécies de aves, duas das quais identificadas equivocadamente como Muscicapa columbina e Thamnophilus sulphuratus, nomes que não existem na literatura, nem mesmo como sinônimos (HELLMAYR; CONOVER, 1918-1948). Além disso, há espécies que não possuem dados 
precisos sobre seu depósito em coleção de referência, como a coleção onde estão depositadas ou mesmo o seu número de tombo (FUHRMANN, 1907).

Os trabalhos de Fuhrmann foram base de diversas revisões (e.g. BAER; BONA, 1960; BEVERIDGE, 1978; BONA, 1994; GEORGIEV; VAUCHER, 2001), porém estas publicações não incluíram novos espécimes de novas coletas, baseando-se nos materiais depositados nas coleções de referência. Recentemente, apenas a revisão de uma espécie descrita por Fuhrmann, Anonchotaenia brasiliensis (PHILLIPS et al., 2014), baseou-se em material recém coletado na Estação Biológica de Boráceia em Salesópolis (SP), em parceria com os pesquisadores da Seção de Aves do Museu de Zoologia da Universidade de São Paulo (MZUSP).

Os primeiros estudos nacionais sobre helmintos tiveram início do final do século XIX, com trabalhos de Silva Lima, Wucherer e Magalhães (FREITAS, 1964; TRAVASSOS, 1965). Em 1898, foram descritas duas espécies de cestódeos parasitas de galinha doméstica (Gallus gallus; MAGALHÃES, 1898), sendo os demais trabalhos eram direcionados apenas para as patologias humanas. O desenvolvimento da helmintologia brasileira, com estudos voltados a parasitas de animais em geral, deu-se a partir de 1913 com a criação do Laboratório de Helmintologia e o estabelecimento da Coleção Helmintológica no Instituto Oswaldo Cruz (CHIOC), no Rio de Janeiro (NORONHA et al., 2009; KNOFF et al., 2010). O acervo inicial da coleção formou-se a partir de doações de coleções particulares, como as de Oswaldo Cruz, Adolpho Lutz e Gomes de Faria, sendo posteriormente acrescido de coleções de outras instituições como o Museu Paulista, Instituto Pasteur de São Paulo, Instituto Bacteriológico de São Paulo, Instituto Butantan e Instituto Biológico de São Paulo (TRAVASSOS, 1917a, 1917b; NORONHA et al., 2004; NORONHA; PINTO, 2007; NORONHA et al., 2009, KNOFF et al., 2010). O primeiro pesquisador responsável pela coleção foi José Gomes de Farias (19131915); no entanto, o crescimento e a consolidação da coleção ocorreram durante a gestão de Lauro Travassos (1915-década de 1940).

As contribuições de Travassos para a helmintologia foram reconhecidas internacionalmente, resultado de 314 trabalhos publicados na área (COURA, 1992; DIAS et al., 1990; KNOFF et al., 2010). Especialista em trematódeos, sua participação na taxonomia de cestódeos no Brasil não foi significativa (TRAVASSOS, 1950, 1965), porém o material coletado em suas excursões à região de Miranda (MS) e os dados resultantes destas expedições foram únicos no Brasil. Em colaboração com pesquisadores de outras instituições 
como o Museu Nacional (RJ), o Departamento de Zoologia da Secretaria de Agricultura de São Paulo e o Instituto Biológico de São Paulo, Travassos coordenou sete expedições à Estrada de Ferro Noroeste do Brasil, na região de Miranda, entre 1938 e 1942. Estas campanhas resultaram em 3.057 vertebrados analisados em busca de parasitas, com 2.960 amostras de helmintos coletadas, sendo 452 amostras de cestódeos; para as aves, foram analisados 1.762 indivíduos pertencentes a cerca de 100 espécies, das quais 389 apresentaram infestação por cestódeos (TRAVASSOS, 1940a, 1940b; 1941a; TRAVASSOS; FREITAS, 1940; 1942; 1943; TRAVASSOS; FREITAS; LENT, 1939). Os helmintos coletados foram depositados na $\mathrm{CHIOC}$ e diversos trabalhos foram baseados neste material (e.g. TRAVASSOS, 1940c; 1941b; MACHADO FILHO, 1940; FREITAS, 1940; KOHN; FERNANDES, 1972), porém não há publicações para os cestódeos parasitas de aves.

Durante a década de 1940, Travassos passou a curadoria da CHIOC para João F.T. Freitas, seu discípulo e colaborador, e foram os pesquisadores por eles formados que deram continuidade às principais pesquisas helmintológicas no país (KNOFF et al., 2010). A CHIOC permaneceu como única coleção de helmintos no Brasil até o início dos anos 1960, com o estabelecimento da Coleção de Helmintologia do Departamento de Zoologia da Secretaria de Agricultura do Estado de São Paulo, atual Coleção de Helmintologia do Museu de Zoologia da Universidade de São Paulo (MZUSP). Sob coordenação de Gertrud Rita Kloss, discípula de Travassos, a coleção iniciou-se com doações de espécimes por seu orientador e chegou a 5.000 números tombo durante os quinze anos de sua curadoria. $\mathrm{A} \mathrm{CHIOC} \mathrm{e} \mathrm{a}$ Coleção de Helmintologia do MZUSP permanecem ativas, entretanto não houve desenvolvimento de linhas de pesquisa de helmintos parasitas de aves em ambas as instituições.

Após as coletas de Travassos em Miranda, não houve registros na literatura sobre expedições extensivas para coletas de helmintos de aves silvestres no Brasil. Os trabalhos publicados sobre o assunto baseiam-se em materiais de coleção ou em coletas ocasionais (e.g. VICENTE; PINTO; NORONHA, 1983; RODRIGUES; RODRIGUES; FARIA, 1990; VICENTE et al., 1995; PINTO; MATI; MELO, 2012), ou em hospedeiros provenientes de criadouros ou centros de triagem de fauna (e.g. MASCARENHAS; KRÜGER; MÜLLER, 2013). A taxonomia de cestódeos foi pouco abordada nas últimas décadas, geralmente em publicações de revisões de espécies ou ocorrências em localidades ou hospedeiros inéditos (e.g. ROLAS, 1976; MUNIZ-PEREIRA; AMATO, 1998; ARRUDA; PINTO; MUNIZ-PEREIRA, 2001; SILVEIRA; AMATO, 
2008; AGUIAR et al., 2011); há poucos registros de novas espécies descritas, em geral resultado de revisões taxonômicas ou amostragens em espécies domésticas (e.g. SCHMIDT, 1986). Estudos acerca de aspectos ecológicos dos cestódeos parasitas de aves foram publicados nas últimas décadas, embora comumente baseados em hospedeiros domésticos ou de algum interesse econômico ou sanitário (e.g. MACHADO et al., 1980; BRASIL; AMATO, 1992; PINTO et al., 2004; MATTOS JÚNIOR et al., 2008).

A carência de pesquisadores voltados para o estudo de cestódeos parasitas de aves no Brasil resulta em uma lacuna no conhecimento destes helmintos tanto geograficamente quanto para alguns grupos de aves. As coletas na região amazônica, por exemplo, restringem-se àquelas realizadas por Natterer, com publicações pontuais após os trabalhos de Fuhrmann (e.g. PINTO; GOMES, 1976). As expedições para coleta e levantamento de aves na região foram contínuas desde então (e.g. SILVEIRA, 2011), entretanto não houve registros de coleta intencional destes helmintos. Consequentemente à falta de esforço amostral, há diversos táxons de aves que não apresentam qualquer cestódeo associado ou formalmente descrito.

Resultante aos estudos feitos sobre cestódeos parasitas de aves no Brasil, o estado da arte desta linha de pesquisa no país não progrediu fundamentalmente além da taxonomia do material coletado no século XIX. Os trabalhos feitos foram, em sua maioria, descritivos, sem abranger áreas como relações ecológicas hospedeiro-parasita, ciclos de vida dos parasitas, biogeografia deste sistema ou inferências sobre coevolução hospedeiroparasita. A descontinuidade na formação de pesquisadores aptos a atuar nesta área também impediu o estabelecimento de colaboração entre grupos de trabalhos ornitológicos e helmintólogos, impossibilitando assim que fossem feitos estudos integrados e mais aprofundados.

\subsection{Diversidade de cestódeos em aves}

Conforme revisões recentes baseadas em dados moleculares (OLSON; CAIRA, 1999; CAIRA; MEGA; RUHNKE, 2005; HEALY et al., 2009; CAIRA et al., 2014), a classe Cestoda é composta por 19 ordens válidas, incluindo a ordem parafilética Tetraphyllidea. Embora 14 destas ordens (Bothriocephalidea, Caryophyllidea, Cathetocephalidea, Diphyllidea, Gyrocotylidea, Haplobothriidea, Lecanicephalidea, Litobothriidea, Nippotaeniidea, 
Phyllobothriidea, Rhinebothriidea, Spathebothriidea, Tetraphyllidea e Trypanorhyncha) estejam associadas exclusivamente a peixes como hospedeiros definitivos, especialmente elasmobrânquios, e 2 estejam presentes tanto em peixes quanto em tetrápodes (Amphilinidae e Onchoproteocephalidae) (WAESCHENBACH; WEBSTER; LITTLEWOOD, 2012; CAIRA et al., 2014), a grande diversificação do grupo para famílias, gêneros e espécies coincide com a transição destes parasitas para tetrápodes como hospedeiros definitivos (LITTLEWOOD; BRAY; WAESCHENBACH, 2015).

A diversidade de cestódeos é comumente atribuída às adaptações em diferentes estágios de desenvolvimento necessárias para completar o ciclo de vida complexo destes parasitas, que apresenta sucessivas transmissões, geralmente tróficas, através de dois ou mais hospedeiros (PARKER; BALL; CHUBB, 2009; BENESH; CHUBB; PARKER, 2011, 2014; LITTLEWOOD; BRAY; WAESCHENBACH, 2015). A diversidade de parasitas em ciclos complexos pode ser relacionada com a diversidade de hospedeiros a que são capazes de infestar em cada estágio do ciclo, considerando a especificidade a fatores morfológicos, fisiológicos, comportamentais e ecológicos mais relevante do que as relações filogenéticas (MACKIEWICZ, 1988; ADAMSON; CAIRA, 1994; MORAN, 1994; POULIN, 2010; KRASNOV; POULIN, 2015). Uma vez que a diversificação dos tetrápodes acarretou na ocupação de diferentes nichos (MILNER, 1990; LONG; GORDON, 2004), a especialização dos cestódeos pode ter acompanhado a diversificação dos hospedeiros, dado que este grupo hospeda 29,4\% das famílias, $54,8 \%$ dos gêneros e $49 \%$ das espécies de solitárias conhecidas; ainda assim, esta transição é difícil de ser reconstruída devido a ausência de registros fósseis (LITTLEWOOD; BRAY; WAESCHENBACH, 2015).

O parasitismo de cestódeos em tetrápodes é conhecido para representantes de 4 ordens: Cyclophyllidea, Dyphyllobothriidea, Onchoproteocephalidea e Tetrabothriidea (CAIRA; LITLEWOOD, 2013; CAIRA et al, 2014), com presença distinta em cada táxon hospedeiro. Os membros de Cyclophyllidea e Dyphyllobothriidea são encontrados parasitando todos os táxons de tetrápodes, enquanto os de Tetrabothriidea são encontrados apenas em aves e mamíferos e os de Onchoproteocephalidea estão em todos os tetrápodes exceto aves (CAIRA; LITLEWOOD, 2013; LITTLEWOOD; BRAY; WAESCHENBACH, 2015). A diversidade de cestódeos nestas ordens é bastante variável e não se mostra dependente do táxon de hospedeiro que parasita, pois os ciclofilídeos abrigam praticamente metade das espécies de cestódeos descritas, cerca de 2300, enquanto os membros de 
Dyphyllobothriidae restringem-se a 129 espécies conhecidas (CAIRA; JENSEN; BARBEAU, 2012; LITTLEWOOD; BRAY; WAESCHENBACH, 2015).

As três ordens de Cestoda com representantes parasitando aves, Cyclophyllidea, Dyphyllobothriidea e Tetrabothriidea, constituem grupos monofiléticos tanto em estudos com dados morfológicos quanto moleculares (HOBERG et al., 1997; HOBERG; MARIAUX; BROOKS, 2001; OLSON et al., 2001; WAESCHENBACH et al., 2007; WAESCHENBACH; WEBSTER; LITTLEWOOD, 2012). A distribuição destes grupos é cosmopolita, com particularidades de acordo com a ordem; ciclofílideos são conhecidos em todo o mundo, com diferenças de distribuição para cada uma de suas 16 famílias, enquanto difilobotrí́deos são bem conhecidos na Eurásia e América do Norte e tem poucos registros na América do Sul e tetrabothríideos são principalmente conhecidos nas regiões polares (KHALIL; JONES; BRAY, 1994). A presença em aves também é variável, pois são conhecidas aproximadamente 20 espécies de difilobotriídeos ( $16 \%$ das espécies da ordem) para estes hospedeiros, todos em ambientes aquáticos, como as aves pertencentes aos gêneros Larus, Mergellus e Rissa (KUCHTA et al., 2008; LITTLEWOOD; BRAY; WAESCHENBACH, 2015) e 55 espécies de tetrabotríideos (74\% das espécies da ordem) todos em aves marinhas, pertencentes a gêneros como Diomedea, Fregata, Fulmarus, Procellaria, Sphesniscus e Sula (HOBERG, 1994; LITTLEWOOD; BRAY; WAESCHENBACH, 2015). A maior diversidade, porém, é encontrada para os ciclofilídeos, uma vez que são registradas aproximadamente 1600 espécies pertencentes a esta ordem parasitando aves (cerca de 70\% das espécies da ordem) (KHALIL; JONES; BRAY, 1994; CAIRA; JENSEN; BARBEAU, 2012).

A ordem Cyclophyllidea é formada por 16 famílias (JONES; BRAY; KHALIL, 1994; HOBERG; JONES; BRAY, 1999), sendo que apenas 4 não apresentam representantes parasitando aves, Catetotaenidae, Dypylidiidae, Taeniidae (parasitas de mamíferos) e Nematotaeniidae (parasitas de anfíbios e répteis) (KHALIL; JONES; BRAY, 1994; CAIRA; JENSEN; BARBEAU, 2012). Estudos moleculares recentes indicam que Mesocestoididae, com membros majoritariamente parasitas de mamíferos, pode ser uma ordem à parte dos ciclofilídeos, porém esta divisão não foi proposta formalmente (CAIRA et al, 2014; LITTLEWOOD; BRAY; WAESCHENBACH, 2015). As famílias Anoplocephalidae, Davaineidae, Dilepididae e Hymenolepididae são encontradas parasitando aves e mamíferos e englobam a maioria das espécies de ciclofilídeos (cerca de 85\%), enquanto a família Gryporhynchidae tem um representante parasita de tartarugas, com os demais encontrados em aves; as 
demais famílias da ordem são encontradas apenas em aves (CAIRA; JENSEN; BARBEAU, 2012).

Entre as famílias de ciclofilídeos parasitas somente de aves, a família Acoleidae é a menos diversa, com 2 gêneros e menos de 10 espécies descritas (CAIRA; JENSEN; BARBEAU, 2012). Seus membros são parasitas de aves Charadriiformes e Ralliformes, como Himantopus e Recurvirostra, mas não há informação acerca de seus hospedeiros intermediários; sua distribuição é cosmopolita, com registros para Eurásia e América do Norte (KHALIL, 1994a; CAIRA; JENSEN; BARBEAU, 2012). Também com poucas espécies, a família Progynotaeniidae é formada por 6 gêneros e 16 espécies consideradas válidas, todas parasitas de Charadriiformes e Phoenicopteriformes e com distribuição cosmopolita, sem dados sobre seus hospedeiros intermediários (KHALIL, 1994b; CAIRA; JENSEN; BARBEAU, 2012). Revisões recentes para a família indicam que sua diversidade pode ser maior se áreas subamostradas, como a região neotropical, forem estudadas mais amplamente (NIKOLOV; GEORGIEV; GULIAEV, 2004; NIKOLOV et al., 2005).

Os membros da família Dioecocestidae também são encontrados parasitando Charadriiformes, além de Ciconiformes e Podicipediformes, sendo recorrentes em espécies de Himantopus e Podiceps; pouco é conhecido sobre seu ciclo de vida, com o único registro de hospedeiro intermediário para libélulas (Odonata) na Rússia (REGEL; GULIAEV; POSPEKHOVA, 2013) e são conhecidas 23 espécies em 4 gêneros, com distribuição cosmopolita (JONES, 1994a; CAIRA; JENSEN; BARBEAU, 2012). Em Podicepidiformes e Phoenicopteriformes também são encontrados cestódeos da família Amabilidae, que possui cerca de 26 espécies em 8 gêneros, a maioria descrita parasitando aves dos gêneros Podiceps e Tachybaptus (JONES, 1994b; CAIRA; JENSEN; BARBEAU, 2012). A família é registrada para África, Américas do Norte e Sul, Ásia e Europa após a revisão de alguns de seus táxons que incluíram espécies de hospedeiros e aumentaram a distribuição destes parasitas (VASILEVA; GIBSON; BRAY, 2003a, 2003b, 2003c), que tem em insetos aquáticos, como larvas de libélulas (Odonata), seus hospedeiros intermediários (BOERTJE, 1966).

Ao contrário das demais famílias de ciclofilídeos que parasitam apenas aves, a família Metadilepididae parasita aves não aquáticas das ordens Coraciiformes, Caprimulgiformes e Passeriformes, sendo composta por 15 espécies pertencentes a 10 gêneros, 8 monoespecíficos (KORNYUSHIN; GEORGIEV, 1994; GEORGIEV; VAUCHER, 2003). Os representantes desta família são registrados para África, Américas Central e do Sul, 
Indonésia, Oceania, Paleártico e Holoártico, porém a maioria das espécies é encontrada na região tropical; esta distribuição pode explicar o baixo número de espécies conhecidas, dado que o esforço amostral de cestódeos é insuficiente para aves nestas regiões (KORNYUSHIN; GEORGIEV, 1994). O ciclo de vida e os hospedeiros intermediários para os metadilepidídeos não são conhecidos (CAIRA; JENSEN; BARBEAU, 2012).

Entre os ciclofílideos que parasitam apenas aves, a família Paruterinidae é que engloba mais espécies, cerca de 120 espécies em 23 gêneros, todas em aves terrestres de diversas ordens, como Apodiformes, Accipitriformes, Cuculiformes, Coraciformes, Galliformes, Passeriformes, Strigiformes e Trogoniformes (GEORGIEV; KORNYUSHIN, 1994; CAIRA; JENSEN; BARBEAU, 2012). A distribuição dos membros desta família é cosmopolita e o ciclo de vida varia de acordo com o gênero dos parasitas, sendo que Paruterina e Cladotaenia apresentam pequenos mamíferos como hospedeiros intermediários (RAUSCH, 1949; FREEMAN, 1957, 1959) e outros gêneros tem suas formas larvais encontradas em insetos, como as larvas de Lyruterina em coleópteros (SMIGUNOVA, 1991; GEORGIEV; BRAY; LITTLEWOOD, 2006). Publicações recentes baseadas em dados moleculares (FORONDA et al., 2004; SHARMA et al., 2016) indicam a não monofilia de Paruterinidae (sensu GEORGIEV; KORNYUSHIN, 1994), o que pode explicar a diversidade de hospedeiros definitivos e intermediários para a família, que necessita de revisão.

As cerca de 100 espécies da família Gryporhynchidae são parasitas de aves aquáticas, exceto por Glossocercus chelodinae, encontrada em tartarugas de água doce Chelodina expansa na Austrália (PICHELIN; CRIBB; BONA, 1998). As espécies encontradas em aves como Ardea, Butorides, Egretta, Ixobrychus, Nyctocorax, Phalacrocorax, Pilherodius e Plegadis são distribuídas cosmopolitanamente e pertencem a 14 gêneros, alguns conhecidos até recentemente apenas por estágios larvais (BONA, 1994; CAIRA; JENSEN; BARBEAU, 2012; ORTEGA-OLIVARES; ROSAS-VALDÉZ; GARCÍA-VARELA, 2013). O ciclo de vida para espécies de Gryporhynchidae incluem 2 hospedeiros intermediários, geralmente crustáceos copépodes e peixes, sendo completo pelas aves como hospedeiro definitivo (SCHOLZ et al., 2004).

A família Davaineidae também apresenta ciclo de vida com 2 hospedeiros intermediários, que podem pertencer aos filos Annelida, Mollusca ou Arthropoda (CAIRA; JENSEN; BARBEAU, 2012), completando-o com mamíferos ou principalmente aves como hospedeiros definitivos (JONES; BRAY, 1994). São conhecidas cerca de 500 espécies para a família, distribuídas em 37 gêneros, sendo que Raillietina engloba mais de 200 espécies e é o 
gênero de cestódeos com mais espécies válidas (SCHMIDT, 1986; CAIRA; JENSEN; BARBEAU, 2012). Os davaineídeos podem ser encontrados em animais silvestres e domésticos, porém diversos estudos voltam-se para os gêneros Raillietina, Davainea e Cotugnia, comumente encontrados em animais de importância econômica como o galo doméstico (Gallus gallus), a galinha d'Angola (Numida meleagris) e o peru (Meleagris gallopavo) (e.g MARTINÉZGUERRERO et al., 2010; NALUBAMBA et al., 2015; SILVA et al., 2016). Em animais silvestres, estes cestódeos podem ser encontrados em diversos táxons de aves terrestres e aquáticas, tendo distribuição cosmopolita (JONES; BRAY, 1994; CAIRA; JENSEN; BARBEAU, 2012).

Os membros da família Anoplocephalidea podem ser encontrados em mamíferos, répteis e aves e estão divididos em cerca de 55 gêneros, com total aproximado de 400 espécies com distribuição cosmopolita (BEVERIDGE; 1994; CAIRA; JENSEN; BARBEAU, 2012). As espécies encontradas em aves pertencem à subfamília Anoplocephalinae, em 12 gêneros divididos em cerca de 40 espécies (BEVERIDGE; 1994). Os hospedeiros intermediários desta subfamília são ácaros orobatídeos (STUNKARD, 1961, 1969) e os hospedeiros definitivos geralmente são psitacídeos como Amazona, Cacatua, Nestor, Platycercus, Psittacula, Pyrrhura e Strigops, além de alguns designados apenas como "papagaios" nas descrições (BEVERIDGE; 1994); os membros do gênero Taufikia são encontrados em Accipitriformes (BEVERIDGE; 1994), há uma espécie de Moniezia descrita para Rhea americana e uma de Paronia descrita para espécies de Rhamphastos (FUHRMANN, 1904; BEVERIDGE; 1978).

A família Dilepididae é a segunda com mais espécies em Cyclophyllidea, com cerca de 750 registros válidos em cerca de 100 gêneros (CAIRA; JENSEN; BARBEAU, 2012). (BONA, 1994). Os dilepidídeos são parasitas predominantemente em aves, com menos de 10 gêneros explorando mamíferos como hospedeiros definitivos (BONA, 1994) e mostram uma grande especificidade às ordens de hospedeiros nas quais são encontrados. Dilepidídeos tem distribuição cosmopolita e podem ser parasitas em diversas ordens de em aves tanto terrestres quanto aquáticas, entre elas Accipitriformes, Anseriformes, Apodiformes, Caprimulgiformes, Ciconiiformes, Charadriiformes, Cuculiformes, Falconiformes, Gruiformes, Galliformes, Passeriformes, Pelecaniformes, Piciformes, Sphenisciformes e Trogoniformes (BONA, 1994; CAIRA; JENSEN; BARBEAU, 2012). A ampla variedade de nichos ocupados pelos hospedeiros definitivos traz, consequentemente, diversidade para os hospedeiros intermediários, que podem ser anelídeos, moluscos, artrópodes ou peixes (BONA, 1994; PIETROCK; SCHOLZ, 2000; SCHOLZ; SALGADO-MALDONADO, 2001; MUZAFFAR; HOBERG; 
JONES, 2006).

A família com o maior número de espécies de cestódeos é Hymenolepididae, encontrada parasitando aves e mamíferos. As cerca de 900 espécies de parasitas estão locadas em 90 gêneros e aproximadamente 700 são parasitas de aves (CAIRA; JENSEN; BARBEAU, 2012). São registrados himenolepidídeos em Anseriformes, Charadriiformes, Ciconiiformes, Columbiformes, Galliformes, Gaviiformes, Gruiformes, Passeriformes, Pelecaniformes, Piciformes, Phoenicopteriformes e Podicipediformes, com maior quantidade de gêneros presentes em Anseriformes, Charadriiformes e Passeriformes (CZAPLINSKI; VAUCHER, 1994). O ciclo de vida pode ser terrestre ou aquático, de acordo com os hábitos dos hospedeiros definitivos, e envolve anelídeos oligoquetas e artrópodes, geralmente insetos ou crustáceos, com registros pontuais de miriápodes (BONDARENKO; KONTRIMAVICHUS, 1978, 2004, 2006a; CAIRA; JENSEN; BARBEAU, 2012). A distribuição de Hymenolepididae é cosmopolita, com a presença de cada gênero variando de acordo com a distribuição das aves nas quais são encontrados (CZAPLINSKI; VAUCHER, 1994).

\subsection{Hospedeiros: família Thamnophilidae (Passeriformes)}

A família Thamnophilidae é endêmica da região Neotropical, incluindo ilhas próximas ao continente na região caribenha e costa brasileira, com algumas espécies encontradas na zona de transição temperada no sul do México e no norte da Argentina (SKUTCH, 1996; ZIMMER; ISLER, 2016). Os tamnofilídeos pertencem a ordem Passeriformes, locados na subordem Tyranni e a origem da família é resultante da radiação dos furnariídeos (sensu IRESTEDT et al., 2002), seguida da diversificação do grupo a partir do sul do continente em direção à região amazônica, provavelmente durante o Mioceno (23 a 5 Ma) (IRESTEDT et al., 2002). A família é a quarta em número de espécies de passeriformes na América do Sul atrás de Thaupidae, Tyrannidae sensu lato e Furnariidae sensu lato (DEL HOYO et al; 2010), sendo conhecidas mais de 230 espécies em 54 gêneros (PIACENTINI et al., 2015; REMSEN et al., 2016). Dados morfológicos, ecológicos e moleculares sustentam a monofilia da família, porém a sistemática do grupo está sob constante revisão devido a complexos de espécies mal delimitados e a inclusão de dados moleculares nos últimos anos vem trazendo resolução a sistemática do grupo (e.g. BELMONTE-LOPES et al., 2012; BRAVO; CHESSER; BRUMFIELD, 2012; BRAVO et al., 2012; ISLER; BRAVO; BRUMFIELD, 2013, 2014a; 2014b; TELLO et al., 
2014). Para o Brasil são registradas 187 espécies, com mais de 230 subespécies (PIACENTINI et al., 2015).

O habitat mais comum para os tamnofilídeos são sub-bosques, em matas de florestas de baixada, com a maior diversidade de espécies observada nas matas de terra firme na Amazônia brasileira (ZIMMER; ISLER, 2016). A ocupação dos nichos dentro do ambiente de sub-bosque ocorre de acordo com a ecologia de cada táxon, sendo que os seguidores de formiga obrigatórios (ver adiante) são comumente encontrados próximos ao solo (ISLER; BRAVO; BRUMFIELD, 2014b), enquanto outros grupos que seguem formigas facultativamente e podem ser encontrados a cerca de $1 \mathrm{~m}$ do solo (ZIMMER; ISLER, 2016). Alguns táxons encontrados no sub-bosque ainda consideram a composição da vegetação do sub-bosque para sua instalação, como a espécie Herpsilochmus gentryi, encontrada em locais de solo com poucos nutrientes e vegetação característica (WHITNEY; ALONSO, 1998). A diversidade de habitats pode ser observada para outros táxons, uma vez que algumas espécies de tamnofilídeos apresentam predileção por ambientes alagados como brejos, como Formicivora paludicola e F. acutirostris (BUZZETTI et al., 2013), há espécies como Myrmotherula cherriei, Aprositornis disjuncta e Ammonastes pelzelni que são encontradas em ambientes mais secos, como campinas (ISLER; BRAVO; BRUMFIELD, 2013), e espécies como Cercomacroides nigrecens e $C$. serva que são encontrados em dosséis de matas de terra firme (TELLO et al., 2014).

Os tamnofilídeos são conhecidos popularmente como papa-formigas devido ao hábito de algumas espécies em seguir as agregações destes insetos para conseguir alimento; entretanto, algumas destas aves não se alimentam diretamente das formigas, mas de outras presas que são afastadas pelas aglomerações de formigas de correição quando estas se deslocam (WILLIS; ONIKI, 1978). A obrigatoriedade deste hábito varia de acordo com o táxon dentro da família, podendo ser seguido regularmente, como fazem indivíduos dos gêneros Phlegopsis e Rhegmatorhina, ou ser facultativo, como os membros do gênero Willisornis (BRUMFIELD et al., 2007). Assim, há tamnofilídeos cuja alimentação é baseada em insetos de diversas ordens, porém há registros de consumo de outros artrópodes, como aracnídeos, miriápodes e crustáceos isópodes, além de pequenos vertebrados como lagartixas, pequenas rãs e filhotes de outras aves (LOPES; FERNANDES; MARINI, 2005; AGUIAR; COLTRO JÚNIOR, 2008; KUPRIYANOV, 2013; ZIMMER; ISLER, 2016). Os registros sobre a alimentação dos tamnofilídeos são, em grande parte, provenientes de observações dos hábitos de 
forrageamento destas aves, como os trabalhos de Willis nas décadas de 1970 e 1980 (e.g. WILLIS; ONIKI, 1972, 1978; WILLIS, 1984a, 1984b, 1985a, 1985b). Os estudos sobre conteúdo estomacal para os papa-formigas são recentes e muitos são baseados em regurgitação induzida (ver MAJOR, 1990), se restringindo a táxons que podem ser capturados em redes de neblina em número razoável de indivíduos (e.g. GOMES; ALVES; RIBEIRO, 2001; DURÃES; MARINI, 2005), portanto é difícil quantificar a composição alimentar para todas as espécies destas aves.

O consumo regular de insetos e outros artrópodes por papa-formigas aliado à grande diversidade destas aves propiciam uma condição favorável para estudos helmintológicos nestas aves, dado que artrópodes são hospedeiros intermediários de dezenas de helmintos parasitas de aves (ver acima) e a relação entre abundância de espécies e ampla distribuição geográfica também se aplica a parasitas (POULIN, 1999). Apesar de diversos estudos abrangerem a ecologia dos tamnofilídeos (ONIKI, 1971; 1975; SKUTCH, 1996; WHITNEY; PACHECO, 1997; WILLIS; ONIKI, 1972; WILLIS, 1967, 1969, 1972a, 1972b, 1973, 1979, 1981, 1982a, 1982b; ZIMMER, 1999), o conhecimento acerca de seus parasitas ainda é muito pequeno, restrito a um registro de duas espécies de trematódeos em Taraba major na Argentina (LUNASCHI; DRAGO, 2013) e poucos registros de protozoários relacionados com a malária aviária (Apicomplexa) (BERTO et al., 2014; RICKLEFS et al., 2014). Devido às observações de cestódeos em papa-formigas feitas por Travassos nas expedições ao estado do Mato Grosso (TRAVASSOS, 1940a, 1940b; 1941a; TRAVASSOS; FREITAS, 1940; 1942; 1943; TRAVASSOS; FREITAS; LENT, 1939), sabe-se que os tamnofílideos são hospedeiros destes parasitas, porém não há, até o momento, dados publicados acerca da associação entre estes dois grupos. Uma vez que se espera que vertebrados apresentem ao menos uma espécie de cestódeo como parasita (SCHMIDT, 1986), o potencial aumento na diversidade de espécies de solitárias com a busca destes helmintos em papa-formigas é enorme dada a quantidade de espécies e subespécies de tamnofilídeos conhecida. 


\section{OBJETIVOS}

Conforme apresentado na Introdução, e dado o atual estágio de conhecimento sobre os cestódeos parasitas de Aves, especialmente dos Thamnophilidae, na América do Sul, são objetivos desta tese:

a) Inventariar a riqueza e a diversidade de cestódeos parasitas de aves da família Thamnophilidae no sul da região Amazônica brasileira, nos seus principais interflúvios e centros de endemismo;

b) Testar, e eventualmente adequar, os diferentes métodos de coleta de cestódeos para a região amazônica;

c) Caracterizar os cestódeos parasitas de aves da família Thamnophilidae coletados nas localidades selecionadas;

d) Verificar a distribuição de cestódeos parasitas de tamnofilídeos em comparação à distribuição de seus hospedeiros;

e) Verificar as relações de especificidade dos cestódeos parasitas de Aves em relação aos seus hospedeiros;

f) Verificar a adequação das técnicas de Microscopia Eletrônica de Varredura na identificação e caracterização dos táxons parasitas de Aves;

g) Testar as chaves identificação disponíveis para os cestódeos parasitas de Aves;

h) Identificar possíveis novos táxons de cestódeos parasitas de Aves. 


\section{MATERIAL E MÉTODOS}

\subsection{Amostragem e coleta dos hospedeiros}

Os tamnofilídeos analisados neste estudo foram coletados entre setembro de 2012 e setembro de 2015 , durante amostragens padronizadas de avifauna realizadas em áreas de floresta amazônica de Terra Firme em ambas as margens do rio Madeira, compreendendo os interflúvios Purus/Madeira e Madeira/Tapajós na região de Porto Velho (RO); em ambas as margens do rio Ji-Paraná, na região do município de Machadinho d’Oeste (RO), no interflúvio Madeira Tapajós, em ambas as margens do rio Xingu, nos interflúvios Tapajós/Xingu e Xingu/Araguaia-Tocantins, no município de Altamira (PA) e na margem esquerda do rio Araguaia, no interflúvio Xingu/Araguaia-Tocantins, no município de Santana do Araguaia (PA), totalizando seis grandes áreas amostrais nos principais Centros de Endemismo para Aves ao sul do rio Amazonas (CRACRAFT, 1985) (ANEXO A, Figura 1).

Os indivíduos utilizados neste estudo foram coletados com autorização do Instituto Brasileiro do Meio Ambiente e dos Recursos Naturais Renováveis (licença 28198-5), e os métodos de eutanásia foram aprovados pelo Comitê de Ética no Uso de Animais do Instituto de Biociências da Universidade de São Paulo (protocolo 01/2016). As aves foram coletadas com auxílio de arma do fogo e redes de neblina, e as que foram capturadas neste último método sendo sacrificadas através de compressão torácica (ver PIACENTINI et al., 2010). A identificação dos hospedeiros foi realizada em campo e posteriormente conferida e refinada através da comparação direta dos exemplares coletados com aqueles presentes na Seção de Aves do Museu de Zoologia da Universidade de São Paulo, em cuja coleção de referência todos os indivíduos amostrados foram depositados. Os nomes atribuídos aos hospedeiros seguem a lista do Comitê Brasileiro de Registros Ornitológicos (PIACENTINI et al., 2015). Como este trabalho teve cunho biogeográfico e um dos seus objetivos foi o de comparar os parasitas e os seus hospedeiros entre grandes áreas ao sul do rio Amazonas, optou-se por identificar as aves em seu menor nível taxonômico (subespécies), dado o fato de que muitos destes táxons estão se revelando como espécies plenas e que os grandes rios amazônicos atuam como barreiras. 


\subsection{Processamento do material biológico em campo}

As primeiras três amostragens de endoparasitas para tamnofilídeos realizadas neste estudo seguiram os protocolos tradicionais para obtenção de helmintos em campo, sem análise in situ (e.g. SCHMIDT, 1986; GEORGIEV; VAUCHER, 2001). Desta forma, as aves foram necropsiadas imediatamente após sua morte, seus intestinos retirados e abertos longitudinalmente, sendo em seguida lavados com solução salina ou água e fixados em formalina a $4 \%$ morna $\left(\sim 75^{\circ} \mathrm{C}\right)$ e posteriormente transferidos para etanol $70 \%$ para armazenamento. Para estudos complementares, alguns intestinos foram fixados em etanol 100\% para posteriores análises moleculares. Para estudos futuros, também foram fixados, em formalina ou etanol, vesículas biliares e fígados para posterior busca de trematódeos, e estômagos para posterior busca de nematódeos e seu conteúdo.

Dadas as condições climáticas muito adversas em campo, a partir da quarta campanha de amostragem o processamento do material in situ foi modificado (ver resultados e discussão). Os hospedeiros coletados foram mantidos resfriados com auxílio de bolsas de gel térmico congelado e transportados em sacolas térmicas e dissecados posteriormente. Os seus intestinos foram retirados e abertos longitudinalmente, em seguida lavados com água morna para relaxamento dos parasitas, fixados em formalina a $10 \%\left(\sim 75^{\circ}\right)$ e posteriormente transferidos para etanol $70 \%$ para armazenamento. Este procedimento também foi adotado na fixação de vesículas biliares, fígados e estômagos e seus conteúdos e o protocolo para fixação de amostras visando estudos moleculares não foi alterado.

\subsection{Processamento do material biológico em laboratório}

As amostras coletadas para estudos morfológicos foram armazenadas em etanol $70 \%$ e o material para estudos moleculares foi armazenado em etanol $100 \%$ e mantido sob refrigeração. Todos os intestinos amostrados, independente de seu meio fixador, foram triados em busca de helmintos visando a obtenção de dados sobre a infestação de cestódeos para cada táxon de hospedeiro. Dentre os helmintos fixados em formalina foram selecionados espécimes para análises de microscopias óptica e eletrônica de varredura e, quando possível, indivíduos foram mantidos em meio líquido para eventuais usos de outras técnicas (e.g. cortes histológicos). 
Os espécimes destinados para obtenção de dados de microscopia óptica foram corados em Carmim Acético Alcoólico de Langeron (LANGERON, 1949), desidratados em séries alcoólicas progressivas, diafanizados em Salicilato de Metila e montados entre lâmina e lamínula com Bálsamo do Canadá. Dados merísticos e morfométricos foram obtidos em um microscópio óptico Olympus BX51 com ocular micrométrica. Dados morfométricos foram medidos através de imagens obtidas pelo software analySIS 5.0 Olympus Soft Images Solutions por uma câmera Olympus SC30 acoplada em um microscópio óptico Olympus BX51.

Os parâmetros taxonômicos considerados neste estudo baseiam-se em Khalil, Jones e Bray (1994) e na literatura pertinente a cada táxon encontrado, publicada posteriormente a esta referência. As definições dos estágios de desenvolvimento de proglótides seguem Georgiev e Vaucher (2001). A identificação de táxons descritos imprecisamente na literatura e de alguns novos táxons foi feita com o auxílio do Dr. Boyko Georgiev, da Academia de Ciências da Bulgária, para quem foram enviadas imagens em alta resolução.

Os espécimes adultos e proglótides destacadas com o cirro evertido destinados à microscopia eletrônica de varredura (M.E.V.) foram selecionados em amostras nas quais a quantidade de espécimes era maior que 3 indivíduos devido a baixa intensidade de infecção encontrada na maioria dos hospedeiros analisados (ver resultados e discussão). Para os espécimes adultos maiores que 2 milímetros, os escóleces foram separados de seus estróbilos, e seus estróbilos foram montados em lâminas permanentes para posterior identificação seguindo o protocolo para preparação de espécimes para microscopia óptica. Os espécimes até 2 milímetros de comprimento foram preparados completos para a M.E.V.. Todas as amostras foram hidratadas em séries alcoólicas regressivas, imersas em solução de Tetróxido de Ósmio 1\% por aproximadamente 1 hora, desidratadas em séries alcoólicas progressivas, imersas em hexametildisalazano, secas ao ar livre por aproximadamente 12 horas, montadas em suportes de alumínio e cobertas com ouro no metalizador Bal-Tec SCD050 Balzers Sputter Coater. Os espécimes foram analisados sob microscópio eletrônico de varredura Zeiss DCM 940 no Laboratório de Biologia Celular e Microscopia Eletrônica e Confocal do Instituto de Biociências (IB-USP). As imagens obtidas foram analisadas com auxílio do programa ImageJ (RASBAND, 1997-2016). A nomenclatura empregada na descrição das microtríquias segue Chervy (2009).

Parâmetros morfométricos estão expressos em micrômetros, exceto se indicado 
outra unidade métrica. Todos os parâmetros são apresentados nesta ordem: variação, média, desvio padrão e número amostral. Para medidas bidimensionais, o comprimento é apresentado antes da largura. Os parâmetros que não foram observados devido ao táxon não apresentar determinado estágio de maturidade foram classificados como não aplicáveis. Os parâmetros que não foram observados devido à indisponibilidade de determinado estágio de maturidade ou região de captura em M.E.V. foram classificados como indisponíveis. 


\section{RESULTADOS E DISCUSSÃO}

\subsection{Processamento do material biológico em campo}

Ao todo, foram obtidos 487 indivíduos pertencentes a 81 táxons (ANEXO B), sendo esta a maior amostragem já feita para a pesquisa de endoparasitas até hoje para esta família de aves. O material coletado nas primeiras amostragens com a utilização dos protocolos tradicionais (e.g. SCHMIDT, 1986; GEORGIEV; VAUCHER, 2001) resultou na obtenção de exemplares de cestódeos satisfatórios para análises morfológicas. Entretanto, a partir da quarta campanha de amostragem, observou-se que a combinação de fatores climáticos (alta temperatura) e logística (distância entre as áreas, transporte do material) estava deixando os espécimes em condições inadequadas para o estudo. Assim, foi necessário adequar os protocolos para um melhor aproveitamento do material biológico coletado. Desenvolvidos em regiões de clima temperado, estes protocolos de análise e fixação de cestódeos requerem que a procura pelos helmintos seja feita imediatamente após a coleta do hospedeiro, restringindo a busca de endoparasitas ao número possível de dissecções feitas durante a amostragem das aves. Uma vez que as amostragens para o presente estudo foram realizadas em localidades amazônicas isoladas, exigiu-se a montagem de bases temporárias para dissecções em campo e este método mostrou-se bem-sucedido durante a estação seca, porém inexequível durante as amostragens em estações chuvosas, tornando necessária uma remodelagem dos protocolos utilizados que permitisse a manutenção dos hospedeiros coletados para posterior busca de endoparasitas.

A adequação dos protocolos para busca de endoparasitas para a estação chuvosa foi baseada na literatura, em busca de um procedimento que pudesse postergar a dissecção das aves. A partir da sugestão de diversos autores em manter os hospedeiros resfriados sem congelamento (e. g. SCHMIDT, 1986; CRIBB; BRAY, 2010; JUSTINE; BRIAND; BRAY, 2012), optou-se por resfriar as aves recém coletadas em campo, com a utilização de bolsas de gel térmico e sacolas térmicas para transporte. Os espécimes de hospedeiros mantidos resfriados foram transportados até o alojamento disponível e então colocados em geladeira por até 8 horas após sua morte, período máximo em que os cestódeos foram observados vivos em seus hospedeiros.

A manutenção das aves resfriadas possibilitou inferências sobre a conservação 
destas, sendo que se observou que espécimes de tamnofilídeos de menor tamanho, como as pertencentes aos gêneros Myrmotherula e Epinecrophylla, apresentam menor resistência ao resfriamento, cerca de 3 horas, devendo ser dissecadas antes das demais. Aves de tamanho médio, como as pertencentes aos gêneros Phlegopsis e Hafferia, apresentaram parasitas sem degeneração mesmo após 6 horas de sua coleta. O procedimento foi testado com aves de outros táxons além dos tamnofilídeos mostrando-se bem-sucedido, principalmente para os psitacídeos e picídeos, nos quais cestódeos vivos e sem degeneração foram observados após 8 horas da morte do hospedeiro. Alguns grupos como caprimulgiformes e trogoniformes, entretanto, apresentaram sinais de deterioração nos órgãos digestórios se mantidos sob refrigeração por mais de 3 horas, indicando que o tempo de adiamento da dissecção deve ser ajustado de acordo com a ave estudada. As observações sobre o tempo de espera para a disseç̧ão em aves que não pertenciam à família Thamnophilidae foram feitas de maneira aleatória, de acordo com as aves coletadas na amostragem de rede para outros estudos da Seção de Aves do MZUSP, e ainda necessitam de uma amostra com mais indivíduos e mais abrangente em relação aos táxons de aves para que seja possível determinar um protocolo preciso, porém os dados obtidos neste estudo já permitem que o material coletado em amostras amplas seja aproveitado de modo mais eficiente.

Adicionalmente à necessidade de adequação do protocolo às condições climáticas, verificou-se que o número de espécimes de tamnofilídeos analisados para presença de endoparasitas estava abaixo daquele observado para a captura destas aves em redes de neblina durante as amostragens nas primeiras três campanhas. Devido a necessidade de que o biólogo responsável pela dissecção das aves estivesse presente no local de coleta e a realizasse em um curto intervalo de tempo, a amostragem estava restrita à presença e capacidade de trabalho deste, resultando em diversos espécimes de aves capturados e não analisados para endoparasitas. Visto que a coleta de aves durante as campanhas realizadas foi feita em diferentes pontos de amostragem simultaneamente (até 10 em algumas amostragens), o potencial número de aves para análise em busca de helmintos era superior ao número de hospedeiros efetivamente amostrado. Além disso, outros táxons de aves além da família Thamnophilidae foram analisados em busca de endoparasitas, resultando em maior aproveitamento do material biológico coletado e viabilizando futuros estudos helmintológicos para a região amazônica.

A simplificação do protocolo de dissecção das aves em busca de endoparasitas e a 
possibilidade de executá-lo posteriormente ao trabalho de campo junto às aves também permitiu que este fosse executado por ornitólogos sem treinamento prévio em parasitologia. A técnica de dissecção e de busca e fixação dos parasitas foi testada com membros da equipe ornitológica em campo e posteriormente apresentada no XXI Congresso Brasileiro de Ornitologia (LUCHETTI; SILVEIRA, 2014), sendo bem recebida por estes profissionais devido a sua fácil execução e melhor aproveitamento das aves coletadas.

\subsection{Triagem das amostras}

A triagem dos 486 intestinos de tamnofilídeos analisados para este estudo resultou em 97 infestados por espécimes de cestódeos, apresentando prevalência de 20\% para estes parasitas nesta família de aves, enquanto a prevalência de cestódeos observada em cada espécie/subespécie de hospedeiro apresentou variação entre 5\% e 100\% (ANEXO C). Entre os gêneros de hospedeiros analisados, 21 dos 29 amostrados apresentaram infestação, ou cerca de $73 \%$, ao passo que a infestação por cestódeos foi observada em cerca de $50 \%$ das 81 espécies ou subespécies de hospedeiros amostrados, em um total de 41 táxons de tamnofilídeos parasitados por pelo menos um morfotipo de solitária (ANEXO C). Outros parâmetros quantitativos para descrição de populações de parasitas, como intensidade e densidade da infestação (BUSH et al., 1997), não foram estabelecidos devido a impossibilidade da contagem exata dos indivíduos parasitas coletados, uma vez que alguns espécimes se partiram durante o processo de coleta e triagem e resultaram em amostras com diversos segmentos parciais. A contagem de espécimes pode ser feita de acordo com o número de escóleces presente na amostra, porém em alguns dos intestinos triados não foram encontrados os escóleces, sendo os fragmentos recuperados apenas estrobilares e inviabilizando a contagem exata de indivíduos. Decidiu-se, portanto, estabelecer parâmetros quantitativos apenas nas amostras em que o número de cestódeos fosse estabelecido com precisão, para cada táxon de parasita observado em relação a cada hospedeiro (ver adiante).

\subsection{Diversidade de cestódeos}

A amostragem de tamnofilídeos resultou em 81 táxons de hospedeiros analisados em busca de cestódeos, com registro de 83 ocorrências (morfotipos) destes parasitas em 41 
táxons de aves (ver adiante). A identificação dos espécimes não pode ser feita com a literatura disponível, uma vez que as descrições de cestódeos para o Brasil são desatualizadas e não incluem caracteres utilizados hoje na taxonomia do grupo, necessitando revisão. O emprego usual da especificidade parasita-hospedeiro na identificação do parasita também se mostrou como um impedimento para determinação dos grupos aos quais os cestódeos encontrados pertenciam, pois não há helmintos descritos parasitando a família Thamnophilidae e não é possível afirmar se estes apresentam especificidade restrita sem o refino de sua taxonomia. Assim, decidiu-se por caracterizar as amostras obtidas de acordo com as principais características das famílias as quais pertencem e seus hospedeiros, afim de possibilitar a diferenciação de morfotipos que permitam agrupamentos para estudos taxonômicos futuros. De acordo com tais parâmetros, tem-se:

\subsubsection{Cercomacroides}

\subsubsection{Cercomacroides nigrecens ochrogyna (Cabanis \& Heine, 1859)}

Localidades amostradas: Altamira, Pará, margem esquerda do rio Xingu, Centro de Endemismo Tapajós (4 espécimes) e margem direita do rio Xingu, Centro de Endemismo Xingu (3 espécimes); Santana do Araguaia, Pará, Fazenda Fartura, margem esquerda do Rio Araguaia, Centro de Endemismo Xingu (1 espécime).

Localidades de hospedeiros infestados: Altamira, Pará, Centro de Endemismo Xingu (1 espécime).

Prevalência da infestação: 12,5\% (1 hospedeiro infestado em 8 analisados).

Intensidade da infestação: indeterminada.

Cestoda observados: 1 morfotipo; Dilepididae (D01; ANEXO D, Figura 2 A-B).

Caracterização D01: Um espécime completo, um espécime incompleto e trinta segmentos incompletos e/ou destacados. Espécime completo imaturo, comprimento total e número de proglótides indeterminados. Escólex com maior largura na região das ventosas $138(n=1)$. Aparato rostelar musculo-glandular, rostelo muscular, bolsa rostelar com parede mediana. Coroa simples de ganchos rostelares, uniformes, arcuatóides, 12 ganchos em número $(n=1)$, $11,60 \mu \mathrm{m}$ de comprimento $(n=1)$. Ventosas redondas, $58 \mu \mathrm{m}$ de diâmetro $(n=1)$, musculares. 
Proglótides craspedotas, com margens arredondadas, proglótide pós madura 156 × 189,30 $(n=1)$, proglótide pré grávida $301,50 \times 231,70(n=1)$. Dutos osmorregulatórios não observados. Poro genital alternado, padrão de alternância indeterminado, a 25\% da margem anterior da proglótide pós madura, a 34\% da margem anterior da proglótide pré grávida. Testículos 7 em número $(n=1), 5$ porais e 2 aporais, posteriores ao ovário. Saco do cirro oval, com parede mediana, cirro sem espinhos visíveis em microscopia óptica. Vitelário mediano, compacto, de forma irregular e posterior ao ovário. Ovário com dois lobos alados, unidos na região mediana por um istmo. Glândula de Mehlis não distinguível. Útero nas proglótides pré grávidas saculiforme, ovos completamente desenvolvidos não disponíveis.

Considerações: Os espécimes de $C$. nigrecens ochrogyna mostraram baixa prevalência na infestação por cestódeos (12,5\%), apesar do número amostral de hospedeiros ser razoável ( $n=8)$ e da ampla distribuição geográfica das amostras (3 localidades). Os cestódeos foram registrados apenas para a região Tapajós, porém a baixa prevalência associada a presença de helmintos restrita a um indivíduo hospedeiro não permite inferir a influência do rio Xingu como barreira na distribuição destes grupos. A qualidade da amostra obtida não permitiu que a identificação dos cestódeos encontrados fosse efetiva, pois não há indivíduos adultos completos disponíveis para observação de caracteres informativos para dilepidídeos, como o padrão de alternância dos poros genitais e desenvolvimento inicial do útero nas proglótides pós maduras e pré grávidas (ver BONA, 1994X). A descrição formal deste morfotipo de cestódeo implica em aumento do esforço amostral para o hospedeiro e, possivelmente, adição de localidades de coleta, uma vez que a área onde a amostra deste estudo foi obtida não é mais acessível.

\subsubsection{Cercomacroides serva hypomelaena (Sclater, 1890)}

Localidade amostrada: Porto Velho, Rondônia, margem esquerda do rio Madeira, Centro de Endemismo Inambari (4 espécimes).

Prevalência da infestação: 25\% (1 hospedeiro infestado em 4 analisados).

Intensidade da infestação: 2 espécimes por hospedeiro (NI01).

Cestoda observados: 1 morfotipo; não identificado (NI01; ANEXO D, Figura 3). 
Caracterização NI01: Dois espécimes completos, em estágio larval anterior ao desenvolvimento do escólex. Região anterior invaginada, lacuna primária ausente, cercomero ausente.

Considerações: De acordo com CHERVY (2002), a classificação dos estágios larvais de cestódeos é baseada primariamente na presença da lacuna primária e na retração ou invaginação do escólex, considerando secundariamente a presença de cercomero. Os espécimes obtidos parasitando C. serva hypomelaena não apresentam tais estruturas diferenciadas, impossibilitando sua identificação e indicando que tais indivíduos podem estar no início de sua diferenciação e ser resultado de infestação recente ou pertencer a algum grupo de cestódeos que não completa seu desenvolvimento neste hospedeiro ou mesmo em aves. Devido ao número restrito de hospedeiros amostrados $(n=4)$ e infestados $(n=1)$ e nenhum helminto adulto ser observado, não é possível inferir quaisquer informações sobre estes parasitas, indicando a necessidade de aumento do esforço amostral para este hospedeiro.

\subsubsection{Clytoctantes}

\subsubsection{Clytoctantes atrogularis Lanyon, Stotz \& Willard, 1991}

Localidade amostrada: Machadinho d'Oeste, Rondônia, margem esquerda do rio Ji-Paraná, Centro de Endemismo Rondônia (2 espécimes).

Prevalência de infestação: nenhum hospedeiro infestado.

Considerações: Os espécimes de $C$. atrogularis analisados neste estudo foram coletados na mesma data e localidade, sugerindo que a ausência de cestódeos nestas aves pode ser resultado da restrição numérica e geográfica dos hospedeiros amostrados. A verificação da presença destes helmintos em indivíduos de $C$. atrogularis depende do aumento do esforço amostral para este hospedeiro, porém a escassez de dados acerca da biologia e distribuição destas aves (ZIMMER et al., 2016) em conjunto com a sua classificação vulnerável na Red List da Bird Life International (2016) dificultam a coleta e análise de um maior número de espécimes. Devido esta restrição na obtenção de novos indivíduos hospedeiros, não é 
possível propor um incremento na coleta destas aves, portanto os dados disponíveis neste estudo dificilmente serão complementados.

\subsubsection{Cymbilaimus}

\subsubsection{Cymbilaimus lineatus intermedius Hartert \& Goodson, 1917}

Localidade amostrada: Porto Velho, Rondônia, margem direita do rio Madeira, Centro de Endemismo Rondônia (1 espécime).

Prevalência de infestação: nenhum hospedeiro infestado.

Considerações: A amostragem da espécie $C$. lineatus intermedius foi restrita a um indivíduo, pois este apresenta seu habitat em dossel em matas de terra firme e não é comumente capturado em redes de neblina (ZIMMER; ISLER, 2016). Os hábitos alimentares da espécie incluem insetos, aracnídeos e pequenos vertebrados, capturados na faixa de 5 a $25 \mathrm{~m}$ do dossel (ZIMMER; ISLER, 2016), com esparsos registros de forrageamento em bandos mistos e não seguindo formigas de correição (THIOLLAY, 1988). As particularidades de habitat e nos hábitos de forrageamento desta espécie não permitem que inferências sobre sua fauna de helmintos associada sejam feitas a partir da fauna encontrada em outras espécies de tamnofilídeos amostradas neste estudo, uma vez que as espécies estudadas são majoritariamente encontradas na faixa de sub-bosque.

\subsubsection{Dichrozona}

\subsubsection{Dichrozona cincta zononota Ridgway, 1888}

Localidade amostrada: Porto Velho, Rondônia, margem esquerda do rio Madeira, Centro de Endemismo Inambari (3 espécimes); Machadinho d'Oeste, Rondônia, margem direita do rio Ji-Paraná, Centro de Endemismo Rondônia (1 espécime).

Prevalência de infestação: nenhum hospedeiro infestado.

Considerações: Os indivíduos de $D$. cincta zononota foram obtidos em pontos de coleta 
distintos e localizações em ambas as margens do rio Madeira, não resultando em nenhum registro de cestódeos associados a esta espécie de ave. A coleta de apenas um indivíduo no Centro de Endemismo Rondônia não permite inferir sobre a associação entre helmintos neste tamnofílideo devido à restrição no número amostral de espécimes, porém a amostra obtida no Centro de Endemismo Inambari, igual a três indivíduos, indica que esta pode ser uma espécie com baixa diversidade e abundância em sua fauna de parasitas. Ambas as regiões necessitam de aumento do esforço amostral deste possível hospedeiro. Os hábitos de forrageamento desta espécie são pouco conhecidos, provavelmente sendo baseados em artrópodes uma vez que os indivíduos são comumente encontrados próximos ao solo (ZIMMER; ISLER, 2016) e indicam que $D$. cincta pode ter parasitas de hábito oioxeno, uma vez que outros tamnofilídeos que costumam forragear próximos ao solo apresentam cestódeos como parasitas (ver adiante) que não são encontrados nesta espécie.

\subsubsection{Epinecrophylla}

\subsubsection{Epinecrophylla amazonica (Ihering, 1905)}

Localidade amostrada: Porto Velho, Rondônia, margem esquerda do rio Madeira, Centro de Endemismo Inambari (11 espécimes).

Prevalência da infestação: 18\% (2 hospedeiros infestados em 11 analisados).

Intensidade da infestação: variável; 1 espécime por hospedeiro (H01 e H02); 2 espécimes por hospedeiro ( $\mathrm{HO3})$.

Cestoda observados: 3 morfotipos; Hymenolepididae (H01; ANEXO D, Figura 4); (H02; ANEXO D, Figura 5); (HO3).

Caracterização H01: Um espécime incompleto. Espécime com proglótides grávidas presentes, comprimento total e número total de segmentos indeterminados. Escólex com maior largura na região das ventosas $363,78(n=1)$. Base rostelar musculo-glandular, rostelo muscular, bolsa rostelar com parede mediana. Coroa simples de ganchos rostelares, uniformes, fraternóides, 26 ganchos em número $(n=1), 34,75 \mu m$ de comprimento $(n=1)$. Ventosas redondas, $123,57 \mu \mathrm{m}$ de diâmetro $(n=1)$, musculares, sem espinhos. Proglótides craspedotas, com margens arredondadas, proglótide madura 102,90 $542(n=1)$, proglótide 
pré grávida 160,55 x 748,80 (n=1), proglótide grávida 214,70 x 805,55 (n=1). Número de dutos osmorregulatórios não determinado. Poro genital unilateral, a 15\% da margem anterior da proglótide madura, a 19\% da margem anterior da proglótide pré grávida. Testículos ovais, 3 em número em todas as proglótides visíveis, em disposição triangular com 1 poral e 2 aporais. Saco do cirro oval, com parede mediana, entre os dutos osmorregulatórios, cirro sem espinhos visíveis em microscopia óptica. Vitelário mediano, compacto, elíptico, posterior aos demais órgãos. Ovário com 3 lobos transversais elongados, mediano. Glândula de Mehlis não distinguível. Útero nas proglótides pré grávidas saculiforme. Ovos esféricos com cerca de $13 \mu \mathrm{m}$ de diâmetro $(n=1)$, oncosferas esféricas com

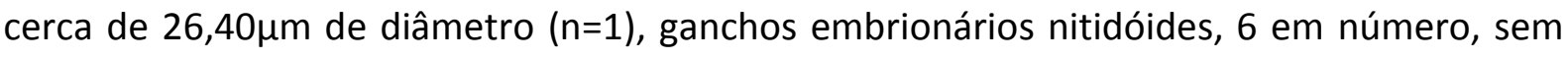
comprimento disponível.

Caracterização H02: Um espécime incompleto, parte reservada para análises moleculares, dados morfométricos não analisados devido à fixação em etanol. Espécime com parte masculina madura ausente e segmentos finais grávidos, comprimento total e número total de segmentos indeterminados. Escólex com maior largura na região das ventosas. Base rostelar muscular, sem parte glandular visível, rostelo muscular, bolsa rostelar com parede mediana. Coroa simples de ganchos rostelares, uniformes, arcuatóides, 8 ganchos em número $(n=1)$. Ventosas redondas, musculares, sem espinhos. Proglótides craspedotas, com margens arredondadas. Número de dutos osmorregulatórios não determinado. Poro genital unilateral, posição anterior na margem lateral da proglótide. Segmentos com testículos ausentes. Saco do cirro oval, com parede mediana, entre os dutos osmorregulatórios, cirro sem espinhos visíveis em microscopia óptica. Vitelário mediano, compacto, achatado transversalmente, posterior aos demais órgãos. Ovário com 3 lobos transversais elongados, mediano. Glândula de Mehlis não distinguível. Útero nas proglótides pré grávidas saculiforme. Ovos esféricos e oncosferas esféricas, ganchos embrionários não visíveis.

Caracterização H03: Dois espécimes incompletos, partes reservadas para análises moleculares, dados morfométricos não analisados devido à fixação em etanol. Espécimes adultos, segmentos finais ausentes, maturidade indeterminada. Escólex com maior largura na região das ventosas. Base rostelar muscular, sem parte glandular visível, rostelo muscular, bolsa rostelar com parede mediana. Coroa simples de ganchos rostelares, 
uniformes, arcuatóides, 32 ganchos em número $(n=2)$. Ventosas redondas, musculares, sem espinhos. Proglótides craspedotas, com margens arredondadas. Número de dutos osmorregulatórios não determinado. Poro genital unilateral, posição anterior na margem lateral da proglótide. Segmentos com testículos ausentes. Saco do cirro oval, com parede mediana, entre os dutos osmorregulatórios, cirro sem espinhos visíveis em microscopia óptica. Vitelário mediano, compacto, achatado transversalmente, posterior aos demais órgãos. Ovário com 3 lobos transversais elongados, mediano. Glândula de Mehlis não distinguível. Segmentos posteriores aos maduros ausentes.

Considerações: A amostra obtida para E. amazonica em busca de cestódeos foi mais ampla que as demais espécies do gênero $(n=11)$, apresentando prevalência $(18 \%)$ próxima à média observada para todas as amostradas analisadas neste estudo (20\%). Os dois indivíduos parasitados mostraram distinção na composição de sua fauna de helmintos, totalizando 3 morfotipos de cestódeos pertencentes a família Hymenolepididae, caracterizados por ganchos arcuatóides e presença de três testículos em proglótides maduras. Os três morfotipos foram diferenciados primariamente em relação ao número de ganchos presentes na coroa rostelar (26 8 8 32), de acordo com Czaplinski e Vaucher (1994). O morfotipo H01 foi observado em um indivíduo, enquanto $\mathrm{HO2}$ e $\mathrm{HO}$ foram encontrados em outro único espécime hospedeiro. A observação dos dutos osmorregulatórios, caractere importante para a determinação da subfamília, não foi possível nestes espécimes e não permitiu a identificação do gênero a que estes cestódeos possam pertencer (ver discussão adiante). A coleta dos hospedeiros em pontos próximos de uma mesma localidade indica que a diversidade dos helmintos destas aves é bastante alta, já que três morfotipos distintos de cestódeos foram observados em apenas uma espécie de hospedeiro.

\subsubsection{Epinecrophylla dentei Whitney, Isler, Bravo, Aristizábal, Schunck, Silveira \&} Piacentini, 2013

Localidade amostrada: Machadinho d'Oeste, Rondônia, margens esquerda e direita do rio JiParaná, Centro de Endemismo Rondônia (4 espécimes)

Prevalência da infestação: 75\% (3 hospedeiros infestados em 4 analisados).

Intensidade da infestação: 2 espécimes por hospedeiro ( $\mathrm{HO4}$ ), indeterminada ( $\mathrm{NIO2).}$ 
Cestoda observados: 2 morfotipos; Hymenolepididae (H04; ANEXO D, Figura 6); não identificado cf. Paruterinidae (NI02; ANEXO D, Figura 7).

Caracterização H04: Um espécime completo e três incompletos. Espécime completo 10,30mm ( $n=1)$, composto por 136 proglótides, proglótides grávidas presentes. Escólex com maior largura na região das ventosas 338,20 (n=1). Base rostelar musculo-glandular, rostelo muscular, bolsa rostelar com parede delgada. Coroa simples de ganchos rostelares, uniformes, arcuatóides, incompleta, ao menos 15 ganchos presentes, 39,95 $\mu \mathrm{m}$ de comprimento $(n=1)$. Ventosas redondas, $174,50 \mu m$ de diâmetro $(n=1)$, musculares, sem espinhos. Proglótides craspedotas, com margens arredondadas, proglótide madura 44,92 $\mathrm{x}$ 195,75 (n=1), proglótide pré grávida 46,55 x $315(n=1)$, proglótide grávida 64,50 x 310,65 $(n=1)$. Número de dutos osmorregulatórios não determinado. Poro genital unilateral, a $24 \%$ da margem anterior da proglótide madura e da proglótide pré grávida, a 19\% da margem anterior da proglótide pré grávida. Testículos ovais, 3 em número em todas as proglótides visíveis, em disposição triangular com 1 anterior central e 2 posteriores laterais. Saco do cirro oval, com parede mediana, entre os dutos osmorregulatórios, cirro sem espinhos visíveis em microscopia óptica. Vitelário mediano, compacto, elíptico, posterior aos demais órgãos. Ovário com 2 lobos transversais elongados, mediano. Glândula de Mehlis não distinguível. Útero nas proglótides pré grávidas saculiforme. Ovos esféricos com cerca de $3,80 \mu \mathrm{m}$ de diâmetro $(n=1)$, oncosferas esféricas com cerca de $14,50 \mu \mathrm{m}$ de diâmetro $(n=1)$, ganchos embrionários não visíveis.

Caracterização NI02: Dois segmentos estrobilares, proglótides pré grávidas e grávidas. Proglótides craspedotas, posição do poro genital indeterminada. Útero em forma de ferradura em proglótides grávidas e arredondado com septos em proglótides grávidas, posterior. Órgão paruterino com paredes medianas, com porção anterior mais desenvolvida e circundando o útero. Ovos esféricos e oncosferas elípticas, ganchos embrionários visíveis na porção central.

Considerações: Os indivíduos de E. dentei que apresentaram infestação de cestódeos foram coletados nas margens direita $(n=2)$ e esquerda $(n=1)$ do rio Ji-Paraná, apresentando distinção nos morfotipos de helmintos de acordo com a localidade em que foram coletados. 
Os hospedeiros provenientes da margem direita estavam parasitados por espécimes pertencentes a um morfotipo da família Hymenolepididae (H04), enquanto na ave coletada na margem esquerda do rio foi encontrado um fragmento estrobilar não identificado, provavelmente pertencente à família Paruterinidae (NIO2). A amostra limitada ( $n=1$ e $n=2$ ) dos hospedeiros provenientes de apenas um ponto de coleta em cada margem não permite afirmar que o rio atue como uma barreira na distribuição destes cestódeos, mas indica que a diversidade dos parasitas para um hospedeiro pode ser maior de acordo com a ampliação de sua distribuição. Os dados obtidos para cestódeos parasitas de E. dentei indicam a necessidade do aumento do esforço amostral para este hospedeiro. A identificação dos morfotipos de helmintos encontrados não foi possível com a literatura disponível.

\subsubsection{Epinecrophylla leucophtalma leucophtalma (Pelzeln, 1868)}

Localidades amostradas: Porto Velho, Rondônia, margem esquerda do rio Madeira, Centro de Endemismo Inambari (4 espécimes) e margem direita do rio Madeira, Centro de Endemismo Rondônia (3 espécimes).

Localidades de hospedeiros infestados: Porto Velho, Rondônia, Centros de Endemismo Inambari (1 espécime) e Rondônia (1 espécime).

Prevalência da infestação: $28,5 \%$ (2 hospedeiros infestados em 7 analisados).

Intensidade da infestação: indeterminada.

Cestoda observados: 1 morfotipo; Paruterinidae; Sphaeruterina cf. (P01; ANEXO D, Figura 8 A-C).

Caracterização P01: Um espécime completo e três espécimes incompletos. Espécime completo grávido, comprimento total e número total de segmentos indeterminados. Escólex com maior largura na região das ventosas $211-264(237,50 \pm 37,48, n=2)$. Rostelo oval, sem parte muscular ou glandular visível. Coroa dupla alternada de ganchos rostelares, uniformes, triangulares, 24 ou 26 em número $(n=2), 22,90 \mu m$ de comprimento $(n=1)$. Ventosas redondas, sem dobras, $98,30 \mu m$ de diâmetro $(n=1)$, musculares, com microtríquias visíveis em microscopia óptica. Proglótides craspedotas, com margens arredondadas, proglótides maduras 120,70-129,80 $(125,3 \pm 6,40, n=2) \times 388,50-396(392,2 \pm 5,30, n=2)$, proglótide grávida 532,5 x $360(n=1)$. Dutos osmorregulatórios não observados em todos os estágios de 
desenvolvimento. Poro genital unilateral ou alternado irregularmente, a $27 \%$ da margem anterior da proglótide madura. Testículos 6 em número $(n=1)$, agrupados, posteriores ao ovário. Saco do cirro oval, lateral aos dutos osmorregulatórios em proglótides maduras. Vitelário mediano, compacto, oval e posterior ao ovário. Ovário com dois lobos alados, unidos na região mediana por um istmo. Glândula de Mehlis não distinguível. Útero em forma de ferradura em proglótides pré grávidas e arredondado com septo dorsal em proglótides grávidas, posterior. Órgão paruterino com paredes espessas, em forma de tubo curvo e porção anterior esférica, anterior ao útero. Ovos esféricos, $20 \mu \mathrm{m}$ de diâmetro $(n=2)$, oncosferas elípticas, 39,50-44,80 (42,82 $\pm 2,83, n=6) \times 31,61-38,18(34,50 \pm 2,24, n=6)$, ganchos embrionários visíveis na porção central.

Considerações: Os espécimes encontrados em E. I. leucophtalma possuem características próximas independente da região em que os seus hospedeiros foram coletados, uma vez que uma das aves infestadas foi obtida no Centro de Endemismo Inambari e a outra no Centro de Endemismo Rondônia. O órgão paruterino dos cestódeos analisados coincide em forma com o observado em espécimes do gênero Sphaeruterina, porém a descrição deste gênero (JOHNSTON, 1914) descreve duas coroas alternadas de ganchos de formas e tamanhos distintos (cerca de 70 e $45 \mu \mathrm{m}$, respectivamente), o que não é observado nos espécimes obtidos neste estudo, que possuem ganchos triangulares uniformes nas duas coroas. A caracterização do gênero proposta por Georgiev e Kornyushin (1994) não cita a forma dos ganchos em cada uma das coroas como um caractere informativo, portanto não é possível excluir os espécimes deste táxon. O gênero Sphaeruterina tem distribuição na Oceania, Europa, África e América do Sul, com as descrições mais recentes de espécies feitas por Fuhrmann (1932) e incluindo uma espécie registrada para o Brasil, parasita de Bucco sp. Devido a ampla distribuição de suas cinco espécies e às breves descrições disponíveis (DUJARDIN, 1845, JOHNSTON, 1914, FUHRMANN, 1932), a inclusão dos espécimes analisados neste estudo nos táxons já existentes não é indicada, uma vez que os caracteres diagnósticos para o grupo são imprecisos e assinalam a necessidade de uma revisão para o gênero. Dados sobre especificidade parasitária para os paruterinídeos são escassos, porém Phillips et al. (2014) indicam que estes cestódeos possuem uma associação menos restrita aos táxons de hospedeiros que infestam quando comparados às outras ordens de solitárias, podendo ser encontrados em diversas espécies e gêneros de uma mesma família de aves. A 
associação extenoxena aos hospedeiros indica que os espécimes de paruterinídeos encontrados em E. I. leucophtalma podem constituir uma nova espécie, considerando que não há nenhuma solitária pertencente a esta família conhecida parasitando tamnofilídeos.

\subsubsection{Epinecrophylla leucophtalma sordida (Todd, 1927)}

Localidades amostradas: Altamira, Pará, margem direita do rio Xingu, Centro de Endemismo Xingu (2 espécimes); Santana do Araguaia, Pará, Fazenda Fartura, margem esquerda do Rio Araguaia, Centro de Endemismo Xingu (1 espécime).

Prevalência de infestação: nenhum hospedeiro infestado.

Considerações: A obtenção de poucos indivíduos pertencentes à subespécie E. leucophtalma sordida $(n=3)$ e provenientes de localidades distintas $(n=2$ e $n=1)$ restringe inferências sobre sua infestação por cestódeos, indicando necessidade de aumento do esforço amostral para esta ave. Uma vez que esta subespécie é encontrada nos Centros de Endemismo Tapajós e Xingu e explora nichos semelhantes aos que E. leucophtalma leucophatalma explora nos Centros de Endemismo Inambari e Rondônia (ZIMMER; ISLER, 2016), um incremento no esforço amostral pode confirmar se a ausência de helmintos em E. leucophtalma sordida é resultado de particularidades da área amostrada.

\subsubsection{Epinecrophylla ornata hoffmannsi (Hellmayr, 1906)}

Localidades amostradas: Altamira, Pará, margem direita do rio Xingu, Centro de Endemismo Xingu (1 espécime); Santana do Araguaia, Pará, Fazenda Fartura, margem esquerda do Rio Araguaia, Centro de Endemismo Xingu (4 espécimes).

Prevalência de infestação: nenhum hospedeiro infestado.

Considerações: As amostras para busca de cestódeos em E. ornata hoffmannsi foram obtidas em pontos de coleta distintos, porém todos localizados no Centro de Endemismo Xingu e apresentando ausência de cestódeos associados. O indivíduo proveniente de Altamira (PA) foi o único exemplar pertencente a E. ornata hoffmannsi coletado nesta 
localidade, não permitindo, portanto, inferências sobre a fauna helmintológica associada a este táxon nesta área. A amostra coletada em Santana do Araguaia $(\mathrm{PA}),(\mathrm{N}=4)$ também não apresentou parasitismo por cestódeos, indicando que esta população de tamnofilídeos pode não possuir cestódeos associados ou apresentar helmintos com baixa abundância local e não detectados em um número amostral de hospedeiros restrito. O hábito de forrageamento semelhante aos demais membros do gênero Epinecrophylla (ZIMMER; ISLER, 2016) sugere que E. ornata hoffmannsi pode se expor às formas infestantes de cestódeos se estas estiverem presentes no ambiente pois estes parasitas são observados em $E$. amazonica, $E$. dentei e E. leucophtalma I., porém sua distribuição simpátrica com E. leucophtalma sordida (ZIMMER; ISLER, 2016), táxon no qual também não foi verificada infestação por cestódeos, indica que fatores intrínsecos àquele ambiente podem ser a causa desta ausência, implicando em aumento de esforço amostral e abrangência das amostras para confirmação.

\subsubsection{Formicivora}

\subsubsection{Formicivora grisea grisea (Boddaert, 1783)}

Localidades amostradas: Altamira, Pará, margem esquerda do rio Xingu, Centro de Endemismo Tapajós (2 espécimes); Santana do Araguaia, Pará, Fazenda Fartura, margem esquerda do Rio Araguaia, Centro de Endemismo Xingu (1 espécime); Porto Velho, Rondônia, margem direita do rio Madeira, Centro de Endemismo Rondônia (2 espécimes).

Prevalência de infestação: nenhum hospedeiro infestado.

Considerações: As amostras de F. grisea grisea foram obtidas em diferentes localidades, abrangendo três regiões biogeográficas distintas e registrando uma ampla distribuição para a espécie, apesar do número de amostras em cada ponto de coleta ser restrita a um ou dois espécimes. Os locais de amostragem destes indivíduos caracterizavam-se como áreas de mata de terra firme, porém há registros de espécimes ocupando diversos ambientes, como áreas de mata secundária ou de borda, permitindo que diversos hábitos de forrageamento possam ser verificados para a espécie (ZIMMER; ISLER, 2016). A variedade de habitats que a F. g. grisea ocupa permite que a espécie explore diferentes nichos e pode alterar a estrutura de sua população local, reduzindo a taxa de infestação por um parasita devido à redução na 
taxa de encontro da forma de transmissão (WOJDAK et al., 2014).

\subsubsection{Frederickena}

\subsubsection{Frederickena unduliger pallida Zimmer, 1944}

Localidade amostrada: Porto Velho, Rondônia, margem esquerda do rio Madeira, Centro de Endemismo Inambari (3 espécimes).

Prevalência de infestação: nenhum hospedeiro infestado.

Considerações: Os espécimes de $F$. unduliger pallida amostrados foram coletados na mesma localidade, porém em pontos distantes e em estações distintas (seca e chuva), indicando que esta espécie pode não apresentar associação com cestódeos ou mesmo baixa prevalência destes helmintos, implicando na necessidade de aumento de esforço amostral. Os hábitos alimentares desta espécie podem ser fator determinante na presença de helmintos em seu intestino, uma vez que há registro do consumo de larvas de lepidópteros por estas aves (ZIMMER, ISLER, DE JUANA, 2016) e observou-se, neste estudo, que a presença das formas larvais destes insetos nos estômagos dos hospedeiros pode estar associada à ausência de cestódeos parasitando os indivíduos, como ocorre também com espécimes de Pygiptila stellaris stellaris.

\subsubsection{Hafferia}

\subsubsection{Hafferia fortis fortis (Sclater \& Salvin, 1868)}

Localidade amostrada: Porto Velho, Rondônia, margem esquerda do rio Madeira, Centro de Endemismo Inambari (5 espécimes).

Prevalência da infestação: 40\% (2 hospedeiros infestados em 5 analisados). Intensidade da infestação: variável; indeterminada (D02); 1 espécime por hospedeiro (H05). Cestoda observados: 2 morfotipos; Dilepididae (D02; ANEXO D, Figura 9); Hymenolepididae (H05; ANEXO D, Figura 10).

Caracterização D02: Sete segmentos estrobilares incompletos, nenhuma escólex observada. 
Proglótides craspedotas com margens arredondadas. Número de dutos osmorregulatórios não determinado. Poro genital em lados alternados no segmento com duas proglótides, padrão de alternância indeterminado, a $37 \%$ da margem anterior da proglótide madura. Testículos 7 em número $(n=1)$, medianos, posteriores ao ovário. Saco do cirro oval, alongado, com parede mediana, cirro coberto por espinhos. Vitelário mediano, compacto, de forma irregular e posterior ao ovário. Ovário com dois lobos alados, unidos na região mediana por um istmo. Glândula de Mehlis não distinguível.

Caracterização H05: Um espécime completo. Espécime completo 12,60mm ( $n=1)$, composto por 177 proglótides, proglótides grávidas presentes. Escólex com maior largura na região das ventosas $237(n=1)$. Base rostelar musculo-glandular, rostelo muscular, bolsa rostelar com parede mediana. Coroa simples de ganchos rostelares, uniformes, arcuatóides, 8 ganchos em número $(n=1), 28,52 \mu m$ de comprimento $(n=1)$. Ventosas redondas, $111,26 \mu m$ de diâmetro $(n=1)$, musculares, sem espinhos. Proglótides craspedotas, com margens arredondadas, proglótide madura 96,50 × 294,60 ( $\mathrm{n}=1)$, proglótide pré grávida 71,45 × 528, $95(n=1)$, proglótide grávida 177,20 x 703,40 (n=1). Número de dutos osmorregulatórios não determinado. Poro genital unilateral, a $29 \%$ da margem anterior da proglótide madura, a $33 \%$ da margem anterior da proglótide pré grávida. Testículos ovais, 3 em número em todas as proglótides visíveis, em disposição triangular com 1 anterior aporal e 2 posteriores aporal e poral, aporais alinhados. Saco do cirro oval, com parede delgada, entre os dutos osmorregulatórios, cirro sem espinhos visíveis em microscopia óptica. Vitelário mediano, compacto, elíptico, posterior aos demais órgãos. Ovário com 3 lobos transversais elongados, mediano. Glândula de Mehlis não distinguível. Útero nas proglótides pré grávidas saculiforme. Ovos esféricos com cerca de $12,30 \mu \mathrm{m}$ de diâmetro $(n=1)$, oncosferas esféricas com cerca de $35 \mu \mathrm{m}$ de diâmetro $(n=1)$, ganchos embrionários visíveis na porção central.

Considerações: Os dois morfotipos de cestódeos observados parasitando Hafferia fortis fortis não foram observados no mesmo indivíduo hospedeiro, tendo sido coletados em pontos de amostragem distintos, ambos caracterizados por mata de terra firme. A alimentação da espécie é baseada em artrópodes, principalmente insetos, obtidos próximos ao solo uma vez que esta apresenta o hábito de seguir formigas de correição (ZIMMER; ISLER, 2016). Este tipo de forrageamento coincide com aquele empregado por espécies 
como Rhegmatorhina melanostica e Phlegopsis erythroptera, todas componentes de bandos mistos (ZIMMER; ISLER, 2016) e hospedeiras de cestódeos, o que pode indicar que esta é uma estratégia de transmissão bem-sucedida para estes parasitas. O impedimento taxonômico observado para os cestódeos neste estudo não permite que inferências sobre diversidade e especificidade destes parasitas sejam verificadas.

\subsubsection{Hylophylax}

\subsubsection{Hylophylax naevius inexpectatus Carriker, 1932}

Localidade amostrada: Porto Velho, Rondônia, margem esquerda do rio Madeira, Centro de Endemismo Inambari (1 espécime).

Prevalência de infestação: nenhum hospedeiro infestado.

Considerações: A amostra de $H$. naevius analisada foi obtida em uma área de mata de terra firme, habitat comum desta espécie (ZIMMER; ISLER, 2016), porém esta não se mostrou muito abundante nas campanhas de coleta realizadas e apenas um espécime foi analisado em busca de parasitas. A espécie possui hábito de vida insetívoro e forrageia próxima ao solo, seguindo formigas de correição eventualmente (ZIMMER; ISLER, 2016), o que sugere exposição às formas de transmissão de cestódeos uma vez que espécimes pertencentes à táxons que possuem hábito semelhante apresentaram infestação por estes helmintos, como Phlegopsis e Rhegmatorhina. A ausência de solitárias em todos os indivíduos do gênero Hylophylax indica possíveis particularidades do táxon em relação à infestação por helmintos (e. g. alta especificidade, baixa densidade da forma transmissível do parasita) ou mesmo ausência de cestódeos associados, porém é necessário que haja aumento no esforço amostral para confirmação.

\subsubsection{Hylophylax n. sp.}

Localidades amostradas: Porto Velho, Rondônia, margem direita do rio Madeira, Centro de Endemismo Rondônia (1 espécime); Machadinho d'Oeste, margem esquerda do rio JiParaná, Centro de Endemismo Rondônia (1 espécime).

Prevalência de infestação: nenhum hospedeiro infestado. 
Considerações: Os registros da nova espécie do gênero Hylophylax foi feito em duas localidades distintas, indicando que o táxon apresenta distribuição ampla, porém a restrição de um indivíduo analisado em cada ponto de amostragem não permite maiores inferências acerca de seu parasitismo. Não há dados disponíveis sobre a ecologia e distribuição deste hospedeiro, ainda não descrito formalmente.

\subsubsection{Hylophylax punctulatus punctulatus (Des Murs, 1856)}

Localidade amostrada: Porto Velho, Rondônia, margem esquerda do rio Madeira, Centro de Endemismo Inambari ( 2 espécimes).

Prevalência de infestação: nenhum hospedeiro infestado.

Considerações: Os dois espécimes de $H$. punctulatus punctulatus analisados em busca de cestódeos foram coletados na mesma localidade, porém em pontos distintos de coleta, ambos em regiões de mata de terra firme. A ausência de helmintos parasitas em ambos os espécimes e em todos os indivíduos pertencentes ao gênero amostrados indica que os hábitos de vida desta ave podem influenciar a não transmissão de cestódeos. 0 forrageamento da espécie dá-se próximo ao solo, em pequenos grupos e raramente há registro desta ave em bandos mistos (ZIMMER; ISLER, 2016), hábito compartilhado com coespecíficos que pode evitar a exposição da ave ao estágio infestante dos parasitas.

\subsubsection{Hylophylax punctulatus subochraceus Zimmer, 1934}

Localidade amostrada: Porto Velho, Rondônia, margem direita do rio Madeira, Centro de Endemismo Rondônia (2 espécimes).

Prevalência de infestação: nenhum hospedeiro infestado.

Considerações: Os dois espécimes de $H$. punctulatus subochraceus analisados em busca de cestódeos foram coletados no mesmo ponto de coleta e na mesma data, restringindo a distribuição deste táxon nesta amostragem. Os espécimes não apresentaram infestação por cestódeos, assim como as demais espécies do gênero Hylophylax. A espécie $H$. punctulatus 
subochraceus possui os mesmos hábitos de H. punctulatus punctulatus (ZIMMER; ISLER, 2016) e apresenta as mesmas características que podem impedir a transmissão de cestódeos, portanto o aumento do esforço amostral também é indicado para este táxon.

\subsubsection{Hypocnemis}

\subsubsection{Hypocnemis ochrogyna Zimmer, 1932}

Localidade amostrada: Porto Velho, Rondônia, margem direita do rio Madeira, Centro de Endemismo Rondônia (6 espécimes).

Prevalência de infestação: nenhum hospedeiro infestado.

Considerações: Os seis espécimes de $H$. ochrogyna analisados foram obtidos em matas de terra firme em diferentes pontos de coleta na mesma localidade, constituindo uma amostragem ampla para a Centro de Endemismo Rondônia em Porto Velho. A ausência de parasitas pode indicar que esta população de hospedeiros não possui fauna parasitária associada ou que esta apresenta baixa prevalência e densidade populacional e não foi detectada com o número amostral de hospedeiros obtido. A disponibilidade de dados sobre as estratégias de forrageamento da espécie é baixa, sendo comum o hábito de buscar alimento sozinha e raramente participando de bandos mistos (ZIMMER; ISLER, 2016). O não compartilhamento de alimentos com outros tamnofilídeos possibilita que sua dieta seja distinta daquela observada em outras aves, impedindo que haja transmissão de formas infestantes de cestódeos.

\subsubsection{Hypocnemis peruviana peruviana Taczanowski, 1884}

Localidade amostrada: Porto Velho, Rondônia, margem esquerda do rio Madeira, Centro de Endemismo Inambari (15 espécimes).

Prevalência da infestação: 26\% (4 hospedeiros infestados em 15 analisados).

Intensidade da infestação: variável; 3-10 espécimes por hospedeiro (D03); 1 espécime por hospedeiro (H06).

Cestoda observados: 2 morfotipos; Dilepididae (D03); Hymenolepididae (H06; ANEXO D, Figura 11). 
Caracterização D03: Três espécimes completos, dezesseis espécimes incompletos. Espécime completo $516 \mu m$ de comprimento $(n=1)$, composto por 7 proglótides $(n=1)$, com proglótide grávida presente. Escólex com maior largura na região das ventosas 101,90 (n=1). Aparato rostelar musculo-glandular, rostelo muscular, bolsa rostelar com parede mediana. Coroa dupla alternada de ganchos rostelares, uniformes, arcuatóides, 14 ganchos em número

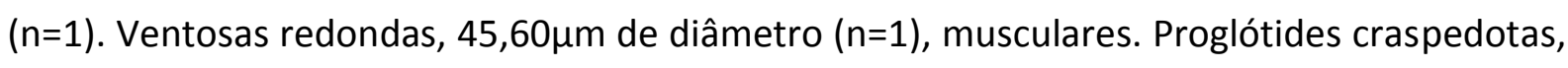
com margens arredondadas, proglótide pós madura $61,72 \times 115(n=1)$, proglótide pré grávida 99 × 148,90 (n=1), proglótide grávida 207,30 x $136(n=1)$. Dutos osmorregulatórios não observados. Poro genital alternando regularmente.

Caracterização H06: Um espécime completo. Espécime $8,87 \mathrm{~mm}$ de comprimento $(n=1)$, composto por 99 proglótides. Escólex com maior largura na região das ventosas 305 (n=1). Base rostelar musculo-glandular, rostelo muscular, bolsa rostelar com parede delgada. Coroa simples de ganchos rostelares, uniformes, arcuatóides, 24 ganchos em número $(n=1)$, $29,22 \mu \mathrm{m}$ de comprimento $(n=1)$. Ventosas redondas, $109,18 \mu \mathrm{m}$ de diâmetro $(n=1)$, musculares, sem espinhos. Proglótides craspedotas, proglótide madura 87,50 x 202,50 (n=1), proglótide pré grávida 119,62 × $296(n=1)$, proglótide grávida 186,15 × 373,20 (n=1). Quatro dutos osmorregulatórios, dutos genitais dorsais. Poro genital unilateral, a $34 \%$ da margem anterior das proglótides madura e pré grávida. Testículos ovais, 3 em número em todas as proglótides visíveis, em disposição triangular com 1 poral, 1 aporal posteriores e 1 central anterior. Saco do cirro oval, com parede mediana, entre os dutos osmorregulatórios, cirro sem espinhos visíveis em microscopia óptica. Vitelário mediano, compacto, elíptico, posterior aos demais órgãos. Ovário com 3 lobos transversais, mediano. Glândula de Mehlis não distinguível. Útero nas proglótides pré grávidas saculiforme, com septo central. Ovos esféricos com cerca de $8,50 \mu \mathrm{m}$ de diâmetro $(n=1)$, oncosferas esféricas com cerca de $23 \mu \mathrm{m}$ de diâmetro $(n=1)$, ganchos embrionários visíveis na porção central, 6 em número, sem comprimento disponível.

Considerações: As amostras obtidas para H. peruviana peruviana foram coletadas em áreas de mata de terra firme em diferentes épocas de ano e pontos de amostragem localizados no Centro de Endemismo Rondônia. Os quatro indivíduos parasitados apresentaram 2 
morfotipos distintos de cestódeos, sendo que a infestação pelo morfotipo D03, pertencente à família Dilepididae, foi observada em todos os hospedeiros, enquanto o morfotipo H06, Hymenolepididae, foi registrado em apenas uma ave, coexistindo com D03. A infestação pelo mesmo parasita de vários indivíduos hospedeiros coletados em pontos distintos indica que as formas transmissíveis deste cestódeo estão disponíveis neste ambiente em maior densidade e distribuição, sendo necessário seu refino taxonômico para obtenção de informações sobre especificidade e possível infestação em outros hospedeiros. O registro de uma segunda espécie de parasita em um mesmo indivíduo hospedeiro indica que esta espécie está exposta à diferentes formas de transmissão destes parasitas, porém os poucos dados disponíveis sobre seus hábitos de forrageamento não permitem inferências mais aprofundadas. Hypocnemis peruviana peruviana foi a única espécie deste gênero que apresentou infestação por cestódeos adultos e possui distribuição no Centro de Endemismo Inambari, ao contrário de $H$. ochrogyna e $H$. rondoni, cujas distribuições restringem-se a Centro de Endemismo Rondônia e nas quais foi observado somente um espécime em estágio larval e não identificável. A observação de infestações diferentes em regiões distintas sugere que cada população hospedeira pode ter sua fauna característica, necessitando que sejam feitos estudos mais aprofundados.

4.3.10.3 Hypocnemis rondoni Whitney, Isler, Bravo, Aristizábal, Schunck, Silveira, Piacentini, Cohn-Haft \& Rêgo, 2013

Localidade amostrada: Machadinho d'Oeste, Rondônia, margem esquerda do rio Ji-Paraná, Centro de Endemismo Rondônia (4 espécimes).

Prevalência da infestação: 25\% (1 hospedeiro infestado em 4 analisados).

Intensidade da infestação: indeterminada.

Cestoda observados: 1 morfotipo; não identificado (NI03; ANEXO D, Figura 12).

Caracterização NI03: Três espécimes completos, em estágio larval anterior ao desenvolvimento do escólex. Região anterior invaginada, lacuna primária ausente, cercomero ausente.

Considerações: De acordo com CHERVY (2002), a classificação dos estágios larvais de 
cestódeos é baseada primariamente na presença da lacuna primária e na retração ou invaginação do escólex, considerando secundariamente a presença de cercomero. Os espécimes obtidos parasitando Hypocnemis rondoni não apresentam tais estruturas diferenciadas, impossibilitando sua identificação e indicando que tais indivíduos podem estar no início de sua diferenciação e ser resultado de infestação recente ou pertencer a algum grupo de cestódeos que não completa seu desenvolvimento neste hospedeiro ou mesmo em aves. Devido ao número restrito de hospedeiros amostrados $(n=4)$ e infestados $(n=1)$ e nenhum helminto adulto ser observado, não é possível inferir quaisquer informações sobre estes parasitas, indicando a possível necessidade de aumento do esforço amostral para este hospedeiro.

\subsubsection{Hypocnemis striata affinis Zimmer, 1932}

Localidade amostrada: Santana do Araguaia, Pará, Fazenda Fartura, margem esquerda do Rio Araguaia, Centro de Endemismo Xingu (1 espécime).

Prevalência de infestação: nenhum hospedeiro infestado.

Considerações: O espécime de Hypocnemis striatta affinis analisado foi coletado em uma área de mata de terra firme, assim como os demais espécimes pertencentes ao gênero amostrados neste estudo, porém a ausência de helmintos parasitas não permite comparações e inferências sobre sua associação com cestódeos. A presença de cestódeos em $H$. peruviana no Centro de Endemismo Inambari com taxa de prevalência igual a $26 \%$ pode indicar que a ausência de helmintos $H$. striata no Centro de Endemismo Xingu deve-se ao número amostral restrito obtido $(n=1)$, porém a ausência de parasitas em $H$. ochrogyna no Centro de Endemismo Rondônia sugere que cada um dos táxons pertencentes a Hypocnemis possui características distintas em relação a sua fauna de helmintos associada. Os dados obtidos neste estudo para estes indivíduos não permitem elucidar se a distribuição geográfica interfere na infestação por helmintos, implicando em aumento do esforço amostral no Centro de Endemismo Xingu para H. striata affinis e uma possível amostragem no Centro de Endemismo Tapajós, onde a espécie $H$. striata implicata pode ser encontrada (ZIMMER; ISLER, 2016) 


\subsubsection{Isleria}

\subsubsection{Isleria hauxwelli hauxwelli (Sclater, 1857) Bravo, Chesser, Brumfield, 2012}

Localidades amostradas: Porto Velho, Rondônia, margem esquerda do rio Madeira, Centro de Endemismo Inambari (14 espécimes) e margem direita do rio Madeira, Centro de Endemismo Rondônia (3 espécimes); Machadinho d'Oeste, Rondônia, margem esquerda do rio Ji-Paraná, Centro de Endemismo Rondônia (1 espécime).

Localidade de hospedeiros infestados: Porto Velho, Rondônia, Centro de Endemismo Inambari (1 espécime).

Prevalência da infestação: 5\% (1 hospedeiros infestados em 18 analisados).

Intensidade da infestação: 1 espécime por hospedeiro.

Cestoda observados: 1 morfotipo; Hymenolepididae (H07; ANEXO D, Figura 13).

Caracterização H07: Um espécime completo partido. Espécime 7,05mm de comprimento ( $n=1)$, composto por 145 proglótides. Escólex com maior largura na região das ventosas 268,30 ( $n=1)$. Escólex com maior largura na região das ventosas $305(n=1)$. Base rostelar musculo-glandular, rostelo muscular, bolsa rostelar com parede mediana. Coroa simples de ganchos rostelares, uniformes, arcuatóides, 36 ganchos em número $(n=1), 32,63 \mu m$ de comprimento $(n=1)$. Ventosas redondas, $120,85 \mu \mathrm{m}$ de diâmetro $(n=1)$, musculares, sem espinhos. Proglótides craspedotas, proglótide madura 57,62 × 298,92 (n=1), proglótide pré grávida 93,88 × 291,05 (n=1), proglótide grávida $116,40 \times 363,45(n=1)$. Dutos osmorregulatórios não observados. Poro genital unilateral, a $40 \%$ da margem anterior da proglótide madura e a $28 \%$ da margem anterior da proglótide pré grávida. Testículos ovais, 3 em número em todas as proglótides visíveis, em disposição triangular quase em linha, 1 poral e 2 aporais. Saco do cirro oval, com parede mediana, cirro sem espinhos visíveis em microscopia óptica. Vitelário mediano, compacto, elíptico, posterior aos demais órgãos. Ovário com 3 lobos transversais, mediano. Glândula de Mehlis não distinguível. Útero nas proglótides pré grávidas saculiforme, com septo central. Ovos esféricos com cerca de $14 \mu \mathrm{m}$ de diâmetro $(n=1)$, oncosferas esféricas com cerca de $27,30 \mu m$ de diâmetro $(n=1)$, ganchos embrionários visíveis na porção central. 
Considerações: A amostragem em busca de cestódeos em Isleria hauxwelli hauxwelli resultou na menor prevalência observada neste estudo, cerca de 5\% de infestação em 18 espécimes de hospedeiros amostrados. As amostras foram coletadas em três localidades distintas nos Centros de Endemismo Inambari e Rondônia, resultando em uma ampla distribuição para este hospedeiro. A observação de apenas um espécime de cestódeo pertencente à família Hymenolepididae ( $\mathrm{H} 07)$ em todas as amostras indica que esta pode apresentar hábito oioxeno e estar presente em baixa densidade apenas na área onde foi obtida, já que a amostra deste ponto igual a 14 tamnofilídeos e seus hábitos de forrageamento podem se sobrepor a táxons associados a diversos cestódeos como Phlegopsis e Rhegmatorhina (ZIMMER; ISLER, 2016). O gênero Isleria foi erguido recentemente (BRAVO; CHESSER; BRUMFIELD, 2012A) e sua fauna de cestódeos, caracterizada por membros da família Hymenolepididae, difere dos helmintos observados para o gênero Myrmotherula, pertencentes às famílias Metadilepididae e Paruterinidae (ver adiante), indicando uma possível especificidade dos cestódeos aos seus hospedeiros. A especificidade parasitária é considerada taxonomicamente informativa para diversos táxons em Cestoda (KHALIL; JONES; BRAY, 1994) e pode refletir a coevolução dos parasitas e seus hospedeiros (CAIRA; JENSEN, 2001), corroborando a divisão do gênero Myrmotherula. A amostra restrita de cestódeos obtida em I. hauxwelli implica em um aumento do esforço amostral em número de indivíduos, subespécies e localidades para que a taxonomia do grupo e estudos sobre especificidade sejam aprofundados, além da amostragem indivíduos pertencentes a Isleria guttata, grupo irmão de I. hauxwelli (BRAVO; CHESSER; BRUMFIELD, 2012A), encontrada na margem norte do rio Amazonas.

\subsubsection{Isleria hauxwelli hellmayri (Snethlage, 1906)}

Localidades amostradas: Altamira, Pará, margem direita do rio Xingu, Centro de Endemismo Xingu (1 espécime); Santana do Araguaia, Pará, Fazenda Fartura, margem esquerda do Rio Araguaia, Centro de Endemismo Xingu (13 espécimes).

Localidades de hospedeiros infestados: Santana do Araguaia, Pará, Centro de Endemismo Xingu (1 espécime).

Prevalência da infestação: 7\% (1 hospedeiros infestados em 14 analisados).

Intensidade da infestação: 1 espécime por hospedeiro. 
Cestoda observados: 1 morfotipo; Hymenolepididae (H08; ANEXO D, Figura 14).

Caracterização H08: Um espécime incompleto. Espécime com proglótides pré grávidas presentes, comprimento total e número total de segmentos indeterminados. Escólex com maior largura na região das ventosas $244(n=1)$. Base rostelar musculo-glandular, rostelo muscular, bolsa rostelar com parede mediana. Coroa simples de ganchos rostelares, uniformes, arcuatóides, incompleta, metade presente com 15 ganchos em número $(n=1)$, $34 \mu \mathrm{m}$ de comprimento $(n=1)$. Ventosas redondas, $108,45 \mu \mathrm{m}$ de diâmetro $(n=1)$, musculares, sem espinhos. Proglótides craspedotas, proglótide madura 42 × 437,60 ( $n=1)$, proglótide pré grávida 133,25 x 494,20 (n=1). Dez dutos osmorregulatórios. Poro genital unilateral. Testículos ovais, 3 em número em todas as proglótides visíveis, em disposição triangular com 1 poral, 1 aporal posteriores e 1 central anterior. Saco do cirro oval, com parede mediana, entre os dutos osmorregulatórios, cirro sem espinhos visíveis em microscopia óptica. Vitelário mediano, compacto, elíptico, posterior aos demais órgãos. Ovário com 3 lobos transversais, mediano. Glândula de Mehlis não distinguível. Útero nas proglótides pré grávidas saculiforme, com septo central. Ovos esféricos.

Considerações: Os indivíduos de Isleria hauxwelli hellmayri amostrados também apresentaram baixa prevalência para infestação por cestódeos, 7\%, indicando que esta pode ser uma característica intrínseca ao gênero. As amostram analisadas foram obtidas em matas de terra firme, em diferentes datas e épocas do ano (ANEXO B), indicando que a sazonalidade pode não ser determinante para a ausência de helmintos neste hospedeiro. A obtenção de apenas um espécime de cestódeo pertencente à família Hymenolepididae (H08) indica que esta também pode apresentar hábito oioxeno e estar presente em baixa densidade apenas na área onde foi obtida, assim como H07, encontrada em I. hauxwelli hauxwelli. Ambas as amostras obtidas para indivíduos do gênero Isleria pertencem à mesma família de cestódeos, indicando uma possível especificidade ao gênero, porém os morfotipos distintos de cestódeos nas diferentes subespécies de hospedeiros aponta especificidade mais restrita e pode estar associada à área coletada. Estudos mais aprofundados são necessários para a confirmação destes dados, conforme discutido acima. 


\subsubsection{Megastictus}

\subsubsection{Megastictus margaritatus (Sclater, 1855)}

Localidades amostradas: Porto Velho, Rondônia, margem esquerda do rio Madeira, Centro de Endemismo Inambari (6 espécimes); Machadinho d'Oeste, Rondônia, margens esquerda e direita do rio Ji-Paraná, Centro de Endemismo Rondônia (4 espécimes).

Localidades de hospedeiros infestados: Porto Velho, Rondônia, Centro de Endemismo Inambari (3 espécimes).

Prevalência da infestação: 33\% (3 hospedeiros infestados em 10 analisados).

Intensidade da infestação: 1 espécime por hospedeiro (D04; H09; P02; M01).

Cestoda observados: 4 morfotipos; Dilepididae: Monopylidium cf. (D04; ANEXO D, Figura 15); Hymenolepididae (H09; ANEXO D, Figura 16 A-B); Paruterinidae (P02; ANEXO D, Figura 17); Metadilepididae: Schmidneila sp. (M01; ANEXO D, Figura 18 A-B).

Caracterização D04: Um espécime completo. Espécime 2,95mm de comprimento, composto por 56 proglótides, última proglótide madura. Escólex com maior largura na região das ventosas 186,35 ( $n=1)$. Aparato rostelar musculo-glandular, rostelo muscular, bolsa rostelar com parede delgada. Coroa dupla alternada de ganchos rostelares, uniformes, arcuatóides, 20 ganchos em número $(n=1)$, anteriores $18 \mu$ m e posteriores $20 \mu m$ de comprimento $(n=1)$. Ventosas redondas, $86,40 \mu \mathrm{m}$ de diâmetro $(n=1)$, musculares. Proglótides craspedotas, proglótide madura 83,60 × 335,70 (n=1). Dutos osmorregulatórios não observados. Poro genital alternado irregularmente, a 44\% margem anterior da proglótide madura. Testículos 16 em número $(n=1)$, posteriores. Saco do cirro oval, com parede mediana, cirro sem espinhos visíveis em microscopia óptica. Vitelário mediano, compacto, de forma irregular e posterior ao ovário. Ovário mediano. Glândula de Mehlis não distinguível.

Caracterização H09: Dois espécimes incompletos. Comprimento total e número de segmentos indeterminados. Escólex com maior largura na região das ventosas 336,65 (n=1). Base rostelar musculo-glandular, rostelo muscular, bolsa rostelar com parede delgada. Coroa simples de ganchos rostelares, uniformes, arcuatóides, 28 ganchos em número $(n=1), 37 \mu m$ de comprimento $(n=1)$. Ventosas redondas, $119,75 \mu m$ de diâmetro $(n=1)$, musculares, sem 
espinhos. Proglótides craspedotas, proglótide madura 134,15 x 442,65 (n=1), proglótide pré grávida 196,80 x 577,80 (n=1). Número de dutos osmorregulatórios não determinado. Poro genital unilateral, a $28 \%$ da margem anterior da proglótide madura, a 32\% da margem anterior da proglótide pré grávida. Testículos ovais, 3 em número em todas as proglótides visíveis, posteriores, em disposição triangular quase em linha, com 1 poral, 1 central pouco anterior aos demais e 1 aporal. Saco do cirro oval, com parede delgada, entre os dutos osmorregulatórios, cirro sem espinhos visíveis em microscopia óptica. Vitelário mediano, compacto, elíptico, posterior aos demais órgãos. Ovário com 3 lobos arredondados, mediano, em disposição triangular. Glândula de Mehlis não distinguível. Útero nas proglótides pré grávidas saculiforme, com septo central. Ovos esféricos com cerca de $12,75 \mu \mathrm{m}$ de diâmetro $(n=1)$.

Caracterização P02: Um espécime incompleto. Espécime sem escólex e com segmentos pré grávidos e grávidos presentes, comprimento e número total de segmentos indeterminado. Proglótides craspedotas. Dutos osmorregulatórios não observados. Poro genital unilateral ou alternado irregularmente. Saco do cirro oval, lateral aos dutos osmorregulatórios em proglótides grávidas. Útero em forma de halteres em proglótides pré grávidas e grávidas, posterior. Órgão paruterino com paredes espessas, em forma piramidal e porção anterior esférica, anterior ao útero. Ovos esféricos, $17,40 \mu m$ de diâmetro $(n=1)$, oncosferas com forma indeterminada.

Caracterização M01: Dois espécime incompletos. Comprimento total e número de segmentos indeterminados. Escólex com maior largura na região das ventosas 315,40 (n=1). Base rostelar muscular, rostelo muscular, bolsa rostelar com parede delgada. Coroa simples de ganchos rostelares, uniformes, triangulares, 25 ganchos em número $(n=1), 22 \mu m$ de comprimento $(n=1)$. Ventosas circulares, $122,42 \mu m$ de diâmetro $(n=1)$, musculares, sem espinhos. Proglótides craspedotas, proglótide madura $69 \times 375,25(n=1)$, proglótide pré grávida $213 \times 442,60(n=1)$, proglótide grávida 537,25 x 568,45 (n=1). Número de dutos osmorregulatórios não determinado. Poro genital unilateral, a $25 \%$ da margem anterior da proglótide madura, a 34\% da margem anterior da proglótide pré grávida. Testículos ovais, 8 em número, posteriores às glândulas femininas. Saco do cirro oval, alongado, com parede delgada, lateral aos dutos osmorregulatórios, cirro sem espinhos visíveis em microscopia 
óptica. Vitelário mediano, compacto, oval. Ovário com 2 lobos arredondados, anterior. Glândula de Mehlis não distinguível. Útero nas proglótides pré grávidas e grávidas lobado, parenquimatoso. Ovos esféricos com cerca de $12 \mu \mathrm{m}$ de diâmetro $(n=1)$, oncosferas fusiformes 75,45 x 29 (n=1), ganchos embrionários não visíveis.

Considerações: A amostragem para espécimes de Megastictus margaritatus foi feita em áreas de terra firme e os indivíduos apresentaram prevalência na infestação por cestódeos acima da média observada para a família neste estudo (33 $\times 20 \%$ ). A presença de helmintos foi observada apenas no Centro de Endemismo Inambari, em metade dos indivíduos amostrados, indicando alta densidade de parasitas na área e sugerindo que a população no Centro de Endemismo Rondônia não está exposta às formas transmissíveis na mesma disponibilidade. Os cestódeos observados foram coletados em três espécimes de hospedeiros e pertencem a quatro diferentes morfotipos de quatro famílias distintas, mostrando alta diversidade e baixa densidade da população de parasitas. Esta espécie de ave possui hábitos de forrageamento bem próximos à outras espécies de tamnofilídeos (ZIMMER; ISLER, 2016) e sua alta diversidade de parasitas pode dever-se à especificidade parasita-hospedeiro uma vez que outros táxons coletados nos mesmos pontos de coleta não exibem infestação semelhante, apesar de estarem expostos às formas de transmissão, porém a confirmação desta relação depende do refino da taxonomia dos espécimes de cestódeos. Os morfotipos de Dilepididae (D04) e Paruterinidae (P02) foram observados em hospedeiros exclusivos, enquanto os espécimes de Hymenolepididae (H09) e Metadilepididae (M01) habitavam o mesmo indivíduo hospedeiro. A identificação dos morfotipos H09 e P02 não foi possível devido ambas amostras serem constituídas por espécimes incompletos.

O espécime pertencente à família Dilepididae (D04) assemelha-se a membros do gênero Monopylidium, sem armamentos na superfície do escólex, ganchos anteriores e posteriores com comprimentos distintos, poros genitais alternando irregularmente e sem espinhos presentes no átrio genital (BONA, 1994). O gênero é conhecido principalmente para a região Paleártica e sua taxonomia necessita ser refinada, uma vez que sua descrição foi baseada em preparações histológicas incompletas e características definidas imprecisamente, com uso de termos como numerosos (BONA, 1994). Para o Brasil são conhecidas duas espécies, M. cayannense e M. secundum, parasitas de Vanellus chilensis e 
descritas por Fuhrmann (1907), que diferem do espécime observado em M. margaritatus no comprimento do espécime $(8-15 \times 2,9 \mathrm{~mm})$, no número de segmentos estrobilares $(20-40 \mathrm{x}$ 56) e no comprimento do escólex $(350 \times 186 \mu \mathrm{m})$. A taxonomia da família Dilepididae considera o táxon ao qual o hospedeiro pertence como um caractere informativo (BONA, 1994) e, uma vez que não há cestódeos descritos para tamnofilídeos e as características disponíveis sobre os parasitas de $V$. chilensis são distintas daquelas observadas no espécime parasita de $M$. margaritatus, este caracteriza-se como pertencente a uma nova espécie, necessitando descrição formal.

O espécime pertencente à família Metadilepididae (M01) apresenta uma coroa de ganchos simples e triangulares com comprimento menor que $30 \mu \mathrm{m}$, oncosferas fusiformes e receptáculo seminal alongado, característicos de espécies do gênero Schimdneila (KORNYUSHIN; GEORGIEV, 1994). O gênero é monoespecífico e S. mathevossiani, parasita de Polioptiliniae na América Central, foi descrita por Spaskii e Spaskaya em 1973. A espécie hospedeira de S. mathevossiani, Rhamphocaenus melanurus rufiventris, apresenta hábitos de forrageamento semelhantes àqueles observados para $M$. margaritatus e outros tamnofilídeos, consumindo basicamente artrópodes e participando eventualmente de bandos mistos (ATWOOD; LERMAN, 2016), indicando exposição comum às formas infestantes. O morfotipo M01 difere de S. mathevossiani no número de ganchos presentes na coroa rostelar $(25 \times 32)$ e pode representar uma nova espécie de metadilepidídeo, a segunda para o gênero Schmdneila e a primeira parasita para a família Thamnophilidae.

\subsubsection{Microrhopias}

\subsubsection{Microrhopias quixensis bicolor (Pelzeln, 1868)}

Localidade amostrada: Porto Velho, Rondônia, margem direita do rio Madeira, Centro de Endemismo Rondônia (4 espécimes).

Prevalência da infestação: 25\% (1 hospedeiro infestado em 4 analisados).

Intensidade da infestação: 1 espécime por hospedeiro (H10).

Cestoda observados: 1 morfotipo; Hymenolepididae (H10; ANEXO D, Figura 19).

Caracterização H06: Um espécime completo. Espécime 8,40mm de comprimento $(n=1)$, 
composto por 135 proglótides. Escólex com maior largura na região das ventosas 160,90 $(n=1)$. Base rostelar musculo-glandular, rostelo muscular, bolsa rostelar com parede delgada. Coroa simples de ganchos rostelares, uniformes, arcuatóides, 12 ganchos em número $(n=1)$, $28,66 \mu \mathrm{m}$ de comprimento $(n=1)$. Ventosas redondas, $57,71 \mu \mathrm{m}$ de diâmetro $(n=1)$, musculares, sem espinhos. Proglótides craspedotas, proglótide madura 64,85 x 134,65 (n=1), proglótide pré grávida $114 \times 347(n=1)$, proglótide grávida 282,20 × 500,35 ( $n=1)$. Dutos osmorregulatórios não observados. Poro genital unilateral, a 35\% da margem anterior da proglótide madura e a $38 \%$ da margem anterior da proglótide pré grávida. Testículos ovais, 3 em número em todas as proglótides visíveis, 2 porais em linha posteriores ao saco do cirro e 1 aporal. Saco do cirro oval, com parede mediana, entre os dutos osmorregulatórios, cirro sem espinhos visíveis em microscopia óptica. Vitelário mediano, compacto, elíptico, posterior aos demais órgãos. Ovário com 3 lobos transversais, mediano. Glândula de Mehlis não distinguível. Útero nas proglótides pré grávidas saculiforme, com septo central. Ovos esféricos com cerca de $11,25 \mu$ m de diâmetro $(n=1)$, oncosferas ovais $31,40 \times 18,63(n=1)$, ganchos embrionários visíveis na porção central, 6 em número, $11,80 \mu \mathrm{m}$ de comprimento $(n=1)$.

Considerações: Os espécimes de Microrhopias quixensis bicolor foram obtidos em áreas de mata de terra firme, em um ponto de coleta. Entre os quatro indivíduos coletados, três foram obtidos em uma mesma amostragem, caracterizando um casal e um indivíduo jovem, sendo encontrados cestódeos apenas neste último. A restrição geográfica da amostra e o hábito de forrageamento em grupos familiares (ZIMMER; ISLER, 2016) indica que os espécimes forrageavam em uma área comum, portanto a presença de helmintos em apenas uma das aves pode indicar baixa densidade das formas transmissíveis dos parasitas no ambiente.

\subsubsection{Microrhopias quixensis emiliae Chapman, 1921}

Localidade amostrada: Altamira, Pará, margem esquerda do rio Xingu, Centro de Endemismo Tapajós (1 espécime)

Prevalência de infestação: nenhum hospedeiro infestado. 
Considerações: A amostra obtida para Microrhopias quixensis emiliae foi restrita a um espécime, coletado em área de mata de terra firme no Centro de Endemismo Tapajós. A ausência de infestação pode ser causada pela baixa densidade de parasitas naquele ponto amostral, pela ausência de parasitas naquela região ou por ausência de parasitas específicos a esta espécie de hospedeiro. A variação na prevalência de infestação para outras espécies do gênero Microrhopias coletadas nos Centros de Endemismo Inambari e Rondônia não permite inferências para a associação de $M$. quixensis emiliae, indicando necessidade no aumento do esforço amostral para o táxon.

\subsubsection{Microrhopias quixensis intercedens Zimmer, 1932}

Localidade amostrada: Porto Velho, Rondônia, margem esquerda do rio Madeira, Centro de Endemismo Inambari (1 espécime).

Prevalência de infestação: nenhum hospedeiro infestado.

Considerações: A coleta de apenas um indivíduo de Microrhopias quixensis intercedens no Centro de Endemismo Inambari implica na necessidade de aumento do esforço amostral e não permite inferências acerca da fauna de cestódeos associada a este tamnofilídeo, uma vez que a população de $M$. quixensis bicolor coletado no Centro de Endemismo Rondônia apresentou prevalência de infestação igual a $25 \%$. O espécime foi coletado em uma área comum a outras espécies de tamnofilídeos que apresentaram fauna de cestódeos associada, portanto a ausência de helmintos nesta espécie de ave pode estar relacionada a sua ecologia, que não o expõe às formas de transmissão dos parasitas ou não permite que esta infeste esta ave (e. g. especificidade).

\subsubsection{Myrmelastes}

\subsubsection{Myrmelastes humaythae (Hellmayr, 1907)}

Localidade amostrada: Porto Velho, Rondônia, margem esquerda do rio Madeira, Centro de Endemismo Inambari (9 espécimes).

Prevalência da infestação: 11\% (1 hospedeiro infestado em 9 analisados). 
Intensidade da infestação: indeterminada.

Cestoda observados: 1 morfotipo; Dilepididae (D05) (ANEXO D, Figuras 20 A-B).

Caracterização D05: Dois espécimes incompletos. Comprimento total e número de proglótides indeterminados. Escólex com maior largura na região das ventosas 132,38 (n=1). Aparato rostelar musculo-glandular, rostelo muscular, bolsa rostelar com parede mediana. Coroa dupla alternada de ganchos rostelares, uniformes, arcuatóides, 16 ganchos em número $(n=1), 11,78 \mu m$ de comprimento $(n=1)$. Ventosas redondas, $52,87 \mu m$ de diâmetro $(n=1)$, musculares. Proglótides craspedotas, com margens arredondadas, proglótide madura 170,65 × 275,10 (n=1), proglótide grávida $429 \times 339(n=1)$. Dutos osmorregulatórios não observados. Poro genital alternado, padrão de alternância indeterminado, a $25 \%$ da margem anterior da proglótide madura. Testículos posteriores ao ovário, número indeterminado. Saco do cirro oval, alongado, com parede mediana, cirro com espinhos visíveis em microscopia óptica. Vitelário mediano, compacto, de forma irregular e posterior ao ovário. Ovário de forma indeterminada, anterior. Glândula de Mehlis não distinguível. Útero na proglótide grávidas saculiforme.

Considerações: A espécie Myrmelastes humaythae apresentou baixa infestação por cestódeos, com apenas um indivíduo parasitado e 11 \% de prevalência. Os espécimes foram todos coletados em área de mata de terra firme, porém em pontos de coleta distintos em uma mesma localidade, resultando em uma amostra ampla para a área de Porto Velho. A espécie forrageia próximo ao solo e segue formigas de correição esporadicamente (ZIMMER; ISLER, 2016), provavelmente estando exposta à infestação por cestódeos, já que tamnofílideos com hábitos semelhantes comumente apresentam fauna de helmintos associada. Assim, a baixa prevalência de cestódeos pode ser relacionada a especificidade parasita-hospedeiro ou baixa densidade da população de helmintos, o que diminui a probabilidade de encontro entre hospedeiro e parasita.

\subsubsection{Myrmelastes rufifacies (Hellmayr, 1929)}

Localidades amostradas: Porto Velho, Rondônia, margem direita do rio Madeira, Centro de Endemismo Rondônia (4 espécimes). 
Prevalência de infestação: nenhum hospedeiro infestado.

Considerações: A espécie Myrmelastes rufifacies é encontrada no Centro de Endemismo Rondônia e não apresenta infestação por cestódeos, apesar de ser coletada em uma área onde estes parasitas estão presentes em outras espécies de tamnofilídeos. A baixa prevalência de parasitas observada para a espécie Myrmelastes humaythae, encontrada no Centro de Endemismo Inambari e cuja ecologia assemelha-se a de M. rufifacies (ZIMMER; ISLER, 2016), pode indicar que este gênero de ave necessita de aumento no esforço amostral para caracterização precisa de sua fauna de parasitas.

\subsubsection{Myrmoborus}

\subsubsection{Myrmoborus leucophrys leucophrys (Tschudi, 1844)}

Localidades amostradas: Altamira, Pará, margem esquerda do rio Xingu, Centro de Endemismo Tapajós (2 espécimes).

Localidades de hospedeiros infestados: Altamira, Pará, Centro de Endemismo Xingu (2 espécimes).

Prevalência da infestação: 100\% (2 hospedeiros infestado em 2 analisados).

Intensidade da infestação: 1 espécime por hospedeiro.

Cestoda observados: 1 morfotipo; Metadilepididae: Schmidneila sp. (M02; ANEXO D, Figura 21).

Caracterização M02: Um espécime completo. Espécime 31,81mm de comprimento, composto por 201 proglótides, última proglótide grávida. Escólex com maior largura na região das ventosas 293,35 (n=1). Base rostelar muscular, rostelo muscular, bolsa rostelar com parede delgada. Coroa simples de ganchos rostelares, uniformes, triangulares, 17 ganchos em número $(n=1), 32,7 \mu m$ de comprimento $(n=1)$. Ventosas circulares, $115,17 \mu m$ de diâmetro $(n=1)$, musculares, sem espinhos. Proglótides craspedotas. Número de dutos osmorregulatórios não determinado. Poro genital unilateral. Testículos ovais, 4 em número, posteriores às glândulas femininas. Saco do cirro oval, alongado, com parede delgada, lateral aos dutos osmorregulatórios, cirro sem espinhos visíveis em microscopia óptica. Vitelário e 
ovário não observados. Glândula de Mehlis não distinguível. Útero nas proglótides pré grávidas e grávidas lobado, parenquimatoso. Ovos esféricos com cerca de 10,60 $\mu \mathrm{m}$ de diâmetro ( $n=1)$, oncosferas ovais alongadas 35,20 x 24,80 ( $n=1)$, ganchos embrionários não visíveis.

Considerações: Os dois indivíduos de Myrmoborus leucophrys leucophrys analisados foram coletados em diferentes pontos de coleta da área de Altamira, caracterizados por mata de terra firme já fragmentada. A observação do mesmo morfotipo de cestódeo nas amostras indica que este hospedeiro possui ampla distribuição geográfica e pode apresentar hábito estenoxeno, uma vez que apresenta semelhanças com o parasita de M. myotherinus ochrolaema (ver adiante). $\mathrm{O}$ cestódeo obtido pertence à família Metadilepididae (M02), com uma coroa de ganchos simples e triangulares com comprimento próximo a 30 $\mu \mathrm{m}$, oncosferas fusiformes e receptáculo seminal alongado, característicos de espécies do gênero Schmidneila (KORNYUSHIN; GEORGIEV, 1994). A identificação deste segundo morfotipo de Schmidneila cf. evidencia que a fauna de cestódeos Neotropicais é pouco conhecida, já que há apenas uma espécie descrita para o gênero. A alta prevalência para cestódeos observada em M. leucophrys leucophrys (100\%) indica que este parasita não é raro na área amostrada, porém o número amostral restrito $(n=2)$ implica em aumento da área amostral para confirmação se está é uma característica intrínseca ao táxon ou somente aos indivíduos distribuídos nesta área.

\subsubsection{Myrmoborus myotherinus ochrolaema (Hellmayr, 1906)}

Localidades amostradas: Altamira, Pará, margem esquerda do rio Xingu, Centro de Endemismo Tapajós (1 espécime) e margem direita do rio Xingu, Centro de Endemismo Xingu (2 espécimes); Santana do Araguaia, Pará, Fazenda Fartura, margem esquerda do Rio Araguaia, Centro de Endemismo Xingu (8 espécimes); Machadinho d'Oeste, margem esquerda do rio Ji-Paraná, Centro de Endemismo Rondônia (2 espécimes).

Localidades de hospedeiros infestados: Altamira, Pará, Centro de Endemismo Xingu (2 espécimes) e Centro de Endemismo Tapajós (1 espécime), Santana do Araguaia, Pará, Centro de Endemismo Xingu (1 espécime).

Prevalência da infestação: 31\% (4 hospedeiros infestados em 13 analisados). 
Intensidade da infestação: variável; indeterminada (D06, D07, H11); um espécime por hospedeiro (H12); 4 espécimes por hospedeiro (M03).

Cestoda observados: 5 morfotipos; Dilepididae (D06; ANEXO D, Figura 22) (D07; ANEXO D, Figura 23); Hymenolepididae (H11; ANEXO D, Figura 24) (H12; ANEXO D, Figura 25), Metadilepididae: Schmidneila sp. (M03; ANEXO D, Figura 26).

Caracterização D06: Dois espécimes incompletos. Comprimento total e número de proglótides indeterminados. Escólex com maior largura na região das ventosas 186,72 ( $\mathrm{n}=1)$. Aparato rostelar musculo-glandular, rostelo muscular, bolsa rostelar com parede mediana. Coroa simples de ganchos rostelares, uniformes, arcuatóides, 10 ganchos em número $(n=1)$, $10,50 \mu \mathrm{m}$ de comprimento $(n=1)$. Ventosas redondas, $63,75 \mu m$ de diâmetro $(n=1)$, musculares. Proglótides craspedotas, com margens arredondadas, proglótide pós madura $203,30 \times 218,85(n=1)$, proglótide pré grávida $252 \times 268(n=1)$, proglótide grávida $440 \times 344$ $(n=1)$. Dutos osmorregulatórios não observados. Poro genital alternado regularmente, a $28 \%$ da margem anterior da proglótide pós madura, a 38\% da margem anterior da proglótide pré grávida. Testículos 10 em número $(n=1)$, posteriores ao ovário. Saco do cirro oval, alongado, com parede mediana, cirro sem espinhos visíveis em microscopia óptica. Vitelário mediano, compacto, de forma irregular e posterior ao ovário. Ovário com dois lobos alados, unidos na região mediana por um istmo. Glândula de Mehlis não distinguível. Útero nas proglótides pré grávidas saculiforme, com parede espessa. Ovos esféricos com cerca de 6,65 $\mu \mathrm{m}$ de diâmetro $(n=1)$, oncosferas esféricas com cerca de $19,85 \mu \mathrm{m}$ de diâmetro $(n=1)$, ganchos embrionários não visíveis.

Caracterização D07: Dois espécimes completos. Espécimes grávidos, 1204-1532,90 de comprimento $(1368,45 \pm 323,56, n=2)$, compostos por 7 proglótides $(n=2)$. Escólex com maior largura na região das ventosas $193(n=1)$. Aparato rostelar musculo-glandular, rostelo muscular, bolsa rostelar com parede mediana. Coroa dupla alternada de ganchos rostelares, uniformes, arcuatóides, 12 ganchos em número $(n=1), 11 \mu m$ de comprimento $(n=1)$. Ventosas redondas, $81 \mu \mathrm{m}$ de diâmetro $(n=1)$, musculares. Proglótides craspedotas, com margens arredondadas, proglótide pós madura $290 \times 344(n=1)$, proglótide grávida $476 \times 384$ $(n=1)$. Dutos osmorregulatórios não observados. Poro genital alternado regularmente, a $36 \%$ da margem anterior da proglótide pós madura. Testículos 9 em número $(n=1)$, posteriores ao 
ovário. Saco do cirro oval, com parede mediana, cirro sem espinhos visíveis em microscopia óptica. Vitelário mediano, compacto, de forma irregular e posterior ao ovário. Ovário com dois lobos alados, unidos na região mediana por um istmo. Glândula de Mehlis não distinguível. Útero nas proglótides pré grávidas saculiforme, com parede espessa. Ovos ausentes, oncosferas esféricas com cerca de $18 \mu \mathrm{m}$ de diâmetro $(n=1)$, ganchos embrionários não visíveis.

Caracterização H11: Um espécime incompleto e três segmentos estrobilares. Comprimento total e número de proglótides indeterminados. Escólex com maior largura na região das ventosas 203,26 (n=1). Base rostelar musculo-glandular, rostelo muscular, bolsa rostelar com parede delgada. Coroa simples de ganchos rostelares, uniformes, arcuatóides, 10 ganchos em número $(n=1), 27,21 \mu \mathrm{m}$ de comprimento $(n=1)$. Ventosas redondas, $81,70 \mu \mathrm{m}$ de diâmetro $(n=1)$, musculares, sem espinhos. Proglótides craspedotas. Dutos osmorregulatórios não observados. Poro genital unilateral. Testículos ovais, 3 em número em todas as proglótides visíveis, 1 poral, 1 central e 1 aporal. Saco do cirro oval, com parede delgada, cirro sem espinhos visíveis em microscopia óptica. Vitelário mediano, compacto, elíptico, posterior aos demais órgãos. Ovário lobado, mediano. Glândula de Mehlis não distinguível. Útero nas proglótides pré grávidas saculiforme, com septo central. Ovos esféricos com cerca de 9,60 $\mu$ m de diâmetro $(n=1)$, oncosferas esféricas com cerca de $28,20 \mu \mathrm{m}$ de diâmetro $(n=1)$, ganchos embrionários visíveis na porção central.

Caracterização H12: Um espécime incompleto. Estróbilo incompleto com 23,84mm e 174 proglótides presentes. Escólex ausente. Proglótides craspedotas, proglótide madura $160 \mathrm{x}$ $431(n=1)$, proglótide pré grávida $138 \times 503(n=1)$, proglótide grávida $373 \times 881(n=1)$. Dutos osmorregulatórios não observados. Poro genital unilateral, a 35\% da margem anterior da proglótide madura. Testículos ovais, 3 em número em todas as proglótides visíveis, em disposição triangular com 1 poral e 2 aporais alinhados. Saco do cirro oval, com parede mediana, cirro sem espinhos visíveis em microscopia óptica. Vitelário mediano, compacto, elíptico, posterior aos demais órgãos. Ovário lobado, mediano. Glândula de Mehlis não distinguível. Útero nas proglótides pré grávidas saculiforme, com septo central. Ovos esféricos com cerca de $11 \mu \mathrm{m}$ de diâmetro $(n=1)$, oncosferas esféricas com cerca de $35,60 \mu \mathrm{m}$ de diâmetro $(n=1)$, ganchos embrionários visíveis na porção central, 6 em número, sem 
comprimento disponível.

Caracterização M03: Um espécime completo e um espécime incompleto. Espécime completo $6,54 \mathrm{~mm}$ de comprimento $(n=1)$, composto por 120 proglótides, última proglótide presente grávida. Escólex com maior largura na região das ventosas 216,80 ( $n=1)$. Base rostelar muscular, rostelo muscular, bolsa rostelar com parede delgada. Coroa simples de ganchos rostelares, uniformes, triangulares, 18 ganchos em número $(n=1), 29,22 \mu \mathrm{m}$ de comprimento $(n=1)$. Ventosas circulares, $101,62 \mu$ m de diâmetro $(n=1)$, musculares, sem espinhos. Proglótides craspedotas, proglótide madura 65 × $196(n=1)$, proglótide pré grávida $101 \times 360(n=1)$, proglótide grávida 251,55 x 373,20 (n=1). Número de dutos osmorregulatórios não determinado. Poro genital unilateral, a 21\% da margem anterior da proglótide madura, a $23 \%$ da margem anterior da proglótide pré grávida. Testículos ovais, 7 em número, posteriores às glândulas femininas. Saco do cirro oval, alongado, com parede delgada, lateral aos dutos osmorregulatórios, cirro sem espinhos visíveis em microscopia óptica. Vitelário mediano, compacto, oval. Ovário com 2 lobos arredondados, anterior. Glândula de Mehlis não distinguível. Útero nas proglótides pré grávidas e grávidas lobado, parenquimatoso. Ovos esféricos com cerca de $12,50 \mu \mathrm{m}$ de diâmetro $(n=1)$, oncosferas fusiformes 25,60 x 12,60 (n=1), ganchos embrionários não visíveis.

Considerações: A maior diversidade de cestódeos observada foi apresentada pela espécie Myrmoborus myotherinus ochrolaema, com cinco morfotipos distintos de cestódeos pertencentes a três famílias, Dilepididae (D06 e D07), Hymenolepididae (H11 e H12) e Metadilepididae (M03). Os morfotipos pertencentes às famílias Dilepididae foram obtidos nos mesmos indivíduos hospedeiros de Hymenolepididae, sendo D06 e H11 provenientes de um indivíduo hospedeiro de Altamira (PA), Centro de Endemismo Xingu, e D07 e H12 obtidos em outro espécime hospedeiro de Santana do Araguaia (PA), Centro de Endemismo Xingu. O espécime pertencente à família Metadilepididade foi encontrado isolado em um hospedeiro de Altamira (PA), Centro de Endemismo Tapajós. As amostras obtidas em três indivíduos de M. myotherinus ochrolaema coletados em três diferentes localidades mostram que a diversidade de cestódeos em membros da família Thamnophilidae pode ser diretamente relacionada à diversidade de ambientes amostrados em busca de hospedeiros destes helmintos. 
A distinção nas amostras de Dilepididae e Hymenolepididae obtidas em uma mesma Centro de Endemismo biogeográfica (Xingu) aponta que a distribuição nas populações de cestódeos não reflete aquela observada para a espécie hospedeira, sugerindo uma maior diversidade para os parasitas em relação aos seus hospedeiros. Para que estudos mais aprofundados sobre as relações de coevolução e distribuição entre estes parasitas e seus hospedeiros sejam feitos, é necessário que a taxonomia de ambos esteja resolvida (CAIRA; JENSEN, 2001), porém a identificação dos helmintos não foi possível com as chaves disponíveis para as famílias Dilepididade e Hymenolepididae (ver KHALIL; JONES; BRAY, 1994). Estas famílias de cestódeos encerram cerca de 1650 espécies de solitárias conhecidas (38\%), porém a fauna parasita de passeriformes da região Neotropical é pouco conhecida e necessita de revisão.

O espécime pertencente à família Metadilepididae proveniente da Centro de Endemismo Tapajós apresenta uma coroa de ganchos simples e triangulares com comprimento menor que $30 \mu \mathrm{m}$, oncosferas fusiformes e receptáculo seminal alongado, característicos de espécies do gênero Schmidneila (KORNYUSHIN; GEORGIEV, 1994). O morfotipo M03, parasita de M. myotherinus ochrolaema, assemelha-se ao morfotipo M02, parasita de M. leucophrys leucophrys, quanto ao número de ganchos (18 x 17) e à localidade de coleta, porém é necessário refinar a taxonomia do gênero, com apenas uma espécie conhecida, para a identificação precisa destes helmintos. A possível infestação de duas espécies simpátricas do gênero Myrmoborus pode indicar o hábito extenoxeno para estes cestódeos, inédito na literatura pertinente a família.

\subsubsection{Myrmoborus myotherinus proximus Todd, 1927}

Localidades amostradas: Porto Velho, Rondônia, margem esquerda do rio Madeira, Centro de Endemismo Inambari (15 espécimes).

Prevalência da infestação: 12,5\% (1 hospedeiro infestado em 8 analisados).

Intensidade da infestação: indeterminada.

Cestoda observados: 1 morfotipo; Hymenolepididae (H13; ANEXO D, Figura 27).

Caracterização H13: Três espécimes incompletos. Comprimento total e número de segmentos indeterminados. Escólex com maior largura na região das ventosas 192,10 (n=1). 
Base rostelar muscular, rostelo muscular, bolsa rostelar com parede delgada. Coroa simples de ganchos rostelares, uniformes, arcuatóides, 8 ganchos em número $(n=1), 27,40 \mu m$ de comprimento $(n=1)$. Ventosas redondas, $97,58 \mu m$ de diâmetro $(n=1)$, musculares, sem espinhos. Proglótides craspedotas. Dutos osmorregulatórios não observados. Poro genital unilateral. Testículos ovais, 3 em número em todas as proglótides visíveis, em disposição triangular com 1 poral anterior, 1 aporal anterior e 1 central posterior. Saco do cirro oval, com parede mediana, entre os dutos osmorregulatórios, cirro sem espinhos visíveis em microscopia óptica. Vitelário mediano, compacto, elíptico, posterior aos demais órgãos. Ovário com 3 lobos transversais, mediano. Glândula de Mehlis não distinguível. Útero nas proglótides pré grávidas saculiforme, com septo central. Ovos esféricos com cerca de $12,25 \mu \mathrm{m}$ de diâmetro $(n=1)$, oncosferas esféricas com cerca de $32,13 \mu \mathrm{m}$ de diâmetro $(n=1)$,

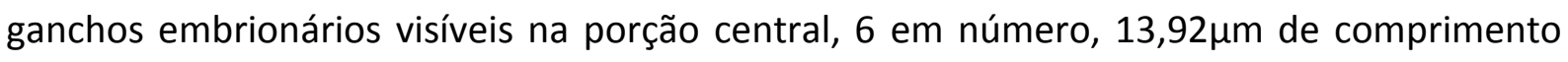
$(n=1)$.

Considerações: Os espécimes de Myrmoborus myotherinus proximus foram amostrados em diferentes pontos de coleta no Centro de Endemismo de Porto Velho (RO), em áreas de mata de terra firme. A prevalência de infestação (12,5\%) e a coleta de apenas um indivíduo hospedeiro podem indicar que este helminto apresenta baixa diversidade e distribuição nesta área. Os dados diferem daqueles observados para as espécies de Myrmoborus amostradas para os Centros de Endemismo Xingu e Tapajós, que apresentaram infestações iguais a 100 e $30 \%$ em suas populações.

\subsubsection{Myrmoborus myotherinus sororius (Hellmayr, 1910)}

Localidade amostrada: Porto Velho, Rondônia, margem direita do rio Madeira, Centro de Endemismo Rondônia (1 espécime).

Prevalência de infestação: nenhum hospedeiro infestado.

Considerações: A coleta de apenas um indivíduo de Myrmoborus myotherinus sororius no Centro de Endemismo Rondônia implica na necessidade de aumento do esforço amostral e a ausência de helmintos associados reflete a baixa prevalência observada para a região de Porto Velho, uma vez que a população de $M$. myotherinus proximus coletado no Centro de 
Endemismo Inambari apresentou prevalência de infestação igual a 12,5\%. O espécime foi coletado em uma área comum a outras espécies de tamnofilídeos que apresentaram fauna de cestódeos associada, portanto a ausência de helmintos nesta espécie de ave pode estar relacionada a sua ecologia, que não o expõe às formas de transmissão dos parasitas ou não permite que esta infeste esta ave (e. g. especificidade).

\subsubsection{Myrmophylax}

\subsubsection{Myrmophylax athrotorax melanura (Ménétriès, 1835)}

Localidades amostradas: Porto Velho, Rondônia, margem direita do rio Madeira, Centro de Endemismo Rondônia (2 espécimes); Santana do Araguaia, Pará, Fazenda Fartura, margem esquerda do Rio Araguaia, Centro de Endemismo Xingu (3 espécimes).

Localidades de hospedeiros infestados: Porto Velho, Rondônia, Centro de Endemismo Rondônia (2 espécimes); Santana do Araguaia, Pará, Centro de Endemismo Xingu (2 espécimes).

Prevalência da infestação: 80\% (4 hospedeiros infestados em 5 analisados).

Intensidade da infestação: 1 espécime por hospedeiro (H14; H15; H16).

Cestoda observados: 3 morfotipos; Hymenolepididae (H14; ANEXO D, Figura 28) (H15; ANEXO D, Figura 29) (H16; ANEXO D, Figura 30).

Caracterização H14: Um espécime partido, proglótides ausentes nas quebras. Espécime com 25,08mm de comprimento e 265 proglótides presentes. Escólex com maior largura na região das ventosas 163,05 ( $n=1)$. Base rostelar musculo-glandular, rostelo muscular, bolsa rostelar com parede delgada. Coroa simples de ganchos rostelares, uniformes, arcuatóides, 8 ganchos em número $(n=1), 34,95 \mu \mathrm{m}$ de comprimento $(n=1)$. Ventosas redondas, $74,05 \mu \mathrm{m}$ de diâmetro $(n=1)$, musculares, sem espinhos. Proglótides craspedotas, proglótide madura $84,50 \times 151,60(n=1)$, proglótide pré grávida $153 \times 418,10(n=1)$, proglótide grávida 303,50 x $451,25(n=1)$. Dutos osmorregulatórios não observados. Poro genital unilateral, a $23 \%$ da margem anterior da proglótide madura e a $27 \%$ da margem anterior da proglótide pré grávida. Testículos ovais, 3 em número em todas as proglótides visíveis, em disposição triangular com 1 poral e 1 central posteriores e 1 aporal anterior. Saco do cirro oval, com 
parede mediana, entre os dutos osmorregulatórios, cirro sem espinhos visíveis em microscopia óptica. Vitelário mediano, compacto, elíptico, posterior aos demais órgãos. Ovário com 3 lobos transversais, mediano. Glândula de Mehlis não distinguível. Útero nas proglótides pré grávidas saculiforme, com septo central. Ovos esféricos com cerca de 8,50 $\mu$ m de diâmetro $(n=1)$, oncosferas esféricas com cerca de $31,25 \mu m$ de diâmetro $(n=1)$, ganchos embrionários visíveis na porção central, 6 em número, 9,43um de comprimento $(n=1)$.

Caracterização H15: Um espécime partido, proglótides ausentes nas quebras. Espécime com $8 \mathrm{~mm}$ de comprimento e 146 proglótides presentes. Escólex com maior largura na região das ventosas 184,35 $(n=1)$. Base rostelar musculo-glandular, rostelo muscular, bolsa rostelar com parede delgada. Coroa simples de ganchos rostelares, uniformes, arcuatóides, 10 ganchos em número $(n=1), 31,97 \mu m$ de comprimento $(n=1)$. Ventosas redondas, $85,82 \mu m$ de diâmetro $(n=1)$, musculares, sem espinhos. Proglótides craspedotas, proglótide madura $59,50 \times 211(n=1)$, proglótide pré grávida 112,27 x 290,62 (n=1), proglótide grávida 135,22 x 293,17 (n=1). Quatro dutos osmorregulatórios, dutos genitais dorsais. Poro genital unilateral, a 36\% da margem anterior da proglótide madura e a 34\% da margem anterior da proglótide pré grávida. Testículos ovais, 3 em número em todas as proglótides visíveis, disposição em linha, medianos. Saco do cirro oval, com parede mediana, entre os dutos osmorregulatórios, cirro sem espinhos visíveis em microscopia óptica. Vitelário mediano, compacto, elíptico, posterior aos demais órgãos. Ovário com 3 lobos transversais, mediano. Glândula de Mehlis não distinguível. Útero nas proglótides pré grávidas saculiforme, com septo central. Ovos esféricos com cerca de $7,70 \mu m$ de diâmetro $(n=1)$, oncosferas esféricas com cerca de 20,50 $\mu$ m de diâmetro $(n=1)$, ganchos embrionários visíveis na porção central, 6 em número, comprimento indeterminado.

Caracterização H16: Um espécime completo, um espécime incompleto. Espécime com 18,55mm de comprimento e 151 proglótides presentes. Escólex com maior largura na região das ventosas $181,80(n=1)$. Base rostelar musculo-glandular, rostelo muscular, bolsa rostelar com parede delgada. Coroa simples de ganchos rostelares, uniformes, arcuatóides, 8 ganchos em número $(n=1), 35,72 \mu \mathrm{m}$ de comprimento $(n=1)$. Ventosas redondas, $84,95 \mu \mathrm{m}$ de diâmetro ( $n=1)$, musculares, sem espinhos. Proglótides craspedotas, proglótide madura $95 \mathrm{x}$ 
$315,50(n=1)$, proglótide pré grávida $121,25 \times 410,65(n=1)$, proglótide grávida 327,55 x $615,65(n=1)$. Quatro dutos osmorregulatórios, dutos genitais dorsais. Poro genital unilateral, a $27 \%$ da margem anterior das proglótides madura e pré grávida. Testículos ovais, 3 em número em todas as proglótides visíveis, em disposição triangular com 1 poral e 1 aporal posteriores e 1 aporal anterior. Saco do cirro oval, com parede mediana, entre os dutos osmorregulatórios, cirro sem espinhos visíveis em microscopia óptica. Vitelário mediano, compacto, elíptico, posterior aos demais órgãos. Ovário com 3 lobos transversais, mediano. Glândula de Mehlis não distinguível. Útero nas proglótides pré grávidas saculiforme, com septo central. Ovos esféricos com cerca de $14,32 \mu m$ de diâmetro $(n=1)$, oncosferas esféricas com cerca de $32,52 \mu \mathrm{m}$ de diâmetro $(n=1)$, ganchos embrionários visíveis na porção central, 6 em número, $11,10 \mu \mathrm{m}$ de comprimento $(n=1)$.

Considerações: Os espécimes de Myrmophylax athrotorax melanura foram coletados em dois pontos amostrais, nos Centros de Endemismo Rondônia e Xingu, apresentando infestação por cestódeos em ambos. Os dois espécimes coletados em Santana do Araguaia (PA) apresentaram infestação por um mesmo morfotipo de cestódeo, enquanto os dois indivíduos amostrados em Porto Velho apresentaram um morfotipo de parasita cada. Todos os cestódeos presentes em $M$. athrotorax melanura pertencem à família Hymenolepididae, diferenciando-se pelo número de ganchos rostelares $(8 \times 8 \times 10)$ e posição relativa dos testículos na proglótide, características consideradas informativas para a família (CZAPLINSK; VAUCHER, 1994). A observação dos dutos osmorregulatórios, caractere importante para a determinação da subfamília, não foi possível nestes espécimes e não permitiu a identificação do gênero a que estes cestódeos possam pertencer. A coleta de três morfotipos de cestódeo em uma mesma espécie de hospedeiro indica que a diversidade dos helmintos destas aves é bastante alta, porém a amostragem de poucos indivíduos, tanto parasitas quanto hospedeiros, não permite inferências mais precisas sobre sua associação.

\subsubsection{Myrmotherula}

\subsubsection{Myrmotherula assimilis assimilis Pelzeln, 1868}

Localidade amostrada: Porto Velho, Rondônia, Ilha de Mutum, margem esquerda do rio 
Madeira, Centro de Endemismo Inambari (7 espécimes).

Prevalência de infestação: nenhum hospedeiro infestado.

Considerações: As amostras da espécie Myrmotherula assimilis assimilis foram obtidas em uma mesma localidade, Iha de Mutum (RO), com ausência de cestódeos associada a esta ave. A ausência de parasitas em todos os espécimes de tamnofilídeos amostrados nesta localidade (ANEXO C) aponta que não houve exposição das aves às formas infestantes dos parasitas, possivelmente não havendo a presença destas nesta localidade, isolada da margem esquerda do rio Madeira. A espécie $M$. assimilis é característica de matas de várzea (ZIMMER; ISLER, 2016), hábito não comum às demais amostradas neste estudo, portanto a possível fauna de helmintos associada a este tamnofilídeo pode diferir daquela observada para as demais em Myrmotherula.

\subsubsection{Myrmotherula axillaris axillaris (Vieillot, 1817)}

Localidades amostradas: Altamira, Pará, margem direita do rio Xingu, Centro de Endemismo Xingu (1 espécime); Santana do Araguaia, Pará, Fazenda Fartura, margem esquerda do Rio Araguaia, Centro de Endemismo Xingu (15 espécimes); Porto Velho, Rondônia, margem direita do rio Madeira, Centro de Endemismo Rondônia (3 espécimes).

Localidades de hospedeiros infestados: Santana do Araguaia, Pará, Centro de Endemismo Xingu (1 espécime); Porto Velho, Rondônia, Centro de Endemismo Rondônia (1 espécime).

Prevalência da infestação: 10\% (2 hospedeiros infestados em 19 analisados).

Intensidade da infestação: 1 espécime por hospedeiro (M04).

Cestoda observados: 1 morfotipo; Metadilepididae: Schmidneila sp. (M04; ANEXO D, Figura 31).

Caracterização M04: Um espécime completo e um espécime incompleto. Espécime 15,45mm de comprimento ( $n=1)$, composto por 145 proglótides. Escólex com maior largura na região das ventosas $271,15(n=1)$. Base rostelar muscular, rostelo muscular, bolsa rostelar com parede delgada. Coroa simples de ganchos rostelares, uniformes, triangulares, $36(n=2)$, $23,50 \mu \mathrm{m}$ de comprimento $(n=1)$. Ventosas circulares, $125,40 \mu \mathrm{m}$ de diâmetro $(n=1)$, musculares, sem espinhos. Proglótides craspedotas, proglótide madura 94,50 × $217(\mathrm{n}=1)$, 
proglótide pré grávida 152 × $426(n=1)$, proglótide grávida 584,40 × $428(n=1)$. Número de dutos osmorregulatórios não determinado. Poro genital unilateral, a $21 \%$ da margem anterior da proglótide madura, a $22 \%$ da margem anterior da proglótide pré grávida. Testículos ovais, 5 em número, posteriores às glândulas femininas. Saco do cirro oval, alongado, com parede delgada, entre os dutos osmorregulatórios, cirro sem espinhos visíveis em microscopia óptica. Vitelário mediano, compacto, oval. Ovário com 2 lobos arredondados, anterior. Glândula de Mehlis não distinguível. Útero nas proglótides pré grávidas e grávidas lobado, parenquimatoso. Ovos esféricos com cerca de 11,25 $\mathrm{mm}$ de diâmetro $(n=1)$, oncosferas fusiformes $44,15 \times 23,60(n=1)$, ganchos embrionários não visíveis.

Considerações: Os espécimes de Myrmotherula axillaris axillaris analisados para presença de cestódeos foram coletados em áreas distintas, porém os dois indivíduos hospedeiros apresentaram um morfotipo de cestódeo em comum, pertencente à família Metadilepididae.

O espécime apresenta uma coroa de ganchos simples e triangulares com comprimento menor que $30 \mu \mathrm{m}$, oncosferas fusiformes e receptáculo seminal alongado, característicos de espécies do gênero Schmidneila (KORNYUSHIN; GEORGIEV, 1994), caracterizando o quarto registro para o gênero neste estudo. Os espécimes amostrados possuem semelhanças quanto ao número de ganchos (34 e 36), número de testículos (5) e morfologia e posição do saco do cirro em relação aos dutos osmorregulatórios, porém diferem em todas estas características dos três morfotipos atribuídos a este gênero já registrados neste estudo. 0 registro do mesmo morfotipo nos Centros de Endemismo Xingu e Rondônia mostram ampla distribuição para este cestódeo, porém é necessário que estes sejam formalmente descritos para inferências acuradas sobre sua abrangência geográfica.

\subsubsection{Myrmotherula axillaris heterozyga Zimmer, 1932}

Localidades amostradas: Porto Velho, Rondônia, margem esquerda do rio Madeira, Centro de Endemismo Inambari (8 espécimes).

Prevalência da infestação: 12,5\% (1 hospedeiro infestado em 8 analisados).

Intensidade da infestação: 1 espécime por hospedeiro (P03). 
Cestoda observados: 1 morfotipo; Paruterinidae (P03; ANEXO D, Figura 32).

Caracterização P02: Um espécime incompleto. Espécime sem escólex e com segmentos pré grávidos e grávidos presentes, comprimento e número total de segmentos indeterminado. Proglótides craspedotas. Dutos osmorregulatórios não observados. Poro genital unilateral ou alternado irregularmente. Saco do cirro oval, lateral aos dutos osmorregulatórios em proglótides grávidas. Útero faseolar em proglótides pré grávidas e grávidas, posterior. Órgão paruterino com paredes espessas, em forma de pirâmide e porção anterior esférica, anterior ao útero. Ovos esféricos, $12,80 \mu \mathrm{m}$ de diâmetro $(n=1)$, oncosferas esféricas, $28 \mu \mathrm{m}$ de diâmetro $(n=1)$.

Considerações: Os espécimes de Myrmotherula axillaris heterozyga foram coletados em pontos distintos na área de Porto Velho, portanto a baixa prevalência de infestação observada para a espécie indica baixa disponibilidade de formas infestantes no ambiente ou fatores intrínsecos às espécies (e. g especificidade) que impedem a associação entre este tamnofilídeo e cestódeos. A identificação do cestódeo não foi possível pela ausência da região anterior do espécime.

\subsubsection{Myrmotherula brachyura (Hermann, 1783) Sclater, 1858}

Localidade amostrada: Porto Velho, Rondônia, margem esquerda do rio Madeira, Centro de Endemismo Inambari (2 espécimes).

Prevalência de infestação: nenhum hospedeiro infestado.

Considerações: A espécie Myrmotherula brachyura é encontrada em dosséis ou copas de árvores em matas de terra firme (ZIMMER; ISLER, 2016) e o hábito arborícola desta espécie a distingue da maioria das demais amostradas neste estudo. Os indivíduos foram coletados em um ponto de coleta na mesma amostragem de $M$. sclateri, espécie também arborícola com infestação por cestódeos positiva, indicando que as formas de transmissão de cestódeos estão presentes no ambiente, porém não completaram seu ciclo em $M$. brachyura. A ausência de cestódeos nesta ave pode ser causada por baixa densidade do parasita no ambiente, por hábito oioxeno do parasita (alta especificidade à espécie $M$. 
sclateri) ou por número amostral insuficiente em uma população caracterizada por baixa infestação, recomendando-se o aumento do esforço amostral para inferências mais aprofundadas.

\subsubsection{Myrmotherula heteroptera Todd, 1927}

Localidade amostrada: Porto Velho, Rondônia, margem esquerda do rio Madeira, Centro de Endemismo Inambari (1 espécime).

Prevalência de infestação: nenhum hospedeiro infestado.

Considerações: O espécime de Myrmotherula heteroptera foi coletado em área de mata de terra firme onde diversos outros indivíduos hospedeiros foram amostrados na localidade de Porto Velho $(\mathrm{RO})$, porém o número amostral restrito $(n=1)$ e não permite conclusões aprofundadas acerca de sua fauna parasitária. As demais espécies de Myrmotherula amostradas nesta localidade apresentaram infestação por cestódeos nula ou restrita a um indivíduo (ANEXO C), indicando que este gênero pode apresentar baixa prevalência parasitária como uma característica intrínseca.

\subsubsection{Myrmotherula longipennis garbei lhering, 1905}

Localidade amostrada: Porto Velho, Rondônia, margem esquerda do rio Madeira, Centro de Endemismo Inambari (3 espécimes).

Prevalência de infestação: nenhum hospedeiro infestado.

Considerações: Os espécimes de Myrmotherula longipennis garbei foram coletados em área de mata de terra firme onde diversos outros indivíduos hospedeiros foram amostrados na localidade de Porto Velho (RO), indicando presença de formas infestantes, porém a baixa ou nula prevalência amostral registrada para o gênero também foi observada nesta amostra, já que nenhum indivíduo de $M$. longipennis garbei foi encontrado com cestódeos associados.

\subsubsection{Myrmotherula longipennis ochrogyna Todd, 1927}


Localidade amostrada: Machadinho d'Oeste, margem esquerda do rio Ji-Paraná, Centro de Endemismo Rondônia (1 espécime).

Prevalência de infestação: nenhum hospedeiro infestado.

Considerações: O espécime de Myrmotherula longipennis ochrogyna coletado no Centro de Endemismo Rondônia não apresentou infestação por cestódeos, assim como os demais espécimes deste táxon coletados nos Centros de Endemismo Inambari e Rondônia, indicando que a baixa amostragem pode não estar relacionada à distribuição geográfica, mas a outros fatores como especificidade parasitária ou baixa densidade populacional e consequente baixa taxa de encontro entre hospedeiro e forma infestante. A baixa ou nula infestação por cestódeos foi observada em diversos táxons de Myrmotherula, porém em amostras com número amostral restrito a poucos espécimes.

\subsubsection{Myrmotherula longipennis paraensis (Todd, 1920)}

Localidade amostrada: Altamira, Pará, margem esquerda do rio Xingu, Centro de Endemismo Tapajós (1 espécime) e margem direita do rio Xingu, Centro de Endemismo Xingu (1 espécime); Santana do Araguaia, Pará, Fazenda Fartura, margem esquerda do Rio Araguaia, Centro de Endemismo Xingu (3 espécimes).

Prevalência de infestação: nenhum hospedeiro infestado.

Considerações: A amostragem de espécimes de Myrmotherula longipennis paraensis em três localidades distintas nos Centros de Endemismo Tapajós e Xingu e a ausência de helmintos associados reflete a prevalência parasitária baixa ou nula observada para este gênero de tamnofilídeo. Como observado para as demais espécies de Myrmotherula, a ausência de cestódeos parasitas pode indicar que esta espécie possui parasitas com distribuição geográfica restrita ou baixa densidade populacional, diminuindo a incidência de infestação do hospedeiro.

\subsubsection{Myrmotherula menetriesii menetriesii (d'Orbigny, 1837)}

Localidades amostradas: Porto Velho, Rondônia, margem esquerda do rio Madeira, Centro 
de Endemismo Inambari (4 espécimes).

Prevalência da infestação: 25\% (1 hospedeiro infestado em 4 analisados).

Intensidade da infestação: 1 espécime por hospedeiro.

Cestoda observados: 1 morfotipo; Metadilepididae: Schmidneila sp. (M05; ANEXO D, Figura 33).

Caracterização M05: Um espécime completo. Espécime 33,37mm de comprimento $(n=1)$, composto por 248 proglótides. Escólex com maior largura na região das ventosas 303,94 $(n=1)$. Base rostelar muscular, rostelo muscular, bolsa rostelar com parede delgada. Coroa simples de ganchos rostelares, uniformes, triangulares, incompleta, ao menos 11 ganchos presentes, $27,90 \mu \mathrm{m}$ de comprimento $(n=1)$. Ventosas circulares, $146,83 \mu \mathrm{m}$ de diâmetro $(n=1)$, musculares, sem espinhos. Proglótides craspedotas, proglótide madura 109,90 x $326,63(n=1)$, proglótide pré grávida 115,90 x 448,84 $(n=1)$, proglótide grávida 421,26 $\times$ 704,24 ( $n=1$ ). Número de dutos osmorregulatórios não determinado. Poro genital unilateral, a $27 \%$ da margem anterior da proglótide madura, a $25 \%$ da margem anterior da proglótide pré grávida. Testículos ovais, 7 em número, posteriores às glândulas femininas. Saco do cirro oval, alongado, com parede delgada, entre os dutos osmorregulatórios, cirro sem espinhos visíveis em microscopia óptica. Vitelário mediano, compacto, oval. Ovário com 2 lobos arredondados, anterior. Glândula de Mehlis não distinguível. Útero nas proglótides pré grávidas e grávidas lobado, parenquimatoso. Ovos esféricos com cerca de 13,20 $\mu \mathrm{m}$ de diâmetro ( $n=1)$, oncosferas elípticas 35,10 x 27,67 (n=1), ganchos embrionários não visíveis.

Considerações: A coleta de quatro indivíduos de Myrmotherula menetriesii menetriesii na mesma localidade com prevalência de infestação por cestódeos igual a 25\% (um indivíduo parasitado) indica que a ampliação do esforço amostral para espécies pertencentes a este gênero é necessária para a obtenção de dados sobre sua fauna de cestódeos associada. A baixa prevalência indica que os parasitas deste grupo apresentam baixa densidade populacional, diminuindo a infestação de hospedeiros. O cestódeo obtido pertence à família Metadilepididae (M02), com uma coroa de ganchos simples e triangulares com comprimento próximo a $30 \mu \mathrm{m}$, oncosferas fusiformes e receptáculo seminal alongado, característicos de espécies do gênero Schmidneila (KORNYUSHIN; GEORGIEV, 1994). A ausência de cerca de dois terços dos ganchos da coroa não permite que o espécime seja 
associado a outro morfotipo de Schmidneila sp. coletados na mesma região, porém o número de testículos (7) e a posição do saco do cirro entre os dutos osmorregulatórios coincidem com o morfotipo de Schmidneila sp. encontrado em M. axillaris axillaris amostrado nesta mesmo região. A descrição formal destes morfotipos aguarda o refino taxonômico necessário para o gênero, permitindo então que seja verificado se a mesma espécie de parasita está presente em dois táxons de hospedeiros apresentando hábito estenoxeno.

\subsubsection{Myrmotherula menetriesii omissa Todd, 1927}

Localidade amostrada: Santana do Araguaia, Pará, Fazenda Fartura, margem esquerda do Rio Araguaia, Centro de Endemismo Xingu (1 espécime).

Prevalência de infestação: nenhum hospedeiro infestado.

Considerações: A amostra de Myrmotherula menetriesii omissa foi igual a um indivíduo sem presença de parasitas associados, exibindo a baixa prevalência amostral observada para as espécies pertencentes a este gênero de tamnofilídeo. Assim como as demais espécies pertencentes a Myrmotherula, a fauna parasitária de $M$. menetriesii omissa pode apresentar distribuição geográfica restrita ou baixa densidade populacional, diminuindo a incidência de infestação do hospedeiro, porém é necessário um incremento no esforço amostral do hospedeiro para verificação.

\subsubsection{Myrmotherula sclateri Snethlage, 1912}

Localidades amostradas: Porto Velho, Rondônia, margem esquerda do rio Madeira, Centro de Endemismo Inambari (2 espécimes) e margem direita do rio Madeira, Centro de Endemismo Rondônia (1 espécime).

Localidades de hospedeiros infestados: Porto Velho, Rondônia, Centro de Endemismo Inambari (1 espécime).

Prevalência da infestação: 33\% (1 hospedeiro infestado em 3 analisados).

Intensidade da infestação: 1 espécime por hospedeiro (M06).

Cestoda observados: 1 morfotipo; Metadilepididae: Schmidneila sp. (M06; ANEXO D, Figura 
34).

Caracterização M06: Dois espécimes incompletos e dois segmentos estrobilares. Comprimento total e número de proglótides indeterminados. Escólex com maior largura na região das ventosas $264(n=1)$. Base rostelar muscular, rostelo muscular, bolsa rostelar com parede delgada. Coroa simples de ganchos rostelares, uniformes, triangulares, incompleta, 34 ganchos presentes, $22,61 \mu \mathrm{m}$ de comprimento $(n=1)$. Ventosas circulares, $116,15 \mu \mathrm{m}$ de diâmetro $(n=1)$, musculares, sem espinhos. Proglótides craspedotas, proglótide madura $71,05 \times 223(n=1)$. Número de dutos osmorregulatórios não determinado. Poro genital unilateral, a $29 \%$ da margem anterior da proglótide madura. Testículos ovais, 4 em número, posteriores às glândulas femininas. Saco do cirro oval, alongado, com parede delgada, entre os dutos osmorregulatórios, cirro sem espinhos visíveis em microscopia óptica. Vitelário mediano, compacto, oval. Ovário com 2 lobos arredondados, anterior. Glândula de Mehlis não distinguível. Útero nas proglótides pré grávidas e grávidas lobado, parenquimatoso. Ovos esféricos com cerca de 13,20 $\mu$ m de diâmetro $(n=1)$, oncosferas elípticas 35,10 x 27,67 ( $n=1)$, ganchos embrionários não visíveis.

Considerações: A amostra obtida para Myrmotherula sclateri foi restrita a três indivíduos provenientes de dois pontos de coleta, um em cada margem do rio, com infestação em apenas um espécime no Centro de Endemismo Inambari. A espécie apresenta hábito arborícola (ZIMMER; ISLER, 2016), o que sugeriria exploração de nicho distinta das demais espécies amostradas para o gênero, encontradas no sub-bosque, e uma possível diferença na fauna de parasitas associada, porém o morfotipo de cestódeo obtido assemelha-se àqueles observados parasitando $M$. axillaris axillaris e $M$. menetriesii menetriesii. O cestódeo obtido pertence à família Metadilepididae (M06), com uma coroa de ganchos simples e triangulares com comprimento inferior a $30 \mu \mathrm{m}$, oncosferas fusiformes e receptáculo seminal alongado, característicos de espécies do gênero Schmidneila (KORNYUSHIN; GEORGIEV, 1994). Os parasitas coletados para as três espécies hospedeiras coincidem na posição do saco do cirro entre os dutos osmorregulatórios, além do número de ganchos na coroa rostelar ser próximo (34 ou 36) nos espécimes que a apresentam completa. A distribuição em três diferentes regiões biogeográficas, o que indicaria hábito extenoxeno e ampla distribuição geográfica, depende do refino taxonômico para a família Metadilepididae. 


\subsubsection{Neoctantes}

\subsubsection{Neoctantes niger (Pelzeln, 1859)}

Localidade amostrada: Porto Velho, Rondônia, margem esquerda do rio Madeira, Centro de Endemismo Inambari (1 espécime).

Prevalência de infestação: nenhum hospedeiro infestado.

Considerações: A coleta de apenas um indivíduo de Neoctantes niger não parasitado por cestódeos não permite inferências sobre a composição de sua fauna de helmintos associada. A espécie possui baixa densidade populacional característica (ZIMMER; ISLER, 2016), indicando que estudos mais aprofundados sobre seus parasitas

\subsubsection{Oneillornis}

\subsubsection{Oneillornis salvini salvini (Berlepsch, 1901)}

Localidades amostradas: Porto Velho, Rondônia, margem esquerda do rio Madeira, Centro de Endemismo Inambari (16 espécimes).

Prevalência da infestação: 50\% (8 hospedeiros infestados em 16 analisados).

Intensidade da infestação: variável; indeterminada (D08, D09); um espécime por hospedeiro (H17).

Cestoda observados: 3 morfotipos; Dilepididae (D08; ANEXO D, Figura 35) (D09; ANEXO D, Figura 36); Hymenolepididae (H17; ANEXO D, Figura 37).

Caracterização D08: 2 espécimes completos, 2 espécimes incompletos. Espécime $962 \mu \mathrm{m}$ de comprimento $(n=1)$, composto por 11 proglótides $(n=1)$. Escólex com maior largura na região das ventosas $152,65(n=1)$. Aparato rostelar musculo-glandular, rostelo muscular, bolsa rostelar com parede mediana. Coroa dupla alternada de ganchos rostelares, uniformes, arcuatóides, 16 ganchos em número $(n=1), 12,77 \mu m$ de comprimento $(n=1)$. Ventosas redondas, $74,28 \mu \mathrm{m}$ de diâmetro $(n=1)$, musculares. Proglótides craspedotas, com margens arredondadas, proglótide pós madura 185,87 x 229,87 (n=1). Dutos osmorregulatórios não 
observados. Poro genital alternado regularmente, a 59\% da margem anterior da proglótide pós madura. Testículos 7 em número $(n=1)$, posteriores ao ovário. Saco do cirro oval, alongado, com parede mediana, cirro sem espinhos visíveis em microscopia óptica. Vitelário mediano, compacto, de forma irregular e posterior ao ovário. Ovário com dois lobos alados, unidos na região mediana por um istmo. Glândula de Mehlis não distinguível. Útero nas proglótides pré grávidas saculiforme, com parede delgada. Ovos esféricos com cerca de $8,05 \mu \mathrm{m}$ de diâmetro $(n=1)$.

Caracterização D09: Um espécime completo, 2 espécimes incompletos. Espécime 1,13mm de comprimento $(n=1)$, composto por 11 proglótides $(n=1)$. Escólex com maior largura na região das ventosas $327,20(n=1)$. Aparato rostelar musculo-glandular, rostelo muscular, bolsa rostelar com parede espessa. Coroa dupla alternada de ganchos rostelares, uniformes, arcuatóides, 19 ganchos em número $(n=1), 14,31 \mu m$ de comprimento $(n=1)$. Ventosas redondas, $86,50 \mu \mathrm{m}$ de diâmetro $(n=1)$, musculares. Proglótides craspedotas, com margens arredondadas, proglótide madura 121,30 x 300,30 ( $n=1)$, proglótide pré grávida 160,65 x $345,75(n=1)$, proglótide grávida 254,50 x 363,35 (n=1). Dutos osmorregulatórios não observados. Poro genital alternado irregularmente, a 43\% da margem anterior da proglótide madura e a $37 \%$ da margem anterior da proglótide pré grávida. Testículos 5 em número $(n=1)$, posteriores ao ovário. Saco do cirro oval, com parede mediana, cirro sem espinhos visíveis em microscopia óptica. Vitelário mediano, compacto, de forma irregular e posterior ao ovário. Ovário com dois lobos alados, unidos na região mediana por um istmo. Glândula de Mehlis não distinguível. Útero nas proglótides pré grávidas saculiforme, com parede mediana. Ovos esféricos com cerca de 6,30 $\mu$ m de diâmetro $(n=1)$, oncosferas esféricas com cerca de $12,10 \mu \mathrm{m}$ de diâmetro $(n=1)$, ganchos embrionários não visíveis.

Caracterização H17: Um espécime incompleto. Comprimento total e número de proglótides indeterminados. Escólex com maior largura na região das ventosas 263,30 (n=1). Base rostelar musculo-glandular, rostelo muscular, bolsa rostelar com parede mediana. Coroa simples de ganchos rostelares, uniformes, arcuatóides, 28 ganchos em número $(n=1)$, $38,57 \mu \mathrm{m}$ de comprimento $(n=1)$. Ventosas redondas, $128 \mu \mathrm{m}$ de diâmetro $(n=1)$, musculares, sem espinhos. Proglótides craspedotas. Dutos osmorregulatórios não observados. Poro genital unilateral. Testículos ovais, 3 em número em todas as proglótides visíveis, 1 poral 
anterior, 1 central posterior e 1 aporal anterior. Saco do cirro oval, com parede delgada, cirro sem espinhos visíveis em microscopia óptica. Vitelário mediano, compacto, elíptico, posterior aos demais órgãos. Ovário lobado, mediano. Glândula de Mehlis não distinguível.

Considerações: Os espécimes de Oneillornis salvini salvini analisados foram coletados em datas distintas e são provenientes de pontos de coleta diferentes da localidade de Porto Velho (RO), resultando em uma amostra ampla e com número de hospedeiros representativo $(n=16)$. A presença de três morfotipos de cestódeos compondo sua fauna de parasitas indica que esta espécie está exposta a diferentes formas de transmissão destes helmintos, exclusivas deste hospedeiro. Assim como as demais espécies seguidoras obrigatórias de formigas de correição (BRUMFIELD et al., 2007) (ver adiante), Oneillornis salvini salvini apresentou uma grande diversidade de morfotipos de parasitas em sua fauna associada, indicando que este hábito de vida pode propiciar maior exposição às formas de transmissão de cestódeos.

\subsubsection{Phlegopsis}

\subsubsection{Phlegopsis borbae Hellmayr, 1907}

Localidades amostradas: Machadinho d'Oeste, margem esquerda do rio Ji-Paraná, Centro de Endemismo Rondônia (2 espécimes).

Prevalência da infestação: 100\% (2 hospedeiros infestados em 2 analisados).

Intensidade da infestação: indeterminada.

Cestoda observados: 3 morfotipos; Hymenolepididae (H18; ANEXO D, Figura 38) (H19; ANEXO D, Figura 39), Metadilepididae: Schmidneila sp. (M07; ANEXO D, Figura 40).

Caracterização H18: Dois espécimes incompletos. Estróbilo incompleto com 17,95mm e 252 proglótides presentes. Escólex com maior largura na região das ventosas 327,50 (n=1). Base rostelar musculo-glandular, rostelo muscular, bolsa rostelar com parede delgada. Coroa simples de ganchos rostelares, uniformes, arcuatóides, 28 ganchos em número $(n=1)$, $35,37 \mu \mathrm{m}$ de comprimento $(n=1)$. Ventosas redondas, $124,70 \mu \mathrm{m}$ de diâmetro $(n=1)$, musculares, sem espinhos. Proglótides craspedotas, proglótide madura 73,15 x 337,45 (n=1), 
proglótide pré grávida 112,05 x $447(n=1)$. Dez dutos osmorregulatórios. Poro genital unilateral, a $57 \%$ da margem anterior da proglótide madura e a 38\% da margem anterior da proglótide pré grávida. Testículos ovais, 3 em número em todas as proglótides visíveis, em disposição triangular com 1 poral, 1 aporal anteriores e 1 central mediano. Saco do cirro oval, com parede mediana, entre os dutos osmorregulatórios, cirro sem espinhos visíveis em microscopia óptica. Vitelário mediano, compacto, elíptico, posterior aos demais órgãos. Ovário com 3 lobos transversais, mediano. Glândula de Mehlis não distinguível. Útero nas proglótides pré grávidas saculiforme, com septo central. Ovos esféricos com cerca de $7 \mu \mathrm{m}$ de diâmetro $(n=1)$.

Caracterização H19: Um espécime completo. Espécime 12,92mm de comprimento $(n=1)$, composto por 274 proglótides. Escólex com maior largura na região das ventosas $321(n=1)$. Base rostelar musculo-glandular, rostelo muscular, bolsa rostelar com parede delgada. Coroa simples de ganchos rostelares, uniformes, arcuatóides, 36 ganchos em número $(n=1)$, $30,81 \mu \mathrm{m}$ de comprimento $(n=1)$. Ventosas redondas, $116,20 \mu \mathrm{m}$ de diâmetro $(n=1)$, musculares, sem espinhos. Proglótides craspedotas. Dutos osmorregulatórios não observados. Poro genital unilateral. Testículos ovais, 3 em número em todas as proglótides visíveis, em disposição triangular com 1 poral, 1 aporal anteriores e 1 central posterior. Saco do cirro oval, com parede mediana, cirro sem espinhos visíveis em microscopia óptica. Vitelário mediano, compacto, elíptico, posterior aos demais órgãos. Ovário com 3 lobos transversais, mediano. Glândula de Mehlis não distinguível. Útero nas proglótides pré grávidas saculiforme, com septo central. Ovos esféricos com cerca de 11,40 $\mu \mathrm{m}$ de diâmetro $(n=1)$, oncosferas esféricas com cerca de $24,70 \mu$ m de diâmetro $(n=1)$.

Caracterização M07: Um espécime completo. Espécime completo 15,56mm de comprimento $(n=1)$, composto por 181 proglótides, última proglótide presente grávida. Escólex com maior largura na região das ventosas 385,35 (n=1). Base rostelar muscular, rostelo muscular, bolsa rostelar com parede delgada. Coroa simples de ganchos rostelares, uniformes, triangulares, 20 ganchos em número $(n=1), 29 \mu m$ de comprimento $(n=1)$. Ventosas circulares, $137,65 \mu \mathrm{m}$ de diâmetro $(n=1)$, musculares, sem espinhos. Proglótides craspedotas, proglótide madura 73,75 × 382,55 (n=1), proglótide pré grávida 144,10 × 612,30 $(n=1)$, proglótide grávida $372,15 \times 587,9(n=1)$. Número de dutos osmorregulatórios não 
determinado. Poro genital unilateral, a $26 \%$ da margem anterior da proglótide madura, a $20 \%$ da margem anterior da proglótide pré grávida. Testículos ovais, 7 em número, posteriores às glândulas femininas. Saco do cirro oval, alongado, com parede delgada, lateral aos dutos osmorregulatórios, cirro sem espinhos visíveis em microscopia óptica. Vitelário mediano, compacto, oval. Ovário com 2 lobos arredondados, anterior. Glândula de Mehlis não distinguível. Útero nas proglótides pré grávidas e grávidas lobado, parenquimatoso. Ovos esféricos com cerca de 14,35 $\mu$ m de diâmetro $(n=1)$, oncosferas ovais $35,30 \times 21,85$ $(n=1), 6$ ganchos embrionários visíveis na porção central.

Considerações: A coleta de 3 morfotipos distintos de cestódeos em dois espécimes de Phlegopsis borbae coletados em um mesmo ponto de amostragem indica que esta espécie de tamnofilídeo está exposta a uma grande diversidade de formas de transmissão de cestódeos. Os indivíduos pertencentes à família Hymenolepididae observados não foram encontrados em nenhuma outra espécie da região, indicando hábito oioxeno ao seu hospedeiro, porém é necessário que a identificação formal da espécie seja feita para possibilitar uma análise mais acurada. $O$ indivíduo pertencente à família Metadilepididae apresenta uma coroa de ganchos simples e triangulares com comprimento inferior a $30 \mu \mathrm{m}$, oncosferas fusiformes e receptáculo seminal alongado, característicos de espécies do gênero Schmidneila (KORNYUSHIN; GEORGIEV, 1994), porém o número de ganchos na coroa rostelar (20) e o comprimento destes $(29 \mu \mathrm{m})$ o diferem daqueles observados em espécimes dos gêneros Myrmoborus e Myrmotherula. Um morfotipo de metadilepidídeo semelhante a este foi observado em Rhegmatorhina hoffmannsi na mesma localidade de Machadinho d'Oeste, indicando que esta espécie pode ter hábito extenoxeno já que ambos os gêneros de hospedeiros são próximos filogeneticamente (BRUMFIELD et al., 2007).

\subsubsection{Phlegopsis erythroptera ustulata Todd, 1927}

Localidades amostradas: Porto Velho, Rondônia, margem esquerda do rio Madeira, Centro de Endemismo Inambari (3 espécimes).

Prevalência da infestação: 66\% (2 hospedeiros infestados em 3 analisados).

Intensidade da infestação: variável; cinco espécimes por hospedeiro (D10); um espécime por hospedeiro (M08). 
Cestoda observados: 2 morfotipos; Dilepididae (D10; ANEXO D, Figura 41), Metadilepididae: Schmidneila sp. (M08; ANEXO D, Figura 42).

Caracterização D10: Cinco espécimes incompletos. Comprimento total e número de proglótides indeterminados. Escólex com maior largura na região das ventosas 154,50 (n=1). Aparato rostelar musculo-glandular, rostelo muscular, bolsa rostelar com parede mediana. Coroa simples de ganchos rostelares, uniformes, arcuatóides, 6 ganchos em número $(n=1)$, $11 \mu \mathrm{m}$ de comprimento $(n=1)$. Ventosas redondas, $75,38 \mu \mathrm{m}$ de diâmetro $(n=1)$, musculares. Proglótides craspedotas. Dutos osmorregulatórios não observados. Poro genital alternado, regularidade indeterminada. Testículos 8 em número $(n=1)$, posteriores ao ovário. Saco do cirro oval, alongado, com parede mediana, cirro sem espinhos visíveis em microscopia óptica. Vitelário mediano, compacto, de forma irregular e posterior ao ovário. Ovário com dois lobos alados, unidos na região mediana por um istmo. Glândula de Mehlis não distinguível. Útero nas proglótides pré grávidas saculiforme, com parede espessa. Ovos esféricos com cerca de $8,25 \mu \mathrm{m}$ de diâmetro $(n=1)$, oncosferas esféricas com cerca de $19,12 \mu \mathrm{m}$ de diâmetro $(n=1)$, ganchos embrionários não visíveis.

Caracterização M08: Um espécime imaturo incompleto. Comprimento total e número de proglótides indeterminados. Escólex com maior largura na região das ventosas 286,80 (n=1). Base rostelar muscular, rostelo muscular, bolsa rostelar com parede delgada. Coroa simples de ganchos rostelares, uniformes, triangulares, 22 ganchos em número $(n=1), 28,50 \mu m$ de comprimento $(n=1)$. Estróbilo imaturo, órgãos não visíveis.

Considerações: A amostra obtida para Phlegopsis erythroptera ustulata apresenta restrição geográfica, uma vez que todas as amostras foram coletadas em um mesmo ponto de amostragem; porém, a presença de dois morfotipos de cestódeos para este hospedeiro indica que estes estão expostos às formas transmissíveis de parasitas neste ambiente. A identificação do morfotipo pertencente à família Dilepididae não foi possível pela ausência de espécimes completos, o que não permite que esta seja comparada com os demais dilepidídeos observados parasitando espécimes do gênero Phlegopsis. O indivíduo pertencente à família Metadilepididae apresentou uma coroa de ganchos simples e triangulares com comprimento inferior a $30 \mu \mathrm{m}$ que o caracteriza como pertencente ao 
gênero Schmidneila (KORNYUSHIN; GEORGIEV, 1994), porém a ausência de estróbilo desenvolvido e órgãos não visíveis indica que a infestação do indivíduo hospedeiro foi recente e não é possível identificá-lo.

\subsubsection{Phlegopsis nigromaculata bowmani Ridgway, 1888}

Localidades amostradas: Altamira, Pará, margem esquerda do rio Xingu, Centro de Endemismo Tapajós (5 espécimes); Porto Velho, Rondônia, margem direita do rio Madeira, Centro de Endemismo Rondônia (2 espécimes); Machadinho d'Oeste, margem esquerda do rio Ji-Paraná, Centro de Endemismo Rondônia (1 espécime) e margem direita do rio JiParaná, Centro de Endemismo Rondônia (1 espécime).

Localidades de hospedeiros infestados: Altamira, Pará, Centro de Endemismo Tapajós (3 espécimes).

Prevalência da infestação: 33\% (3 hospedeiros infestados em 9 analisados).

Intensidade da infestação: variável; de um a mais de vinte espécimes por hospedeiro.

Cestoda observados: 1 morfotipo; Dilepididae (D11; ANEXO D, Figura 43).

Caracterização D11: Um espécime completo. Espécime 796,30 $\mu m$ de comprimento $(n=1)$, composto por 8 proglótides. Escólex com maior largura na região das ventosas 115,55 ( $n=1)$. Aparato rostelar musculo-glandular, rostelo muscular envolto por tecido glandular, bolsa rostelar com parede mediana. Coroa simples de ganchos rostelares, uniformes, arcuatóides, 8 ganchos em número $(n=1), 10,60 \mu m$ de comprimento $(n=1)$. Ventosas redondas, $67,70 \mu m$ de diâmetro $(n=1)$, musculares. Proglótides craspedotas, com margens arredondadas, proglótide madura $132,25 \times 263,55(n=1)$, proglótide pré grávida $201,50 \times 347,35(n=1)$. Dutos osmorregulatórios não observados. Poro genital alternado irregularmente, a $21 \%$ da margem anterior da proglótide pós madura, a 12\% da margem anterior da proglótide pré grávida. Testículos 6 em número $(n=1)$, posteriores ao ovário. Saco do cirro oval, alongado, com parede mediana, cirro sem espinhos visíveis em microscopia óptica. Vitelário mediano, compacto, de forma irregular e posterior ao ovário. Ovário com dois lobos alados, unidos na região mediana por um istmo. Glândula de Mehlis não distinguível. Útero nas proglótides pré grávidas saculiforme, com parede mediana. 
Considerações: Os espécimes de dilepidídeos amostrados parasitando Phlegopsis nigromaculata bowmani foram coletados em uma mesma data e ponto de coleta, pertencendo a uma mesma população, porém apresentaram intensidade de infestação variável, entre 2 e mais de 50 indivíduos parasitas em um mesmo espécime de hospedeiro. Esta variação pode ser causada por característica intrínsecas ao indivíduo hospedeiro, que podem variar desde uma infestação anterior aos demais hospedeiros até condições imunológicas daquele indivíduo. Os cestódeos observados em P. nigromaculata bowmani não foram observados nos demais tamnofilídeos na mesma localidade ou do mesmo gênero em localidades distintas, indicando hábito oioxeno deste parasita.

\subsubsection{Phlegopsis nigromaculata paraensis Hellmayr, 1904}

Localidades amostradas: Santana do Araguaia, Pará, Fazenda Fartura, margem esquerda do Rio Araguaia, Centro de Endemismo Xingu (13 espécimes).

Localidades de hospedeiros infestados: Altamira, Pará, Centro de Endemismo Tapajós (4 espécimes).

Prevalência da infestação: 31\% (4 hospedeiros infestados em 13 analisados).

Intensidade da infestação: variável; indeterminada (D12); 1 espécime por hospedeiro (H20; H21; M09).

Cestoda observados: 4 morfotipos; Dilepididae (D12; ANEXO D, Figura 44 A-B); Hymenolepididae (H20; ANEXO D, Figura 45), (H21; ANEXO D, Figura 46); Metadilepididae: Schmidneila sp. (M09; ANEXO D, Figura 47).

Caracterização D12: Duas proglótides grávidas soltas. Comprimento total e número total de proglótides do espécime indeterminados.

Caracterização H20: Um espécime completo. Espécime 7,50mm de comprimento $(n=1)$, composto por 224 proglótides. Escólex com maior largura na região das ventosas 99 proglótides. Escólex com maior largura na região das ventosas 382,95 ( $n=1)$. Base rostelar musculo-glandular, rostelo muscular, bolsa rostelar com parede delgada. Coroa simples de ganchos rostelares, uniformes, arcuatóides, 32 ganchos em número $(n=1), 29,85 \mu m$ de comprimento $(n=1)$. Ventosas redondas, $172,30 \mu m$ de diâmetro $(n=1)$, musculares, sem 
espinhos. Proglótides craspedotas, proglótide pré grávida 61,05 x 524,65 ( $n=1)$, proglótide grávida 110,65 x 668,90 ( $\mathrm{n}=1)$. Dez dutos osmorregulatórios. Poro genital unilateral. Testículos ovais, 3 em número em todas as proglótides visíveis, em disposição triangular com 1 poral e 1 aporal anteriores e 1 central posterior. Saco do cirro oval, com parede mediana, cirro sem espinhos visíveis em microscopia óptica. Vitelário não distinguível. Ovário com 3 lobos transversais, mediano. Glândula de Mehlis não distinguível. Útero nas proglótides pré grávidas saculiforme, com septo central. Ovos esféricos com cerca de 9,2um de diâmetro $(n=1)$, oncosferas esféricas com cerca de $14,30 \mu \mathrm{m}$ de diâmetro $(n=1)$, ganchos embrionários não distinguíveis.

Caracterização H21: Um espécime completo. Espécime 14,34mm de comprimento $(n=1)$, composto por 224 proglótides. Escólex com maior largura na região das ventosas 235,12 $(n=1)$. Base rostelar musculo-glandular, rostelo muscular, bolsa rostelar com parede delgada. Coroa simples de ganchos rostelares, uniformes, arcuatóides, 10 ganchos em número $(n=1)$, $28,81 \mu \mathrm{m}$ de comprimento $(n=1)$. Ventosas redondas, $109,18 \mu \mathrm{m}$ de diâmetro $(n=1)$, musculares, sem espinhos. Proglótides craspedotas, proglótide madura $35 \times 295,50(n=1)$, proglótide pré grávida $69 \times 622,25(n=1)$, proglótide grávida 262,20 × 901,35 (n=1). Seis dutos osmorregulatórios. Poro genital unilateral. Testículos ovais, 3 em número em todas as proglótides visíveis, em disposição triangular com 1 poral posterior, 1 aporal posteriores e 1 aporal anterior. Saco do cirro oval, com parede mediana, entre os dutos osmorregulatórios, cirro sem espinhos visíveis em microscopia óptica. Vitelário mediano, compacto, elíptico, posterior aos demais órgãos. Ovário com 3 lobos transversais, mediano. Glândula de Mehlis não distinguível. Útero nas proglótides pré grávidas saculiforme, com septo central. Ovos esféricos com cerca de $11,80 \mu m$ de diâmetro $(n=1)$, oncosferas esféricas com cerca de $33,25 \mu \mathrm{m}$ de diâmetro $(n=1)$, ganchos embrionários visíveis na porção central, 6 em número, sem comprimento disponível.

Caracterização M09: Um espécime incompleto, última proglótide presente pré grávida. Comprimento total e número de proglótides indeterminados. Escólex com maior largura na região das ventosas $360,30(n=1)$. Base rostelar muscular, rostelo muscular, bolsa rostelar com parede delgada. Coroa simples de ganchos rostelares, uniformes, triangulares,

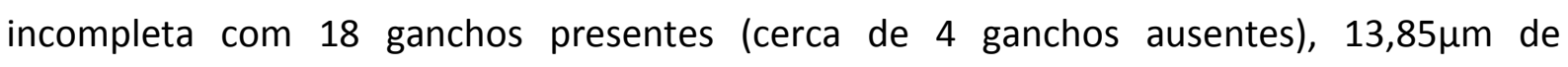


comprimento $(n=1)$. Ventosas circulares, $156 \mu m$ de diâmetro $(n=1)$, musculares, sem espinhos. Proglótides craspedotas, proglótide madura 77,65 x 508,55 ( $n=1)$, proglótide pré grávida 302,30 x 678,20 (n=1). Número de dutos osmorregulatórios não determinado. Poro genital unilateral, a $30 \%$ da margem anterior da proglótide madura, a $21 \%$ da margem anterior da proglótide pré grávida. Testículos ovais, 4 em número, posteriores às glândulas femininas. Saco do cirro oval, alongado, com parede delgada, lateral aos dutos osmorregulatórios, cirro sem espinhos visíveis em microscopia óptica. Vitelário mediano, compacto, oval. Ovário com 2 lobos arredondados, anterior. Glândula de Mehlis não distinguível. Útero nas proglótides pré grávidas e grávidas lobado, parenquimatoso. Ovos esféricos com cerca de $14,40 \mu \mathrm{m}$ de diâmetro $(n=1)$.

Considerações: A diversidade de cestódeos observada em Phlegopsis nigromaculata paraensis é considerada alta, dada a observação de quatro morfotipos distintos de parasitas coletados em uma mesma localidade. Os morfotipos de cestódeos observados apresentaram infestação exclusiva a um indivíduo hospedeiro, não sendo observada convivência de mais de um táxon para cada espécime de ave, resultando em restrição do número amostral de parasitas para as famílias Hymenolepididae e Metadilepididae $(n=1)$. 0 espécime pertencente à família Metadilepididae apresenta uma coroa de ganchos simples e triangulares com comprimento inferior a $30 \mu \mathrm{m}$ que o caracteriza como pertencente ao gênero Schmidneila (KORNYUSHIN; GEORGIEV, 1994), porém o comprimento dos ganchos rostelares e o número reduzido de testículos o difere daqueles indivíduos encontrados em $P$. borbae e R. hoffmannsi ustulata amostrados na área de Machadinho d'Oeste.

\subsubsection{Pygiptila}

\subsubsection{Pygiptila stellaris stellaris (Spix, 1825)}

Localidade amostrada: Porto Velho, Rondônia, margem esquerda do rio Madeira, Centro de Endemismo Inambari (4 espécimes) e Ilha de Mutum, margem esquerda do rio Madeira, Centro de Endemismo Inambari (2 espécimes).

Prevalência de infestação: nenhum hospedeiro infestado. 
Considerações: Os espécimes de Pygiptila stellaris stellaris analisados foram coletados em diferentes pontos de amostragem na área de Porto Velho (RO), incluindo a Ilha de Mutum, porém não foi observada infestação por cestódeos para este táxon. A presença de cestódeos em outros indivíduos coletados nas mesmas localidades indicam que os espécimes de $P$. stellaris estão expostos às formas de transmissão destes parasitas, porém características dos hospedeiros podem determinar sua infestação. Os hábitos alimentares de $P$. stellaris incluem larvas de lepidópteros em sua composição (ZIMMER; ISLER, 2016) e observou-se, neste estudo, que a presença das formas larvais destes insetos nos estômagos dos hospedeiros pode estar associada à ausência de cestódeos parasitando os indivíduos, porém é necessário que correlações mais aprofundadas sobre a composição alimentar e a presença de parasitas sejam feitas para inferências acerca do ciclo de vida destes cestódeos.

\subsubsection{Pyriglena}

\subsubsection{Pyriglena leuconota interposita Pinto, 1947}

Localidades amostradas: Altamira, Pará, margem direita do rio Xingu, Centro de Endemismo Xingu (2 espécimes); Santana do Araguaia, Pará, Fazenda Fartura, margem esquerda do Rio Araguaia, Centro de Endemismo Xingu (8 espécimes).

Localidades de hospedeiros infestados: Santana do Araguaia, Pará, Centro de Endemismo Xingu (3 espécimes).

Prevalência da infestação: 33\% (3 hospedeiros infestados em 10 analisados).

Intensidade da infestação: um espécime por hospedeiro (H22; H23; M10; NI04).

Cestoda observados: 4 morfotipos; Hymenolepididae (H22; ANEXO D, Figura 48) (H23; ANEXO D, Figura 49), Metadilepididae: Schmidneila sp. (M10; ANEXO D, Figura 50); não identificado (NIO4; ANEXO D, Figura 51).

Caracterização H22: Um espécime completo, última proglótide madura. Espécime 15,35mm de comprimento $(n=1)$, composto por 112 proglótides. Escólex com maior largura na região das ventosas 574,20 ( $n=1)$. Base rostelar musculo-glandular, rostelo muscular, bolsa rostelar com parede delgada. Coroa simples de ganchos rostelares, uniformes, arcuatóides, 38 ganchos em número $(n=1), 41,64 \mu \mathrm{m}$ de comprimento $(n=1)$. Ventosas redondas, $144,85 \mu \mathrm{m}$ 
de diâmetro $(n=1)$, musculares, sem espinhos. Proglótides craspedotas, proglótide madura 250,40 x $508(n=1)$. Dez dutos osmorregulatórios. Poro genital unilateral, a 38\% da margem anterior da proglótide madura. Testículos ovais, 3 em número em todas as proglótides visíveis, em disposição triangular com 1 poral anterior, 1 poral posterior e 1 aporal posterior. Saco do cirro oval, com parede mediana, entre os dutos osmorregulatórios, cirro sem espinhos visíveis em microscopia óptica. Vitelário mediano, compacto, forma indefinida, posterior aos demais órgãos. Ovário com 3 lobos transversais, mediano. Glândula de Mehlis não distinguível.

Caracterização H23: Um espécime completo. Espécime 17,15mm de comprimento ( $n=1)$, composto por 166 proglótides. Escólex com maior largura na região das ventosas 247,65 $(n=1)$. Base rostelar musculo-glandular, rostelo muscular, bolsa rostelar com parede delgada. Coroa simples de ganchos rostelares, uniformes, arcuatóides, 10 ganchos em número $(n=1)$, $24,50 \mu \mathrm{m}$ de comprimento $(n=1)$. Ventosas redondas, $106,75 \mu \mathrm{m}$ de diâmetro $(n=1)$, musculares, sem espinhos. Proglótides craspedotas, proglótide madura 123,75 x 295,95 $(n=1)$, proglótide pré grávida 160,55 x 403,50 $(n=1)$, proglótide grávida 235,65 x 652,55 $(n=1)$. Quatro dutos osmorregulatórios. Poro genital unilateral, a 25\% da margem anterior da proglótide madura e a $25 \%$ da margem anterior da proglótide pré grávida. Testículos ovais, 3 em número em todas as proglótides visíveis, em disposição triangular com 1 poral anterior, 1 poral posterior e 1 aporal anterior. Saco do cirro oval, com parede mediana, entre os dutos osmorregulatórios, cirro sem espinhos visíveis em microscopia óptica. Vitelário mediano, compacto, elíptico, posterior aos demais órgãos. Ovário com 3 lobos transversais, mediano. Glândula de Mehlis não distinguível. Útero nas proglótides pré grávidas saculiforme, com septo central. Ovos esféricos com cerca de 9,50 $\mu$ m de diâmetro $(n=1)$, oncosferas esféricas com cerca de $27,82 \mu \mathrm{m}$ de diâmetro $(n=1)$, ganchos embrionários visíveis na porção central, 6 em número, $14,30 \mu \mathrm{m}$ de comprimento.

Caracterização M10: Um espécime incompleto, última proglótide presente pós madura. Comprimento total e número de proglótides indeterminados. Escólex com maior largura na região das ventosas $650(n=1)$. Base rostelar muscular, rostelo muscular, bolsa rostelar com parede delgada. Coroa simples de ganchos rostelares, uniformes, triangulares, 20 ganchos em número $(n=1), 25,50 \mu m$ de comprimento $(n=1)$. Ventosas circulares, $230,90 \mu m$ de 
diâmetro $(n=1)$, musculares, sem espinhos. Proglótides craspedotas, proglótide madura $184,90 \times 442,50(n=1)$, proglótide pré grávida $232,10 \times 803,70(n=1)$. Número de dutos osmorregulatórios não determinado. Poro genital unilateral, a $24 \%$ da margem anterior da proglótide madura, a 29\% da margem anterior da proglótide pré grávida. Testículos ovais, 3 em número, posteriores às glândulas femininas. Saco do cirro oval, alongado, com parede delgada, lateral aos dutos osmorregulatórios, cirro sem espinhos visíveis em microscopia óptica. Vitelário mediano, compacto, oval. Ovário com 2 lobos arredondados, anterior. Glândula de Mehlis não distinguível. Útero nas proglótides pré grávidas e grávidas lobado, parenquimatoso. Ovos esféricos com cerca de $16 \mu \mathrm{m}$ de diâmetro $(n=1)$.

Caracterização N104: Estróbilo. Proglótides maduras. Testículos ovais, 3 em número, em disposição em L, 2 porais e 1 aporal. Ovário lobado, mediano. Vitelário posterior, compacto.

Considerações: Os espécimes de Pyriglena leuconota interposita analisados foram obtidos em duas localidades distintas, apresentando prevalências de infestação por cestódeos distintas. Os quatro morfotipos de cestódeos observados foram encontrados em espécimes coletados em Santana do Araguaia (PA), enquanto nenhum indivíduo foi encontrado parasitado entre os provenientes de Altamira (PA), indicando que a diversidade e disponibilidade de formas de transmissão variam de acordo com a localidade amostrada. Os morfotipos de cestódeos pertencentes à família Hymenolepididae encontrados não foram observados em outros hospedeiros, indicando hábito oioxeno, enquanto o morfotipo de Metadilepididae assemelha-se àquele coletado em Megastictus margaritatus da região de Porto Velho (RO). Este parasita apresenta uma coroa de ganchos simples e triangulares com comprimento inferior a $30 \mu \mathrm{m}$ que o caracteriza como pertencente ao gênero Schmidneila (KORNYUSHIN; GEORGIEV, 1994) indicando hábito extenoxeno para este parasita.

\subsubsection{Pyriglena leuconota similis Zimmer, 1931}

Localidades amostradas: Altamira, Pará, margem esquerda do rio Xingu, Centro de Endemismo Xingu (6 espécimes).

Prevalência da infestação: $100 \%$.

Intensidade da infestação: indeterminada. 
Cestoda observados: 4 morfotipos; Dilepididae (D13); Hymenolepididae (H24; ANEXO D, Figura 52) (H25; ANEXO D, Figura 53), Metadilepididae: Schmidneila sp. (M11; ANEXO D, Figura 54).

Caracterização D13: Proglótides grávidas soltas. Útero saculiforme com paredes medianas. Oncosferas esféricas.

Caracterização H24: Um espécime incompleto. Comprimento total e número de proglótides indeterminados. Escólex com maior largura na região das ventosas 296,85 (n=1). Base rostelar musculo-glandular, rostelo muscular, bolsa rostelar com parede delgada. Coroa simples de ganchos rostelares, uniformes, arcuatóides, 38 ganchos em número $(n=1)$, $38,12 \mu \mathrm{m}$ de comprimento $(n=1)$. Ventosas redondas, $126,90 \mu \mathrm{m}$ de diâmetro $(n=1)$, musculares, sem espinhos. Proglótides craspedotas. Dutos osmorregulatórios não observados. Poro genital unilateral. Testículos não observados. Saco do cirro não observado. Vitelário não observado. Ovário não observado.

Caracterização H25: Dois espécimes incompletos. Comprimento total e número de proglótides indeterminados. Escólex com maior largura na região das ventosas 151,75 (n=1). Base rostelar musculo-glandular, rostelo muscular, bolsa rostelar com parede delgada. Coroa simples de ganchos rostelares, uniformes, arcuatóides, 30 ou 32 ganchos $(n=2), 38,78 \mu m$ de comprimento $(n=1)$. Ventosas redondas, $75,30 \mu m$ de diâmetro $(n=1)$, musculares, sem espinhos. Proglótides craspedotas, proglótide madura 84 × 145,95 (n=1), proglótide pré grávida 45,25 x 291,65 (n=1), proglótide grávida 72,90 x 296,15(n=1). Dutos osmorregulatórios não observados. Poro genital unilateral, a 13\% da margem anterior da proglótide madura e a $17 \%$ da margem anterior da proglótide pré grávida. Testículos ovais, 3 em número em todas as proglótides visíveis, em disposição triangular com 1 poral posterior, 1 aporal posterior e 1 central anterior. Saco do cirro oval, com parede mediana, entre os dutos osmorregulatórios, cirro sem espinhos visíveis em microscopia óptica. Vitelário mediano, compacto, elíptico, posterior aos demais órgãos. Ovário com 3 lobos transversais, mediano. Glândula de Mehlis não distinguível. Útero nas proglótides pré grávidas

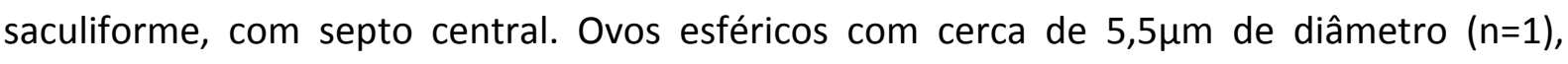
oncosferas esféricas com cerca de $11 \mu \mathrm{m}$ de diâmetro $(n=1)$. 
Caracterização M11: Um espécime completo. Espécime 9,54mm de comprimento $(n=1)$, número total de proglótides indeterminado. Escólex com maior largura na região das ventosas $347,15(n=1)$. Base rostelar muscular, rostelo muscular, bolsa rostelar com parede delgada. Coroa simples de ganchos rostelares, uniformes, triangulares, 20 ganchos em número $(n=1), 26,25 \mu \mathrm{m}$ de comprimento $(n=1)$. Ventosas circulares, $156,30 \mu \mathrm{m}$ de diâmetro $(n=1)$, musculares, sem espinhos. Proglótides craspedotas. Número de dutos osmorregulatórios não determinado. Posição do poro genital não determinada. Testículos, saco do cirro, vitelário, ovário e útero não distinguíveis.

Considerações: Os espécimes de Pyriglena leuconota similis foram coletados em diferentes pontos de amostragem na área de Altamira (PA), resultando em uma amostra com ampla distribuição nesta área. A presença de mais de um indivíduo de parasita pertencente à diferentes táxons em um mesmo indivíduo hospedeiro indica alta diversidade de cestódeos nesta área, além de grande disponibilidade de formas de transmissão no ambiente. A identificação dos indivíduos de Hymenolepididae não foi possível devido à necessidade de refino na taxonomia do grupo, porém a disposição dos testículos no morfotipo H25 não possui correspondente na literatura (ver CZAPLINSKI; VAUCHER, 1994) e indica pertencer a um gênero não descrito. $O$ espécime de metadilepidídeo amostrado apresenta uma coroa de ganchos simples e triangulares com comprimento inferior a $30 \mu \mathrm{m}$ que o caracteriza como pertencente ao gênero Schmidneila (KORNYUSHIN; GEORGIEV, 1994), porém o número de ganchos $(20)$ e o comprimento destes $(25 \mu \mathrm{m})$ o diferenciam daquele observado em $P$. leuconota interposita, com maior quantidade de ganchos (23) mais curtos (19 $\mu \mathrm{m})$.

\subsubsection{Rhegmatorhina}

\subsubsection{Rhegmatorhina gymnops Ridgway, 1888}

Localidades amostradas: Altamira, Pará, margem esquerda do rio Xingu, Centro de Endemismo Tapajós (1 espécime).

Prevalência da infestação: $100 \%$.

Intensidade da infestação: Um espécime por hospedeiro (H26).

Cestoda observados: 1 morfotipo; Hymenolepididae (H26; ANEXO D, Figura 55). 
Caracterização H26: Um espécime incompleto. Comprimento total e número de proglótides indeterminados. Escólex com maior largura na região das ventosas 351,90 (n=1). Base rostelar musculo-glandular, rostelo muscular, bolsa rostelar com parede delgada. Coroa simples de ganchos rostelares, uniformes, arcuatóides, coroa incompleta. Ventosas redondas, $155,85 \mu \mathrm{m}$ de diâmetro $(n=1)$, musculares, sem espinhos. Proglótides craspedotas. Dez dutos osmorregulatórios. Poro genital unilateral. Testículos ovais, 3 em número em todas as proglótides visíveis, 1 poral, 1 central e 1 aporal, em linha posterior. Saco do cirro oval, com parede delgada, cirro sem espinhos visíveis em microscopia óptica. Vitelário mediano, compacto, elíptico, posterior aos demais órgãos. Ovário lobado, mediano. Glândula de Mehlis não distinguível. Útero nas proglótides pré grávidas saculiforme, com septo central. Ovos esféricos com cerca de 9,10 $\mu$ m de diâmetro $(n=1)$.

Considerações: A coleta de apenas um indivíduo de Rhegmatorhina gymnops resultou na obtenção de uma amostra restrita de parasitas, igual a um espécime de cestódeo, não permitindo inferências sobre a diversidade ou densidade desta população. A identificação deste morfotipo de cestódeo não foi possível devido à necessidade de refino taxonômico para a família Hymenolepididae, porém a distribuição em linha dos testículos observada nas proglótides maduras deste parasita não foi verificada em nenhum outro espécime analisado neste estudo. Uma vez que a posição relativa dos testículos nas proglótides maduras é considerada como caractere taxonomicamente informativo para a família (CZAPLINSKI; VAUCHER, 1994), este espécime pode representar um gênero para os himenolepidídeos, podendo ser considerada oioxena por não ter sido registrada em nenhuma outra espécie de tamnofilídeo.

\subsubsection{Rhegmatorhina hoffmannsi Hellmayr, 1907}

Localidades amostradas: Machadinho d'Oeste, margem esquerda do rio Ji-Paraná, Centro de Endemismo Rondônia (5 espécimes).

Prevalência da infestação: 80\% (4 espécimes infestados em 5 analisados).

Intensidade da infestação: variável; indeterminada (D14), um espécime por hospedeiro (H27; M12)

Cestoda observados: 3 morfotipos; Dilepididae (D14; ANEXO D, Figura 56); Hymenolepididae 
(H27; ANEXO D, Figura 57); Metadilepididae: Schmidneila sp. (M12, ANEXO D, Figura 58 A-C).

Caracterização D14: Dois espécimes incompletos e uma proglótide madura destacada. Comprimento total e número de proglótides indeterminados. Escólex com maior largura na região das ventosas $312,10-341,05(326,57 \pm 20,47, n=2)$. Aparato rostelar musculoglandular, rostelo muscular, bolsa rostelar com parede espessa. Coroa simples de ganchos rostelares, uniformes, arcuatóides, 8 ganchos em número $(n=1), 13,60 \mu m$ de comprimento $(n=1)$. Ventosas redondas, 145,05-156,20 $(150,62 \pm 7,88, n=2) \mu m$ de diâmetro, musculares. Proglótides craspedotas, com margens arredondadas. Dutos osmorregulatórios não observados. Poro genital alternado irregularmente. Testículos 11 em número $(n=1)$, posteriores ao ovário. Saco do cirro oval, alongado, com parede mediana, cirro sem espinhos visíveis em microscopia óptica. Vitelário mediano, compacto, de forma irregular e posterior ao ovário. Ovário com dois lobos alados, unidos na região mediana por um istmo. Glândula de Mehlis não distinguível.

Caracterização H27: Um espécime incompleto. Comprimento total e número de proglótides indeterminados. Escólex com maior largura na região das ventosas 325,25 ( $n=1)$. Base rostelar musculo-glandular, rostelo muscular, bolsa rostelar com parede delgada. Coroa simples de ganchos rostelares, uniformes, arcuatóides, 32 ganchos em número $(n=1)$, 30,91 $\mu \mathrm{m}$ de comprimento $(n=1)$. Ventosas redondas, $150,20 \mu \mathrm{m}$ de diâmetro $(n=1)$, musculares, sem espinhos. Proglótides craspedotas. Dez dutos osmorregulatórios. Poro genital unilateral. Testículos ovais, 3 em número em todas as proglótides visíveis, 1 poral posterior, 1 central anterior e 1 aporal posterior. Saco do cirro oval, com parede delgada, cirro sem espinhos visíveis em microscopia óptica. Vitelário mediano, compacto, elíptico, posterior aos demais órgãos. Ovário lobado, mediano. Glândula de Mehlis não distinguível. Útero nas proglótides pré grávidas saculiforme, com septo central. Ovos esféricos com cerca de $9 \mu \mathrm{m}$ de diâmetro $(n=1)$, oncosferas esféricas com cerca de $18,50 \mu \mathrm{m}$ de diâmetro $(n=1)$, ganchos embrionários não visíveis.

Caracterização M12: Um espécime completo. Espécime completo 55,06mm de comprimento $(n=1)$, composto por 263 proglótides. Escólex com maior largura na região das ventosas $313,33(n=1)$. Base rostelar muscular, rostelo muscular, bolsa rostelar com parede 
delgada. Coroa simples de ganchos rostelares, uniformes, triangulares, cerca de metade da coroa presente com 15 ganchos, $28,75 \mu \mathrm{m}$ de comprimento $(n=1)$. Ventosas circulares, 143,33 $\mu \mathrm{m}$ de diâmetro $(n=1)$, musculares, sem espinhos. Proglótides craspedotas, proglótide madura 108,66 × 241 (n=1), proglótide pré grávida 189,81 x 482,85 (n=1), proglótide grávida 635,36 x 431,23 (n=1). Número de dutos osmorregulatórios não determinado. Poro genital unilateral, a 31\% da margem anterior da proglótide madura, a 34\% da margem anterior da proglótide pré grávida. Testículos ovais, 6 em número, posteriores às glândulas femininas. Saco do cirro oval, alongado, com parede delgada, lateral aos dutos osmorregulatórios, cirro sem espinhos visíveis em microscopia óptica. Vitelário mediano, compacto, oval. Ovário com 2 lobos arredondados, anterior. Glândula de Mehlis não distinguível. Útero nas proglótides pré grávidas e grávidas lobado, parenquimatoso. Ovos esféricos com cerca de 13,32 $\mu \mathrm{m}$ de diâmetro $(n=1)$, oncosferas ovais $12 \times 27(n=1)$, ganchos embrionários não visíveis.

Considerações: Os espécimes de Rhegmatorhina hoffmannsi amostrados foram coletados na mesma região, denotando alta diversidade de parasitas na área com 4 morfotipos de cestódeos registrados, porém com baixa densidade populacional já que apenas um ou dois indivíduos de cada táxon de Cestoda foram coletados. Assim como as demais espécies seguidoras obrigatórias de formigas de correição, $R$. hoffmannsi apresenta uma fauna de cestódeos associada diversa, indicando alta exposição às formas de transição destes parasitas. Entre os cestódeos analisados, o morfotipo M12 apresenta uma coroa de ganchos simples e triangulares com comprimento inferior a $30 \mu \mathrm{m}$ que o caracteriza como pertencente ao gênero Schmidneila (KORNYUSHIN; GEORGIEV, 1994) com ganchos e testículos $(28,7 \mu \mathrm{m}, \mathrm{n}=6)$ com características próximas àqueles observados em Phlegopsis borbae $(29,5, n=7)$ coletado na mesma área e Phlegopsis erythroptera $(28,5, n=6)$ amostrado na região de Porto Velho (RO), indicando hábito extenoxeno ao parasita.

\subsubsection{Rhegmatorhina melanosticta purusiana (Snethlage, 1908)}

Localidades amostradas: Porto Velho, Rondônia, margem esquerda do rio Madeira, Centro de Endemismo Inambari (7 espécimes).

Prevalência da infestação: 42\% (3 hospedeiros infestados em 7 analisados).

Intensidade da infestação: variável; indeterminada (D15, D16); um espécime por hospedeiro 
(H28; M13).

Cestoda observados: 4 morfotipos; Dilepididae (D15; ANEXO D, Figura 59 A-B) (D16; ANEXO D, Figura 60); Hymenolepididae (H28; ANEXO D, Figura 61), Metadilepididae: Schmidneila sp. (M13; ANEXO D, Figura 62).

Caracterização D15: Um espécime incompleto e um estróbilo. Comprimento total e número de proglótides indeterminados. Escólex com maior largura na região das ventosas 124,45 $(n=1)$. Aparato rostelar musculo-glandular, rostelo muscular, bolsa rostelar com parede mediana. Coroa simples de ganchos rostelares, uniformes, arcuatóides, incompleta. Ventosas redondas, $64,27 \mu \mathrm{m}$ de diâmetro $(n=1)$, musculares. Proglótides craspedotas, proglótide pós madura 173,07 x 199,75 (n=1), proglótide pré grávida 249,15 x 232,20 (n=1), proglótide grávida 426,20 x 313,82 (n=1). Dutos osmorregulatórios não observados. Poro genital alternado regularmente. Testículos 7 em número $(n=1)$, posteriores ao ovário. Saco do cirro oval, alongado, com parede mediana, cirro sem espinhos visíveis em microscopia óptica. Vitelário mediano, compacto, de forma irregular e posterior ao ovário. Ovário com dois lobos alados, unidos na região mediana por um istmo. Glândula de Mehlis não distinguível. Útero nas proglótides pré grávidas saculiforme, com parede espessa. Ovos esféricos com cerca de $12,20 \mu m$ de diâmetro $(n=1)$, oncosferas esféricas com cerca de $20,22 \mu \mathrm{m}$ de diâmetro $(\mathrm{n}=1)$, ganchos embrionários não visíveis.

Caracterização D16: Um estróbilo. Comprimento total e número de proglótides indeterminados. Proglótides craspedotas, proglótide pós madura 121,60 x $249(\mathrm{n}=1)$, proglótide pré grávida 165,15 x 240,40 ( $n=1)$, proglótide grávida 397,75 x 205,55 (n=1). Dutos osmorregulatórios não observados. Poro genital alternado regularmente. Testículos 7 em número $(n=1)$, posteriores ao ovário. Saco do cirro oval, alongado, com parede mediana, cirro sem espinhos visíveis em microscopia óptica. Vitelário mediano, compacto, de forma irregular e posterior ao ovário. Ovário com dois lobos alados, unidos na região mediana por um istmo. Glândula de Mehlis não distinguível. Útero nas proglótides pré grávidas saculiforme, com parede espessa. Ovos esféricos com cerca de $10,50 \mu m$ de diâmetro $(n=1)$, oncosferas esféricas com cerca de $21,35 \mu$ m de diâmetro $(n=1)$, ganchos embrionários não visíveis. 
Caracterização H28: Um espécime completo partido. Comprimento total e número de proglótides indeterminados. Escólex com maior largura na região das ventosas $304,05(n=1)$. Base rostelar musculo-glandular, rostelo muscular, bolsa rostelar com parede delgada. Coroa simples de ganchos rostelares, uniformes, arcuatóides, 32 ganchos em número $(n=1)$, $31,32 \mu \mathrm{m}$ de comprimento $(n=1)$. Ventosas redondas, $127,70 \mu \mathrm{m}$ de diâmetro $(n=1)$, musculares, sem espinhos. Proglótides craspedotas, proglótide madura 46,35 x 272,95 (n=1), proglótide pré grávida $60 \times 440,10(n=1)$, proglótide grávida 78,75 x 332,95 (n=1). Dutos osmorregulatórios não observados. Poro genital unilateral. Testículos ovais, 3 em número em todas as proglótides visíveis, em disposição triangular com 1 poral e 1 aporal posteriores e 1 central anterior. Saco do cirro oval, com parede mediana, entre os dutos osmorregulatórios, cirro sem espinhos visíveis em microscopia óptica. Vitelário mediano, compacto, elíptico, posterior aos demais órgãos. Ovário com 3 lobos transversais, mediano. Glândula de Mehlis não distinguível. Útero nas proglótides pré grávidas saculiforme, com septo central. Ovos esféricos com cerca de $8,50 \mu \mathrm{m}$ de diâmetro $(n=1)$, oncosferas esféricas com cerca de $16 \mu \mathrm{m}$ de diâmetro $(n=1)$, ganchos embrionários não visíveis.

Caracterização M13: Um espécime incompleto (parte anterior e estróbilo). Comprimento total e número de segmentos indeterminados. Escólex com maior largura na região das ventosas $265(n=1)$. Base rostelar muscular, rostelo muscular, bolsa rostelar com parede delgada. Coroa simples de ganchos rostelares, uniformes, triangulares, incompleta. Ventosas circulares, $125,40 \mu \mathrm{m}$ de diâmetro $(n=1)$, musculares, sem espinhos. Proglótides craspedotas. Número de dutos osmorregulatórios não determinado. Poro genital unilateral. Número e posição de testículos indeterminados. Saco do cirro não observado. Vitelário não observado. Ovário não observado. Útero nas proglótides pré grávidas lobado, parenquimatoso. Ovos esféricos com cerca de $17 \mu \mathrm{m}$ de diâmetro $(n=1)$.

Considerações: A observação de quatro morfotipos de cestódeos associados a Rhegmatorhina melanosticta purusiana indica exposição desta à diversas formas de transmissão de cestódeos no ambiente com alta diversidade de parasita, uma vez que todos os indivíduos hospedeiros foram amostrados na mesma área. A identificação dos morfotipos de Dilepididae e Hymenolepididae não foi possível com a literauta disponível, porém o espécime pertencente à Metadilepididae apresenta uma coroa de ganchos simples e 
triangulares com comprimento inferior a $30 \mu \mathrm{m}$ que o caracteriza como pertencente ao gênero Schmidneila (KORNYUSHIN; GEORGIEV, 1994). O indivíduo foi encontrado partido e incompleto e não pode ser comparado aos demais amostrados para identificação, porém representa o 13을 registro do gênero parasitando espécies de tamnofilídeos, um aumento considerável em sua diversidade atual, igual a uma espécie descrita.

\subsubsection{Sciaphylax}

\subsubsection{Sciaphylax hemimelaena (Sclater, 1857)}

Localidades amostradas: Porto Velho, Rondônia, margem esquerda do rio Madeira, Centro de Endemismo Inambari (18 espécimes); Altamira, Pará, margem esquerda do rio Xingu, Centro de Endemismo Tapajós (1 espécime).

Localidades de hospedeiros infestados: Porto Velho, Rondônia, Centro de Endemismo Inambari (3 espécimes); Altamira, Pará, Centro de Endemismo Tapajós (1 espécime).

Prevalência da infestação: 16\% (4 hospedeiros infestados em 19 analisados).

Intensidade da infestação: indeterminada (D17; D18).

Cestoda observados: 2 morfotipos; Dilepididae (D17; ANEXO D, Figura 63) (D18; ANEXO D, Figura 64).

Caracterização D17: Cinco espécimes completos e sete proglótides soltas. Espécime 1,67mm de comprimento $(n=1)$, composto por 9 proglótides. Escólex com maior largura na região das ventosas 142,92 ( $\mathrm{n}=1)$. Aparato rostelar musculo-glandular, rostelo muscular, bolsa rostelar com parede espessa. Coroa simples de ganchos rostelares, uniformes, arcuatóides, 8 ganchos em número $(n=1), 9,91 \mu \mathrm{m}$ de comprimento $(n=1)$. Ventosas redondas, $58,95 \mu \mathrm{m}$ de diâmetro $(n=1)$, musculares. Proglótides craspedotas, com margens arredondadas, proglótide madura 186,87 × 248,25 (n=1), proglótide pré grávida 323 × $256(n=1)$, proglótide grávida 690,92 x $288(n=1)$. Dutos osmorregulatórios não observados. Poro genital alternado irregularmente, a 36\% da margem anterior da proglótide madura, a 38\% da margem anterior da proglótide pré grávida. Testículos 10 em número $(n=1), 5$ porais e 5 aporais, posteriores ao ovário. Saco do cirro oval, com parede mediana, cirro sem espinhos visíveis em microscopia óptica. Vitelário mediano, compacto, de forma irregular e posterior ao ovário. 
Ovário com dois lobos alados, unidos na região mediana por um istmo. Glândula de Mehlis não distinguível. Útero nas proglótides pré grávidas e grávidas saculiforme. Ovos esféricos com cerca de $12 \mu \mathrm{m}$ de diâmetro $(n=1)$, oncosferas ovais $26,02 \times 13,57(n=1)$, ganchos embrionários não visíveis.

Caracterização D18: Dois espécimes incompletos e cinco proglótides destacadas. Comprimento total e número de segmentos indeterminados. Escólex com maior largura na região das ventosas 195,97 (n=1). Aparato rostelar musculo-glandular, rostelo muscular, bolsa rostelar com parede espessa. Coroa simples de ganchos rostelares, uniformes, arcuatóides, 16 ou 20 ganchos em número $(n=2), 10,61 \mu m$ de comprimento $(n=1)$. Ventosas redondas, $83,32 \mu \mathrm{m}$ de diâmetro $(n=1)$, musculares. Proglótides craspedotas, com margens arredondadas, proglótide madura 112,95 x 225,57 ( $n=1)$. Dutos osmorregulatórios não observados. Poro genital alternado irregularmente. Testículos 9 em número $(n=1), 4$ porais e 5 aporais, posteriores ao ovário. Saco do cirro oval, com parede espessa, cirro sem espinhos visíveis em microscopia óptica. Vitelário mediano, compacto, de forma irregular e posterior ao ovário. Ovário com dois lobos alados, unidos na região mediana por um istmo. Glândula de Mehlis não distinguível. Útero nas proglótides pré grávidas e grávidas saculiforme. Ovos esféricos com cerca de $12 \mu \mathrm{m}$ de diâmetro $(n=1)$, oncosferas ovais $17,07 \times 12,09(n=1)$, ganchos embrionários não visíveis.

Considerações: A prevalência de infestação por cestódeos para Sciaphylax hemimelaena observada nas diferentes regiões de coleta foi discrepante, igual a $16 \%$ na região de Porto Velho (RO) e $100 \%$ na região de Santana do Araguaia (PA), indicando que este dado pode não ser informativo em amostras com número amostral restrito. A observação de morfotipos distintos de dilepidídeos nas duas regiões indica que a população de parasitas está relacionada com a localidade onde esta foi obtida, independente da distribuição da espécie de hospedeiro. A identificação dos parasitas não foi possível devido à necessidade de refino taxonômico para família Dilepididae.

\subsubsection{Sciaphylax pallens (Berlepsch \& Hellmayr, 1905)}

Localidades amostradas: Porto Velho, Rondônia, margem direita do rio Madeira, Centro de 
Endemismo Rondônia (1 espécime); Machadinho d'Oeste, margem esquerda do rio JiParaná, Centro de Endemismo Rondônia (1 espécime).

Localidades de hospedeiros infestados: Porto Velho, Rondônia, Centro de Endemismo Rondônia (1 espécime); Machadinho d'Oeste, Rondônia, Centro de Endemismo Rondônia (1 espécime).

Prevalência da infestação: $100 \%$.

Intensidade da infestação: indeterminada (D19), um espécime por hospedeiro (H29) e dois espécimes por hospedeiro (NI05).

Cestoda observados: 3 morfotipos; Dilepididae (D19; ANEXO D, Figura 65); Hymenolepididae (H29; ANEXO D, Figura 66), não identificado (NI05).

Caracterização D19: Dois estróbilos, nenhuma escólex observada. Comprimento total e número de segmentos indeterminados. Proglótides craspedotas, com margens arredondadas, proglótide madura 125,55 x 138,50 (n=1), proglótide pós madura 180,10 x 163,60 ( $n=1)$, proglótide grávida 321,97 x 160,25 (n=1). Dutos osmorregulatórios não observados. Poro genital alternado irregularmente, a 52\% da margem anterior da proglótide madura, a $38 \%$ da margem anterior das proglótides pós madura e grávida. Testículos 4 em número $(n=1)$, posteriores ao ovário. Saco do cirro oval, com parede mediana, cirro com espinhos visíveis em microscopia óptica. Vitelário mediano, compacto, de forma irregular e posterior ao ovário. Ovário com dois lobos alados, unidos na região mediana por um istmo. Glândula de Mehlis não distinguível. Útero nas proglótides grávidas saculiforme. Oncosferas esféricas 11,37 ( $n=1)$, ganchos embrionários não visíveis.

Caracterização H29: Um espécime incompleto. Comprimento total e número de segmentos indeterminados. Escólex com maior largura na região das ventosas 124,50 (n=1). Base rostelar musculo-glandular, rostelo muscular, bolsa rostelar com parede delgada. Coroa simples de ganchos rostelares, uniformes, arcuatóides, 10 ganchos em número $(n=1)$, $22,25 \mu \mathrm{m}$ de comprimento $(n=1)$. Ventosas redondas, $47,15 \mu \mathrm{m}$ de diâmetro $(n=1)$, musculares, sem espinhos. Proglótides craspedotas. Quatro dutos osmorregulatórios. Poro genital lateral, alternância indeterminada. Testículos ovais, 3 em número em todas as proglótides visíveis, posteriores, em disposição triangular 1 poral mediano, 1 aporal anterior e 1 aporal posterior. Saco do cirro oval, com parede delgada, entre os dutos 
osmorregulatórios, cirro sem espinhos visíveis em microscopia óptica. Vitelário mediano, compacto, elíptico, posterior aos demais órgãos. Ovário com 3 lobos arredondados, mediano, em disposição triangular. Glândula de Mehlis não distinguível. Útero nas proglótides pré grávidas saculiforme, com septo central. Ovos esféricos com cerca de

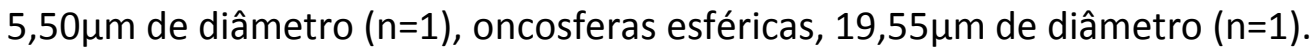

Caracterização NI05: Dois espécimes completos, em estágio larval anterior ao desenvolvimento do escólex. Região anterior invaginada, lacuna primária ausente, cercomero ausente.

Considerações: A observação de dois morfotipos de cestódeos para hospedeiros pertencentes a Sciaphylax pallens coletados em duas áreas diferentes pertencentes à mesma região biogeográfica indica que a diversidade de cestódeos associada a estes hospedeiros varia de acordo com a região amostrada. A identificação dos espécimes não foi possível devido à necessidade de refino taxonômico para os cestódeos.

\subsubsection{Sclateria}

\subsubsection{Sclateria naevia toddi Hellmayr, 1924}

Localidades amostradas: Altamira, Pará, margem esquerda do rio Xingu, Centro de Endemismo Tapajós (1 espécime).

Prevalência da infestação: $100 \%$.

Intensidade da infestação: 2 espécimes por hospedeiro (H30).

Cestoda observados: 1 morfotipo; Hymenolepididae (H30; ANEXO D, Figura 68).

Caracterização H30: Dois estróbilos, nenhuma escólex observada. Comprimento total e número de segmentos indeterminados. Proglótides craspedotas, proglótide madura 92,95 x $313,20(n=1)$, proglótide pré grávida $89 \times 515,15(n=1)$, proglótide grávida 253,85 x 595,45 $(n=1)$. Dez dutos osmorregulatórios, dutos genitais dorsais. Poro genital unilateral $35 \%$ da margem anterior das proglótides madura e pré grávida. Testículos ovais, 3 em número em todas as proglótides visíveis, 1 mediano anterior, 1 mediano posterior e 1 aporal posterior. 
Saco do cirro oval, com parede mediana, entre os dutos osmorregulatórios, cirro sem espinhos visíveis em microscopia óptica. Vitelário mediano, compacto, elíptico, posterior aos demais órgãos. Ovário com 3 lobos transversais, mediano. Glândula de Mehlis não distinguível. Útero nas proglótides pré grávidas saculiforme, com septo central. Ovos esféricos com cerca de $12,15 \mu \mathrm{m}$ de diâmetro $(n=1)$, oncosferas esféricas com cerca de $26,40 \mu \mathrm{m}$ de diâmetro $(\mathrm{n}=1)$, ganchos embrionários não visíveis.

Considerações: A amostra de Sclateria naevia toddi analisada foi obtida em uma área de mata de terra firme, habitat comum desta espécie (ZIMMER; ISLER, 2016), apenas um espécime foi analisado em busca de parasitas. A espécie possui hábito de vida insetívoro e forrageia próxima ao solo, seguindo formigas de correição eventualmente (ZIMMER; ISLER, 2016), o que sugere exposição maior às formas de transmissão de cestódeos. A prevalência igual a $100 \%$ observada para a espécie não é informativa devido à restrição no número amostral do hospedeiro e a coleta de dois espécimes incompletos de cestódeos não permite maiores inferências sobre a fauna de parasitas associada.

\subsubsection{Sclateria naevia argentata (Des Murs, 1856)}

Localidade amostrada: Porto Velho, Rondônia, margem esquerda do rio Madeira, Centro de Endemismo Inambari (1 espécime) e margem direita do rio Madeira, Centro de Endemismo Rondônia (1 espécime).

Prevalência de infestação: nenhum hospedeiro infestado.

Considerações: O espécime de Sclateria naevia argentata analisado foi coletado em uma área de mata de terra firme, assim como o espécime de $S$. naevia toddi amostrado neste estudo, porém a ausência de helmintos parasitas não permite comparações e inferências sobre sua associação com cestódeos. A presença de cestódeos em outros táxons de tamnofilídeos na mesma área indica que esta população está exposta a formas infestantes, porém estas podem não ser capazes de infestar estes hospedeiros por razões de especificidade parasitária ou hábitos de exploração de nicho pelo hospedeiro. A amostragem de apenas um indivíduo de $S$. naevia toddi não permite maiores inferências sobre a prevalência de infestação neste gênero de tamnofilídeo, portanto os dados obtidos neste 
estudo para estes indivíduos não permitem elucidar se a distribuição geográfica interfere na infestação por helmintos.

\subsubsection{Taraba}

\subsubsection{Taraba major borbae (Pelzeln, 1868)}

Localidades amostradas: Porto Velho, Rondônia, margem direita do rio Madeira, Centro de Endemismo Rondônia (2 espécimes).

Prevalência da infestação: 50\% (1 hospedeiro infestado em 2 analisados).

Intensidade da infestação: 1 espécime por hospedeiro (M14).

Cestoda observados: 1 morfotipo; Metadilepididae: Hamatofuhrmannia macracantha cf. (M14; ANEXO D, Figura 69).

Caracterização M14: Um espécime incompleto. Comprimento total e número de segmentos indeterminados. Escólex com maior largura na região das ventosas $374,85(n=1)$. Base rostelar muscular, rostelo muscular, bolsa rostelar com parede delgada. Coroa simples de ganchos rostelares, uniformes, triangulares, 11 ganchos em número $(n=1), 91,27 \mu m$ de comprimento $(n=1)$. Ventosas circulares, $195,25 \mu$ m de diâmetro $(n=1)$, musculares, sem espinhos. Proglótides craspedotas. Número de dutos osmorregulatórios não determinado. Poro genital alternado irregularmente. Testículos em número não determinado, posteriores às glândulas femininas. Saco do cirro oval, alongado, com parede delgada, alcançando os dutos osmorregulatórios, cirro sem espinhos visíveis em microscopia óptica. Vitelário mediano, compacto, oval. Ovário com 2 lobos arredondados, anterior. Glândula de Mehlis não distinguível. Útero nas proglótides pré grávidas e grávidas saculiforme, com parede

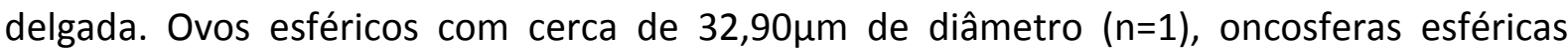
$34,10 \mu m$ de diâmetro $(n=1)$, ganchos embrionários não visíveis no centro, 3 em número $(n=2)$.

Considerações: As amostras para busca de cestódeos em Taraba major borbae foram obtidas em um ponto de coleta, com observação de um espécime parasita pertencente à família Metadilepididae. Ao contrário dos demais helmintos pertencentes a este táxon que 
foram obtidos parasitando os tamnofilídeos, pertencentes ao gênero Schmdneila, o parasita de T. major borbae possui ganchos robustos, longos e oncosferas esféricas, características do gênero Hamatofuhrmannia. A espécie tipo do gênero foi descrita por Fuhrmann (1908) parasitando um papa-formiga proveniente da América do Sul, sem identificação precisa do hospedeiro, designado como Furnariidae e seguido de um ponto de interrogação. A imprecisão na identificação do hospedeiro não permite a associação deste com tamnofilídeos, porém é possível estabelecer uma relação próxima do parasita com este grupo de hospedeiros, uma vez que a família Thamnophilidae estava inserida na família Furnariidae quando Hamatofuhrmannia foi descrito. A obtenção de apenas um espécime de Hamatofuhrmannia em 486 amostras de hospedeiros, incluindo outro indivíduo de T. major borbae, indica que este é um táxon pouco abundante no ambiente e pode apresentar hábito oioxeno ao seu hospedeiro, já que não foram observados parasitas deste grupo em outras aves.

\subsubsection{Taraba major melanurus (Sclater, 1855)}

Localidade amostrada: Porto Velho, Rondônia, margem esquerda do rio Madeira, Centro de Endemismo Inambari (1 espécime).

Prevalência de infestação: nenhum hospedeiro infestado.

Considerações: O espécime de Taraba major melanurus analisado foi coletado em uma área de mata de terra firme, assim como os demais espécimes pertencentes ao gênero amostrados neste estudo, porém a ausência de helmintos parasitas não permite comparações e inferências sobre sua associação com cestódeos. A presença de um morfotipo raro de cestódeo em T. major borbae, Hamatofuhrmannia, indica que este grupo de aves pode ter uma fauna de helmintos associada peculiar, exigindo que o número amostral de hospedeiros seja aumentado.

\subsubsection{Taraba major semifasciatus (Cabanis, 1872)}

Localidade amostrada: Altamira, Pará, margem direita do rio Xingu, Centro de Endemismo Xingu (1 espécime). 
Prevalência de infestação: nenhum hospedeiro infestado.

Considerações: A amostra de Taraba major semifasciatus restringiu-se a apenas um indivíduo coletado em zona de mata de terra firme, sem presença de cestódeos associados. A presença de um morfotipo raro de cestódeo em T. major borbae, Hamatofuhrmannia, no Centro de Endemismo Inambari indica que o número amostral restrito dos hospedeiros pode não ser informativo para o estudo de parasitas, exigindo uma maior quantidade de indivíduos.

\subsubsection{Thamnomanes}

\subsubsection{Thamnomanes ardesiacus ardesiacus (Sclater \& Salvin, 1867)}

Localidades amostradas: Porto Velho, Rondônia, margem esquerda do rio Madeira, Centro de Endemismo Inambari (16 espécimes).

Prevalência da infestação: 19\% (3 hospedeiros infestados em 16 analisados).

Intensidade da infestação: 1 espécime por hospedeiro (H31; P04).

Cestoda observados: 2 morfotipos; Hymenolepididae (H31; ANEXO D, Figura 70), Paruterinidae (P04; ANEXO D, Figura 71).

Caracterização H31: Um espécime completo. Espécime $6 \mathrm{~mm}$ de comprimento $(n=1)$, composto por 118 proglótides. Escólex com maior largura na região das ventosas $360(n=1)$. Base rostelar musculo-glandular, rostelo muscular, bolsa rostelar com parede espessa. Coroa simples de ganchos rostelares, uniformes, arcuatóides, 34 ganchos em número $(n=1)$, $35,17 \mu \mathrm{m}$ de comprimento $(\mathrm{n}=1)$. Ventosas redondas, $144,70 \mu \mathrm{m}$ de diâmetro $(\mathrm{n}=1)$, musculares, sem espinhos. Proglótides craspedotas, proglótide madura 71,50 x 381,15 ( $n=1)$, proglótide pré grávida 73,70 × 511,10 (n=1), proglótide grávida 176,05 x 473,60 (n=1). Dutos osmorregulatórios não observados. Poro genital unilateral. Testículos ovais, 3 em número em todas as proglótides visíveis, em disposição triangular com 1 poral anterior, 1 poral posterior e 1 aporal posterior. Saco do cirro oval, com parede mediana, entre os dutos osmorregulatórios, cirro sem espinhos visíveis em microscopia óptica. Vitelário mediano, compacto, elíptico, posterior aos demais órgãos. Ovário com 3 lobos transversais, mediano. 
Glândula de Mehlis não distinguível. Útero nas proglótides pré grávidas saculiforme, com septo central. Ovos esféricos com cerca de $7,65 \mu \mathrm{m}$ de diâmetro $(n=1)$, oncosferas esféricas com cerca de $21,70 \mu \mathrm{m}$ de diâmetro $(n=1)$, ganchos embrionários não visíveis.

Caracterização P04: Dois segmentos estrobilares. Nenhuma escólex observada. Comprimento e número total de proglótides indeterminados. Proglótides craspedotas. Dutos osmorregulatórios não observados. Poro genital unilateral ou alternado irregularmente. Saco do cirro oval, lateral aos dutos osmorregulatórios em proglótides grávidas. Útero oval. Órgão paruterino com paredes espessas, dorsal ao útero, anterior nas proglótides mais desenvolvidas. Ovos esféricos, $13,50 \mu m$ de diâmetro $(n=1)$, oncosferas ovais, $34,65 \times 28,50$ $(n=1)$.

Considerações: A amostra de Thamnomanes ardesiacus ardesiacus para obtenção de cestódeos resultou em três indivíduos infestados, com dois morfotipos de parasitas observados. A amostra compreendeu um número razoável de indivíduos, ao contrário da maioria dos táxons amostrados, coletados em diferentes pontos amostrais e constituindo uma amostragem ampla geograficamente. A obtenção de um morfotipo de cestódeo (P04) em dois hospedeiros coletados em pontos distintos e com intervalo de 11 meses entre as coletas indica ampla distribuição para estes helmintos.

\subsubsection{Thamnomanes caesius hoffmannsi Hellmayr, 1906}

Localidade amostrada: Altamira, Pará, margem direita do rio Xingu, Centro de Endemismo Xingu (2 espécimes); Santana do Araguaia, Pará, Fazenda Fartura, margem esquerda do Rio Araguaia, Centro de Endemismo Xingu (11 espécimes).

Prevalência de infestação: nenhum hospedeiro infestado.

Considerações: A coleta de 13 espécimes de Thamnomanes caesius hoffmannsi em duas localidades distintas e a ausência de cestódeos associados a estes hospedeiros indicam que a ausência de helmintos nestas aves provavelmente não está associada ao esforço amostral empregado, portanto fatores como a distribuição dos parasitas e hospedeiros, disponibilidade das formas infestantes de parasitas e estratégias de encontro entre parasitas 
e possíveis hospedeiros podem ser a causa desta negativa (WODJAK et al., 2014). A presença de helmintos em outros táxons de Thamnomanes indica que prevalência nula para $T$. caesius hoffmannsi pode ser decorrente da localidade amostrada, indicando necessidade no aumento amostral do táxon.

\subsubsection{Thamnomanes caesius persimilis Hellmayr, 1907}

Localidades amostradas: Porto Velho, Rondônia, margem esquerda do rio Madeira, Centro de Endemismo Inambari (14 espécimes), margem direita do rio Madeira, Centro de Endemismo Rondônia (2 espécimes); Machadinho d'Oeste, margem esquerda do rio JiParaná, Centro de Endemismo Rondônia (1 espécime).

Localidades de hospedeiros infestados: Porto Velho, Rondônia, Centro de Endemismo Inambari (2 espécimes).

Prevalência da infestação: 12\% (2 hospedeiros infestados em 17 analisados).

Intensidade da infestação: 1 espécime por hospedeiro (H32).

Cestoda observados: 1 morfotipo; Hymenolepididae (H32; ANEXO D, Figura 72).

Caracterização H32: Um espécime completo. Um espécime completo. Espécime 20,71mm de comprimento $(n=1)$, composto por 207 proglótides. Escólex com maior largura na região das ventosas $387,60(n=1)$. Base rostelar musculo-glandular, rostelo muscular, bolsa rostelar com parede espessa. Coroa simples de ganchos rostelares, uniformes, arcuatóides, 34 ganchos em número $(n=1), 33,62 \mu \mathrm{m}$ de comprimento $(n=1)$. Ventosas redondas, $167 \mu \mathrm{m}$ de diâmetro $(n=1)$, musculares, sem espinhos. Proglótides craspedotas, proglótide madura $111,65 \times 399,70(n=1)$, proglótide pré grávida $120 \times 463,90(n=1)$, proglótide grávida 231,50 x $384,65(n=1)$. Dutos osmorregulatórios não observados. Poro genital unilateral, a $24 \%$ da margem anterior nas proglótides maduras e a 18\% da margem anterior nas proglótides pré grávidas. Testículos ovais, 3 em número em todas as proglótides visíveis, em disposição em L, 1 poral posterior, 1 aporal anterior e 1 aporal posterior. Saco do cirro oval, com parede mediana, entre os dutos osmorregulatórios, cirro sem espinhos visíveis em microscopia óptica. Vitelário mediano, compacto, elíptico, posterior aos demais órgãos. Ovário com 3 lobos transversais, mediano. Glândula de Mehlis não distinguível. Útero nas proglótides pré grávidas saculiforme, com septo central. Ovos esféricos com cerca de $9 \mu \mathrm{m}$ de diâmetro 
$(n=1)$, oncosferas esféricas com cerca de $17,50 \mu m$ de diâmetro $(n=1)$, ganchos embrionários não visíveis.

Considerações: A amostra obtida para Thamnomanes caesius persimilis foi coletada em três localidades distintas, porém a infestação por cestódeos foi observada apenas em indivíduos provenientes do Centro de Endemismo Inambari, com registro de infestação nulo para os espécimes provenientes do Centro de Endemismo Rondônia. A diferença entre número amostral obtido em cada uma destas áreas (14 x 3) não permite afirmar que os parasitas estão presentes apenas no Centro de Endemismo Inambari, pois apenas 2 hospedeiros foram observados em uma amostra total de 14 indivíduos.

\subsubsection{Thamnomanes saturninus saturninus (Pelzeln, 1868)}

Localidades amostradas: Porto Velho, Rondônia, margem direita do rio Madeira, Centro de Endemismo Rondônia (5 espécimes); Machadinho d'Oeste, margem esquerda do rio JiParaná, Centro de Endemismo Rondônia (2 espécimes) e margem direita do rio Ji-Paraná, Centro de Endemismo Rondônia (2 espécimes).

Localidades de hospedeiros infestados: Porto Velho, Rondônia, Centro de Endemismo Rondônia (1 espécimes), Machadinho d'Oeste, Rondônia, Centro de Endemismo Rondônia (2 espécimes).

Prevalência da infestação: 33\% (3 hospedeiros infestados em 9 analisados).

Intensidade da infestação: variável; 1 espécime por hospedeiro (P05; NI06), 2 espécimes por hospedeiro (M15).

Cestoda observados: 3 morfotipos; Paruterinidae: Anonchotaenia brasiliensis cf. (P05; ANEXO D, Figura 73), Metadilepididae: Schmidneila sp. (M15; ANEXO D, Figura 74), não identificado (NI06; ANEXO D, Figura 75).

Caracterização P05: Um espécime incompleto. Comprimento total e número total de segmentos indeterminados. Escólex com maior largura na região das ventosas 553,85 (n=1). Rostelo ausente, sem ganchos ou armamento. Ventosas redondas, sem dobras, 221,25 $\mu \mathrm{m}$ de diâmetro $(n=1)$, musculares. Proglótides craspedotas, proglótides maduras 58,20 (n=1) x $548(n=1)$, proglótide pré grávida 290,25 x 512,05 (n=1). Dutos osmorregulatórios não 
observados em todos os estágios de desenvolvimento. Poro genital alternado irregularmente. Testículos não distinguíveis, número e posição indeterminados. Saco do cirro indistinguível. Vitelário indistinguível. Ovário indistinguível. Glândula de Mehlis indistinguível. Útero oval. Órgão paruterino com paredes espessas, dorsal ao útero, anterior nas proglótides mais desenvolvidas. Ovos esféricos $18,25 \mu \mathrm{m}$ de diâmetro $(n=1)$.

Caracterização M15: Dois estróbilos. Comprimento total e número de segmentos indeterminados. Proglótides craspedotas, proglótide madura 237,30 x 558,8 (n=1), proglótide pré grávida 249,05 × 653,10 (n=1), proglótide grávida 448 × $934(n=1)$. Número de dutos osmorregulatórios não determinado. Poro genital unilateral, a $48 \%$ da margem anterior da proglótide madura, a 43\% da margem anterior da proglótide pré grávida e a 53\% da margem anterior da proglótide grávida. Testículos ovais, 6 em número, posteriores às glândulas femininas. Saco do cirro oval, alongado, com parede delgada, lateral aos dutos osmorregulatórios, cirro sem espinhos visíveis em microscopia óptica. Vitelário mediano, compacto, oval. Ovário com 2 lobos arredondados, anterior. Glândula de Mehlis não distinguível. Útero nas proglótides pré grávidas e grávidas lobado, parenquimatoso. Ovos esféricos com cerca de $16 \mu \mathrm{m}$ de diâmetro ( $n=1)$, oncosferas fusiformes 69,35 x 25,75 (n=1), ganchos embrionários não visíveis.

Caracterização NI06: Um espécime completo, em estágio larval anterior ao desenvolvimento do escólex. Região anterior invaginada, lacuna primária ausente, cercomero ausente.

Considerações: A presença de três morfotipos diferentes de cestódeos em três indivíduos de Thamnomanes saturninus saturninus provenientes de pontos de coleta distintos indica alta diversidade de parasitas na região, variando de acordo com a distribuição destes hospedeiros. A presença de Anonchotaenia brasiliensis cf. na região de Porto Velho amplia a distribuição desta espécie, revista recentemente e com registros para São Paulo e Argentina (PHILLIPS et al.,2014), porém a atribuição de hábito eurixeno a espécie implica em nova revisão do gênero, pois esta não foi observada na região amazônica com a mesma abundância e ampla distribuição.

O morfotipo pertencente a Metadilepididae obtido apresenta receptáculo seminal alongado e oncosferas fusiformes, característicos de espécies do gênero Schimdneila 
(KORNYUSHIN; GEORGIEV, 1994), porém não é possível determinar se este morfotipo assemelha-se a algum outro observado neste estudo, pois nenhuma escólex foi encontrada na amostra.

De acordo com CHERVY (2002), a classificação dos estágios larvais de cestódeos é baseada primariamente na presença da lacuna primária e na retração ou invaginação do escólex, considerando secundariamente a presença de cercomero. Os espécimes obtidos parasitando Thamnomanes saturninus saturninus não apresentam tais estruturas diferenciadas, impossibilitando sua identificação e indicando que tais indivíduos podem estar no início de sua diferenciação e ser resultado de infestação recente ou pertencer a algum grupo de cestódeos que não completa seu desenvolvimento neste hospedeiro ou mesmo em aves. Devido a presença de outros táxons de cestódeos neste hospedeiro, é possível que esta seja uma forma larval de uma destas espécies ou uma forma larval de outra espécie disponível no ambiente. Em ambos os casos, a infestação pode ser recente e não ter havido tempo hábil para o desenvolvimento de estruturas no espécime que permitissem sua identificação.

\subsubsection{Thamnophilus}

\subsubsection{Thamnophilus aethiops atriceps Todd, 1927}

Localidade amostrada: Santana do Araguaia, Pará, Fazenda Fartura, margem esquerda do Rio Araguaia, Centro de Endemismo Xingu (1 espécime).

Prevalência de infestação: nenhum hospedeiro infestado.

Considerações: A amostra obtida para Thamnophilus aethiops atriceps foi restrita a um espécime, coletado em área de mata de terra firme no Centro de Endemismo Xingu. A ausência de infestação pode ser causada pela baixa densidade de parasitas naquele ponto amostral, pela ausência de parasitas naquela região ou por ausência de parasitas específicos a esta espécie de hospedeiro. A presença de cestódeos em outras espécies do gênero Thamnophilus não permite inferências para a associação T. aethiops atriceps, indicando necessidade no aumento do esforço amostral para o táxon. 


\subsubsection{Thamnophilus aethiops injunctus Zimmer, 1933}

Localidade amostrada: Porto Velho, Rondônia, margem esquerda do rio Madeira, Centro de Endemismo Inambari (2 espécimes).

Prevalência de infestação: nenhum hospedeiro infestado.

Considerações: Os dois espécimes de Thamnophilus doliatus radiatus analisados em busca de cestódeos foram coletados no mesmo ponto de coleta e na mesma data, restringindo a distribuição deste táxon nesta amostragem. Os espécimes não apresentaram infestação por cestódeos, assim como outras espécies do gênero Thamnophilus indicando aumento do esforço amostral também é indicado para este táxon.

\subsubsection{Thamnophilus aethiops punctuliger Pelzeln, 1868}

Localidades amostradas: Porto Velho, Rondônia, margem direita do rio Madeira, Centro de Endemismo Rondônia (4 espécimes); Machadinho d'Oeste, margem esquerda do rio JiParaná, Centro de Endemismo Rondônia (2 espécimes) e margem direita do rio Ji-Paraná, Centro de Endemismo Rondônia (1 espécime).

Localidades de hospedeiros infestados: Porto Velho, Rondônia, Centro de Endemismo Rondônia (1 espécime), Machadinho d'Oeste, Rondônia, Centro de Endemismo Rondônia (1 espécime).

Prevalência da infestação: 28\% (3 hospedeiros infestados em 7 analisados).

Intensidade da infestação: variável; 2 espécimes por hospedeiro (H33); 1 espécime por hospedeiro (M16).

Cestoda observados: 2 morfotipos; Hymenolepididae (H33; ANEXO D, Figura 76); Metadilepididae: Schmidneila sp. (M16; ANEXO D, Figura 77).

Caracterização H33: Um estróbilo. Comprimento total e número de segmentos indeterminados. Proglótides craspedotas. Número de dutos osmorregulatórios não determinado. Poro genital unilateral. Testículos não distinguíveis. Saco do cirro não distinguível. Vitelário não distinguível. Ovário não distinguível. Glândula de Mehlis não distinguível. Útero nas proglótides pré grávidas saculiforme, com septo central. Ovos 
esféricos com cerca de $13,12 \mu \mathrm{m}$ de diâmetro $(n=1)$, oncosferas esféricas com cerca de $25,32 \mu \mathrm{m}$ de diâmetro $(n=1)$.

Caracterização M16: Um espécime completo. Espécime 17,13mm de comprimento $(n=1)$, composto por 255 proglótides. Escólex com maior largura na região das ventosas 304,70 $(n=1)$. Base rostelar muscular, rostelo muscular, bolsa rostelar com parede delgada. Coroa simples de ganchos rostelares, uniformes, triangulares, incompleta, 18 ganchos presentes $(n=1), 23,50 \mu m$ de comprimento $(n=1)$. Ventosas circulares, $114,05 \mu m$ de diâmetro $(n=1)$, musculares, sem espinhos. Proglótides craspedotas, proglótide madura 82,85 x 359,85 (n=1), proglótide pré grávida 245,50 x 750,85 (n=1), proglótide grávida 470,60 x 585,75 (n=1). Número de dutos osmorregulatórios não determinado. Poro genital unilateral, a $29 \%$ da margem anterior da proglótide madura, a 34\% da margem anterior da proglótide pré grávida. Testículos em número indeterminado, posteriores às glândulas femininas. Saco do cirro oval, alongado, com parede delgada, entre os dutos osmorregulatórios, cirro sem espinhos visíveis em microscopia óptica. Vitelário mediano, compacto, oval. Ovário com 2 lobos arredondados, anterior. Glândula de Mehlis não distinguível. Útero nas proglótides pré grávidas e grávidas lobado, parenquimatoso. Ovos esféricos com cerca de $16 \mu \mathrm{m}$ de diâmetro $(n=1)$, oncosferas fusiformes $54,10 \times 19,40(n=1)$, ganchos embrionários não visíveis.

Considerações: A coleta de três indivíduos hospedeiros em sete amostrados de Thamnophilus aethiops punctuliger mostra uma maior prevalência de infestação para o táxon em relação aos demais do gênero Thamnophilus, porém a presença de dois morfotipos de cestódeos indica que a diversidade de parasitas associada a esta espécie não é tão ampla. Não foi possível identificar o morfotipo pertencente à família Hymenolepididae devido à sua fixação em etanol, porém o espécime pertencente à família Metadilepididae apresenta uma coroa de ganchos simples e triangulares com comprimento menor que $30 \mu \mathrm{m}$, oncosferas fusiformes e receptáculo seminal alongado, característicos de espécies do gênero Schimdneila (KORNYUSHIN; GEORGIEV, 1994), representando o décimo quinto registro do gênero para tamnofilídeos. O espécime possui características como número (18) e tamanho do gancho $(23,5)$ próximos àqueles observados para os parasitas de $P$. nigromaculata paraensis e $P$. leuconota similis amostrados no Centro de Endemismo Xingu, porém a diversidade de hospedeiros e a distribuição ampla indicam necessidade de aumento 
no esforço amostral para confirmação na identificação deste cestódeo.

\subsubsection{Thamnophilus amazonicus obscurus Zimmer, 1933}

Localidade amostrada: Altamira, Pará, margem esquerda do rio Xingu, Centro de Endemismo Tapajós (1 espécime).

Prevalência de infestação: nenhum hospedeiro infestado.

Considerações: A amostra obtida para Thamnophilus amazonicus obscurus foi restrita a um espécime, coletado em área de mata de terra firme no Centro de Endemismo Tapajós. A ausência de infestação pode ser causada pela baixa densidade de parasitas naquele ponto amostral, pela ausência de parasitas naquela região ou por ausência de parasitas específicos a esta espécie de hospedeiro. A presença de cestódeos em outras espécies do gênero Thamnophilus não permite inferências para a associação T. amazonicus obscurus, indicando necessidade no aumento do esforço amostral para o táxon.

\subsubsection{Thamnophilus doliatus difficilis Hellmayr, 1903}

Localidade amostrada: Santana do Araguaia, Pará, Fazenda Fartura, margem esquerda do Rio Araguaia, Centro de Endemismo Xingu (2 espécimes)

Prevalência de infestação: nenhum hospedeiro infestado.

Considerações: A obtenção de dois indivíduos pertencente a espécie Thamnophilus doliatus difficilis em um mesmo ponto de amostragem restringe inferências sobre sua infestação por cestódeos, que pode ser causada pela baixa densidade de parasitas naquele ponto amostral, pela ausência de parasitas naquela região ou por ausência de parasitas específicos a esta espécie de hospedeiro, indicando necessidade de aumento do esforço amostral para esta ave e ampliação na distribuição das amostras.

\subsubsection{Thamnophilus doliatus radiatus Vieillot, 1816}

Localidade amostrada: Porto Velho, Rondônia, Centro de Endemismo margem direita do rio 
Madeira, Centro de Endemismo Rondônia (2 espécimes).

Prevalência de infestação: nenhum hospedeiro infestado.

Considerações: A obtenção de dois indivíduos pertencente a espécie Thamnophilus doliatus radiatus em um mesmo ponto de amostragem restringe inferências sobre sua infestação por cestódeos, indicando necessidade de aumento do esforço amostral para esta ave e ampliação na distribuição das amostras.

\subsubsection{Thamnophilus murinus canipennis Todd, 1927}

Localidades amostradas: Porto Velho, Rondônia, margem esquerda do rio Madeira, Centro de Endemismo Inambari (4 espécimes).

Localidades de hospedeiros infestados: Porto Velho, Rondônia, Centro de Endemismo Inambari (1 espécimes).

Prevalência da infestação: 25\% (1 hospedeiro infestado em 4 analisados).

Intensidade da infestação: 1 espécime por hospedeiro (P06).

Cestoda observados: 1 morfotipo; Paruterinidae (P06; ANEXO D, Figura 78).

Caracterização P06: Um espécime completo. Espécime 19,23mm de comprimento, composto por 95 proglótides. Escólex com maior largura na região das ventosas 424,65 $(n=1)$. Rostelo circular, sem parte muscular ou glandular visível. Coroa dupla alternada de ganchos rostelares, triangulares, 24 ganchos da coroa anterior, 18,83 $\mu \mathrm{m}$ de comprimento $(n=1)$ e 25 ganchos na coroa posterior, $16,53 \mu \mathrm{m}$ de comprimento $(n=1)$. Ventosas redondas, sem dobras, $158,15 \mu \mathrm{m}$ de diâmetro $(n=1)$, musculares, com microtríquias visíveis em microscopia óptica. Proglótides craspedotas, proglótides maduras 131 x 280,20 (n=1), proglótide grávida $214,75 \times 421,10(n=1)$, proglótide grávida $543 \times 475,55(n=1)$. Dutos osmorregulatórios não observados em todos os estágios de desenvolvimento. Poro genital alternado irregularmente, a $36 \%$ da margem anterior da proglótide madura e a $44 \%$ da margem anterior da proglótide pré grávida. Testículos 8 em número $(n=1)$, agrupados, posteriores ao ovário. Saco do cirro oval, lateral aos dutos osmorregulatórios em proglótides maduras. Vitelário mediano, compacto, oval e posterior ao ovário. Ovário com dois lobos alados, unidos na região mediana por um istmo. Glândula de Mehlis não distinguível. Útero 
em forma de ferradura em proglótides pré grávidas e grávidas, posterior. Órgão paruterino com paredes espessas, piriforme, dorsal ao útero. Ovos esféricos, $12,55 \mu \mathrm{m}$ de diâmetro $(n=2)$, oncosferas esféricas $31,55 \mu m$ de diâmetro $(n=1)$, ganchos embrionários visíveis na porção central.

Considerações: A obtenção de apenas um indivíduo hospedeiro entre as amostras obtidas para Thamnophilus murinus canipennis indica que esta espécie pode apresentar baixa diversidade de parasitas associada para a região amostrada, uma vez que todas as amostras obtidas são provenientes do mesmo ponto de coleta. O espécime parasita pertence à família Paruterinidae, que mostrou baixa diversidade na composição da fauna associada a tamnofilídeos, com apenas 6 registros para todos os táxons hospedeiros.

\subsubsection{Thamnophilus palliatus palliatus (Lichtenstein, 1823)}

Localidade amostrada: Altamira, Pará, margem esquerda do rio Xingu, Centro de Endemismo Tapajós (1 espécime)

Prevalência de infestação: nenhum hospedeiro infestado.

Considerações: A obtenção de apenas um indivíduo pertencente a espécie Thamnophilus palliatus palliatus restringe inferências sobre sua infestação por cestódeos, indicando necessidade de aumento do esforço amostral para esta ave.

\subsubsection{Thamnophilus palliatus puncticeps Sclater, 1890}

Localidade amostrada: Porto Velho, Rondônia, margem direita do rio Madeira, Centro de Endemismo Rondônia (2 espécimes).

Prevalência de infestação: nenhum hospedeiro infestado.

Considerações: A obtenção de apenas dois indivíduos pertencentes a espécie Thamnophilus palliatus puncticeps restringe inferências sobre sua infestação por cestódeos, pois fatores como a distribuição dos parasitas e hospedeiros, disponibilidade das formas infestantes de parasitas e estratégias de encontro entre parasitas e possíveis hospedeiros podem ser a 
causa desta ausência, indicando necessidade de aumento do esforço amostral para esta ave.

\subsubsection{Thamnophilus schistaceus schistaceus d'Orbigny, 1837}

Localidade amostrada: Porto Velho, Rondônia, margem direita do rio Madeira, Centro de Endemismo Rondônia (4 espécimes); Machadinho d'Oeste, margem esquerda do rio JiParaná, Centro de Endemismo Rondônia (1 espécime); Altamira, Pará, margem esquerda do rio Xingu, Centro de Endemismo Tapajós (4 espécimes).

Prevalência de infestação: nenhum hospedeiro infestado.

Considerações: A obtenção de apenas dois indivíduos pertencentes a espécie Thamnophilus schistaceus schistaceus restringe inferências sobre sua infestação por cestódeos, pois fatores como a distribuição dos parasitas e hospedeiros, disponibilidade das formas infestantes de parasitas e estratégias de encontro entre parasitas e possíveis hospedeiros podem ser a causa desta ausência, indicando necessidade de aumento do esforço amostral para esta ave.

\subsubsection{Thamnophilus stictocephalus stictocephalus Pelzeln, 1868}

Localidade amostrada: Altamira, Pará, margem direita do rio Xingu, Centro de Endemismo Xingu (1 espécime)

Prevalência de infestação: nenhum hospedeiro infestado.

Considerações: A obtenção de apenas um indivíduo pertencente a espécie Thamnophilus stictocephalus stictocephalus restringe inferências sobre sua infestação por cestódeos, indicando que esta população de hospedeiros não possui fauna parasitária associada ou que esta apresenta baixa prevalência e densidade populacional e não foi detectada com o número amostral de hospedeiros obtido, sugerindo necessidade de aumento do esforço amostral para esta ave.

\subsubsection{Willisornis}


Localidades amostradas: Porto Velho, Rondônia, margem esquerda do rio Madeira, Centro de Endemismo Inambari (15 espécimes) e margem direita do rio Madeira, região Rondônia (7 espécimes); Machadinho d'Oeste, margem esquerda do rio Ji-Paraná, Centro de Endemismo Rondônia (5 espécimes).

Localidades de hospedeiros infestados: Porto Velho, Rondônia, Centro de Endemismo Inambari ( 3 espécimes) e Centro de Endemismo Rondônia (1 espécime).

Prevalência da infestação: 15\% (4 hospedeiros infestados em 27 analisados).

Intensidade da infestação: indeterminada (D20; D21).

Cestoda observados: 2 morfotipos; Dilepididae (D20; ANEXO D, Figura 79) (D21; ANEXO D, Figura 80).

Caracterização D20: Um espécime completo. Espécime 1,21 $\mathrm{mm}$ de comprimento, composto por 9 proglótides, última proglótide pós madura. Escólex com maior largura na região das ventosas 158,25 ( $n=1)$. Aparato rostelar musculo-glandular, rostelo muscular, bolsa rostelar com parede delgada. Coroa dupla alternada de ganchos rostelares, arcuatóides, 17 ganchos em número $(n=1), 9$ anteriores, $18 \mu$ m de comprimento $(n=1)$ e 8 posteriores, $9 \mu m$ de comprimento $(n=1)$. Ventosas redondas, $77,25 \mu m$ de diâmetro $(n=1)$, musculares. Proglótides craspedotas, proglótide madura 196,32 x 229,10 ( $n=1)$, proglótide pós madura $248,85 \times 288,47(n=1)$. Dutos osmorregulatórios não observados. Poro genital alternado regularmente, a $40 \%$ margem anterior da proglótide madura e a 38\% margem anterior da proglótide pós madura. Testículos 5 em número $(n=1)$, posteriores. Saco do cirro oval, com parede mediana, cirro sem espinhos visíveis em microscopia óptica. Vitelário mediano, compacto, de forma irregular e posterior ao ovário. Ovário mediano. Glândula de Mehlis não distinguível.

Caracterização D21: Um espécime completo. Espécime 1,31mm de comprimento, composto por 14 proglótides. Escólex com maior largura na região das ventosas 139,30 (n=1). Aparato rostelar musculo-glandular, rostelo muscular, bolsa rostelar com parede delgada. Coroa dupla alternada de ganchos rostelares, arcuatóides, incompleta. Ventosas redondas, $63,20 \mu \mathrm{m}$ de diâmetro $(n=1)$, musculares. Proglótides craspedotas, proglótide madura $148 x$ $246,50(n=1)$, proglótide pós madura 232,35 x 247,05 ( $n=1)$, proglótide grávida 379,25 x 
$318,20(n=1)$. Dutos osmorregulatórios não observados. Poro genital alternado regularmente, a $45 \%$ margem anterior da proglótide madura e pós madura e a $43 \%$ margem anterior da proglótide grávida. Testículos 10 em número $(n=1)$, posteriores. Saco do cirro oval, com parede mediana, cirro sem espinhos visíveis em microscopia óptica. Vitelário mediano, compacto, de forma irregular e posterior ao ovário. Ovário mediano. Glândula de Mehlis não distinguível. Útero saculiforme. Oncosferas esféricas 24,60 $(n=1)$, ganchos embrionários não visíveis.

Considerações: O levantamento de dados para cestódeos de W. poecilinotus griseiventris foi o segundo mais extensivo registrado neste estudo $(n=27)$ e o mais regular, com indivíduos coletados em todas as amostragens e estações secas e chuvosas. A baixa prevalência observada para os helmintos nestes hospedeiros (15\%) associada ao número de espécimes analisados indica que amostras restritas a alguns indivíduos podem não ser informativas, necessitando de aumento do esforço amostral. Os dois morfotipos de Dilepididae observados parasitando W. poecilinotus griseiventris foram coletados em diferentes pontos de amostragem, um na margem esquerda do rio Madeira (D20) e o outro na margem direita (D21), indicando que a presença de cestódeos nestas aves pode estar associada à distribuição do hospedeiro, tornando necessário o aprofundamento dos estudos destes parasitas para este hospedeiro.

\subsubsection{Willisornis vidua vidua (Hellmayr, 1905)}

Localidade amostrada: Santana do Araguaia, Pará, Fazenda Fartura, margem esquerda do Rio Araguaia, Centro de Endemismo Xingu (30 espécimes).

Prevalência de infestação: nenhum hospedeiro infestado.

Considerações: A amostragem de $W$. vidua vidua em busca de cestódeos foi a mais extensiva deste estudo $(n=30)$, porém nenhum indivíduo analisado apresentou infestação por cestódeos. A ausência de helmintos nestas aves provavelmente não está associada ao esforço amostral empregado, portanto fatores como a distribuição dos parasitas e hospedeiros, disponibilidade das formas infestantes de parasitas e estratégias de encontro entre parasitas e possíveis hospedeiros podem ser a causa desta negativa (WODJAK et al., 
2014). O gênero Willisornis não apresentou infestação por cestódeos abundante, porém o registro de dois morfotipos distintos de dilepidídeos em espécimes de $W$. poecilinotus em regiões distintas sugere que o aumento do esforço amostral deve ser feito para acrescentar localidades aos pontos de coleta já estudados.

\subsection{Microscopia Eletrônica de Varredura}

A obtenção de dados utilizando Microscopia Eletrônica de Varredura (MEV) foi realizada para cinco amostras de cestódeos, de acordo com a quantidade de espécimes encontrados em cada hospedeiro. Devido às características de infestação próprias a cada família de cestódeos, apenas espécimes pertencentes à família Dilepididae foram encontrados em infestações com número de indivíduos maior que três espécimes completos, permitindo, portanto, que apenas espécimes deste grupo fossem analisados em busca de dados que utilizassem esta técnica. As cinco amostras foram obtidas em espécies diferentes de tamnofilídeos. Os dados obtidos, de acordo com os hospedeiros (ANEXO E), são:

\subsubsection{Hypocnemis peruviana}

Localidade: Porto Velho, Rondônia, margem esquerda do rio Madeira, Centro de Endemismo Inambari.

Táxon: Dilepididae (D03).

Material examinado: Quatro espécimes completos e três proglótides destacadas com cirro evertido.

Descrição: Espécimes com rostelo contraído, coroa de ganchos invertida e não exposta (ANEXO D, Figura 81A). Região apical no entorno do rostelo coberta por espinitríquias gladiadas $7-11 / \mu m^{2}(8,8 \pm 1,48, n=5), 0,53-0,60(0,56 \pm 0,04, n=5) \times 0,19-0,22(0,21 \pm 0,01$, $\mathrm{n}=5$ ) (ANEXO D, Figura $81 \mathrm{C}$ ) até a região dos botrídeos. Região periférica dos botrídeos coberta por espinitríquias gladiadas $10-13 / \mu m^{2}(10,8 \pm 1,64, n=5), 0,64-0,72(0,67 \pm 0,04$, $\mathrm{n}=4) \times 0,23-0,29(0,25 \pm 0,03, \mathrm{n}=4)$ (ANEXO D, Figura 81D); região central dos botrídeos coberta por espinitríquias gladiadas $1-2 / \mu m^{2}(1,33 \pm 0,58, n=3), 0,82(n=1) \times 0,2(n=1)$ distribuídas entre espinitríquias bifurcadas $4-5 / \mu m^{2}(4,33 \pm 0,58, n=3), 0,52(n=1) \times 0,27-0,32$ 
$(0,3 \pm 0,04, n=2)$ (ANEXO D, Figura 81E). Região de crescimento coberta por espinitríquias gladiadas continuamente até o estróbilo; superfície das proglótides coberta por espinitríquias gladiadas $9-11 / \mu \mathrm{m}^{2}(9,6 \pm 0,89, \mathrm{n}=5), 0,80-0,84(0,82 \pm 0,02, \mathrm{n}=4) \times 0,32-0,40$ $(0,37 \pm 0,03, n=4)$ (ANEXO D, Figura 81F). Cirro coberto por espinitríquias coniformes e colunares (ANEXO D, Figuras 81B, G); na extremidade distal espinitríquias coniformes 2$3 / \mu m^{2}(2,4 \pm 0,55, n=5), 1,75-1,85(1,8 \pm 0,07, n=2) \times 0,16-0,17(0,17 \pm 0,01, n=2)$ e espinitríquias colunares $0,05-0,06(0,06 \pm 0,01, n=2)$ de largura.

\subsubsection{Oneillornis salvini}

Localidade: Porto Velho, Rondônia, margem esquerda do rio Madeira, Centro de Endemismo Inambari.

Táxon: Dilepididae (D09).

Material examinado: Dois espécimes completos e uma proglótide destacada com cirro evertido.

Descrição: Espécimes com rostelo contraído, coroa de ganchos invertida e não exposta (ANEXO D, Figura 82A). Região apical no entrono do rostelo coberta por espinitríquias gladiadas $9-12 / \mu \mathrm{m}^{2}(10,2 \pm 1,3, \mathrm{n}=5), 0,50-0,61(0,55 \pm 0,05, \mathrm{n}=4) \times 0,18-0,21(0,2 \pm 0,01$, $\mathrm{n}=4$ ) (ANEXO D, Figura 82C, D) até a região dos botrídeos. Região periférica dos botrídeos coberta por espinitríquias gladiadas $14-18 / \mu m^{2}(16,2 \pm 1,64, n=5)$ (ANEXO D, Figura 82E); região central do botrídeo coberta por espinitríquias gladiadas $5-8 / \mu m^{2}(6,5 \pm 1,29, n=4)$, $0,55-0,58(0,56 \pm 0,01, \mathrm{n}=4) \times 0,17-0,18(0,18 \pm 0,01, \mathrm{n}=4)$ distribuídas entre espinitríquias colunares 3-5/ $\mu \mathrm{m}^{2}(4,25 \pm 0,96, \mathrm{n}=4), 0,48-0,63(0,56 \pm 0,11, \mathrm{n}=2) \times 0,09(0,09, \mathrm{n}=2)$ (ANEXO D, Figura 82F). Região de crescimento coberta por espinitríquias gladiadas continuamente até o estróbilo; superfície das proglótides coberta por espinitríquias gladiadas $18-22 / \mu \mathrm{m}^{2}$ $(20,5 \pm 2,08, n=3$ ) (ANEXO D, Figura 82G). Cirro coberto por espinitríquias coniformes e colunares (ANEXO D, Figuras 82B, H); na extremidade proximal espinitríquias coniformes $2 / \mu m^{2}(n=1), 3,64(n=1) \times 0,22(n=1)$ e espinitríquias colunares $0,05(n=1)$ de largura.

\subsubsection{Phlegopsis nigromaculata bowmani}

Localidade: Altamira, Pará, margem esquerda do rio Xingu, Centro de Endemismo Tapajós. 
Táxon: Dilepididae (D11).

Material examinado: Dois espécimes completos e uma proglótide destacada com cirro evertido.

Descrição: Espécime com rostelo protraído, coroa de ganchos parcialmente exposta (ANEXO D, Figuras 83A, C). Região apical posterior ao rostelo coberta por espinitríquias gladiadas até a região dos botrídeos. Região periférica dos botrídeos coberta por espinitríquias gladiadas $25-34 / \mu m^{2}(0,61 \pm 0,05, n=2), 0,57-0,64(0,18 \pm 0,01, n=2) \times 0,17-0,18(28,3 \pm 4,93, n=3)$ (ANEXO D, Figura 83D); região entre botrídeos coberta por espinitríquias gladiadas 13$21 / \mu m^{2}(17 \pm 5,66, n=2), 0,46-0,50(0,48 \pm 0,03, n=2) \times 0,18-0,19(0,19 \pm 0,01, n=2)$ (ANEXO

D, Figura 83E). Região de crescimento coberta por espinitríquias gladiadas com descontinuidade na distribuição antes do estróbilo (ANEXO D, Figura 83F); superfície das proglótides coberta por espinitríquias gladiadas $\left.9-12 / \mu m^{2} 10 \pm 1,22, n=5\right), 0,58-0,63(0,60 \pm$ $0,02, n=5) \times 0,21-0,29(0,24 \pm 0,03, n=5)$ (ANEXO D, Figura 83G). Cirro coberto por espinitríquias coniformes e colunares (ANEXO D, Figuras 83B, H); na extremidade distal espinitríquias coniformes $0,39(n=1)$ de largura e espinitríquias colunares $0,07(n=1)$ de largura; na extremidade proximal, espinitríquias coniformes $4,98(n=1) \times 0,39(n=1)$ e espinitríquias colunares $0,07(n=1)$ de largura.

\subsubsection{Sciaphylax hemimelaena}

Localidade: Porto Velho, Rondônia, margem esquerda do rio Madeira, Centro de Endemismo Inambari.

Táxon: Dilepididae (D17).

Material examinado: Dois espécimes completos e uma proglótide destacada com cirro evertido.

Descrição: Espécimes com rostelo contraído, coroa de ganchos invertida e não exposta (ANEXO D, Figura 84A). Região apical no entorno do rostelo coberta por espinitríquias gladiadas $9-12 / \mu m^{2}(10,5 \pm 1,29, n=4), 0,45-0,56(0,51 \pm 0,06, n=3) \times 0,19-0,23(0,21 \pm 0,02$, n=3) (ANEXO D, Figura 84C) até a região dos botrídeos. Região periférica dos botrídeos coberta por espinitríquias gladiadas $6-9 / \mu m^{2}(7,8 \pm 1,3, n=5), 0,44-0,51(0,48 \pm 0,03, n=5) x$ 0,16-0,20 $(0,17 \pm 0,02, n=5)$ (ANEXO D, Figura 84D); região central dos botrídeos coberta por espinitríquias gladiadas $14-16 / \mu \mathrm{m}^{2}(15,4 \pm 0,89, \mathrm{n}=5), 0,63(\mathrm{n}=1) \times 0,15(\mathrm{n}=1)$ (ANEXO D, 
Figura 84E). Região de crescimento coberta por espinitríquias gladiadas continuamente até o estróbilo 25-34/ $\mu \mathrm{m}^{2}(28,3 \pm 4,27, \mathrm{n}=4$ ) (ANEXO D, Figura 84F); superfície das proglótides coberta por espinitríquias gladiadas $25-31 / \mu m^{2}(28,7 \pm 3,21, n=3), 0,51-0,54(0,53 \pm 0,02$, $n=2) \times 0,18(0,18, n=2)$ (ANEXO D, Figura 84G). Cirro coberto por espinitríquias coniformes e colunares (ANEXO D, Figuras 84B, H); na extremidade distal espinitríquias coniformes 0,37 $(n=1)$ de largura e espinitríquias colunares $0,41(n=1)$ de largura.

\subsubsection{Willisornis poecilinotus griseiventris}

Localidade: Porto Velho, Rondônia, margem esquerda do rio Madeira, Centro de Endemismo Inambari.

Táxon: Dilepididae (D20).

Material examinado: Um espécime completo e um estróbilo com duas proglótides com cirro evertido.

Descrição: Espécime com rostelo incompleto, coroa de ganchos ausente (ANEXO D, Figura 85A). Região apical anterior aos botrídeos coberta por espinitríquias gladiadas (ANEXO D, Figura $85 \mathrm{~A})$. Região periférica dos botrídeos coberta por espinitríquias gladiadas $6-7 / \mu \mathrm{m}^{2}$ $(6,5 \pm 0,71, n=2), 0,57-0,60(0,59 \pm 0,02, n=2) \times 0,19-0,24(0,22 \pm 0,04, n=2)$ (ANEXO D, Figura 85C). Região de crescimento coberta por espinitríquias gladiadas continuamente até o estróbilo; superfície das proglótides coberta por espinitríquias gladiadas $11-14 / \mu m^{2}(12,8 \pm$ $1,1, n=5), 0,41-0,48(0,45 \pm 0,04, n=3) \times 0,15-0,18(0,17 \pm 0,02, n=3)$ (ANEXO D, Figura 85D). Cirro coberto por espinitríquias coniformes e colunares (ANEXO D, Figuras 85B, E); na extremidade distal espinitríquias coniformes $4,02(n=1) \times 0,41(n=1)$ e espinitríquias colunares $0,12(n=1)$ de largura (ANEXO D, Figura 85F); na extremidade proximal espinitríquias coniformes 4,22-4,44 (4,31 $\pm 0,13, n=2) \times 0,31-0,34(0,33 \pm 0,02, n=2)$ e espinitríquias colunares 0,03 $(n=1)$ de largura (ANEXO D, Figura 85G).

\subsubsection{Considerações taxonômicas}

A importância taxonômica das estruturas tegumentares em cestódeos é conhecida há mais de um século (ver CHERVY, 2009), porém limitava-se às estruturas com dimensões visíveis ao microscópio óptico. A partir da década de 1970, a técnica de microscopia 
eletrônica de varredura foi empregada nos primeiros estudos acerca da superfície destes helmintos, confirmando que a diversidade de estruturas tegumentares em cestódeos, conhecidas como microtríquias, era maior do que a microscopia óptica permitia analisar (e.g. ANDERSEN, 1975; BOYCE, 1976; HESS; GUGGENHEIM, 1977; VOGE; SOGANDARES-BERNAL; MARTIN, 1979). Nas duas últimas décadas, o uso de dados provenientes de M.E.V. tornou-se frequente nas descrições e revisões taxonômicas para o grupo (e.g. SCHOLZ; DRÁBEK; HANZELOVÁ, 1998; RUHNKE; CAIRA; CARPENTER, 2006; MENORET; IVANOV, 2014; OROS et al., 2016), principalmente devido ao desenvolvimento da tecnologia dos microscópios que permitiram que espécimes diminutos também fossem analisados. Para táxons como Lecanicephalidea, Rhinebothriidea, Trypanorhyncha e os grupos dentro de Tetraphyllidea, a disponibilidade de dados acerca de microtríquias é vasta, com diversos morfotipos destas estruturas registrados para estes parasitas (e. g. PALM, 2004; JENSEN, 2005; MALEK; CAIRA; HASELI, 2010; RUHNKE; CAIRA; COX, 2015).

Apesar dos primeiros cestódeos observados sob M.E.V., Hymenolepis diminuta e $H$. nana, pertencerem à ordem Cyclophyllidea (BERGER; METTRICK, 1971), o número de estudos sobre microtríquias utilizando esta técnica no grupo não é proporcional à quantidade de espécies este encerra. Famílias como Taeniidae, Davaineidae e Hymenolepididae são muito exploradas, porém os estudos restringem-se muitas vezes a táxons com importância médica ou econômica (e.g. BECKER et al., 1980; BASHTAR et al., 2011) ou a poucas espécies de alguns gêneros mais diversos (e.g. CONN, 1985; BÂ; SENE; MARCHAND, 1995). Para algumas famílias de ciclofilídeos, o uso de M.E.V. restringe-se a imagens gerais, sem detalhamento das estruturas tegumentares, como por exemplo os dilepidídeos. Nas últimas décadas não há publicações sobre o emprego de M.E.V. para espécimes deste táxon, exceto na descrição de Bonaia africana (MARIAUX; VAUCHER, 1990), na qual os autores reportam microtríquias alongadas na superfície do escólex e estruturas espinhosas diminutas na superfície do cirro, sem citar dados como densidade ou dimensões destas. Assim, os dados obtidos no presente estudo a partir da análise dos dilepidídeos parasitas de Hypocnemis peruviana, Oneillornis salvini, Phlegopsis nigromaculata bowmani, Sciaphylax hemimelaena e Willisornis poecilinotus griseiventris são os primeiros registros morfométricos acerca das microtríquias encontradas neste grupo de cestódeos, além de serem os primeiros observados para dilepidídeos após a padronização da nomenclatura destas estruturas (CHERVY, 2009). 
As cinco amostras de dilepidídeos parasitas de tamnofilídeos analisadas sob M.E.V. apresentaram microtríquias do tipo espiniforme gladiada distribuídas na região apical, desde a região ao redor do rostelo até as margens anteriores dos botrídeos. Para as amostras em que foi possível verificar as dimensões e distribuição destas estruturas (ou seja, amostras em que a base das microtríquias estava exposta) (ANEXO E), parasitas de H. peruviana, O. salvini e S. hemimelaena, apresentaram sobreposição nas densidades (7-11 × 9-12 × 9-12/ $\left.\mu \mathrm{m}^{2}\right)$, comprimentos $(0,53-0,60 \times 0,50-0,61 \times 0,50-0,61)$ e larguras $(0,19-0,22 \times 0,18-0,21 \times 0,19$ 0,23 ) obtidos, indicando, portanto, que estas não são taxonomicamente informativas.

As microtríquias observadas na região dos botrídeos dos dilepidídeos analisados mostraram-se distintas de acordo com o táxon a qual pertenciam. Na região periférica do botrídeo, foram observadas apenas microtríquias do tipo espiniforme gladiada, porém com densidades e dimensões diferentes para cada grupo de parasita (ANEXO E). Os parasitas de S. hemimelaena $\left(6-9 / \mu \mathrm{m}^{2}\right)$ e $W$. poecilinotus $\left(6-7 / \mu \mathrm{m}^{2}\right)$ possuem a menores densidades de espinitríquias gladiadas nesta região, seguidas de $H$. peruviana $\left(10-13 / \mu m^{2}\right)$, O. salvini (14$\left.18 / \mu \mathrm{m}^{2}\right)$ e $P$. nigromaculata $\left(25-34 / \mu \mathrm{m}^{2}\right)$. Devido à sobreposição dos valores obtidos para os helmintos de $S$. hemimelaena e $W$. poecilinotus e por estes dois grupos apresentarem características distintas que os diferem em outras regiões (ver adiante), conclui-se que esta característica não pode ser utilizada para a delimitação precisa de espécies, porém pode auxiliar na distinção de grupos como, por exemplo, os helmintos de $P$. nigromaculata dos demais.

A região central do botrídeo apresentou os padrões de microtríquias mais informativos para os dilepidídeos analisados, apesar de ser de difícil visualização em espécimes contraídos e não poder ser observada para helmintos de $P$. nigromaculata e $W$. poecilinotus (ANEXO E). Para todos os helmintos analisados, esta região apresentou espinitríquias gladiadas em densidades distintas, permitindo diferenciar espécimes parasitas de H. peruviana $\left(1-2 / \mu \mathrm{m}^{2}\right)$, O. salvini $\left(5-8 / \mu \mathrm{m}^{2}\right)$ e S. hemimelaena $\left(14-16 / \mu \mathrm{m}^{2}\right)$. Entretanto, a distinção dos grupos pode ser feita de maneira mais acurada devido à presença de outros tipos de microtríquias nesta área. Os parasitas de $H$. peruviana apresentaram espinitríquias bifurcadas distribuídas entre as espinitríquias gladiadas (ANEXO D, Figura E), tipo de estrutura que não foi observada para os demais espécimes. As espinitríquias bifurcadas não são comumente encontradas, sendo registradas apenas para espécies pertencentes a ordem Trypanorhyncha (CHERVY, 2009). A presença desta estrutura tegumentar em dilepidídeos 
indica que a ausência de esforços voltados para a obtenção de dados de ultraestrutura em ciclofilídeos pode ocultar caracteres potencialmente informativos para a resolução da taxonomia do grupo e necessitam ser mais explorados.

Além do primeiro registro de espinitríquias bifurcadas para Cyclophyllidea, também foram observadas espinitríquias morfologicamente distintas das gladiadas na superfície central do botrídeo de O. salvini. De acordo com Chervy (2009), estas microtríquias não devem ser classificadas como gladiadas devido a sua base ser oval e mais larga que sua lâmina e a diminuição da largura entre estas áreas não ser continua, porém não há uma descrição que se assemelhe ao morfotipo observado no presente estudo. Entre os tipos de microtríquias listados na unificação da terminologia destas estruturas (CHERVY, 2009), o mais próximo daquelas observadas nos helmintos de $O$. salvini é a espinitríquia cirrilionada, registrada apenas para uma espécie da ordem Phyllobothriidea, com uma base oval e uma pequena ponta cônica que se distingue da base abruptamente, porém este tipo de microtríquia não possui a lâmina achatada e longa como as observadas na superfície do espécime objeto deste estudo. Este morfotipo pode representar um novo tipo de morfologia para microtríquias ou uma redefinição de um tipo de espinitríquia já conhecido e está sendo discutido com o Dr. Reyda, da Universidade de Oneonta (E.U.A.), autor da descrição da espinitríquia cirrilionada (REYDA, 2008). Isso indica, novamente, que este é um componente inexplorado na taxonomia de ciclofilídeos e pode ser potencialmente informativo na delimitação de táxons. Além disso, sua descrição também reforça que os cestódeos parasitas de aves neotropicais são pouco conhecidos e precisam ser melhor estudados.

As microtríquias localizadas além da região do escólex também se mostraram potencialmente informativas para os dilepidídeos. Na superfície das proglótides foram observadas apenas microtríquias espiniformes gladiadas, porém em densidades e dimensões distintas (ANEXO E). Para os espécimes parasitas de $H$. peruviana $\left(9-11 / \mu m^{2}\right), \quad P$. nigromaculata $\left(9-12 / \mu \mathrm{m}^{2}\right)$ e $W$. poecilinotus $\left(11-14 / \mu \mathrm{m}^{2}\right)$, foram observadas menores densidades com sobreposição de intervalos, enquanto os helmintos de O. salvini (18$\left.22 / \mu \mathrm{m}^{2}\right)$ e $S$. hemimelaena $\left(25-31 / \mu \mathrm{m}^{2}\right)$ diferenciaram-se pela maior quantidade de microtríquias por área. Na comparação entre as dimensões destas estruturas, os cestódeos em $H$. peruviana $(0,80-0,84 \times 0,32-0,40)$ apresentaram as maiores medidas, permitindo a distinção destes em relação aos parasitas de $P$. nigromaculata $(0,58-0,63 \times 0,21-0,29), S$. hemimelaena $(0,51-0,54 \times 0,18)$ e $W$. poecilinotus $(0,41-0,48 \times 0,15-0,18)$. 
Os padrões de distribuição e morfometria de microtríquias observadas na superfície do cirro de cestódeos tem se mostrado informativas para diversos grupos (e.g. IVANOV, 2008; LUCHETTI; MARQUES; CHARVET-ALMEIDA, 2008; REYDA, 2008), emprego que também pode ser verificado para os dilepidídeos. Observou-se dois tipos de espinitríquias na superfície da estrutura copulatória masculina, colunares e coniformes, de dimensões distintas entre os táxons (ANEXO E). A densidade das microtríquias do cirro em sua porção distal pode ser contada apenas para os espécimes parasitas de $H$. peruviana $\left(2-3 / \mu m^{2}\right)$, pois este táxon apresentou espinitríquias coniformes com menores dimensões $(1,75-1,85 \times 0,16$ $0,17)$ que permitiram a visualização de sua base, ao contrário dos espécimes provenientes de O. salvini (indisponível), P. nigromaculata (0,39 de largura), S. hemimelaena (0,37 de largura) e $W$. Poecilinotus $(4,02 \times 0,41)$. A disposição de microtríquias mais robustas em uma estrutura cilíndrica como o cirro muitas vezes não permite que as medidas sejam verificadas devido a posição destas nas imagens obtidas. Para a porção proximal do cirro não foram observadas discrepâncias nos valores obtidos, porém não foi possível analisar esta região para espécimes parasitas de $H$. peruviana, que mostrou diferenças na porção distal em relação aos demais helmintos observados (ANEXO E).

As descrições dos padrões de estruturas tegumentares para espécimes pertencentes a Dilepididae são inéditas na literatura e a obtenção destes dados para os parasitas de tamnofilídeos neste estudo busca preencher esta lacuna. A ausência destas informações pode ter diversas causas, entre elas a indisponibilidade de material para o emprego de técnicas de M.E.V.. Uma vez que muitas amostras apresentam um número restrito de espécimes com tamanho diminuto (menores de 1mm; CAIRA; JENSEN; BARBEAU, 2012), o que dificulta sua preparação para o uso nesta técnica, muitos pesquisadores podem preferir priorizar o uso de técnicas tradicionais (e. g. microscopia óptica ou cortes histológicos) para a tomada de dados nas descrições dos táxons. O tamanho dos espécimes também pode ser um impedimento para o emprego da M.E.V. por restrições tecnológicas, pois alguns espécimes demandam análises feitas com amplificação a partir de 50.000 vezes, aumentos que os equipamentos mais antigos não atingiam com imagens de boa qualidade.

Conforme discutido anteriormente, a taxonomia da família necessita ser refinada e, uma vez que as espécies encontradas neste estudo não foram formalmente descritas, não é possível atribuir os padrões de microtríquias observados a um táxon específico. A identificação formal das espécies de dilepidídeos amostrados neste estudo possibilitará a 
verificação da importância taxonômica destas estruturas. Além disso, o registro de microtríquias bifurcadas para o grupo e a verificação de um possível novo morfotipo de espinitríquia indicam que este é um campo com ampla necessidade de refino, que pode trazer diversos dados novos e informativos não só para os Cyclophyllidea, mas também para os demais grupos de cestódeos.

\subsection{Distribuição de cestódeos: áreas amostradas e condições climáticas}

\subsubsection{Amostragem dos hospedeiros}

Os 487 espécimes pertencentes à família Thamnophilidae analisados foram coletados nas seis grandes áreas de estudo amostradas, todas com registros de aves com infestação por cestódeos (ANEXO C). As áreas onde os hospedeiros infestados foram amostrados caracterizavam-se principalmente por vegetação de floresta de terra firme (não inundável), matas de várzea (inundáveis periodicamente) e igapós (inundados permanentemente) (IBGE, 2012), em diferentes níveis de preservação e impactos ambientais. As amostragens foram realizadas em diferentes pontos de cada localidade, buscando a maior abrangência de cada tipo de habitat e sua fauna associada.

Para as áreas de Porto Velho (RO) e Santana do Araguaia (PA) foram realizadas amostragens periódicas em diferentes estações do ano (chuva e seca), buscando verificar a influência das condições climáticas no registro de espécimes de cestódeos nos hospedeiros. Devido a questões logísticas, as áreas de Altamira (PA) e Machadinho d'Oeste (RO) foram visitadas em apenas uma oportunidade, assim com a Ilha de Mutum, localizada na região de Porto Velho (RO). A influência climática não foi analisada para os dados obtidos nas amostragens destas áreas.

\subsubsection{Porto Velho (RO)}

Os dados analisados para localidade de Porto Velho (RO) foram obtidos em seis amostragens, entre junho de 2013 e novembro de 2014 (ANEXO B). As amostras foram coletadas em quatro campanhas na estação seca e duas na estação chuvosa. A diferença no número de amostragens é devida à impossibilidade de acesso a algumas áreas durante os 
meses de janeiro a março, quando há registros dos mais altos índices pluviométricos na região. Ao todo, foram registrados 51 táxons de tamnofilídeos para esta área, em um total de 284 espécimes coletados, ou 58\% do total de amostras analisadas neste estudo (ANEXO B).

As duas primeiras amostragens na área de Porto Velho (RO) seguiram os protocolos tradicionais de coleta de helmintos, portanto o número de aves analisado foi inferior ao potencial número de hospedeiros presentes da área. Devido à alteração do protocolo de coleta, não foi possível comparar o número amostral de tamnofilídeos infestados obtido em todas as campanhas; portanto, a prevalência de infestação de cestódeos foi empregada como o parâmetro para análise dos dados obtidos. A presença de cestódeos foi verificada em todos os pontos de coleta dentro da área amostrada exceto a llha de Mutum, analisada à parte por possuir características intrínsecas que a diferem dos demais pontos.

A prevalência média de infestação por cestódeos observada para a área de Porto Velho (RO) foi de $18,7 \%$, registrando a média de $15,7 \%$ na estação chuvosa e $24,9 \%$ na estação seca. Apesar da diferença entre os valores médios obtidos, verificou-se que as condições climáticas não são um fator determinante no número de amostras obtidas nesta área, já que há um declínio constante na prevalência média de cestódeos observados em todas as amostragens, com exceção da terceira campanha, realizada em novembro de 2013 (ANEXO F, Gráfico 1). Esta amostragem registrou prevalência média de infestação por cestódeos igual a 10,6\%, com apenas 10 indivíduos infestados em um total de 94 tamnofilídeos analisados em busca de helmintos, mostrando um valor médio abaixo da diminuição observada nas demais amostragens.

O número de espécimes de tamnofilídeos coletados nas demais amostragens em Porto Velho (RO) variou entre 13 e 54 indivíduos, com registro de 3 a 11 infestados por cestódeos (ANEXO C). O aumento no esforço amostral na terceira campanha realizada na área mostra que a análise de um número maior de aves não implica em aumento do número de registro de infestação por parasitas, porém a composição da amostra pode influir no número de hospedeiros registrados. Para as campanhas com até 54 espécimes de aves amostrados, foram coletados indivíduos de 9 a 22 táxons de tamnofilídeos (ANEXO B), enquanto na terceira amostragem foram relatados espécimes pertencentes a 35 espécies e subespécies distintas. O aumento do esforço amostral foi excepcional nesta coleta e não se relaciona a condição climática chuvosa, pois a amostragem realizada no ano seguinte na 
mesma época exibe resultados semelhantes às demais coletas realizadas em estações secas (ANEXO F, Gráfico 1).

Apesar de indicar que a composição da amostra é um fator importante na caracterização dos dados parasitológicos desta área, os dados obtidos não permitem concluir que a infestação por cestódeos em membros de Thamnophilidae esteja restrita a poucos táxons, pois o aumento da diversidade da amostra da terceira campanha deve-se a registros de espécies menos comuns nas amostragens com rede de neblina, como Myrmothrula brachyura $(n=2)$, Myrmotherula sclateri $(n=2)$, Neoctantes niger $(n=1)$ e Taraba major melanurus $(n=1)$. Devido a observação dAe baixas prevalências para algumas espécies de tamnofilídeos mais comuns registradas para a área de Porto Velho (RO), como Isleria hauxwelli (1 indivíduo infestado em 17 analisados) e Willisornis poecilinotus griseiventris (4 indivíduos infestados em 27 analisados), a análise de um número amostral restrito destas espécies não permite inferir se estas possuem cestódeos associados a estes táxons, implicando na indicação de aumento do esforço amostral.

As prevalências médias observadas para as coletas em Porto Velho (RO) indicam um declínio constante no registro de cestódeos em tamnofilídeos no período amostrado (ANEXO F, Gráfico 1). O impedimento taxonômico observado para os espécimes de cestódeos amostrados não permite verificar se houve queda na diversidade de parasitas coletados, mas a presença destes foi menos constante a cada amostragem realizada. A distinção deste padrão para o observado na área de Santana do Araguaia (PA) sugere que esta diminuição não é característica dos táxons de hospedeiros e parasitas e está relacionado à área amostrada. Devido às alterações recentes na fisionomia ambiental local uma vez que os pontos de amostragem localizam-se na área de influência da recém-construída UHE Jirau, é possível que alterações ambientais influenciem a transmissão dos parasitas para novos hospedeiros (e.g. interrupção no ciclo de vida por indisponibilidade do hospedeiro intermediário) e esta se estabilize após o período de construção do empreendimento.

\subsubsection{Ilha de Mutum (RO)}

A llha de Mutum localiza-se próxima à foz do rio Jamari e é formada por um recorte da margem esquerda do rio Madeira em um de seus meandros, sendo resultado da dinâmica hidrológica deste rio, que em sua porção média apresenta trechos de traçado retilíneo com 
aumento da velocidade de suas águas e consequente alteração das feições morfológicas de suas margens (SOUZA; ARAÚJO, 2001; ADAMY; DANTAS, 2004; ROSSETO, 2013). A alteração na delimitação desta ilha é documentada desde a década de 1970, a partir do projeto RADAM BRASIL (ADAMY; DANTAS, 2004), porém não há na literatura determinação do período em que foi separada da margem, impossibilitando inferências sobre a influência desta separação na presença ou não de espécies de solitárias em sua área.

Na localidade da llha de Mutum foram amostrados 3 táxons de tamnofilídeos: Myrmotherula assimilis assimilis, Pygiptila stellaris stellaris e Thamnophilus doliatus radiatus, todos com ocorrência em ambas as margens do rio Madeira e característicos de áreas de bosque e sub-bosque inundáveis ou próximas às matas de várzeas ou igapós (ZIMMER; ISLER, 2016; ZIMMER; ISLER; CHRISTIE, 2016). Não houve registros de infestação por cestódeos nas amostras obtidas, diferenciando esta área das demais amostradas na margem esquerda do rio Madeira.

A Ilha de Mutum foi a única localidade de coleta do táxon Myrmotherula assimilis assimilis; portanto, todos os indivíduos coletados restringiam-se a uma área isolada e pertenciam a uma mesma população. A ausência de indivíduos infestados pode ser resultado do isolamento desta população em uma área onde não há presença de parasitas e consequentemente não é possível a transmissão pelo isolamento da área, já que estas aves não costumam transpor barreiras físicas como o rio (ZIMMER; ISLER, 2016). Apesar do número de indivíduos coletados ser significativo para estas aves $(n=7)$, a restrição na área de coleta torna a amostra não representativa para estudos aprofundados sobre ecologia dos parasitas, que necessita ampliação da abrangência geográfica (CONRATHS; STAUBACH; TACKMANN, 2003).

Para as espécies Pygiptila stellaris stellaris e Thamnophilus doliatus radiatus, o número de indivíduos coletados foi restrito a um, não permitindo inferir quais fatores influenciaram a ausência de infestação por helmintos nesta localidade. Ambos os táxons foram coletados em pontos de coleta no continente ( $n=5$ e $n=2$, respectivamente) e também apresentaram infestação negativa para helmintos, apesar de terem sido coletados em pontos onde outros tamnofilídeos foram registrados como hospedeiros de cestódeos, indicando que algum fator na ecologia das aves (e. g. hábitos alimentares) pode ser determinante para a presença de parasitas, independente da área onde este foi amostrado. 


\subsubsection{Machadinho d'Oeste (RO)}

A amostragem para presença de parasitas em Machadinho d'Oeste (RO) ocorreu nos meses de janeiro e fevereiro de 2014, em uma campanha durante a estação chuvosa. Foram coletados 44 espécimes de tamnofilídeos pertencentes a 18 espécies e subespécies, com 15 indivíduos parasitados resultando em prevalência de infestação por cestódeos igual a 34,1\%. A população de tamnofilídeos observada nesta localidade assemelha-se àquela encontrada nos pontos amostrais da margem direita do rio Madeira, exceto pelo registro exclusivo de Clytoctantes atrogularis, Epinecrophylla dentei, Hypocnemis rondoni, Phlegopsis borbae e Rhegmatorhina hoffmannsi. A vegetação na área amostrada assemelha-se àquela encontrada na área de Porto Velho; porém, os impactos ambientais da área ainda eram mínimos no período em que as amostras foram obtidas.

A infestação por cestódeos foi verificada em 15 espécimes pertencentes a 7 táxons, com a maior amostra igual a 5 indivíduos, para Rhegmatorhina hoffmannsi e Willisornis poecilinotus griseiventris. As prevalências observadas diferem de acordo com cada táxon, sendo igual a $80 \%$ para $R$. hoffmannsi, $75 \%$ para $P$. borbae e nula para $W$. poecilinotus, indicando que a exploração de nicho por cada uma destas aves pode ser um fator determinante na sua infestação por cestódeos, uma vez que estes três táxons encontram-se na mesma área e são próximos filogeneticamente, porém apresentam hábitos de forrageamento distintos (BRUMFIELD et al., 2007).

A composição da fauna de cestódeos observada na área de Machadinho d'Oeste (RO) foi diferente daquela amostrada para hospedeiros pertencentes ao mesmo táxon coletados no Centro de Endemismo Rondônia, na área de Porto Velho (RO). Entre todos os táxons de hospedeiros amostrados em ambas as áreas, três apresentaram diversidades e morfotipos distintos de cestódeos compondo sua fauna de helmintos associada em Porto Velho (RO) e Machadinho d'Oeste (RO), Sciaphylax pallens (D19) e (H29, NI05), Thamnomanes saturninus saturninus (M15, P05) e (NI06) e Thamnophilus aethiops punctuliger (M16) e (H33). Apesar da indeterminação genérica e específica dos helmintos, a identificação das famílias aos quais os cestódeos pertencem já permite verificar que populações de áreas distintas diferem em sua composição, indicando que a distribuição destes parasitas não é apenas dependente do táxon ao qual seu hospedeiro pertence, portanto pode ser variável dentro de uma mesma região biogeográfica. 


\subsubsection{Altamira (PA)}

A área de Altamira (PA) foi amostrada em setembro de 2012, durante a estação seca. Os pontos de coleta localizavam-se em ambas as margens do rio Xingu, onde foram coletados 46 espécimes pertencentes a 22 táxons de tamnofilídeos, com uma taxa de prevalência de $37,8 \%$. Esta amostragem foi realizada antes da adequação do protocolo de coleta e fixação de helmintos, sendo composta por poucos indivíduos e não refletindo o potencial número de hospedeiros da localidade. Os tamnofilídeos coletados pertencem, em sua maioria, a espécies comumente encontradas, com Cercomacroides nigrecens, Phlegopsis nigromaculata bowmani e Pyriglena leuconota similis representando $40 \%$ dos hospedeiros amostrados.

A coleta de um número limitado de espécimes para a maioria dos tamnofilídeos na região de Altamira (PA), com número amostral igual a um espécime para 12 dos táxons coletados (55\%) e dois espécimes para 6 deles (27\%), resultou em prevalências iguais a 0 ou $100 \%$, com exceção de Cercomacroides nigrecens $(14 \%, n=7)$ e Phlegopsis nigromaculata bowmani $(60 \%, \mathrm{n}=5)$. Entre os hospedeiros que apresentaram $100 \%$ de indivíduos infestados, apenas os de Pyriglena leuconota similis na região foram coletados em uma amostra considerada representativa, com seis indivíduos provenientes de quatro pontos de coleta distintos, nos quais obteve-se quatro morfotipos de cestódeos pertencentes a três famílias (ANEXO C). Os dados obtidos para C. nigrecens, $P$. nigromaculata bowmani e $P$. leuconota similis indicam que a densidade de helmintos nesta área apresenta maior variação do que a observada para as demais espécies, sugerindo que as prevalências obtidas para grandes regiões não são informativas devido a heterogeneidade das amostras de hospedeiros obtidas.

O esforço amostral para o número de espécimes de tamnofilídeos em cada uma das margens do rio Xingu foi semelhante, com 24 espécimes coletados na margem esquerda, região do interflúvio Tapajós/Xingu, e 22 coletados na margem direita, região do interflúvio Xingu/Araguaia-Tocantins. Observou-se, entretanto, uma discrepância na distribuição e diversidade de cestódeos amostrados, pois dos 13 morfotipos registrados para Altamira (PA), apenas 3 foram obtidos no Centro de Endemismo Xingu, em duas espécies de hospedeiros, Cercomacroides nigrecens (D01) e Myrmoborus myotherinus ochrolaema (D06 
e H11). Para a margem esquerda do rio Xingu, região do interflúvio Tapajós/Xingu, foram registrados 10 morfotipos de cestódeos em 6 táxons de tamnofilídeos, Myrmoborus leucophrys leucophrys (M02), Myrmoborus myotherinus ochrolaema (M03); Phlegopsis nigromaculata bowmani (D11), Pyriglena leuconota similis (H24, H25 e M09), Rhegmatorhina gymnops (H26), Sciaphylax hemimelaena (voucher em etanol não analisado) e Sclateria naevia (H30). A observação de parasitas distintos nas amostras de $M$. myothrinus ochrolaema coletadas em cada uma das margens do rio mostra que a diversidade de cestódeos em um hospedeiro pode ser determinada pela localidade na qual esta foi coletada, assim como a presença de 3 morfotipos de parasitas em $P$. leuconota similis na região Tapajós/Xingu e nenhum em $P$. leuconota interposita na região Xingu/AraguaiaTocantins. Entretanto, não é possível afirmar que a divisão causada pelo rio em duas regiões biogeográficas seja determinante para este padrão, pois a presença de 4 morfotipos de cestódeos em P. leuconota interposita (H22, H23, M10 e N104) amostrados em Santana do Araguaia (PA), região do interflúvio Xingu/Araguaia-Tocantins, indica que a diversidade de cestódeos varia entre localidades de uma mesma região, exigindo que as amostras para estudos de distribuição sejam mais abrangentes geograficamente, assim como observado para os cestódeos coletados no Centro de Endemismo Rondônia. O refino taxonômico dos parasitas é necessário para que estudos mais aprofundados sobre as diferenças das populações, sejam elas provenientes de localidades de uma mesma região biogeográfica ou regiões distintas, possam ser conduzidos.

\subsubsection{Santana do Araguaia (PA)}

A área da Fazenda Fartura (PA) foi visitada em quatro amostragens, entre abril de 2014 e setembro de 2015 (ANEXO B). As coletas realizadas nos meses de fevereiro e abril ocorreram durante a estação chuvosa naquela região, enquanto as campanhas realizadas em agosto e setembro aconteceram durante a estação seca. Ao todo, foram coletados 113 espécimes de tamnofilídeos, pertencentes a 17 táxons. As amostragens foram realizadas em regiões de mata de terra firme, nas quais não foram observadas áreas inundáveis ou inundadas, localizadas em áreas preservadas circundadas por áreas de pastagem de gado. 0 esforço amostral observado para as coletas realizadas na estação seca foi semelhante, com número de indivíduos amostrados próximo (23 e 26) (ANEXO F, Gráfico 2) e de espécimes 
infestados igual (2), porém nas amostragens em estação chuvosa foi observada distinção no número de tamnofilídeos coletados (54 e 11), sem alteração na composição de espécies da amostra (ANEXO B).

A infestação por cestódeos na localidade de Santana do Araguaia (PA) foi observada em 6 espécies de tamnofilídeos, ou 35\% das espécies amostradas. A diversidade de helmintos apresentou variação de acordo com o hospedeiro, pois apenas um morfotipo de cestódeo foi observado parasitando as espécies Isleria hauxwelli hellmayri, Myrmoborus myotherinus ochrolaema e Myrmotherula axillaris axillaris, enquanto dois morfotipos foram observados em Myrmophylax athrotorax melanura e quatro morfotipos de cestódeo foram registrados em Phlegopsis nigromaculata paraensis e Pyriglena leuconota interposita. 0 registro de treze morfotipos de cestódeos na área indica que as formas infestantes destes hospedeiros estão presentes no ambiente e fatores como especificidade parasitária devem influir na sua dispersão, já que espécies de tamnofilídeos como Willisornis vidua vidua, que possui hábitos de forrageamento próximo a Phlegopsis e Pyriglena, foram amostradas exaustivamente $(n=30)$ e não apresentaram nenhuma forma de cestódeo associada.

A prevalência média de infestação por cestódeos verificada em Santana do Araguaia (PA) foi igual a 11,4\%, porém nesta localidade foi observada uma distinção entre os resultados obtidos nas amostragens durante as estações seca e chuvosa. Na estação chuvosa a prevalência média de cestódeos foi igual a $14,6 \%$ e na estação seca igual a 8,2\%, com variação constante durante o período amostrado (ANEXO F, Gráfico 2). Ao contrário do padrão decrescente observado para a região de Porto Velho (RO) (ANEXO F, Gráfico 1), as amostras obtidas em Santana do Araguaia (PA) apresentam uma flutuação em sua prevalência de acordo com a época do ano amostrada, o que pode indicar uma estabilidade no sistema parasita-hospedeiro nesta localidade, com disponibilidade de formas de transmissão constante e pouco influenciadas pelo clima. Assim como a área amostrada em Porto Velho (RO), a paisagem da área estudada na Fazenda Fartura foi modificada por alterações ambientais uma vez que a propriedade foi estabelecida para pastagens na década de 1960, porém a regularidade nas taxas de coleta de hospedeiros e prevalência de cestódeos obtidas indica que a transmissão dos parasitas para novos hospedeiros apresenta maior estabilidade do que aquela observada para a área de Porto Velho. 


\section{CONCLUSÕES}

a. Um total de 81 táxons de Thamnophilidae foi amostrado em busca de cestódeos. Este inventário resultou na coleta de 487 indivíduos de Thamnophilidae, distribuídos nos principais interflúvios e centros de endemismo ao sul da Amazônia brasileira. Este estudo é o levantamento mais extenso do ponto de vista geográfico e temporal já realizado para cestódeos de Aves na América do Sul;

b. As técnicas tradicionais de coleta e amostragem de cestódeos foram aperfeiçoadas levando-se em conta as especificidades de clima e logística características da região amazônica;

c. Nos 487 indivíduos de Thamnophilidae amostrados foram coletados aproximadamente 1.500 indivíduos de cestódeos das famílias Dilepididae, Hymenolepididae, Paruterinidae e Metadilepididae, todas pertencentes à Ordem Cyclophyllidea;

d. Entre os 1.500 indivíduos coletados foram caracterizados 83 morfotipos, que podem representar 83 novas espécies, além de novos gêneros em todas as famílias de Cyclophyllidea encontradas;

e. Os 83 morfotipos foram devidamente caracterizados e ilustrados e serão descritos formalmente em breve;

f. A técnica de Microscopia Eletrônica de Varredura foi utilizada pela primeira vez para caracterizar os táxons da família Dilepididae, mostrando-se informativa na distinção dos morfotipos;

g. As chaves de identificação disponíveis para os representantes das quatro famílias de Cyclophyllidea não são suficientes para permitir a identificação dos táxons encontrados nos Thamnophilidae porque consideram a especificidade dos parasitas a seus hospedeiros, e não eram conhecidos até o momento os parasitas de Thamnophilidae, sendo necessária uma ampla revisão das mesmas;

h. A clássica relação de especificidade parasita-hospedeiro não foi verificada na maioria dos casos, sendo o mais frequente uma relação ecológica entre hábitos alimentares dos hospedeiros e as diferentes famílias de parasitas;

i. Os grandes rios amazônicos não atuam como barreiras para os parasitas, sendo encontrados os mesmos morfotipos em táxons de aves distintos e separados pelos 
rios;

j. A influência das relações ecológicas entre os hospedeiros parece ser um fator mais relevante na distribuição dos parasitas, pois populações de aves em um mesmo interflúvio, oriundas de diferentes localidades, apresentavam uma comunidade de cestódeos muito distinta;

k. A diversidade de cestódeos ainda é extremamente subestimada na região Neotropical, e este impedimento taxonômico dificulta a realização de análises mais aprofundadas, sendo fundamental que a taxonomia esteja mais bem resolvida para os membros desta Classe;

I. Este estudo foi pioneiro na caracterização dos cestódeos parasitas de Thamnophilidae, e abre uma nova e promissora linha de pesquisa nesta área em nada explorada. 


\section{REFERÊNCIAS BIBLIOGRÁFICAS}

ABULADZE, K. I. Taeniata of animals and man and diseases caused by them. In: Essentials of Cestodology. Volume IV. Moscow: Nauka, 1964. 549 pp. [em russo]

ADAMSON, M. L.; CAIRA, J. N. Evolutionary factors influencing the nature of parasite specificity. Parasitology, v. 109, p. S85-S95, 1994.

AGUIAR, G. B. et al. Relato de infecção natural por Raillietina tetragona em pica-pau-docampo (Colaptes campestris) provenientes do município de Afonso Cláudio, Espírito Santo-Brasil. Ciência Veterinária nos Trópicos, v. 14, p. 49-53, 2011.

AGUIAR, K. M. O.; COLTRO JÚNIOR, L. A. Dietas de algumas espécies de aves das Famílias Thamnophilidae, Grallariidae e Formicariidae do Amapá. Revista Brasileira de Ornitologia, v. 16, n. 4, p. 376-379, 2008.

AHERN, W. B.; SCHIMDT, G. D. Parasitic helminths of the American avocet Recurvirostra americana: four new species of the families Hymenolepididae and Acoleidae (Cestoda: Cyclophyllidea). Parasitology, v. 73, p. 381-398, 1976.

ANDERSEN, K. Comparison of surface topography of three species of Diphyllobothrium (Cestoda, pseudophyllidea) by scanning electron microscopy. International Journal for Parasitology, v. 5, n. 3, p. 293-300, 1975.

ARRUDA, V. S.; PINTO, R. M.; MUNIZ-PEREIRA, L. C. New host and geographical records for helminths parasites of Ardeidae (Aves, Ciconiiformes) in Brazil. Revista Brasileira de Zoologia, v. 18, p. 225-232, 2001. Suplemento 1.

ARTYUKH, E. S. Davaineata, cestodes of wild and domestic animals. In: Essentials of Cestodology. Volume V. Moscow: Nauka, 1966. 511 pp. [em russo]

BÂ, C. T.; SENE, T.; MARCHAND, B. Scanning electron microscope examination of scale-like 
spines on the rostellumm of five Davaineinae (Cestoda, Cyclophyllidea). Parasite, v. 2, n. 1, p. 63-67, 1995.

BAER, J. G. Contributions à la faune helminthologique sud-africaine. Note préliminaire. Annals of Parasitology, v. 2, p. 239-247, 1924.

BAER, J. G. Quelques cestodes d'oiseaux nouvex et peu connus. Bulletin de la Société des Science Naturelles de Neuchâtel, v. 49, p. 138-154, 1925.

BAER, J. G. Notes sur les Ténias des autruches. Bulletin de la Société des Science Naturelles de Neuchâtel, v. 52, p. 7-13, 1928.

BAER, J. G. Un genre nouveau de cestodes d'oiseaux. Bulletin de la Société des Science Naturelles de Neuchâtel, v. 62, p. 149-456, 1937.

BAER, J. G. Some avian tapeworms from Antigua. Parasitology, v. 32, p. 174-197, 1940.

BAER, J.G. Otto Fuhrmann. The Journal of Parasitology, v. 32, n.2, p. 205-207, 1946.

BAER, J. G. Revision critique de la sous-famille Idiogeninae Fuhrmann 1932 (Cestodes: Davains. eidae) et étude analytique de la distribution des espèces. Revue Suisse de Zoologie, v. 62S, p. 1-51, 1955

BAER, J. G.; BONA, F. Revision des cestodes Dilepididae Fuhrm., 1907 des Ardéiformes. Note Préliminaire. Bollettino dell'Istituto e museo di zoologia della Università di Torino, v. 6, p. 1-53, 1960.

BASHTAR, A. R. et al. Studies on monieziasis of sheep I. Prevalence and antihelminthic effects of some plant extracts, a light and electron microscopic study. Parasitology Research, v. 108, n. 1, p. 177-186, 2011.

BECKER, B. et al. Scanning and transmission electron microscope studies on the efficacy of 
praziquantel on Hymenolepis nana (Cestoda) in vitro. Zeitschrift für Parasitenkunde, v. 61, n. 2, p. 121-133, 1980.

BELMONTE-LOPES, R. et al. Genetic and morphological data support placement of Myrmotherula gularis (Spix) in the monotypic genus Rhopias Cabanis and Heine (Aves: Passeriformes: Thamnophilidae). Zootaxa, v. 3451, p. 1-16, 2012.

BENESH, D. P.; CHUBB, J. C.; PARKER, G. A. Exploitation of the same trophic link favors convergence of larval life-history strategies in complex life cycle helminths. Evolution, v. 65, n. 8, p. 2286-2299, 2011.

BENESH, D. P.; CHUBB, J. C.; PARKER, G. A. The trophic vacuum and the evolution of complex life cycles in trophically transmitted helminths. Proceedings of the Royal Society B Biological Sciences, $\quad$ v. 281, 2014. Disponível em <http://dx.doi.org/10.1098/rspb.2014.1462>. Acesso em 31 Out. 2016.

BERGER, J; METTRICK, D. F. Microtrichial polymorphism among hymenolepid tapeworms as seen by scanning electron microscopy. Transactions of the American Microscopical Society, v. 90, p. 393-403, 1971.

BERTO, P. B. et al. Coccidial dispersion across trans- and cis-Andean antbirds (Passeriformes: Thamnophilidae): Isospora sagittulae (Apicomplexa: Eimeriidae) from nonsympatric hosts. Canadian Journal of Zoology, v. 92, p. 383-388, 2014.

BEVERIDGE, I. A taxonomic revision of the genera Cittotaenia Riehm, 1881, Ctenotaenia Railliet, 1893, Mosgovoyia Spasskii, 1951 and Pseudocittotaenia Tenora, 1976. (Cestoda: Anoplocephalidae). Mémoires du Muséum National d'Histoire Naturelle v. 107, p. 1-64, 1978.

BEVERIDGE, I. Family Anoplocephalidae. In: KHALIL, L. F.; JONES, A.; BRAY, R. A. Keys to the Cestode Parasite of Vertebrates. Capítulo 17. Wallingford: CAB International, 1994. p. 315-366. 
BIRDLIFE INTERNATIONAL. IUCN Red List for birds. World Wide Web electronic publication. 2012. Disponível em <www.www.birdlife.org >. Acesso em 20. Dez. 2016.

BOERTJE, S. B. Life cycle and host-parasite relationships of Schistotaenia tenuicirrus (Cestoda: Amabiliidae). 1966. 110p. Tese (Doutorado em Filosofia, área de concentração Parasitologia). lowa State University, lowa, E.U.A., 1966.

BONA, F. V. Etude critique et taxonomique des Dilepididae Fuhrm., 1907 (Cestoda) parasites de Ciconiiformes. Considérations sur la specificité et la spéciation. Monitore Zoologico Italiano N.S. Monografia 1, 1975. 750 p.

BONA, F. V. The genus Clelandia Johnston, 1909 and its affinities with Parvitaenia and Neogryporhynchus (Cestoda, Dilepididae). Annales de Parasitologie Humaine et Comparée, v. 53, p. 163-180, 1978.

BONA, F. V. Three new species and genera of Dilepididae (Cestode, Cyclophyllidea) from Neotropical Picidae (Aves). Revue Suisse de Zoologie, v. 101, p. 195-213, 1994.

BONA, F. V. Family Dilepididae. In: KHALIL, L. F.; JONES, A.; BRAY, R. A. Keys to the Cestode Parasite of Vertebrates. Capítulo 25. Wallingford: CAB International, 1994. p. 443-554.

BONA, F. V.; BOSCO, M. C.; MAFFI, A. Tre nuove specie del genere Paruterina (Cestoda, Paruterinidae) in Trogoniformi (Aves) neotropicali. Bolletino del Museo Regionale de Scienze Naturali, v. 4, p. 1-61, 1986.

BONA, F. V.; MAFFI, A. La estructura del genero Paruterina Fuhrm., 1906, y consideraciones sobre los generos Biuterina Fuhrm. 1902, Proparuterina Fuhrm. 1911 y Sphaeruterina Johnston, 1914 (Cestoda Paruterinidae). Bolletino del Museo Regionale de Scienze Naturali, v. 2, p. 411-444, 1984a.

BONA, F. V.; MAFFI, A. Paruterina similita n. sp. (Cestoda, Paruterinidae) em Cuculidae (Aves) 
del Norte de Argentina. Bolletino del Museo Regionale de Scienze Naturali, v. 2, p. 181$198,1984 b$.

BONA, F. V.; MAFFI, A. Los Paruterinidae (Cestoda) con ganchos de patron 'rectanguloide'. Parte I. Observaziones sobre los ganchos rectanguloides y revision de la literatura. Bolletino del Museo Regionale de Scienze Naturali, v. 5, p. 455-489, 1987.

BONDARENKO, S; KONTRIMAVICHUS, V. Life cycle of the cestode Wardium calumnacantha (Schmidt, 1963) comb.n. (Hymenolepididae) from common snipe, Gallinago gallinago (L). Folia Parasitologica, v. 25, p. 35-39, 1978.

BONDARENKO, S; KONTRIMAVICHUS, V. Life-cycles of cestodes of the genus Branchiopodataenia Bondarenko \& Kontrimavichus, 2004 (Cestoda: Hymenolepididae) from gulls in Chukotka. Systematic Parasitology, v. 57, p. 191-199, 2004.

BONDARENKO, S; KONTRIMAVICHUS, V. Aploparaksis kornyushini n. sp. (Cestoda: Hymenolepididae), a parasite of the woodcock Scolopax rusticola (L.), and its life-cycle. Systematic Parasitology, v. 63, p.45-52, 2006 a.

BONDARENKO, S. K.; KONTRIMAVICHUS, V. L. Aploparaksidae of wild and domesticated birds. In: MOVSESYAN, S. O. (Ed.) Essentials of Cestodology. Volume XIV. Moskow: Nauka, 2006b. 433 p. [em russo]

BONDARENKO, S. K.; KONTRIMAVICHUS, V. L.; VAUCHER, C. Revision of Aploparaksis crassirostris and A. sinensis (Cestoda: Hymenolepididae). Parazitologiia, v. 36, n. 12, p. 117-131, 2002. [em russo]

BOYCE, N. P. A new organ in cestode surface ultrastructure. Canadian Journal of Zoology, v. 54, n. 4, p. 610-613, 1976.

BRASIL, M. C.; AMATO, S. B. Faunistic analysis of the helminths of sparrows (Passer domesticus L., 1758) captured in Campo Grande, Rio de Janeiro, RJ. Memórias do 
Instituto Oswaldo Cruz, v. 87, p. 43-48, 1992. Suplemento I.

BRAVO, G. A. et al. DNA sequence data reveal a subfamily-level divergence within Thamnophilidae (Aves: Passeriformes). Molecular Phylogenetics and Evolution, v. 65, p. 287-293, 2012.

BRAVO, G. A.; CHESSER, R. T.; BRUMFIELD, R. T. Isleria, a new genus of antwren (Aves: Passeriformes: Thamnophilidae). Zootaxa, v. 3195, p. 61-67, 2012.

BRUMFIELD, R. T. et al. Phylogenetic conservatism and antiquity of a tropical specialization: Army-ant-following in the typical antbirds (Thamnophilidae). Molecular Phylogenetics and Evolution, v. 45, p. 113, 2007.

BURT, D. R. R.; BURT, M. D. B. On Davainea minuta Cohn, 1901 (Cestoda: Cyclophyllidea) and its variation on North American Recurvirostridae (Aves). Journal of Natural History, v. 18, p. 15-23, 1984.

BUSH, A. O. et al. Parasitism: The Diversity and Ecology of Animal Parasites. Cambridge: Cambridge University Press, 2001. 576 p.

BUZZETTI, D. R. C. et al. A new species of Formicivora Swainson, 1824 (Thamnophilidae) from the state of São Paulo, Brazil. Revista Brasileira de Ornitologia, v. 21, n.4, p. 269-291, 2013.

CAIRA, J. N. et al. Orders out of chaos--molecular phylogenetics reveals the complexity of shark and stingray tapeworm relationships. International Journal for Parasitology, v. 44, n. 1 , p. $55-73,2014$

CAIRA, J. N.; JENSEN, K.; BARBEAU, E. (Ed.). Global Cestode Database. World Wide Web electronic publication. 2012. Disponível em <www.tapewormdb.uconn.edu>. Acesso em 31 Out. 2016. 
CAIRA, J. N.; LITTLEWOOD, D. T. J., Worms, Platyhelminthes. In: LEVIN, S.A. (Ed.), Encyclopedia of Biodiversity, 2 ed, volume 7. San Diego: Elsevier, 2013. p. 437-469.

CAIRA, J. N.; MEGA, J.; RUHNKE, T. R. An unusual blood sequestering tapeworm (Sanguilevator yearsleyi n. gen., n. sp.) from Borneo with description of Cathetocephalus resendezi n. sp. from Mexico and molecular support for the recognition of the order Cathetocephalidea (Platyhelminthes: Eucestoda). International Journal for Parasitology, v. 35, p. 1135-1152, 2005.

CAPOOR, V. N.; SRIVASTAVA, V. C. On a new dioecious cestode Hymenocoelia chauhani n. g., n. sp. From the Inadian pigeon Columba livia (Gmelin) with diagnosis on the new sunfamily Hymenocoelinae and the key to the family Dioecoscestidae Southwell, 1930. Journal of the Zoological Society of India, v. 16, p. 99-104, 1966.

CAPOOR, V. N.; SRIVASTAVA, V. C. On a synonymity of the genus Columbia Srivastava \& Capoor, 1966 with Killigrewia Meggit, 1927 and on a new combination Killigrewia allahabadi n. comb. and with its redescription. Journal of the Zoological Society of India, v. 17, p. 123-124, 1967.

CAPOOR, V. N.; SRIVASTAVA, V. C. On a new cestode, Barbusa passeri n.g., n. sp., (Cestoda: Davaineidae) from Passer domesticus from India along with provisional definition of a new tribe Barbuseini n. tribe. Proceedings of the National Academy of India 45B, v. II, p. 101-104, 1975.

CHERTKOVA A.N.; KOSUPKO G.A. Suborder Mesocestoidata Skrjabin, 1940. In: RYZHIKOV, K.M. (Ed.), Essentials of Cestodology. Volume IX. Moskow: Nauka, 1978. p. 118-229. [em russo]

CHERVY, L. Unified terminology for cestode microtriches: a proposal from the International Workshop on Cestode Systematics in 2002-2008. Folia Parasitologica, v. 56, p. 199-230, 2009. 
CONN, D, B. Scanning electron microscopy and histochemistry of embryonic envelopes of the porcupine tapeworm, Monoecocestus americanus (Cyclophyllidea: Anoplocephalidae). Canadian Journal of Zoology, v. 63, n. 5, p. 1194-1198, 1985.

CONRATHS, F. J.; STAUBACH, C.; TACKMANN, KIRSTEN. Statistics and sample design in epidemiological studies of Echinococcus multilocularis in fox populations. Acta Tropica, v. 85, p. 183-189, 2003.

COURA, J. R. The scientific production and international reputation of Lauro Travassos. Memórias do Instituto Oswaldo Cruz, v.87, n. 1, p. VII-X, 1992.

CRACRAFT, J. Historical biogeography and patterns of differentiation within the South American avifauna: areas of endemisms. Ornithological Monographs, v. 36, p. 49-84, 1985.

CZAPLINSKI, B.; VAUCHER, C. Family Hymenolepididae. In: KHALIL, L. F.; JONES, A.; BRAY, R. A. Keys to the Cestode Parasite of Vertebrates. Capítulo 29. Wallingford: CAB International, 1994. p. 595-664.

DEL HOYO, J. et al. (Ed.), Handbook of the Birds of the World. 17 Volumes. Barcelona: Lynx Editions, 2010. 13367 p.

DELYAMURE, S. L.; SKRYABIN, A. S.; SERDYUKOV, A. M. Diphyllobothriids - cestodes of man, mammals and birds. In: RYZHIKOV, K. M. (Ed.) Essentials of Cestodology. Volume XI. Moskow: Nauka, 1985. 198 p. [em russo]

DIAS, A. A. S. R. et al 1990. Lauro Travassos (1890-1990): Bibliografia. Fundação Oswaldo Cruz, Biblioteca de Manguinhos, 1990. 142 p.

DIESING, K. M. Systema Helminthum. Viena: Ed. Cramer, 1850. 670 p. 
Akademie der Wissenschaften Wien Mathematisch-Naturwissenschaftiche Klasse, Abteilung I, v. 13, p. 555-616, 1854.

DIMITROVA, Y. D.; MARIAUX, J.; GEORGIEV, B. B. Pseudangularia gonzalezi n. sp. and Gibsonilepis swifti (Singh, 1952) n. g., n. comb. (Cestoda, Dilepididae) from the House Swift, Apus affinis (JE Gray) (Aves, Apodiformes) from Franceville, Republic of Gabon. Systematic Parasitology, v. 86, p. 215-236, 2013.

DIXIR, G R.; CAPOOR, V. N. A new cestode Sternolepis contri n. g., n. sp. (Cestoda: Hymenolepididae Railliet et Henry, 1909) from Sternus contra (Linn.) from Allahabad, India. Indian Journal of Helminthology, v. 40, p. 130-134, 1988.

DUJARDIN, F. Histoire Naturelle des Helminthes ou Vers Intestinaux. Paris: Librairie Encyclopédique de Roret, 1845. $654+12$ p.

DURÃES, R.; MARINI, M. A. A Quantitative Assessment of Bird Diets in the Brazilian Atlantic Forest, with Recommendations for Future Diet Studies. Ornitologia Neotropical, v. 16, n. 1, p. 65-84, 2005.

EDLER, F. C. 2011. A Medicina no Brasil Imperial: clima, parasitas e patologia tropical. Rio de Janeiro: Editora FIOCRUZ, 2011. 298 p.

FORONDA, P. et al. Molecular systematics of several cyclophyllid families (Cestoda) based on the analysis of 18 S ribosomal DNA gene sequences. Parasitology Research, v. 93, p. 279282, 2004.

FREEMAN, R. S. Life cycle and morphology of Paruterina rauschi n. sp. and P. candelabria (Goeze, 1792) (Cestoda) from owls, and significance of plerocercoids in the order Cyclophyllidea. Canadian Journal of Zoology, v. 32, n. 3, p. 349-370, 1957.

FREEMAN, R. S. On the taxonomy of the genus Cladotaenia, the life histories of $C$. globifera (Batsch, 1758) and C. circi Yamaguti, 1935, and a note on distinguishing between the 
plerocercoids of the genera Paruterina and Cladotaenia. Canadian Journal of Zoology, v.37, n. 3, p. 317-340, 1959.

FREEZE, V. I. Proteocephalata in Fish, amphibians and reptiles. In: Essentials of Cestodology. Volume V. Moscow: Nauka, 1965. 538 pp. [em russo]

FREITAS, J. F. T. Sobre um interessante nematódeo parasito de réptil (Spiruroidea). Memórias do Instituto Oswaldo Cruz, v. 35, n. 3, p. 603-605, 1940.

FREITAS, J. F. T. Contribuição para o Inventário Crítico da Zoologia no Brasil. Fauna Helmintológica: I. Nematódeos Parasitos de Vertebrados - II. Trematódeos. Publicações Avulsas do Museu Nacional, ed. 47, p. 1-11, 1964.

FUHRMANN, O. Neue Anoplocephaliden der Vögel (Vorläufige Mitteilung). Zoologischer Anzeiger, v. 27, p. 384-388, 1904.

FUHRMANN, O. Die Tänien der Raubvögel. Centralblatt für Bakteriologie, Parasitenkunde und Infektionskrankheiten, v. 41, p. 79-89, 1906a.

FUHRMANN,O. Die Tänien der Raubvögel. Centralblatt für Bakteriologie, Parasitenkunde und Infektionskrankheiten, v.41, p. 212-221, $1906 \mathrm{~b}$.

FUHRMANN, O. Bekannte und neue Arten und Genera von Vogeltänien. Centralblatt für Bakteriologie, Parasitenkunde und Infektionskrankheiten, v. 45, p. 516-536, 1907a.

FUHRMANN, O. Die Systematik der Ordnung der Cyclophyllidea. Zoologischer Anzeigner, v. 32 , p. 289-297, $1907 b$.

FUHRMANN, O. Die Cestoden der Vögel. Zoologische Jahrbücher, p. 1-232, 1908a. Suplemento 10.

FUHRMANN, O. Das Genus Anonchotaenia und Biuterina. Centralblatt für Bakteriologie, 
Parasitenkunde und Infektionskrankheiten, v. 48, p. 412-428, $1908 \mathrm{~b}$.

FUHRMANN, O. Nouveaux Ténias d'Oiseaux. Revue Suisse de Zoologie, v.16, p. 27-74, 1908c.

FUHRMANN, O. Die Cestoden der Vögel des weissen Nils. In: JÄGERKIÖLD, L. A. Results of Swedish Zoological Expedition to Egypt and the White Nile, 1901, volume III. Uppsala: The Library of the Royal University of Uppsala, 1909. 506p.

FUHRMANN, O. Vogelcestoden der Aru-Inseln. Abhandlungen der senckenbergischen naturforschenden Gesellschaft, v. 34, p. 251-266, 1911.

FUHRMANN, O. Vogelcestoden, Nova Guinea. Résultats de l'expedition scientifique néerlandaise à la Nouvelle Guinée, 1910. Zoologie, v. 9, p. 467-470, 1913.

FUHRMANN, O. Cestodes des oiseaux de la Nouvelle-Calédonie et des lles Loyalty. Nova Caledonia, v. 2, p. 399-449, 1918.

FUHRMANN, O. Considérations générales sur les Davainea. Festschrift fü Zschokke Bale, 1920. $19 \mathrm{p}$.

FUHRMANN, O. Die Cestoden der Deutschen Südpolar Expedition, 1901-1903. Zoologie, v. 8, p. 469-524, 1920.

FUHRMANN, O. Brasilianische Cestoden aus Reptilien und Vögeln. Abhandlungen der Senckenbergischen Naturforschenden Gesellschaft, v. 40, p. 389-401, 1927.

FUHRMANN, O. Les Ténias des Oiseaux. Mémories de l'Université de Nuchâtel, v. 8, p. 1383, 1932.

FUHRMANN, O. Un singulier Ténia d'oiseaux, Gynandrotaenia stanmeri n.g., n. sp. Annals of Parasitology, v. 14, p. 261-271, 1936. 
GEORGIEV, B. B. et al. The genus Biuterina Fuhrmann, 1902 (Cestoda, Paruterinidae) in the Old World: Redescriptions of four species from Afrotropical passeriformes. Systematic Parasitology, v. 52, p. 111-128, 2002.

GEORGIEV, B. B. et al. The genus Biuterina Fuhrmann, 1902 (Cestoda, Paruterinidae) in the Old World: Redescriptions of three species from Palaearctic Passeriformes. Systematic Parasitology, v. 57, p. 67-85, 2004.

GEORGIEV, B. B. et al. Larval helminths in the invasive American brine shrimp Artemia franciscana throughout its annual cycle. Acta Parasitologica, v. 59, n. 3, p. 380-389, 2014.

GEORGIEV, B. B.; BRAY, R. A.; LITTLEWOOD, D. T. J. Cestodes of small mammals: taxonomy and life cycles. In: MORAND, S.; KRASNOV, B. R.; POULIN, R. (Ed). Micromammals and Macroparasites: From Evolutionary Ecology to Management. Tokyo: Springer, 2006. p. 29-60.

GEORGIEV, B. B.; GARDNER, S. L. New species of Cinclotaenia Macy, 1973 (Cyclophyllidea : Dilepididae) from Cinclus leucocephalus Tschudi (Passeriformes: Cinclidae) in Bolivia. Journal of Parasitology, v. 90, n. 5, p. 1073-1084, 2004.

GEORGIEV, B. B.; GENOV, T. Redescription of the type-species of the cestode genus Deltokeras (Cyclophyllidea: Paruterinoidea). Folia Parasitologica, v. 45, p. 44-46, 1998.

GEORGIEV, B. B.; GIBSON, D. I. Description of Triaenorhina burti n. sp. (Cestoda: Paruterinidae) from the Malabar trogon Harpactes fasciatus (Pennant) (Aves: Trogoniformes: Trogonidae) in Sri Lanka. Systematic Parasitology, v. 63, n. 1, p. 51-58, 2006.

GEORGIEV, B. B.; KORNYUSHIN, V. V. Family Paruterinidae. In: KHALIL, L. F.; JONES, A.; BRAY, R. A. Keys to the Cestode Parasite of Vertebrates. Capitulo 27. Wallingford: $C A B$ International, 1994. p. 559-584. 
GEORGIEV, B. B.; MARIAUX, J. Cestodes of the genus Biuterina Fuhrmann, 1902 (Cyclophyllidea: Paruterinidae) from passeriform and piciform birds in the Ivory Coast, with a key to the species of the genus. Revue suisse de zoologie; annales de la Société zoologique suisse et du Muséum d'histoire naturelle de Genève, v. 114, p. 114-174, 2007.

GEORGIEV, B. B.; VASILEVA, G.P. Dendrometra ginesi Jordano and Diaz-Ungria, 1956 transferred to Orthoskrjabinia Spasskii, 1947 (Cestoda: Paruterinidae). Helminthologia, v. 38, p. 145-149, 2001.

GEORGIEV, B. B.; VAUCHER, C. Chimaerula bonai sp n. (Cestoda : Dilepididae) from the barefaced ibis, Phimosus infuscatus (Lichtenstein) (Aves : Threskiornithidae) in Paraguay. Folia Parasitologica, v. 47, n. 4, p. 303-308, 2000.

GEORGIEV, B. B.; VAUCHER, C. Revision of the genus Parvirostrum Fuhrmann, 1908 (Cestoda, Cyclophillidea, Paruterinidae). Systematic Parasitology, v. 50, p. 13-29, 2001.

GEORGIEV, B. B.; VAUCHER, C. Revision of the Metadilepididae (Cestoda: Cyclophyllidea) from Caprimulgiformes (Aves). Revue suisse de zoologie; annales de la Société zoologique suisse et du Muséum d'histoire naturelle de Genève, v. 110, p. 491-532, 2003.

GEORGIEV, B. B.; VAUCHER, C. Arlenelepis harpiprioni gen. et sp. n. (Cestoda: Dilepididae) from Harpiprion caerulescens (Vieillot) (Aves: Threskiornithidae) in Paraguay. Folia Parasitologica, v. 51, n. 4, p. 327-332, 2004.

GOELDI, E. A. Johannes von Natterer. Boletim do Museu Paraense de História Natural e Ethnographia, v. I, n. 3, p. 189-217, 1895.

GOEZE, J. A. E. Versuch einer Naturgeschichte der Eingeweidewürmer thierischer Körper. Blakenburg, 1792. $471+44 \mathrm{p}$. 
GOMES, V. S. M.; ALVES, V. S.; RIBEIRO, J. R. I. Itens alimentares encontrados em amostras de regurgitação de Pyriglena leucoptera (Vieillot) (Aves, Thamnophilidae) em uma floresta secundária no Estado do Rio de Janeiro. Revista Brasileira de Zoologia, v. 18, n. 4, p. 1073-1079, 2001.

GULYAEV, V. D.; VASILEVA, G. P.; KONYAEV, S. V. Redescription of Diporotaenia colymbi Spasskaya, Spassky et Borgarenko, 1971 (Cestoda, Cyclophyllidea, Schistotaeniidae) and amended diagnoses of Diporotaenia Spasskaya, Spassky et Borgarenko, 1971 and Diporotaeniinae Ryzhikov et Tolkacheva, 1975. Acta Parasitologica, v. 55, n. 4, p. 340-348, 2010.

HALAJIAN, A. et al. Gastrointestinal Helminths of Magpies (Pica pica), Rooks (Corvus frugilegus) and Carrion Crows (Corvus corone) in Mazandaran Province, North of Iran. Iranian Journal of Parasitology, v. 6, n. 2, p. 38-44, 2011.

HALTON, D. W. Nutritional Adaptations to Parasitism within the Platyhelminthes. International Journal for Parasitology, v. 27, n.6, p. 693-704, 1997.

HAUKISALMI, V. Checklist of tapeworms (Platyhelminthes, Cestoda) of vertebrates in Finland. ZooKeys, v. 533, p. 1-61, 2015.

HEALY, C. J. et al. Proposal for a new tapeworm order, Rhinebothriidea. International Journal for Parasitology, v. 39, p. 497-511, 2009.

HELLMAYR, C. E.; CONOVER, B. Catalogue of birds of the Americas and the adjacent islands in Field Museum of Natural History. Chicago: Field Museum Press, 1918-1948. XI volumes.

HESS, E; GUGGENHEIM, R. A study of the microtriches and sensory processes of the tetrathyridium of Mesocestoides corti Hoeppli, 1925, by transmission and scanning electron microscopy. Zeitschrift für Parasitenkunde, v. 53, n. 2, p. 189-199, 1977. 
HOBERG, E. P. Order Tetrabothriidea. In: KHALIL, L. F.; JONES, A.; BRAY, R. A. Keys to the Cestode Parasite of Vertebrates. Capítulo 14. Wallingford: CAB International, 1994. p. 295-304.

HOBERG, E. P. et al. Phylogeny of the Orders of the Eucestoda (Cercomeromorphae) Based on Comparative Morphology: Historical Perspectives and a New Working Hypothesis. Journal of Parasitology, v. 83, n. 6, p. 1128-1147, 1997.

HOBERG, E. P.; JONES, A.; BRAY, R. A. Phylogenetic analysis among the families of the Cyclophyllidea (Eucestoda) based on comparative morphology, with new hypotheses for co-evolution in vertebrates. Systematic Parasitology, v. 42, p. 51-73, 1999.

HOBERG, E. P; MARIAUX, J. BROOKS, D. R. Phylogeny among orders of the Eucestoda (Cercomeromorphae): integrating morphology, molecules and total evidence. In: LITTLEWOOD, D. T. J.; BRAY, R. A. Interrelationships of the Platyhelminthes, Londres e Nova lorque: Taylor \& Francis, 2001. p. 112-126.

IRESTEDT, M. et al. Systematic relationships and biogeography of the tracheophone suboscines (Aves: Passeriformes). Molecular Phylogenetics and Evolution, v. 23, p. 499$512,2002$.

ISLER, M. L.; BRAVO, G. A. ; BRUMFIELD, R. T. Taxonomic revision of Myrmeciza (Aves: Passeriformes: Thamnophilidae) into 12 genera based on phylogenetic, morphological, behavioral, and ecological data. Zootaxa, v. 3717, n.4, p. 469-497, 2013.

ISLER, M. L.; BRAVO, G. A.; BRUMFIELD, R. T. Inundicola Bravo, Isler, and Brumfield 2013 is a junior synonym of Akletos Dunajewski 1948 (Aves: Passeriformes: Thamnophilidae). Zootaxa, v. 3779, n. 3, p. 399-400, 2014a.

ISLER, M. L.; BRAVO, G. A.; BRUMFIELD, R. T. Systematics of the obligate ant-following clade of antbirds (Aves: Passeriformes: Thamnophilidae). The Wilson Journal of Ornithology, v. 
126, n. 4, p. 635-648, 2014b.

IVANOV, V. Orygmatobothrium spp. (Cestoda: Tetraphyllidea) from Triakid Sharks in Argentina: Redescription of Orygmatobothrium schmittii and Description of a New Species. The Journal of Parasitology, v. 94, n. 5, p. 1087-1097, 2008.

JENSEN K. A Monograph on the Lecanicephalidea (Platyhelminthes, Cestoda). Tapeworms of Elasmobranchs Part I. Lincoln, Nebraska: University of Nebraska State Museum, 2005. $241 \mathrm{p}$.

JOHNSTON, T, H.; CLARCK, H. G. A new cestode, Raillietina (R.) leipoae, from the mallee hen, Records of the South Australian Museum, v. 9, p. 87-91, 1948.

JONES, A. Proteocephalus pentastoma (Klaptocz, 1906) and Polyonchobothrium polyptery (Leydig, 1853) from species of a Polypterus Geoffroy, 1802 in the Sudan. Journal of Helminthology, v. 54, p. 25-38, 1980.

JONES, A. A redescription of Triuterina anoplocephaloides (Fuhrmann, 1902) Cestoda: Anoplocephalidae) from African parrots. Systematic Parasitology, v. 4, p. 253-255, 1982.

JONES, A. Family Dioecocestidae. In: KHALIL, L. F.; JONES, A.; BRAY, R. A. Keys to the Cestode Parasite of Vertebrates. Capítulo 22. Wallingford: CAB International, 1994a. p. 391-398.

JONES, A. Family Amabiliidae. In: KHALIL, L. F.; JONES, A.; BRAY, R. A. Keys to the Cestode Parasite of Vertebrates. Capítulo 23. Wallingford: CAB International, 1994b. p. 399-406.

JONES, A.; BRAY, R. A. Family Devaineidae. In: KHALIL, L. F.; JONES, A.; BRAY, R. A. Keys to the Cestode Parasite of Vertebrates. Capítulo 24. Wallingford: CAB International, 1994. p. 407-442.

JONES, A.; KHALIL, L. F. The helminth parasites of the lesse flamingo, Phoeniconais miner (Geoffroy), from Lake Nakuro, Kenya, including a new cestode, Phoenicolepis nakurensis 
n. g., n. sp. Systematic Parasitology, v. 2, p. 61-76, 1980.

JONES, A.; KHALIL, L. F. Pluviataenia kassalensis n.g., n.sp. (Davaineidae), a new cestode from the Egyptian plover Pluavianus aegyptius (L) in the Sudan. Systematic Parasitology, v. 22, p. 205-213, 1992.

JOYEUX, C; BAER, J. G. Sur quelques cestodes de la région d'Entebbé (Uganda). Annals of Parasitology, v. 6, p. 179-181, 1928.

KHALIL, L. F. Family Acoleidae. In: KHALIL, L. F.; JONES, A.; BRAY, R. A. Keys to the Cestode Parasite of Vertebrates. Capítulo 21. Wallingford: CAB International, 1994a. p. 387-390.

KHALIL, L. F. Family Acoleidae. In: KHALIL, L. F.; JONES, A.; BRAY, R. A. Keys to the Cestode Parasite of Vertebrates. Capítulo 20. Wallingford: CAB International, 1994b. p. 381-386.

KHALIL, L. F.; JONES, A.; BRAY, R. A. Keys to the Cestode Parasite of Vertebrates. Wallingford: CAB International, 1994. 768 p.

KNOFF, M. et al. Coleção Helmintológica do Instituto Oswaldo Cruz (CHIOC). In: LAMONTHEARGUMEDO, R. et al (Ed). Guide of Helminthological Collections of Latin America. Buenos Aires: Universidad Nacional de La Plata, 2010. 62 p.

KOHN, A.; FERNANDES, B. M. M. Sobre a validade das espécies pertencentes ao gênero Prosthogonimus Luehe, 1899, da Coleção Helmintológica do Instituto Oswaldo Cruz. Memórias do Instituto Oswaldo Cruz, v. 70, n. 3, p. 69-94, 1972.

KOMISAROVAS, J.; GEORGIEV, B. B. Redescriptions of Monosertum parinum (Dujardin, 1845) and M. mariae (Mettrick, 1958) n. comb. from European passerine birds, with an amended generic diagnosis of Monosertum Bona, 1994 (Cestoda: Dilepididae). Systematic Parasitology, v. 66, n. 1, p. 43-53, 2007. 
(Dujardin, 1845) and M. albani (Mettrick, 1958) n. comb. (Cestoda : Dilepididae) from European passerine birds. Systematic Parasitology, v. 68, n. 2, p. 87-96, 2007.

KORNIENKO, S. A. et al. Neoskrjabinolepis nuda n. sp. from shrews on Sakhalin Island, Russia, with a taxonomic review of Neoskrjabinolepis Spasskii, 1947 (Cestoda: Cyclophyllidea: Hymenolepididae). Systematic Parasitology, v. 70, n. 2, p. 148-158, 2008.

KORNYUSHIN, V. V. et al. Spiniglans sharpiloi sp. n. (Cestoda, Dilepididae), a parasite of the Common Magpie, Pica pica, in the Palaearctic. Vestnik Zoologii, p. 85-93, 2009. Suplemento n. 23.

KORNYUSHIN, V. V.; GEORGIEV, B. B. Family Metadilepididae. In: KHALIL, L. F.; JONES, A.; BRAY, R. A. Keys to the Cestode Parasite of Vertebrates. Capítulo 28. Wallingford: $C A B$ International, 1994a. p. 443-554.

KRABBE, H. Bidrag til Kundskab Fuglenes Baendelorme. Copenhagen: Lundos. 1869. 120 p.

KRASNOV, B. R.; POULIN, R. Relationships between parasite diversity and host diversity. In: Parasite Diversity and Diversification: Evolutionary Ecology Meets Phylogenetics. MORAND, S.; KRASNOV, B.R.; LITTLEWOOD, D. T. J (Ed.). Cambridge: Cambridge University Press, 2015. p. 27-38.

KUCHTA, R. et al. Suppression of the tapeworm order Pseudophyllidea (Platyhelminthes: Eucestoda) and the proposal of two new orders, Bothriocephalidea and Diphyllobothriidea. International Journal for Parasitology, v. 38, p. 49-55, 2008.

KUPRIYANOV, V. M. S. Análise de conteúdo estomacal de aves Furnariida (Passeriformes). 2013. Dissertação (Mestrado em Ciências, Área Zoologia). Instituto de Biociências, Universidade de São Paulo, São Paulo, Brasil, 2013.

LANGERON, M. Prècis de Microscopie. 7 ed. Paris: Masson \& Cie, 1949. 429 p. 
LINTON, E. Notes on Cestodes parasites of Birds. Proceedings of U.S. National Museum, v. 70, n. 7, p. 1-90, 1927.

LITERÁK, I. et al. First record of metacestodes of Mesocestoides sp. in the common starling (Sturnus vulgaris) in Europe, with an 18S rDNA characterisation of the isolate. Folia Parasitologica, v. 51, n. 1, p. 45-49, 2004.

LITTLEWOOD, D. T. J. et al. Phylogeny of the Platyhelminthes and the Evolution of parasitism. Biological Journal of the Linnean Society, v. 68, p. 257-287, 1999.

LITTLEWOOD, D. T. J.; BRAY, R. A.; WAESCHENBACH, A. Phylogenetic patterns of diversity in cestodes and trematodes. In: Parasite Diversity and Diversification: Evolutionary Ecology Meets Phylogenetics. MORAND, S.; KRASNOV, B.R.; LITTLEWOOD, D. T. J (Ed.). Cambridge: Cambridge University Press, 2015. p. 304-319.

LITTLEWOOD, D. T. J.; ROHDE, K.; CLOUGH, K. A. The interrelationships of all major groups of Platyhelminthes: phylogenetic evidence from morphology and molecules. Biological Journal of the Linnean Society, v. 66, p. 5-114, 1999.

LONG, J.; GORDON, M. S. The Greatest Step in Vertebrate History: A Paleobiological Review of the Fish-Tetrapod Transition. Physiological and Biochemical Zoology, v. 77, n. 5, p. 700-719, 2004.

LOPES, L. E.; FERNANDES, A. M.; MARINI, M. A. Predation on vertebrates by neotropical passerine birds. Lundiana, v. 6 p. 57-66, 2005.

LOSS-FRANK, B. Mesocestoides leptothylacus n. sp. and the problem of nomenclature in the genus Mesocestoides Vaillant, 1863 (Cestoda, Mesocestoididae). Tropenmedizin und Parasitologie, v. 31, n.1, p. 2-14. 1980. [em alemão]

LUChetTI, N. M.; MARQUeS, F. P. L.; CHERVET-ALMEIDA, P. A new species of Potamotrygonocestus Brooks \& Thorson, 1976 (Eucestoda: Tetraphyllidea) from 
Plesiotrygon iwamae Rosa, Castello \& Thorson (Mylliobatoidea: Potamotrygonidae) and a redescription of Potamotrygonocestus chaoi Marques, Brooks \& Araujo, 2003. Systematic Parasitology, v. 70, p. 131-145, 2008.

LUCHETTI, N. M.; SILVEIRA, L. F. Reconhecimento, identificação e preservação de helmintos parasitas de aves em campo. In: XXI Congresso Brasileiro de Ornitologia, 2014, Rio de Janeiro. XXI Congresso Brasileiro de Ornitologia: Livro de resumos: "A Ornitologia como ciência", 2014, p. 164.

LUNASCHI, L. I.; DRAGO, F. B. Digenean parasites of the great antshrike, Taraba major (Aves: Thamnophilidae), from Argentina, with a description of a new species of the genus Strigea (Strigeidae). Folia Parasitologica, v. 60, n. 4, p. 331-338, 2013.

MACHADO, R. Z. et al. Helminth parasites of Gallus gallus domesticus from the municipality of Jaboticabal, São Paulo, Brazil. Arquivos da Escola de Veterinária da Universidade Federal de Minas Gerais, v. 32, n. 2, p. 241-243, 1980.

MACHADO FILHO, D. A. Pesquisas helmintológicas realizadas no Estado de Mato Grosso Acanthocephala. Memórias do Instituto Oswaldo Cruz, v. 35, n. 3, p. 593-601, 1940.

MACKIEWICZ, J.S. Cestode transmission patterns. Journal of Parasitology, v. 74, p.60-71, 1988.

MAGALHÃES, P. S. Notes d'helminthologie brésilienne 8. Deux nouveaux ténias de la poule domestique. Archives de Parasitologie, v. 1, p. 442-449, 1898.

MAJOR, R. E. Stomach Flushing of an Insectivorous Bird - an Assessment of Differential Digestibility of Prey and the Risk to Birds. Australian Wildlife Research, v. 17, n. 6, p. 647657, 1990.

MALEK, M; CAIRA, J. N.; HASELI, M. Two new species of Paraorygmatobothrium Ruhnke, 1994 (Cestoda: Tetraphyllidea) from the carcharhinid shark Carcharhinus cf. dussumieri 
(Müller \& Henle) in the Persian Gulf. Systematic Parasitology, v. 76, n. 1, p. 59-68, 2010.

MARCGRAVE, G. Historiae rerum naturalium Brasiliae. Amsterdam: Lungdunum Batavorum, 1648. 292 p.

MARIAUX, J. Cestodes of birds from the Ivory Coast. Yapolepis yapolepis n. g., n. sp., a new Metadilepididae (Cyclophyllidea: Paruterinoidea) parasite of the icterine greenbul (Aves: Pycnonotidae). Systematic Parasitology, v. 18, p. 187-191, 1991a.

MARIAUX, J. Cestodes of birds from the Ivory Coast. Species of the genus Anonchotaenia Cohn, 1900. Systematic Parasitology, v. 20, p. 109-120, 1991b.

MARIAUX, J. Cestode systematics: Any progress? International Journal for Parasitology, v. 26, n. 3, p. 231-243, 1996.

MARIAUX, J. A Molecular Phylogeny of the Eucestoda. The Journal of Parasitology, v. 84, n. 1, p. 114-124, 1998.

MARIAUX, J.; BONA, F. V.; VAUCHER, C. A new genus of Metadilepididae (Cestoda: Cyclophyllidea) parasitic in Terpsiphone rufiventer (Aves: Muscicapidae) from the Ivory Coast. Journal of Parasitology, v. 78, n. 2, p. 309-313, 1992.

MARIAUX, J.; VAUCHER, C. Cestodes d'oiseaux de Côte-d'Ivoire. II. Parasites de Coraciiformes et Piciformes. Systematic Parasitology, v. 14, p. 117-133, 1989.

MARIAUX, J; VAUCHER, C. A New Genus of Dilepididae (Cestoda) of the Yellowbill Ceuthmochares aereus (Cuculidae)from the Ivory Coast. The Journal of Parasitology, v. 76, n. 1, p. 22-26, 1990.

MARINOVA, M. H.; GEORGIEV, B. B.; VASILEVA, G. P. A Checklist of Cestodes (Platyhelminthes: Cestoda) of Waterfowl (Aves: Anseriformes) in Bulgaria. Acta Zoologica Bulgarica, v. 65, n. 4, p. 537-546, 2013. 
MARINOVA, M. H.; GEORGIEV, B. B.; VASILEVA, G. P. Description of Diorchis thracica n. sp. (Cestoda, Hymenolepididae) from the ruddy shelduck Tadorna ferruginea (Pallas) (Anseriformes, Anatidae) in Bulgaria. Systematic Parasitology, v. 91, p. 261-271, 2015.

MARTINÉZ-GUERRERO, J. H. et al. Gould's turkey (Meleagris gallopavo mexicana) gastrointestinal parasites: abundance, prevalence and diversity. Agrociencia, v. 44, p. 541-547, 2010.

MASCARENHAS, C. S.; KRÜEGER, C.; MÜLLER, G. The helminth fauna of the red-crested cardinal (Paroaria coronata) Passeriformes: Emberezidae in Brazil. Parasitology Research, v. 105, n. 5, p. 1359-1363, 2013.

MATHEVOSYAN, E. M. Dilepidoidea - Cestode Helminths of Domestic and Wild Animals. In: Essentials of Cestodology, Vol. III. Moscow: Akademiya Nauka SSSR, 1963, 687 p. [em russo]

MATHEVOSYAN, E. M. The analysis of some hymenolepidids (Cestoda: Hymenolepididae). Trudy Vsesoyuznogo Institura Gel'mintologii, v. 14, p. 229-232, 1968. [em russo]

MATHEVOSYAN, E. M. Paruterinoidea - tapeworms of domesticated and wild birds. In: Essentials of Cestodology, Vol. VII. Moscow: Akademiya Nauka SSSR, 1969, 301 p. [em russo]

MATTOS JÚNIOR, D. G. et al. Prevalência de helmintos em patos domésticos Cairina moschata dom. (Linné) (Anseriformes, Anatidae, Cairinini, Cairina) provenientes de criações extensivas no estado do Rio de Janeiro, Brasil. Revista Brasileira de Ciências Veterinárias, v. 15, n. 3, p. 140-142, 2008.

MAYHEW, R. L. Studies on the avian species of the cestode family Hymenolepididae. Illinois Biological Monographs, v. X, n. 1, p. 1-521, 1925. 
MENORET, A; IVANOV, V. A. Eutetrarhynchid trypanorhynchs (Cestoda) from elasmobranchs off Argentina, including the description of Dollfusiella taminii sp. n. and Parachristianella damiani sp. n., and amended description of Dollfusiella vooremi (São Clemente et Gomes, 1989). Folia Parasitologica, v. 61, n. 5, p. 411-431, 2014.

MILNER, A. C. Terrestrialization of Vertebrates. In: BRIGGS, D. E. G.; CROWTHER, P. R (Ed.) Paleobiology: A Synthesis. Oxford: Blackwell Scientific, 1990. 600 p.

MORAN, N. A. Adaptation and constraint in the complex life cycles of animals. Annual Review of Ecology and Systematics, v. 25, p. 573-600, 1994.

MUNIZ-PEREIRA, L. C.; AMATO, S. B. Fimbrilaria fasciolaris and Cloacotaenia megalops (Eucestoda, Hymenolepididae), Cestodes from Brazilian waterfowl. Memórias do Instituto Oswaldo Cruz, v. 96, n. 6, p. 767-772, 1998.

MUZAFFAR, S. B.; HOBERG, E. P; JONES, I. L. Possible Recent Range Expansion of Alcataenia longicervica (Eucestoda: Dilepididae) Parasitic in Murresuria spp. (Alcidae) into the North Atlantic [Short Communications]. Faculty Publications from the Harold W. Manter $\begin{array}{lllll}\text { Laboratory } & \text { of } & \text { Parasitology. } & \text { Disponível }\end{array}$ <http://digitalcommons.unl.edu/parasitologyfacpubs/779>. Acesso em 31 Out. 2016.

NALUBAMBA, K. S. et al. Prevalence and burden of gastrointestinal helminths in wild and domestic guineafowls (Numida meleagris) in the Southern Province of Zambia. Asian Pacific Journal of Tropical Biomedicine, v. 5, n. 8, p. 663-670, 2015.

NIKOLOV, P N. ; GEORGIEV, B. B.; GULIAEV, V. D. New data on the morphology of species of Leptotaenia Cohn, 1901 (Cestoda : Progynotaeniidae). Systematic Parasitology, v. 58, n. 1, p. 1-15, 2004. 
NIKOLOV, P. N. et al. Taxonomic revision of the cestodes of the family Progynotaeniidae (Cyclophyllidea) parasitising stone curlews (Charadriiformes: Burhinidae). Systematic Parasitology, v. 61, n. 2, p. 123-142, 2005.

NIKOLOV, P. N.; GEORGIEV, B. B. Taxonomic revision and phylogenetic analysis of the cestode genus Paraprogynotaenia Rysavy, 1966 (Cyclophyllidea: Progynotaeniidae). Systematic Parasitology, v. 71, n. 3, p. 159-187, 2008.

NORONHA, D. et al. Coleções particulares incorporadas à Coleção Helmintológica do Instituto Oswaldo Cruz (CHIOC): I. Coleção do Instituto Pasteur de São Paulo. Revista Brasileira de Zoologia, v. 21, n. 2, p. 303-305, 2004.

NORONHA, D., et al. Adolpho Lutz e a Coleção Helmintológica do Instituto Oswaldo Cruz. Rio de Janeiro: Museu Nacional, 2009. 154 p.

NORONHA, D.; PINTO, R. M. Considerações finais sobre os helmintos da Coleção do Instituto Bacteriológico de São Paulo, incorporada à Coleção Helmintológica do Instituto Oswaldo Cruz. Revista Brasileira de Zoologia, v. 24, n. 4, p. 1186-1187, 2007.

OLSON, P. D. et al. Interrelationships and Evolution of the Tapeworms (Platyhelminthes: Cestoda). Molecular Phylogenetics and Evolution, v. 19, n. 3, p. 443-467, 2001.

OLSON, P. D.; CAIRA, J. N. Evolution of the major lineages of tapeworms (Platyhelminthes: Cestoidea) inferred from $18 \mathrm{~S}$ ribosomal DNA and elongation factor-1a. Journal of Parasitology, v. 85, p. 1134-1159, 1999.

ONIKI, Y. Parental care and nesting in the Rufous-throated Antbird, Gymnopithys rufigula, in Amapá, Brazil. Wilson Bulletin, v. 83, n. 4, p. 347-351, 1971.

ONIKI, Y. The behavior and ecology of Slaty Antshrikes (Thamnophilus punctatus) on Barro Colorado Island, Panama Canal zone. Anais da Academia Brasileira de Ciências, v. 47, n. 3 e 4, p. 471-515, 1975. 
OROS, M. et al. A synoptic review of Promonobothrium Mackiewicz, 1968 (Cestoda: Caryophyllidea), parasites of suckers (Catostomidae) in North America, with description of two new species. Folia Parasitologica, v. 63, p. 8, 2016.

ORTEGA-OLIVARES, M.P.; ROSAS-VALDÉZ, R.; GARCÍA-VARELA, M. First description of adults of the type species of the genus Glossocercus Chandler, 1935 (Cestoda: Gryporhynchidae). Folia Parasitologica, v. 60, n. 1, p. 35-42, 2013.

PACHECO, J. F. \& WHITNEY, B. Um tributo ao naturalista Friedrich Sellow (1789-1831): Recontando a sua passagem pela Bahia e o destino desafortunado de seu acervo ornitológico. Atualidades Ornitológicas, v. 100, p. 6, 2001.

PALM, H. W. The Trypanorhyncha Diesing, 1863. Bogor: PKSPL-IPB Press, 2004. 710 p.

PARKER, G. A.; BALL, M. A.; CHUBB, J. C. To grow or not to grow? Intermediate andparatenic hosts as helminth life cycle strategies. Journal of Theoretical Biology, v. 258, p. 135-147, 2009.

PHILLIPS, A. J. et al. Two new and two redescribed species of Anonchotaenia (Cestoda: Paruterinidae) from South American birds. Folia Parasitologica, v. 61, n. 5, p. 441-461, 2014.

PHILLIPS, A. J.; MARIAUX, J.; GEORGIEV, B. B. Cucolepis cincta gen. n. et sp n. (Cestoda: Cyclophyllidea) from the squirrel cuckoo Piaya cayana Lesson (Aves: Cuculiformes) from Paraguay. Folia Parasitologica, v. 59, n. 4, p. 287-294, 2012.

PIACENTINI, V. Q.; SILVEIRA, L. F.; STRAUBE, F. C. 2010. A coleta de aves e sua preservação em coleções científicas. In: VON MATTER, S. et al. (Org.). Ornitologia e conservação: ciência aplicada, técnicas de pesquisa e conservação, Volume I. Rio de Janeiro: Technical Books, 2010. p. 329-346. 
PIACENTINI, V. Q. et al. Annotated checklist of the birds of Brazil by the Brazilian Ornithological Records Committee/Lista comentada das aves do Brasil pelo Comitê Brasileiro de Registros Ornitológicos. Revista Brasileira de Ornitologia, v.23, n. 2, p. 91298, 2015.

PICHELIN, S; CRIBB, T. H.; BONA, F. V. Glossocercus chelodinae (MacCallum, 1921) n. comb. (Cestoda: Dilepididae) from freshwater turtles in Australia and a redefinition of the genus Bancroftiella Johnston, 1911. Systematic Parasitology, v. 39, n. 3, p. 165-181, 1998.

PIETROCK, M.; SCHOLZ, T. Morphometrics and seasonal occurrence of metacestodes of Neogryporhynchus cheilancristrotus (Cyclophyllidea: Dilepididae) in the blue bream (Abramis ballerus) from the Oder River (Germany/Poland). Folia Parasitologica, v. 47, p. 181-185, 2000.

PINTO, R.M. et al. Prevalence and pathology of helminths of ciconiiform birds from the Brazilian swamplands. Journal of helmintology, v. 78, n. 3, p. 259-264, 2004.

PINTO, R.M.; GOMES, D.C. Contribuição ao conhecimento da fauna helmintológica da região amazônica - cestódeos. Memórias do Instituto Oswaldo Cruz, v. 74, n. 1, p. 52-63, 1976.

PINTO, H. A.; MATI, V. L. T.; MELO, A. L. Valipora minuta (Coil, 1950) (Cyclophyllidea: Gryporhynchidae) in Butorides striata (Linnaeus, 1758) (Aves: Ardeidae): The first record from Brazil and a new host record. CheckList, v. 8, n. 5, p. 914-916, 2012.

POULIN, R. The intra and interspecific relationships between abundance and distribution in helminth parasites of birds. Journal of Animal Ecology, v. 68, p. 719-725, 1999.

POULIN, R. Evolutionary Ecology of Parasites. 2 ed. Princeton: Princeton University Press, 2007. 332 p.

POULIN, R. Network analysis shining light on parasite ecology and evolution. Trends in Parasitology, v. 26, p. 492-498, 2010. 
POULIN, R.; MORAND, S. The Diversity of Parasites. The Quarterly Review of Biology, v.75, n.3, p. 277-293, 2000.

PROTASOVA, E. N. Bothriocephalids - tapeworm helminths of fish. In: Essentials of Cestodology. Volume VII. Moscow: Nauka, 1977. 298 pp. [em russo]

PROTASOVA, E N.; ROITMAN, V. A. Cyathocephalates, Tapeworm Helminths of Marine and Freshwater Fishes (Cestoda: Pseudophyllidea: Cyathocephalata). In: Essentials of Cestodology. Volume XII. Moskow: Nauka, 1995. 134 p.

RAILLIET A. Sur un tenia du pigeon domestique représentant une espèce nouvelle (Taenia delafondi). Comptes Rendus des Séances et Mémoires de la Société de Biologie. v. 4, p. 49-53, 1892a.

RAILLIET, A. Notices parasitologiques: Taenia tenuirostris Rud. chez l'oie domestique: remarques sur la classification des cestodes parasites des oiseaux. Bulletin de la Société Zologique de France, v. 17, p. 110-117, 1892b.

RAILLIET. A. Les cestodes des oiseaux. (A propos de la communication precedente). Determination du parasite. Revue De Pathologie Comparee, v. 16, p. 307-308, 1916.

RAILLIET. A. Les cestodes des oiseaux domestiques. Determination pratique. Recueil de Medecine Veterinaire, v. 97, p. 185-205, 1921.

RAILLIET, A.; HENRY, A. Les Cestodes des oiseaux, par M. le Dr. O. Fuhrmann, de Neuchatel. Recueil de Medecine Veterinaire, v. 86, p. 337-338, 1909.

RAILLIET, A.; HENRY, A. Helminthes recueillis par L'Expédition Antarctique Française du Pourquoi-Pas. I. Cestodes d'Oiseaux. Bulletin du Muséum national d'histoire naturelle, v. 18, p. 35-39, 1912. 
RAILLIET, A.; LUCET, A. Sur le Davainea proglottina Davaine. Bulletin de la Societe Zoologique de France, v. 17, p. 105-106, 1982.

RANSOM, B. H. The taenioid cestodes of north American Birds. Smithsonian Institute, U.S. National Museum Bulletin, v. 69, p. 1-141, 1909.

RASBAND, W. S. ImageJ. U. S. National Institutes of Health, Bethesda, Maryland, USA, 19972016. Disponível em <http://imagej.nih.gov/ij/>. Acesso em 31. Jul. 2016.

RAUSCH, R. L. Observations on the life cycle and larval development of Paruterina candelabria (Goeze, 1792) (Cestoda: Dilepididae). American Midland Naturalist, v. 42, p. 713-721, 1949.

RAUSCH, R. L. Studies on the helminth fauna of Alaska. XLV. Schistotaenia srivastavai $\mathrm{n} . \mathrm{sp}$. (Cestoda: Amabiliidae) from the red-necked grebe, Podiceps grisegena (Boddarert). In: SINGH, K. S.; TANDAN, B. K. (Ed.). H.D Srivastava Commemoration Volume, Indian Veterinary Research Institute, Izatnagar: Uttar Pradesh, 1970. p. 109-115.

RAUSCH, R. L. The Biology of Avian Parasites: Helminths. In: FARNER, D. S.; KING, J. R; PARKLES, K. C. (Ed). Avian Biology, Volume III. Nova Iorque: Academic Press, 1983. p. 367442.

REGEL, K. V.; GULIAEV, V. D.; POSPEKHOVA, N. A. On the life cycle and morphology of metacestodes Dioecocestus asper (Cyclophyllidea: Dioecocestidae). Parazitologiia, v. 47, n. 1 , p. 3-22, 2013. [em russo]

REGO, A. A. Expedições e coletas helmintológicas no Brasil. Ciência e Cultura, v. 34, n. 4, p. 507-509, 1982.

REMSEN, J. V. et al. A classification of the bird species of South America. American Ornithologists' Union. Version 8 November 2016. Disponível em <http://www.museum.Isu.edu/ Remsen/SACCBaseline.htm>. Acesso em 10 Nov. 2016. 
REYDA, F. B. Intestinal helminths of freshwater stingrays in southeastern Peru, and a new genus and two new species of cestode. Journal of Parasitology, v. 94, p. 684-699, 2008.

RICKLEFS, R. E. et al. Species formation by host shifting in avian malaria parasites. PNAS, v. 111, n. 41, 2014. Disponível em <www.pnas.org/cgi/doi/10.1073/pnas.1416356111>. Acesso em 31 Out. 2016.

RIEDL-DORN, C. Johann Natterer e a Missão Austríaca para o Brasil. Petrópolis: Editora Index, 1999. 192 p.

RODRIGUES, H. O.; RODRIGUES, S. S.; FARIA, Z. Contribution to the knowledge of the helminthological fauna of vertebrates of Maricá, Rio de Janeiro state, Brasil. Memórias do Instituto Oswaldo Cruz, v. 85, n. 1, p. 115-116, 1990.

ROLAS, F. J. T. Contribuição para o conhecimento de alguns cestódeos do gênero Raillietina Fuhrmann, 1920, (Cestoda-Davaineidae), parasitos de Columbiformes. Memórias do Instituto Oswaldo Cruz, v. 74, n. 1, p. 64-69, 1976.

ROSICKÝ, B. Czechoslovak and Soviet parasitology: history, interrelations and work. Folia parasitologica, v. 4, n. 4, p. 289-294, 1967.

RUDOLPHI, K. A. Entozoorum Synopsis cui Accedunt Mantesia Duplex et Indices Locupletissimi. Berolini. 1819. 811 p.

RUHNKE, T. R.; CAIRA, J. N.; CARPENTER, S. D. Orectolobicestus n. g. (Cestoda: Tetraphyllidea), with the description of five new species and the transfer of Phyllobothrium chiloscyllii to the new genus. Systematic Parasitology, v. 65, p. 215-233, 2006.

RUHNKE, T. R.; CAIRA, J. N.; COX, A. The cestode order Rhinebothriidea no longer family-less: A molecular phylogenetic investigation with erection of two new families and description 
of eight new species of Anthocephalum. Zootaxa, v. 3904, n. 1, p. 51-81, 2015.

RYSAVY, B. Nuevas especies de céstodos (Cestoda: Cyclophyllidea) de aves para Cuba. Poeyana, Serie A, v. 19, p. 1-22, 1966.

RYSAVY, B. Centenary of the birth of the academician K. I. Skryabin. Folia Parasitologica, v. 26, p. 193-194, 1979.

RYSAVY, B.; MACKO, J. K. Bird cestodes of Cuba. I. Cestodes of birds of the orders Podicipediformes, Pelecaniformes and Ciconiiformes. Anales del Instituto de Biologia, Universidad Nacional Autonoma, Mexico, Serie Zoologia, v. 42, p. 1-28, 1973.

RYZHIKOV, K. M.; TOLKACHEVA, L. M. Acoleata - Cestodes of Birds. In: Essentials of Cestodology. Volume X. Moscow: Nauka, 1981. 215 p. [em russo]

SÁNCHEZ, M. I. et al. High prevalence cestodes in Artemia spp. throughout the annual cycle: relationship with abundance of avian final hosts. Parasitology Reasearch, v. 112, n. 5, p. 1913-1923, 2013.

ŚWIDERSKI, Z.; GEORGIEV, B. B. Fundamentals of Cestodology. Volume 14. Aploparaksidae of wild and domesticated birds, by S.K. Bondarenko and V.L. Kontrimavichus (Ed. S.O. Movsesyan). Published by NAUKA, Moscow, 2006, ISBN 5-02-035612-3, 433 pp. (In Russian). Acta Parasitologica, v. 53, n. 1, p. 115-116, 2008.

SCHIMDT, G. D. Cyclophyllidean cestodes of Australian birds, with three new species. Journal of Parasitology, v. 58, p. 1085-1094, 1972.

SCHIMDT, G. D. CRC handbook of tapeworm identification. Boca Raton, Florida: CRC Press, 1986. 675p.

SCHMIDT, G. D.; BAUERLE, S. R.; WERTHEIM, G. Cloacotaeniella tringae n. gen., n. sp. (Cestoidea: Hymenolepididae) from a redshanck Tringa totatnus (Charadriiformes) in 
Israel. Journal of Parasitology, v. 74, p. 868-869, 1988.

SCHOLZ, T. et al. Larvae of gryporhynchid cestodes (Cyclophyllidea) from fish: a review. Folia Parasitologica, v. 51, p. 131-152, 2004.

SCHOLZ, T; DRÁBEK, R.; HANZELOVÁ, V. Scolex morphology of Proteocephalus tapeworms (Cestoda: Proteocephalidae), parasites of freshwater fish in the Palaearctic Region. Folia Parasitologica, v. 45, p. 27-43, 1998.

SCHOLZ, T.; SALGADO-MALDONADO, G. Metacestodes of the family Dilepididae (Cestoda: Cyclophyllidea) parasitising fishes in Mexico. Systematic Parasitology, v. 49, p. 23-40, 2001.

SHARMA, S. et al. Molecular phylogeny of Cyclophyllidea (Cestoda: Eucestoda): an in-silico analysis based on mtCOI gene. Parasitology Research, v. 115, p. 3329-3335, 2016.

SHINDE, G. B. On a new genus Yogeshwaria malabrica from a lapwing in India. Rivista di Parassitologia, v. 29, p. 257-260, 1968.

SHINDE, G. B. New avian cestodes of the genus Lapwingia Singh, 1952 in India. Marathwada University Journal of Science, v. 11, n. 4, p. 21-29, 1972.

SILVA, G. S. et al. Helminthic Parasites of Chickens (Gallus domesticus) in Different Regions of São Paulo State, Brazil. Revista Brasileira de Ciência Avícola, v. 18, n. 1, p. 163-168, 2016.

SILVEIRA, L.F. (ed). Revista Brasileira de Ornitologia, v. 19, n. 2, p. 1-208, 2011.

SILVEIRA, E. F.; AMATO, S. B. Diploposthe laevis (Bloch) Jacobi (Eucestoda, Hymenolepididae) from Netta peposaca (Vieillot) (Aves: Anatidae): first record for the Neotropical Region and a new host. Revista Brasileira de Zoologia, v. 25, n. 1, p. 83-88, 2008. 
Systematic, Geographie und Biologie, v. 37, p. 411-492, 1914.

SKRYABIN, K. I.; MATEVOSYAN, E. M. Corretions to errors and controversies in the taxonomy of the cestodes of the family Hymenolepididae. Doklady Akademii Mauk SSSR, n. 36, p. 188-191, 1942. [em russo]

SKRYABIN, K. I.; MATEVOSYAN, E. M. Tapeworms - Hymenolepididaes of Domestic and Game Birds. Moscow: Selkhozgiz, 1945. 488 p. [em russo]

SKUTCH, A. F. Antbirds and Ovenbirds. Their Lives and Homes. Austin: University of Texas Press, 1996. 288 p.

SMIGUNOVA, I. N. Life-cycle of the cestode Lyruterina nigropunctata (Crety, 1890) Spasskaya \& Spasskii, 1971 (Cestoda: Idiogenidae). Izvestiya Akademii Nauk Kazakhskoi SSR Seriya Biologicheskaya, n. 5, p. 44-47, 1991.

SOUTHWELL, T. Description of nine new species of cestode parasites, including two new genera from marine fishes of Ceylon. Ceylon Marine Biological Report, v. 1, p. 216-225, 1911.

SOUTHWELL, T. Cestodes from Indian birds with a note on Ligula intestinalis. Annals of Tropical Medicine and Parasitology, v. 16, p. 355-382, 1922.

SOUTHWELL, T. Cestodes in the collection of the Liverpool School of Tropical Medicine. Annals of Tropical Medicine and Parasitology, v. 20, p. 221-228, 1926.

SOUTHWELL, T. On the classification of Cestoda. Ceylon Journal of Science, v. 15, p. 49-72, 1929.

SOUTHWELL, T.; HILMY, I. S. Jardugia paradoxa, A New Genus and Species of Cestode with Some Notes on the Families Acoleidæ and Diploposthidæ. Annals of Tropical Medicine \& Parasitology, v. 23, n. 3, p. 397-406, 1929. 
SPASSKAYA, L. P. Helminth fauna of birds from the Barabinsk Stppe. (From material collected by the $257^{\text {th }}$ Soviet Helminthological Expedition). Trudy Gel'mintologicheskoi Laboratorii, v. 7, p. $390-392,1954$. [em russo]

SPASSKAYA, L. P. Cestodes of birds from the autonomous Territory of Tuva, URSS. I. Dilepididae. Acta Veterinaria Academiae Scientarium Hungaricae, v. 9, p. 77-100, 1959. [em russo]

SPASSKAYA, L. P. Cestodes of birds in Tuva. VII. Hymenolepididae. Acta Veterinaria Academiae Scientarium Hungaricae, v. 14, p. 13-34, 1964. [em russo]

SPASSKAYA, L. P. Cestodes of Birds of the URSS. Hymenolepididae. Moscow: Izdatel'stvo Nauka, 1966. 698 p. [em russo]

SPASSKAYA, L. P.; SPASSKII, A. A. Cestodes of Birds in Tuva. Kisshinev: Izdatel'stvo 'Shtiinta', 1971. 252 p. [em russo]

SPASSKAYA, L. P.; SPASSKII, A. A. Dictymetra belopolskajae sp. n. (Cestoda: Dilepididae) - a new cestode of birds. Izvestyia Akademii Nauk Moldavskoi SSR, n. 4, p. 63-68, 1973. [em russo]

SPASSKAYA, L. P.; SPASSKII, A. A. Cestodes of Birds in the URSS. Dilepididae of Terrestrial Birds. Moscow: Izdatel'stvo Nauka, 1977. 299 p. [em russo]

SPASSKAYA, L. P.; SPASSKII, A. A. Cestodes of Birds in the URSS. Dilepididae of Limnophilous Birds. Moscow: Izdatel'stvo Nauka, 1978. 314 p. [em russo]

SPASSKII, A. A. Anoplocephalata. In: Essentials of Cestodology. Volume I. Moscow: Nauka, 1951. 783 p. [em russo]

STUNKARD, H. W. Cycloskrjabina taborensis (Loewen, 1934), a cestode from the red bat, Lasiurus boraelis (Mueller, 1776), and a review of the family Anoplocephalidae. Journal of 
Parasitology, v. 47, p. 847-855, 1961.

STUNKARD, H. W. Panceriella nom. n., for Pancerina Fuhrmann, 1899, preoccupied by Pancerina Chun, 1879 , and systematic relations of the genus. Journal of Parasitology, v. 55, p. 1162-1168, 1969.

TEMIROVA, S. I.; SKRYABIN, A. S. Tetrabothriata and Mesocestoidata - cestodes of birds and mammals. In: RYZHIKOV, K.M. (Ed.), Essentials of Cestodology. Volume IX. Moskow: Nauka, 1978. 231 p. [em russo]

TELLO, J. G. et al. Reassessment of the systematics of the widespread Neotropical genus Cercomacra (Aves: Thamnophilidae). Zoological Journal of the Linnean Society, v. 170, p. 546-565, 2014.

THIOLLAY, J. M. Comparative Foraging Success of Insectivorous Birds in Tropical and Temperate Forests: Ecological Implications. Oikos, v. 53, n. 1, p. 17-30, 1988.

TRAVASSOS, L. Alguns helminthos da collecção do Instituto Bacteriológico de S. Paulo. Brazil Medico, v. 31, n. 12, p. 99-100, 1917a.

TRAVASSOS, L. Helminthos das collecções do Museu Paulista. Brazil Medico, v. 31, n. 15, p. 121-122, 1917b.

TRAVASSOS, L. Relatório da terceira excursão do Instituto Oswaldo Cruz à zona da Estrada de Ferro Noroeste do Brasil realizada em fevereiro e março de 1940. Memórias do Instituto Oswaldo Cruz, v. 35, n. 3, p. 607-696, 1940a.

TRAVASSOS, L. Relatório da quarta excursão do Instituto Oswaldo Cruz à zona da Estrada de Ferro Noroeste do Brasil, realizada em agosto e setembro de 1940. Memórias do Instituto Oswaldo Cruz, v. 35, n. 4, p. 697-722, 1940b.

TRAVASSOS, L. Espécies do gênero "Ornithostrongylus" Travassos, 1914, capturadas em 
Salobra (Estado de Mato Grosso) (Nematoda: Strongyloidea). Memórias do Instituto Oswaldo Cruz, v. 35, n. 3, p. 571-574, 1940c.

TRAVASSOS, L. Relatório da quinta excursão do Instituto Oswaldo Cruz, realizada à zona da Estrada de Ferro Noroeste do Brasil, em janeiro de 1941. Memórias do Instituto Oswaldo Cruz, v. 36, n. 3, p. 263-300, 1941a.

TRAVASSOS, L. Lutztrema n.g. (Trematoda: Dicrocoelidae). Memórias do Instituto Oswaldo Cruz, v. 36, n. 3, p. 335-343, 1941 b.

TRAVASSOS, L. Introdução ao estudo da helmintologia. Revista Brasileira de Biologia. p. 1$173,1950$.

TRAVASSOS, L. Contribuição para o Inventário Crítico da Zoologia no Brasil. Fauna Helmintológica: Considerações Preliminares - Cestódeos. Publicações Avulsas do Museu Nacional, ed. 50, p. 1-84, 1965.

TRAVASSOS, L.; FREITAS, J. F. T. Relatório da excursão científica realizada na zona da Estrada de Ferro Noroeste do Brasil em julho de 1939. Memórias do Instituto Oswaldo Cruz, v. 35, n. 3, p. 525-556, 1940.

TRAVASSOS, L.; FREITAS, J. F. T. Relatório da sexta excursão científica do Instituto Oswaldo Cruz, realizada à zona da Estrada de Ferro Noroeste do Brasil, em novembro de 1941. Memórias do Instituto Oswaldo Cruz, v. 37, n. 3, p. 259-286, 1942.

TRAVASSOS, L.; FREITAS, J. F. T. Relatório da sétima excursão científica do Instituto Oswaldo Cruz, realizada à zona da Estrada de Ferro Noroeste do Brasil, em maio de 1942. Memórias do Instituto Oswaldo Cruz, v. 38, n. 3, p. 385-412, 1943.

TRAVASSOS, L.; FREITAS, J. F. T.; LENT, H. Relatório da excursão científica do Instituto Oswaldo Cruz realizada à zona da Estrada de Ferro Noroeste do Brasil, em Outubro de 1938; II. Pesquisas Helmintológicas. Boletim Biológico, v. 4, n. 2, p. 221-249, 1939. 
VASILEVA, G. P. et al. Taxonomic revision of Hilmylepis Skryabin \& Matevosyan, 1942 (Cyclophyllidea: Hymenolepididae). Systematic Parasitology, v. 59, n. 1, p. 45-63, 2004.

VASILEVA, G. P.; GEORGIEV, B. B. Cestode communities in non-breeding populations of four grebe species (Aves: Podicipedidae) from the Bulgarian Black Sea Coast. Parasite, v. 6, n. 3, p. 249-258, 1999.

VASILEVA, G. P.; GEORGIEV, B. B. New Records of Hymenolepidid Cestodes (Cestoda: Hymenolepididae) from Charadriiform Birds in Bulgaria. Acta Zoologica Bulgarica, v. 57, p. 371-384, 2005.

VASILEVA, G. P.; GEORGIEV, B. B.; GENOV, T. Redescription of Hymenolepis hoploporus Dollfus, 1951, with the erection of the new genus Dollfusilepis (Gestoda, Hymenolepididae). Revue suisse de zoologie; annales de la Société zoologique suisse et du Muséum d'histoire naturelle de Genève, v. 105, p. 319-329, 1998.

VASILEVA, G. P.; GEORGIEV, B. B.; GENOV, T. Palaearctic species of the genus Confluaria Ablasov (Cestoda, Hymenolepididae): A redescription and synonymy of C. capillaris (Rudolphi, 1810). Systematic Parasitology, v. 43, n. 1, p. 49-57, 1999.

VASILEVA, G. P.; GEORGIEV, B. B.; GENOV, T. Palaearctic species of the genus Confluaria Ablasov (Cestoda, Hymenolepididae): Redescriptions of C. podicipina (Szymanski, 1905) and C. furcifera (Krabbe, 1869), description of C. pseudofurcifera n. sp., a key and final comments. Systematic Parasitology, v. 45, n. 2, p. 109-130, 2000.

VASILEVA, G. P.; GIBSON, D. I.; BRAY, R. A. Taxonomic revision of Tatria Kowalewski, 1904 (Cestoda: Amabiliidae): Redescriptions of T. appendiculata Fuhrmann, 1908 and $T$. duodecacantha Olsen, 1939, a key and an amended diagnosis of Tatria (sensu stricto). Systematic Parasitology, v. 55, n. 2, p. 97-113, 2003 a.

VASILEVA, G. P.; GIBSON, D. I.; BRAY, R. A. Taxonomic revision of Joyeuxilepis Spassky, 1947 
(Cestoda: Amabiliidae): Redescriptions of J. biuncinata (Joyeux \& Baer, 1943), J. decacantha (Fuhrmann, 1913) and J. pilatus Borgarenko \& Gulyaev, 1991. Systematic Parasitology, v. 56, n. 1, p. 17-36, 2003b.

VASILEVA, G. P.; GIBSON, D. I.; BRAY, R. A. Taxonomic revision of Joyeuxilepis Spassky, 1947 (Cestoda: Amabiliidae): Redescriptions of J. acanthorhyncha (Wedl, 1855) and J. fuhrmanni (Solomon, 1932), a key and a new generic diagnosis. Systematic Parasitology, v. 56, n. 3 , p. $219-233,2003$ c.

VASILEVA, G. P.; SKIRNISSON, K.; GEORGIEV, B. B. Cestodes of the horned grebe Podiceps auritus (L.) (Aves: Podicipedidae) from Lake Myvatn, Iceland, with the description of Confluaria islandica n. sp. (Hymenolepididae). Systematic Parasitology, v. 69, n. 1, p. 51$58,2008$.

VICENTE, J. J. et al. Nematode Parasites of Brazilian ciconiformes birds: a general survey with new records for the species. Memórias do Instituto Oswaldo Cruz, v. 90, n 3, p. 389393, 1995.

VICENTE, J. J.; PINTO, R. M.; NORONHA, D. Skrjaninclava tupacincai Freitas, Vicente \& Ibañez, 1970 in Brazil and some other helminths from tyrannidae birds. Memórias do Instituto Oswaldo Cruz, v. 78, n. 1, p. 95-100, 1983.

VOGE, M.; SOGANDARES-BERNAL, F; MARTIN, J.H. Fine Structure of the Tegument of Mesocestoides tetrathyridia by Scanning and Transmission Electron Microscopy. The Journal of Parasitology, v. 65, n. 4, p. 562-567, 1979.

WAESCHENBACH, A. et al. Added resolution among ordinal level relationships of tapeworms (Platyhelminthes: Cestoda) with complete small and large subunit nuclear ribosomal RNA genes. Molecular Phylogenetics and Evolution, v. 45, p. 311-325, 2007.

WAESCHENBACH, A; WEBSTER, B. L.; LITTLEWOOD, D. T. J. Adding resolution to ordinal level relationships of tapeworms (Platyhelminthes: Cestoda) with large fragments of mtDNA. 
Molecular Phylogenetics and Evolution, v. 63, p. 834-847, 2012.

WHITNEY, B. M.; ALONSO, J. A. A New Herpsilochmus Antwren (Aves: Thamnophilidae) from Northern Amazonian Peruand Adjacent Ecuador: The Role of Edaphic Heterogeneity of Terra firme Forest. The Auk, v. 115, n. 3, p. 559-576, 1998.

WHITNEY, B. M.; PACHECO, J. F. Behavior, vocalizations, and relationships of some Myrmotherula antwrens (Thamnophilidae) in eastern Brazil, with comments on the "Plain-winged" group. Ornithological Monographs, v. 48, p. 809-819, 1997.

WIDMER, V. C.; GEORGIEV, B. B.; MARIAUX, J. A new genus of the family Hymenolepididae (Cestoda) from Sephanoides sephaniodes (Apodiformes, Trochilidae) in Northern Patagonia (Chile). Acta Parasitologica, v. 58, n. 1, p. 105-111, 2013.

WILLIS, E. O. The Behavior of Bicolored Antbirds. University of California Publications in Zoology 79. Berkeley \& Los Angeles: University of California Press, 1967. 132p.

WILLIS, E. O. On the behavior of five species of Rhegmatorhina, ant-following antbirds of the Amazon basin. Wilson Bulletin, v. 81, n. 4, p. 362-395, 1969.

WILLIS, E. O. Breeding of the White-plumed Antbird (Pithys albifrons). The Auk, v. 89, n. 1, p. 192-193, 1972a.

WILLIS, E. O. The Behavior of Spotted Antbirds. Ornithological Monographs 10. Washington, D.C.: American Ornithologists' Union, 1972b. 162 p.

WILLIS, E. O. The Behavior of Ocellated Antbirds. Smithsonian Contributions to Zoology, v. 144, p. 1-57, 1973.

WILLIS, E. O. Comportamento e ecologia da Mãe-de-Taoca, Phlegopsis nigromaculata (D'Orbigny \& Lafresnaye) (Aves, Formicariidae). Revista Brasileira de Biologia, v. 39, p. 117-159, 1979. 
WILLIS, E. O. Diversity in adversity: the behaviors of two subordinate antbirds. Arquivos de Zoologia, v. 30, p. 159-234, 1981.

WILLIS, E. O. The behavior of Scale-backed Antbirds. Wilson Bulletin, v. 94, n. 4, p. 447-462, 1982a.

WILLIS, E. O. The behavior of Black-headed Antbirds (Percnostola rufifrons) (Formicariidae). Revista Brasileira de Biologia, v. 42, p. 233-247, 1982b.

WILLIS, E. O. Myrmotherula Antwrens (Aves, Formicariidae) as army ant followers. Revista Brasileira Zoologia, v. 2, n. 3, p. 153-158, 1984a.

WILLIS, E. O. Phlegopsis erythroptera (Gould, 1855) and relatives (Aves, Formicariidae) as army ant followers. Revista Brasileira Zoologia, v. 2, n. 3, p. 165-170, 1984b.

WILLIS, E. O. Cercomacra and related antbirds (Aves, Formicariidae) as army ant followers. Revista Brasileira de Zoologia, v. 2, n. 7, p. 427-432, 1985a.

WILLIS, E. O. Myrmeciza and related antbirds (Aves: Formicariidae) as army ant followers. Revista Brasileira de Zoologia, v. 2, n. 7, p. 433-442, 1985b.

WILLIS, E. O.; ONIKI, Y. Ecology and nesting behavior of the Chestnut-backed Antbird (Myrmeciza exsul). Condor, v. 74, n. 1, p. 87-98, 1972.

WILLIS, E. O.; ONIKI, Y. Birds and Army Ants. Annual Review of Ecology and Systematics, v. 9, p. 243-263, 1978.

WOJDAK, J M , EDMAN, R. M., WYDERKO, J. A., ZEMMER, S.A., BELDEN, L.K. Host Density and Competency Determine the Effects of Host Diversity on Trematode Parasite Infection. PLoS ONE 9(8): e105059. doi:10.1371/journal.pone.0105059. 2014 
YAMAGUTI, S. Studies on the Helminth Fauna of Japan. Part 6. Cestodes of birds, I. Japanese Journal of Zoology, v. 6, n. 2, p. 183-232, 1935.

YAMAGUTI, S. Studies on the Helminth Fauna of Japan. Part 30. Cestodes of birds, II. Japanese Journal of Medicial Sciences. VI. Bacteriology and Parasitology, v. 1, p. 175211, 1940.

YAMAGUTI, S. Studies on the Helminth Fauna of Japan. Part 50. Cestodes of birds, III. Published by the author. 1956. 23p.

YAMAGUTI, S. Systema helminthum. Volume II. The Cestodes of Vertebrates. New York \& London: Interscience Publishers, 1959. 860 p.

ZEHNDER, M. P.; MARIAUX, J. Molecular systematic analysis of the order Proteocephalidea (Eucestoda) based on mitochondrial and nuclear rDNA sequences. International Journal for Parasitology, v. 29, n. 11, p. 1841-1852, 1999.

ZELMER, D. A. An evolutionary definition of parasitism. International Journal of Parasitology, v. 28, p. 531-533, 1998.

ZIMMER, K. J. Behavior and vocalizations of the Caura and the Yapacana antbirds. Wilson Bulletin, v. 111, n. 2, p. 195-209, 1999.

ZIMMER, K.; ISLER, M. L. Typical Antbirds (Thamnophilidae). In: DEL HOYO, J. et al. (Ed.). Handbook of the Birds of the World Alive. Barcelona: Lynx Edicions, 2016. Disponível em <http://www.hbw.com/node/52291> . Acesso em 31 Out. 2016. 


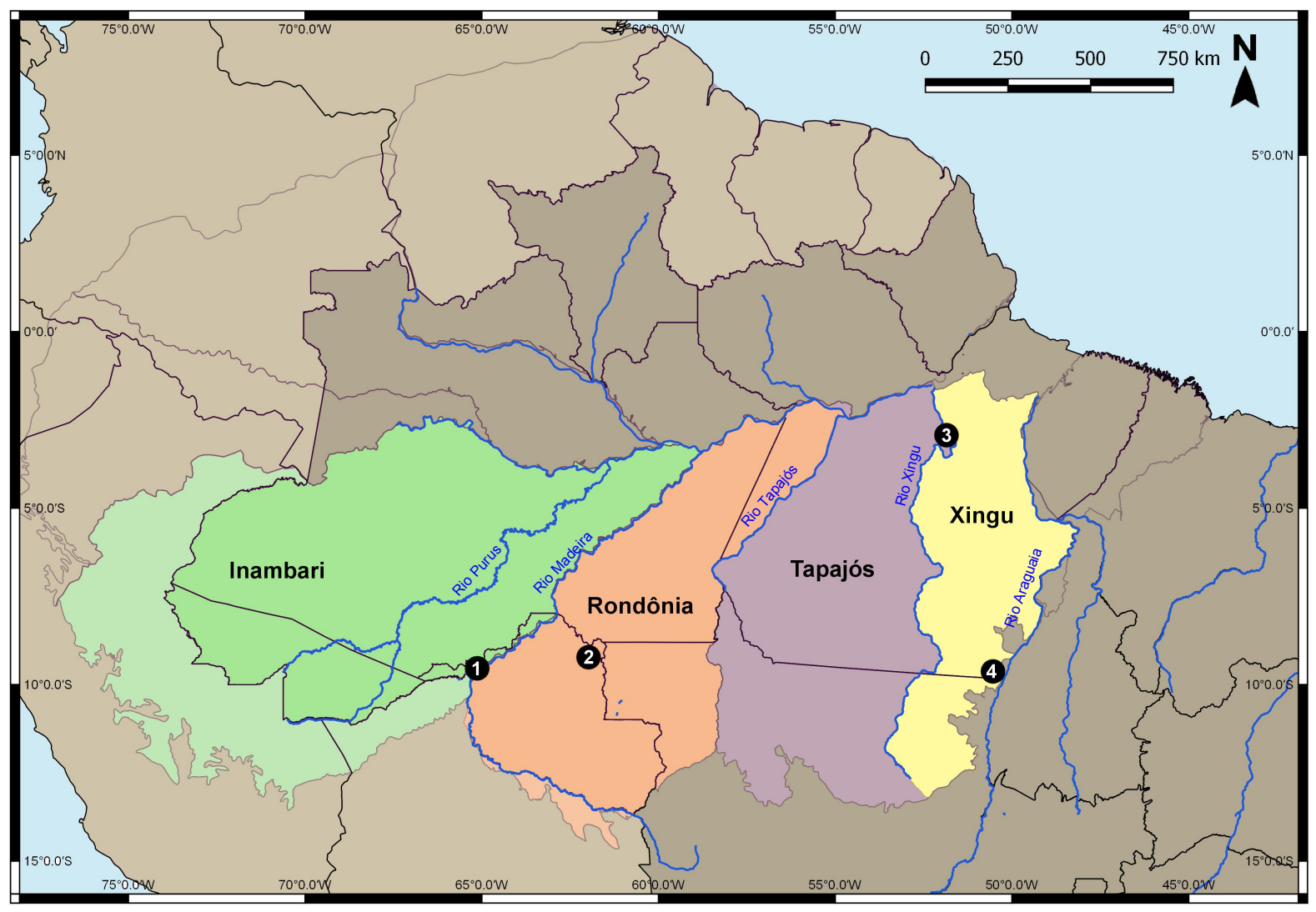

ANEXO A. Figura 1. Localidades de coleta dos hospedeiros amostrados neste estudo. 1. Porto Velho (RO), UHE Jirau, ambas as margens do rio Madeira. 2. Machadinho d'Oeste (RO), UHE Tabajara, ambas as margens do rio Machadinho d'Oeste. 3. Altamira (PA), UHE Belo Monte, ambas as margens do rio Xingu. 4. Santana do Araguaia (TO), Fazenda Fartura, margem esquerda do rio Araguaia. Áreas biogeográficas (Cracraft, 1985) delimitadas no mapa. 


\begin{tabular}{|c|c|c|c|c|}
\hline Espécie & $\mathrm{N}$ amostral total & Município, Estado & Localidade geográfica & Data \\
\hline \multirow[t]{2}{*}{ Cercomacroides nigrecens ochrogyna } & \multirow[t]{2}{*}{8} & Altamira, PA & $03^{\circ} 08^{\prime} 41^{\prime \prime}$; $51^{\circ} 47^{\prime} 49^{\prime \prime O}$ & Setembro/Outubro, 2012 \\
\hline & & Santana do Araguaia, PA & $09^{\circ} 40^{\prime} 03^{\prime \prime} \mathrm{S} ; 50^{\circ} 23^{\prime} 19^{\prime \prime O}$ & Fevereiro, 2015 \\
\hline Cercomacroides serva hypomelaena & 4 & Porto Velho, RO & $09^{\circ} 35^{\prime} 52^{\prime \prime} \mathrm{S} ; 65^{\circ} 21^{\prime} 12^{\prime \prime O}$ & Agosto/Novembro, 2013 \\
\hline Clytoctantes atrogularis & 2 & Machadinho d'Oeste, RO & $08^{\circ} 55^{\prime} 19^{\prime \prime} \mathrm{S} ; 61^{\circ} 34^{\prime} 03^{\prime \prime O}$ & Janeiro, 2014 \\
\hline Cymbilaimus lineatus intermedius & 1 & Porto Velho, RO & $09^{\circ} 35^{\prime} 52^{\prime \prime} \mathrm{S} ; 65^{\circ} 21^{\prime} 12^{\prime \prime O}$ & Setembro, 2013 \\
\hline \multirow[t]{3}{*}{ Dichrozona cincta zononota } & \multirow[t]{3}{*}{4} & Porto Velho, RO & $09^{\circ} 35^{\prime} 52^{\prime \prime} \mathrm{S} ; 65^{\circ} 21^{\prime} 12^{\prime \prime O}$ & Novembro, 2013 \\
\hline & & & & Junho/Novembro, 2014 \\
\hline & & Machadinho d'Oeste, RO & $08^{\circ} 55^{\prime} 19^{\prime \prime} \mathrm{S} ; 61^{\circ} 34^{\prime} 03^{\prime \prime O}$ & Fevereiro, 2014 \\
\hline \multirow[t]{2}{*}{ Epinecrophylla amazonica } & \multirow[t]{2}{*}{11} & \multirow[t]{2}{*}{ Porto Velho, RO } & $09^{\circ} 35^{\prime} 52^{\prime \prime} \mathrm{S} ; 65^{\circ} 21^{\prime} 12^{\prime \prime} \mathrm{O}$ & Maio/Junho/Novembro, 2013 \\
\hline & & & & Setembro/Novembro/Dezembro, 2014 \\
\hline Epinecrophylla dentei & 4 & Machadinho d'Oeste, RO & $08^{\circ} 55^{\prime} 19^{\prime \prime} \mathrm{S} ; 61^{\circ} 34^{\prime} 03^{\prime \prime O}$ & Janeiro/Fevereiro, 2014 \\
\hline \multirow[t]{2}{*}{ Epinecrophylla leucophtalma leucophtalma } & \multirow[t]{2}{*}{7} & \multirow[t]{2}{*}{ Porto Velho, RO } & $09^{\circ} 35^{\prime} 52^{\prime \prime} \mathrm{S} ; 65^{\circ} 21^{\prime} 12^{\prime \prime O}$ & Junho/Agosto/Novembro, 2013 \\
\hline & & & & Setembro/Novembro, 2014 \\
\hline \multirow[t]{2}{*}{ Epinecrophylla leucophtalma sordida } & \multirow[t]{2}{*}{3} & Altamira, PA & $03^{\circ} 08^{\prime} 41^{\prime \prime} \mathrm{S} ; 51^{\circ} 47^{\prime} 49^{\prime \prime O}$ & Setembro, 2012 \\
\hline & & Santana do Araguaia, PA & $09^{\circ} 40^{\prime} 03^{\prime \prime}$; $50^{\circ} 23^{\prime} 19^{\prime \prime O}$ & Abril, 2014 \\
\hline \multirow[t]{3}{*}{ Epinecrophylla ornata hoffmannsi } & \multirow[t]{3}{*}{5} & Altamira, PA & $03^{\circ} 08^{\prime} 41^{\prime \prime}$; $51^{\circ} 47^{\prime} 49^{\prime \prime O}$ & Setembro, 2012 \\
\hline & & Santana do Araguaia, PA & $09^{\circ} 40^{\prime} 03^{\prime \prime} \mathrm{S} ; 50^{\circ} 23^{\prime} 19^{\prime \prime} \mathrm{O}$ & Agosto, 2014 \\
\hline & & & & Setembro, 2015 \\
\hline \multirow[t]{4}{*}{ Formicivora grisea grisea } & \multirow[t]{4}{*}{5} & Altamira, PA & $03^{\circ} 08^{\prime} 41^{\prime \prime} \mathrm{S} ; 51^{\circ} 47^{\prime} 49^{\prime \prime O}$ & Setembro, 2012 \\
\hline & & Santana do Araguaia, PA & $09^{\circ} 40^{\prime} 03^{\prime \prime} \mathrm{S} ; 50^{\circ} 23^{\prime} 19^{\prime \prime} \mathrm{O}$ & Abril, 2014 \\
\hline & & Porto Velho, RO & $09^{\circ} 35^{\prime} 52^{\prime \prime} \mathrm{S} ; 65^{\circ} 21^{\prime} 12^{\prime \prime} \mathrm{O}$ & Novembro, 2013 \\
\hline & & & & Dezembro, 2014 \\
\hline \multirow[t]{2}{*}{ Frederickena unduliger pallida } & \multirow[t]{2}{*}{3} & \multirow[t]{2}{*}{ Porto Velho, RO } & \multirow[t]{2}{*}{$09^{\circ} 35^{\prime} 52^{\prime \prime} \mathrm{S} ; 65^{\circ} 21^{\prime} 12^{\prime \prime O}$} & Agosto, 2013 \\
\hline & & & & Setembro, 2014 \\
\hline \multirow[t]{2}{*}{ Hafferia fortis fortis } & \multirow[t]{2}{*}{5} & \multirow[t]{2}{*}{ Porto Velho, RO } & \multirow[t]{2}{*}{$09^{\circ} 35^{\prime} 52^{\prime \prime} \mathrm{S} ; 65^{\circ} 21^{\prime} 12^{\prime \prime O}$} & Agosto, 2013 \\
\hline & & & & Novembro/Dezembro, 2014 \\
\hline Hylophylax naevius inexpectatus & 1 & Porto Velho, RO & $09^{\circ} 35^{\prime} 52^{\prime \prime} \mathrm{S} ; 65^{\circ} 21^{\prime} 12^{\prime \prime O}$ & Novembro, 2013 \\
\hline \multirow[t]{2}{*}{ Hylophylax naevius n. sp. } & 1 & Machadinho d'Oeste, RO & $08^{\circ} 55^{\prime} 19^{\prime \prime} \mathrm{S} ; 61^{\circ} 34^{\prime} 03^{\prime \prime} \mathrm{O}$ & Janeiro, 2014 \\
\hline & 1 & Porto Velho, RO & $09^{\circ} 35^{\prime} 52^{\prime \prime} \mathrm{S} ; 65^{\circ} 21^{\prime} 12^{\prime \prime O}$ & Setembro, 2014 \\
\hline Hylophylax punctulatus punctulatus & 4 & Porto Velho, RO & $09^{\circ} 35^{\prime} 52^{\prime \prime} \mathrm{S} ; 65^{\circ} 21^{\prime} 12^{\prime \prime} \mathrm{O}$ & Novembro, 2013 \\
\hline \multirow[t]{2}{*}{ Hypocnemis ochrogyna } & \multirow[t]{2}{*}{6} & \multirow{2}{*}{ Porto Velho, RO } & \multirow[t]{2}{*}{$09^{\circ} 35^{\prime} 52^{\prime \prime S} ; 65^{\circ} 21^{\prime} 12^{\prime \prime O}$} & Agosto, 2013 \\
\hline & & & & Novembro/Dezembro, 2014 \\
\hline
\end{tabular}




\begin{tabular}{|c|c|c|c|c|}
\hline Espécie & $\mathrm{N}$ amostral total & Município, Estado & Localidade geográfica & Data \\
\hline \multirow[t]{2}{*}{ Hypocnemis peruviana peruviana } & 15 & Porto Velho, RO & $09^{\circ} 35^{\prime} 52^{\prime \prime} \mathrm{S} ; 65^{\circ} 21^{\prime} 12^{\prime \prime O}$ & Maio/Junho/Agosto/Novembro, 2013 \\
\hline & & & & Setembro/Novembro, 2014 \\
\hline Hypocnemis rondoni & 4 & Machadinho d'Oeste, RO & $08^{\circ} 55^{\prime} 19^{\prime \prime} \mathrm{S} ; 61^{\circ} 34^{\prime} 03^{\prime \prime O}$ & Janeiro, 2014 \\
\hline Hypocnemis striata affinis & 1 & Santana do Araguaia, PA & $09^{\circ} 40^{\prime} 03^{\prime \prime} \mathrm{S} ; 50^{\circ} 23^{\prime} 19^{\prime \prime O}$ & Agosto, 2014 \\
\hline \multirow[t]{3}{*}{ Isleria hauxwelli hauxwelli } & 18 & Porto Velho, RO & $09^{\circ} 35^{\prime} 52^{\prime \prime} \mathrm{S} ; 65^{\circ} 21^{\prime} 12^{\prime \prime} \mathrm{O}$ & Junho/Agosto/Novembro, 2013 \\
\hline & & & & Setembro/Novembro/Dezembro, 2014 \\
\hline & 14 & Machadinho d'Oeste, RO & $08^{\circ} 55^{\prime} 19^{\prime \prime} \mathrm{S} ; 61^{\circ} 34^{\prime} 03^{\prime \prime O}$ & Fevereiro, 2014 \\
\hline \multirow[t]{3}{*}{ Isleria hauxwelli hellmayri } & & Altamira, PA & $03^{\circ} 08^{\prime} 41^{\prime \prime} \mathrm{S} ; 51^{\circ} 47^{\prime} 49^{\prime \prime O}$ & Setembro, 2012 \\
\hline & & Santana do Araguaia, PA & $09^{\circ} 40^{\prime} 03^{\prime \prime} \mathrm{S} ; 50^{\circ} 23^{\prime} 19^{\prime \prime O}$ & Abril/Agosto, 2014 \\
\hline & & & & Fevereiro/Setembro, 2015 \\
\hline \multirow[t]{3}{*}{ Megastictus margaritatus } & 10 & Porto Velho, RO & $09^{\circ} 35^{\prime} 52^{\prime \prime} \mathrm{S} ; 65^{\circ} 21^{\prime} 12^{\prime \prime O}$ & Novembro, 2013 \\
\hline & & & & Junho/Setembro, 2014 \\
\hline & & Machadinho d'Oeste, RO & $08^{\circ} 55^{\prime} 19^{\prime \prime} \mathrm{S} ; 61^{\circ} 34^{\prime} 03^{\prime \prime O}$ & Janeiro/Fevereiro, 2014 \\
\hline Microrhopias quixensis bicolor & 4 & Porto Velho, RO & $09^{\circ} 35^{\prime} 52^{\prime \prime} \mathrm{S} ; 65^{\circ} 21^{\prime} 12^{\prime \prime O}$ & Novembro, 2014 \\
\hline Microrhopias quixensis emiliae & 1 & Altamira, PA & $03^{\circ} 08^{\prime} 41^{\prime \prime} \mathrm{S} ; 51^{\circ} 47^{\prime} 49^{\prime \prime O}$ & Outubro, 2012 \\
\hline Microrhopias quixensis intercedens & 1 & Porto Velho, RO & $09^{\circ} 35^{\prime} 52^{\prime \prime} \mathrm{S} ; 65^{\circ} 21^{\prime} 12^{\prime \prime} \mathrm{O}$ & Novembro, 2013 \\
\hline \multirow[t]{2}{*}{ Myrmelastes humaythae } & 9 & Porto Velho, RO & $09^{\circ} 35^{\prime} 52^{\prime \prime} \mathrm{S} ; 65^{\circ} 21^{\prime} 12^{\prime \prime} \mathrm{O}$ & Julho/Novembro, 2013 \\
\hline & & & & Junho/Setembro/Novembro/Dezembro, 2014 \\
\hline \multirow[t]{2}{*}{ Myrmelastes rufifacies } & 4 & Porto Velho, RO & $09^{\circ} 35^{\prime} 52^{\prime \prime} \mathrm{S} ; 65^{\circ} 21^{\prime} 12^{\prime \prime O}$ & Novembro, 2013 \\
\hline & & & & Setembro/Novembro, 2014 \\
\hline Myrmoborus leucophrys leucophrys & 2 & Altamira, PA & $03^{\circ} 08^{\prime} 41^{\prime \prime} \mathrm{S} ; 51^{\circ} 47^{\prime} 49^{\prime \prime O}$ & Setembro, 2012 \\
\hline \multirow[t]{3}{*}{ Myrmoborus myotherinus ochrolaema } & 13 & Altamira, PA & $03^{\circ} 08^{\prime} 41^{\prime \prime} \mathrm{S} ; 51^{\circ} 47^{\prime} 49^{\prime \prime O}$ & Setembro, 2012 \\
\hline & & Santana do Araguaia, PA & $09^{\circ} 40^{\prime} 03^{\prime \prime} \mathrm{S} ; 50^{\circ} 23^{\prime} 19^{\prime \prime O}$ & Abril/Agosto, 2014 \\
\hline & & & & Fevereiro, 2015 \\
\hline \multirow[t]{2}{*}{ Myrmoborus myotherinus proximus } & 8 & Porto Velho, RO & $09^{\circ} 35^{\prime} 52^{\prime \prime} \mathrm{S} ; 65^{\circ} 21^{\prime} 12^{\prime \prime O}$ & Junho/Setembro/Novembro, 2013 \\
\hline & & & & Setembro/Novembro/Dezembro, 2014 \\
\hline Myrmoborus myotherinus sororius & 1 & Porto Velho, RO & $09^{\circ} 35^{\prime} 52^{\prime \prime} \mathrm{S} ; 65^{\circ} 21^{\prime} 12^{\prime \prime O}$ & Dezembro, 2014 \\
\hline \multirow[t]{2}{*}{ Myrmophylax atrothorax melanura } & 5 & Santana do Araguaia, PA & $09^{\circ} 40^{\prime} 03^{\prime \prime} \mathrm{S} ; 50^{\circ} 23^{\prime} 19^{\prime \prime} \mathrm{O}$ & Setembro, 2015 \\
\hline & & Porto Velho, RO & $09^{\circ} 35^{\prime} 52^{\prime \prime} \mathrm{S} ; 65^{\circ} 21^{\prime} 12^{\prime \prime O}$ & Junho, 2013; Setembro, 2014 \\
\hline Myrmotherula assimilis assimilis & 7 & Porto Velho, RO & $09^{\circ} 35^{\prime} 52^{\prime \prime} \mathrm{S} ; 65^{\circ} 21^{\prime} 12^{\prime \prime} \mathrm{O}$ & Dezembro, 2013 \\
\hline
\end{tabular}




\begin{tabular}{|c|c|c|c|c|}
\hline Espécie & $\mathrm{N}$ amostral total & Município, Estado & Localidade geográfica & Data \\
\hline \multirow[t]{4}{*}{ Myrmotherula axillaris axillaris } & 20 & Altamira, PA & $03^{\circ} 08^{\prime} 41^{\prime \prime} \mathrm{S} ; 51^{\circ} 47^{\prime} 49^{\prime \prime O}$ & Setembro, 2012 \\
\hline & & Santana do Araguaia, PA & $09^{\circ} 40^{\prime} 03^{\prime \prime} \mathrm{S} ; 50^{\circ} 23^{\prime} 19^{\prime \prime O}$ & Abril/Agosto, 2014 \\
\hline & & & & Fevereiro/Setembro, 2015 \\
\hline & & Porto Velho, RO & $09^{\circ} 35^{\prime} 52^{\prime \prime S}$; $65^{\circ} 21^{\prime} 12^{\prime \prime O}$ & Junho/Agosto, 2013 \\
\hline \multirow[t]{2}{*}{ Myrmotherula axillaris heteroziga } & 8 & Porto Velho, RO & $09^{\circ} 35^{\prime} 52^{\prime \prime} \mathrm{S} ; 65^{\circ} 21^{\prime} 12^{\prime \prime} \mathrm{O}$ & Junho/Novembro, 2013 \\
\hline & & & & Junho/Novembro, 2014 \\
\hline Myrmotherula brachyura & 2 & Porto Velho, RO & $09^{\circ} 35^{\prime} 52^{\prime \prime S} ; 65^{\circ} 21^{\prime} 12^{\prime \prime O}$ & Novembro, 2013 \\
\hline Myrmotherula iheringi heteroptera & 1 & Porto Velho, RO & $09^{\circ} 35^{\prime} 52^{\prime \prime} \mathrm{S} ; 65^{\circ} 21^{\prime} 12^{\prime \prime} \mathrm{O}$ & Junho, 2013 \\
\hline \multirow[t]{2}{*}{ Myrmotherula longipennis garbei } & 3 & Porto Velho, RO & $09^{\circ} 35^{\prime} 52^{\prime \prime} \mathrm{S} ; 65^{\circ} 21^{\prime} 12^{\prime \prime O}$ & Novembro, 2013 \\
\hline & & & & Setembro, 2014 \\
\hline Myrmotherula longipennis ochrogyna & 1 & Machadinho d'Oeste, RO & $08^{\circ} 55^{\prime} 19^{\prime \prime S} ; 61^{\circ} 34^{\prime} 03^{\prime \prime O}$ & Fevereiro, 2014 \\
\hline \multirow[t]{2}{*}{ Myrmotherula longipennis paraensis } & 5 & Altamira, PA & $03^{\circ} 08^{\prime} 41^{\prime \prime} \mathrm{S} ; 51^{\circ} 47^{\prime} 49^{\prime \prime O}$ & Setembro, 2012 \\
\hline & & Santana do Araguaia, PA & $09^{\circ} 40^{\prime} 03^{\prime \prime} \mathrm{S} ; 50^{\circ} 23^{\prime} 19^{\prime \prime O}$ & Abril, 2014; Setembro, 2015 \\
\hline Myrmotherula menetriesii omissa & 1 & Santana do Araguaia, PA & $09^{\circ} 40^{\prime} 03^{\prime \prime} \mathrm{S} ; 50^{\circ} 23^{\prime} 19^{\prime \prime O}$ & Agosto, 2014 \\
\hline \multirow[t]{2}{*}{ Myrmotherula menetriesii menetriesii } & 4 & Porto Velho, RO & $09^{\circ} 35^{\prime} 52^{\prime \prime} \mathrm{S} ; 65^{\circ} 21^{\prime} 12^{\prime \prime} \mathrm{O}$ & Agosto, 2013 \\
\hline & & & & Setembro/Novembro, 2014 \\
\hline Myrmotherula sclateri & 3 & Porto Velho, RO & $09^{\circ} 35^{\prime} 52^{\prime \prime} \mathrm{S} ; 65^{\circ} 21^{\prime} 12^{\prime \prime} \mathrm{O}$ & Novembro, 2013 \\
\hline Neoctantes niger & 1 & Porto Velho, RO & $09^{\circ} 35^{\prime} 52^{\prime \prime} \mathrm{S} ; 65^{\circ} 21^{\prime} 12^{\prime \prime} \mathrm{O}$ & Novembro, 2013 \\
\hline \multirow[t]{2}{*}{ Oneillornis salvini } & 16 & Porto Velho, RO & $09^{\circ} 35^{\prime} 52^{\prime \prime} \mathrm{S} ; 65^{\circ} 21^{\prime} 12^{\prime \prime} \mathrm{O}$ & Junho/Agosto/Novembro, 2013 \\
\hline & & & & Junho/Setembro/Novembro/Dezembro, 2014 \\
\hline Phlegopsis borbae & 2 & Machadinho d'Oeste, RO & $08^{\circ} 55^{\prime} 19^{\prime \prime S} ; 61^{\circ} 34^{\prime} 03^{\prime \prime O}$ & Janeiro/Fevereiro, 2014 \\
\hline Phlegopsis erythroptera ustulata & 3 & Porto Velho, RO & $09^{\circ} 35^{\prime} 52^{\prime \prime} \mathrm{S} ; 65^{\circ} 21^{\prime} 12^{\prime \prime} \mathrm{O}$ & Junho/Novembro, 2014 \\
\hline \multirow[t]{3}{*}{ Phlegopsis nigromaculata bowmani } & 9 & Altamira, PA & $03^{\circ} 08^{\prime} 41^{\prime \prime} \mathrm{S} ; 51^{\circ} 47^{\prime} 49^{\prime \prime O}$ & Setembro, 2012 \\
\hline & & Porto Velho, RO & $09^{\circ} 35^{\prime} 52^{\prime \prime} \mathrm{S} ; 65^{\circ} 21^{\prime} 12^{\prime \prime} \mathrm{O}$ & Novembro, 2013 \\
\hline & & Machadinho d'Oeste, RO & $08^{\circ} 55^{\prime} 19^{\prime \prime} \mathrm{S} ; 61^{\circ} 34^{\prime} 03^{\prime \prime O}$ & Fevereiro, 2014 \\
\hline \multirow[t]{2}{*}{ Phlegopsis nigromaculata paraensis } & 13 & Santana do Araguaia, PA & $09^{\circ} 40^{\prime} 03^{\prime \prime} \mathrm{S} ; 50^{\circ} 23^{\prime} 19^{\prime \prime} \mathrm{O}$ & Abril/Agosto, 2014 \\
\hline & & & & Setembro, 2015 \\
\hline Pygiptila stellaris stellaris & 6 & Porto Velho, RO & $09^{\circ} 35^{\prime} 52^{\prime \prime} \mathrm{S} ; 65^{\circ} 21^{\prime} 12^{\prime \prime} \mathrm{O}$ & Junho/Julho/Agosto/Novembro/Dezembro, 2013 \\
\hline \multirow[t]{3}{*}{ Pyriglena leuconota interposita } & 9 & Altamira, PA & $03^{\circ} 08^{\prime} 41^{\prime \prime} \mathrm{S} ; 51^{\circ} 47^{\prime} 49^{\prime \prime O}$ & Setembro, 2012 \\
\hline & & Santana do Araguaia, PA & $09^{\circ} 40^{\prime} 03^{\prime \prime} \mathrm{S} ; 50^{\circ} 23^{\prime} 19^{\prime \prime O}$ & Abril, 2014 \\
\hline & & & & Fevereiro/Setembro, 2015 \\
\hline Pyriglena leuconota similis & 6 & Altamira, PA & $03^{\circ} 08^{\prime} 41^{\prime \prime} \mathrm{S} ; 51^{\circ} 47^{\prime} 49^{\prime \prime O}$ & Setembro, 2012 \\
\hline
\end{tabular}




\begin{tabular}{|c|c|c|c|c|}
\hline Espécie & $\mathrm{N}$ amostral total & Município, Estado & Localidade geográfica & Data \\
\hline Rhegmatorhina hoffmannsi & 5 & Machadinho d'Oeste, RO & $08^{\circ} 55^{\prime} 19^{\prime \prime} \mathrm{S} ; 61^{\circ} 34^{\prime} 03^{\prime \prime O}$ & Janeiro/Fevereiro, 2014 \\
\hline \multirow[t]{2}{*}{ Rhegmatorhina melanosticta purusiana } & 7 & Porto Velho, RO & $09^{\circ} 35^{\prime} 52^{\prime \prime} \mathrm{S} ; 65^{\circ} 21^{\prime} 12^{\prime \prime O}$ & Junho/Novembro, 2013 \\
\hline & & & & Setembro/Novembro, 2014 \\
\hline Rhegmatorina gymnops & 1 & Altamira, PA & $03^{\circ} 08^{\prime} 41^{\prime \prime}$; $51^{\circ} 47^{\prime} 49^{\prime \prime O}$ & Setembro, 2012 \\
\hline \multirow[t]{3}{*}{ Sciaphylax hemimelaena } & 1 & Altamira, PA & $03^{\circ} 08^{\prime} 41^{\prime \prime}$; $51^{\circ} 47^{\prime} 49^{\prime \prime O}$ & Setembro, 2012 \\
\hline & & Porto Velho, RO & $09^{\circ} 35^{\prime} 52^{\prime \prime} \mathrm{S} ; 65^{\circ} 21^{\prime} 12^{\prime \prime O}$ & Junho/Agosto/Novembro, 2013 \\
\hline & & & & Junho/Setembro/Novembro, 2014 \\
\hline \multirow[t]{2}{*}{ Sciaphylax pallens } & 2 & Porto Velho, RO & $09^{\circ} 35^{\prime} 52^{\prime \prime} \mathrm{S} ; 65^{\circ} 21^{\prime} 12^{\prime \prime O}$ & Agosto, 2013 \\
\hline & & Machadinho d'Oeste, RO & $08^{\circ} 55^{\prime} 19^{\prime \prime} \mathrm{S} ; 61^{\circ} 34^{\prime} 03^{\prime \prime O}$ & Janeiro, 2014 \\
\hline Sclateria naevia toddi & 1 & Altamira, PA & $03^{\circ} 08^{\prime} 41^{\prime \prime S} ; 51^{\circ} 47^{\prime} 49^{\prime \prime O}$ & Outubro, 2012 \\
\hline Sclateria naevia argentata & 2 & Porto Velho, RO & $09^{\circ} 35^{\prime} 52^{\prime \prime} \mathrm{S} ; 65^{\circ} 21^{\prime} 12^{\prime \prime O}$ & Novembro, 2013 \\
\hline Taraba major borbae & 2 & Porto Velho, RO & $09^{\circ} 35^{\prime} 52^{\prime \prime} \mathrm{S} ; 65^{\circ} 21^{\prime} 12^{\prime \prime O}$ & Agosto, 2013 \\
\hline Taraba major melanurus & 1 & Porto Velho, RO & $09^{\circ} 35^{\prime} 52^{\prime \prime} \mathrm{S} ; 65^{\circ} 21^{\prime} 12^{\prime \prime O}$ & Novembro, 2013 \\
\hline Taraba major semifasciatus & 1 & Altamira, PA & $03^{\circ} 08^{\prime} 41^{\prime \prime} \mathrm{S} ; 51^{\circ} 47^{\prime} 49^{\prime \prime O}$ & Setembro, 2012 \\
\hline \multirow[t]{2}{*}{ Thamnomanes ardesiacus ardesiacus } & 16 & Porto Velho, RO & $09^{\circ} 35^{\prime} 52^{\prime \prime} \mathrm{S} ; 65^{\circ} 21^{\prime} 12^{\prime \prime O}$ & Setembro/Novembro, 2013 \\
\hline & & & & Junho/Setembro/Novembro, 2014 \\
\hline \multirow[t]{3}{*}{ Thamnomanes caesius hoffmannsi } & 13 & Altamira, PA & $03^{\circ} 08^{\prime} 41^{\prime \prime}$; $51^{\circ} 47^{\prime} 49^{\prime \prime O}$ & Setembro, 2012 \\
\hline & & Santana do Araguaia, PA & $09^{\circ} 40^{\prime} 03^{\prime \prime}$; $50^{\circ} 23^{\prime} 19^{\prime \prime O}$ & Abril/Agosto, 2014 \\
\hline & & & & Fevereiro/Setembro, 2015 \\
\hline \multirow[t]{3}{*}{ Thamnomanes caesius persimilis } & 17 & Porto Velho, RO & $09^{\circ} 35^{\prime} 52^{\prime \prime} \mathrm{S} ; 65^{\circ} 21^{\prime} 12^{\prime \prime O}$ & Agosto/Novembro, 2013 \\
\hline & & & & Setembro/Novembro, 2014 \\
\hline & & Machadinho d'Oeste, RO & $08^{\circ} 55^{\prime} 19^{\prime \prime} \mathrm{S} ; 61^{\circ} 34^{\prime} 03^{\prime \prime O}$ & Janeiro, 2014 \\
\hline \multirow[t]{3}{*}{ Thamnomanes saturninus saturninus } & 9 & Porto Velho, RO & $09^{\circ} 35^{\prime} 52^{\prime \prime} \mathrm{S} ; 65^{\circ} 21^{\prime} 12^{\prime \prime O}$ & Junho, 2013 \\
\hline & & & & Dezembro, 2014 \\
\hline & & Machadinho d'Oeste, RO & $08^{\circ} 55^{\prime} 19^{\prime \prime} \mathrm{S} ; 61^{\circ} 34^{\prime} 03^{\prime \prime O}$ & Fevereiro, 2014 \\
\hline Thamnophilus aethiops atriceps & 1 & Santana do Araguaia, PA & & Abril, 2014 \\
\hline \multirow[t]{2}{*}{ Thamnophilus aethiops injunctus } & 2 & Porto Velho, RO & $09^{\circ} 35^{\prime} 52^{\prime \prime}$; $65^{\circ} 21^{\prime} 12^{\prime \prime O}$ & Junho, 2013 \\
\hline & & & & Setembro, 2014 \\
\hline \multirow[t]{2}{*}{ Thamnophilus aethiops punctuliger } & 7 & Porto Velho, RO & $09^{\circ} 35^{\prime} 52^{\prime \prime} \mathrm{S} ; 65^{\circ} 21^{\prime} 12^{\prime \prime O}$ & Junho, 2013/Novembro, 2013 \\
\hline & & Machadinho d'Oeste, RO & $08^{\circ} 55^{\prime} 19^{\prime \prime}$; $61^{\circ} 34^{\prime} 03^{\prime \prime O}$ & Janeiro/Fevereiro, 2014 \\
\hline Thamnophilus amazonicus obscurus & 1 & Altamira, PA & $03^{\circ} 08^{\prime} 41^{\prime \prime} \mathrm{S} ; 51^{\circ} 47^{\prime} 49^{\prime \prime O}$ & Setembro, 2012 \\
\hline Thamnophilus doliatus difficilis & 2 & Santana do Araguaia, PA & $09^{\circ} 40^{\prime} 03^{\prime \prime}$; $50^{\circ} 23^{\prime} 19^{\prime \prime O}$ & Fevereiro, 2015 \\
\hline
\end{tabular}




\begin{tabular}{|c|c|c|c|c|}
\hline Espécie & $\mathrm{N}$ amostral total & Município, Estado & Localidade geográfica & Data \\
\hline Thamnophilus doliatus radiatus & 2 & Porto Velho, RO & $09^{\circ} 35^{\prime} 52^{\prime \prime} \mathrm{S} ; 65^{\circ} 21^{\prime} 12^{\prime \prime O}$ & Agosto/Dezembro, 2013 \\
\hline \multirow[t]{2}{*}{ Thamnophilus murinus canipennis } & 4 & Porto Velho, RO & $09^{\circ} 35^{\prime} 52^{\prime \prime} \mathrm{S} ; 65^{\circ} 21^{\prime} 12^{\prime \prime} \mathrm{O}$ & Junho/Novembro, 2013 \\
\hline & & & & Novembro, 2014 \\
\hline Thamnophilus palliatus palliatus & 1 & Altamira, PA & $03^{\circ} 08^{\prime} 41^{\prime \prime S} ; 51^{\circ} 47^{\prime} 49^{\prime \prime O}$ & Setembro, 2012 \\
\hline Thamnophilus palliatus puncticeps & 2 & Porto Velho, RO & $09^{\circ} 35^{\prime} 52^{\prime \prime} \mathrm{S} ; 65^{\circ} 21^{\prime} 12^{\prime \prime} \mathrm{O}$ & Junho, 2013 \\
\hline \multirow[t]{3}{*}{ Thamnophilus schistaceus schistaceus } & 6 & Altamira, PA & $03^{\circ} 08^{\prime} 41^{\prime \prime S} ; 51^{\circ} 47^{\prime} 49^{\prime \prime O}$ & Setembro, 2012 \\
\hline & & Porto Velho, RO & $09^{\circ} 35^{\prime} 52^{\prime \prime S} ; 65^{\circ} 21^{\prime} 12^{\prime \prime O}$ & Agosto/Novembro, 2013 \\
\hline & & Machadinho d'Oeste, RO & $08^{\circ} 55^{\prime} 19^{\prime \prime S} ; 61^{\circ} 34^{\prime} 03^{\prime \prime O}$ & Janeiro, 2014 \\
\hline Thamnophilus stictocephalus stictocephalus & 1 & Altamira, PA & $03^{\circ} 08^{\prime} 41^{\prime \prime} \mathrm{S} ; 51^{\circ} 47^{\prime} 49^{\prime \prime O}$ & Setembro, 2012 \\
\hline \multirow[t]{3}{*}{ Willisornis poecilinotus griseiventris } & 27 & Porto Velho, RO & $09^{\circ} 35^{\prime} 52^{\prime \prime} \mathrm{S} ; 65^{\circ} 21^{\prime} 12^{\prime \prime O}$ & Junho/Agosto/Novembro, 2013 \\
\hline & & & & Junho/Setembro/Novembro/Dezembro, 2014 \\
\hline & & Machadinho d'Oeste, RO & $08^{\circ} 55^{\prime} 19^{\prime \prime} \mathrm{S} ; 61^{\circ} 34^{\prime} 03^{\prime \prime O}$ & Janeiro/Fevereiro, 2014 \\
\hline \multirow[t]{2}{*}{ Willisornis vidua vidua } & 30 & Santana do Araguaia, PA & $09^{\circ} 40^{\prime} 03^{\prime \prime} \mathrm{S} ; 50^{\circ} 23^{\prime} 19^{\prime \prime} \mathrm{O}$ & Abril/Agosto, 2014 \\
\hline & & & & Fevereiro/Setembro, 2015 \\
\hline
\end{tabular}




\begin{tabular}{|c|c|c|c|c|}
\hline Espécie & $\begin{array}{c}n \\
\text { amostral }\end{array}$ & $\begin{array}{c}n \\
\text { infestação }\end{array}$ & Prevalência & Cestódeos \\
\hline Cercomacroides nigrecens ochrogyna & 8 & 1 & $12,5 \%$ & Dilepididae (D01) \\
\hline Cercomacroides serva hypomelaena & 4 & 1 & $25 \%$ & não identificado (NI01) \\
\hline Clytoctantes atrogularis & 2 & 0 & & \\
\hline Cymbilaimus lineatus intermedius & 1 & 0 & & \\
\hline Dichrozona cincta zononota & 4 & 0 & & \\
\hline Epinecrophylla amazonica & 11 & 2 & $18,2 \%$ & Hymenolepididae (H01; H02; H03) \\
\hline Epinecrophylla dentei & 4 & 3 & $75 \%$ & Hymenolepididae (H04); não identificado (NI02) \\
\hline Epinecrophylla leucophtalma leucophtalma & 7 & 2 & $28,6 \%$ & Paruterinidae (P01) \\
\hline Epinecrophylla leucophtalma sordida & 3 & 0 & & \\
\hline Epinecrophylla ornata hoffmannsi & 5 & 0 & & \\
\hline Formicivora grisea grisea & 5 & 0 & & \\
\hline Frederickena unduliger pallida & 3 & 0 & & \\
\hline Hafferia fortis fortis & 5 & 2 & $40 \%$ & Dilepididae (D02); Hymenolepididae (H05) \\
\hline Hylophylax naevius inexpectatus & 1 & 0 & & \\
\hline Hylophylax naevius n. sp. & 2 & 0 & & \\
\hline Hylophylax punctulatus punctulatus & 4 & 0 & & \\
\hline Hypocnemis ochrogyna & 6 & 0 & & \\
\hline Hypocnemis peruviana peruviana & 15 & 4 & $26,7 \%$ & Hymenolepididae (H06); Dilepididae (D03) \\
\hline Hypocnemis rondoni & 4 & 1 & $25 \%$ & não identificado (NIO3) \\
\hline Hypocnemis striata affinis & 1 & 0 & & \\
\hline Isleria hauxwelli hauxwelli & 18 & 1 & $5,6 \%$ & Hymenolepididae (H07) \\
\hline Isleria hauxwelli hellmayri & 14 & 1 & $7,2 \%$ & Hymenolepididae (H08) \\
\hline Megastictus margaritatus & 10 & 3 & $30 \%$ & Dilepididae (D04); Hymenolepididae (H09); Paruterinidae (P02): Metadilepididae (M01) \\
\hline Microrhopias quixensis bicolor & 4 & 1 & $25 \%$ & Hymenolepididae $(\mathrm{H} 10)$ \\
\hline Microrhopias quixensis emiliae & 1 & 0 & & \\
\hline Microrhopias quixensis intercedens & 1 & 0 & & \\
\hline Myrmelastes humaythae & 9 & 1 & $11,1 \%$ & Dilepididae (D05) \\
\hline Myrmelastes rufifacies & 4 & 0 & & \\
\hline Myrmoborus leucophrys leucophrys & 2 & 2 & $100 \%$ & Metadilepididae (M02) \\
\hline Myrmoborus myotherinus ochrolaema & 13 & 4 & $30,8 \%$ & Dilepididae (D06; D07); Hymenolepididae (H11; H12); Metadilepididae (M03) \\
\hline Myrmoborus myotherinus proximus & 8 & 1 & $12,5 \%$ & Hymenolepididae (H13) \\
\hline
\end{tabular}




\begin{tabular}{|c|c|c|c|c|}
\hline Espécie & $\begin{array}{c}n \\
\text { amostral }\end{array}$ & $\begin{array}{c}n \\
\text { infestação }\end{array}$ & Prevalência & Cestódeos \\
\hline Myrmoborus myotherinus sororius & 1 & 0 & & \\
\hline Myrmophylax atrothorax melanura & 5 & 4 & $80 \%$ & Hymenolepididae (H14; H15; H16) \\
\hline Myrmotherula assimilis assimilis & 7 & 0 & & \\
\hline Myrmotherula axillaris axillaris & 19 & 2 & $10,5 \%$ & Metadilepididae (M04) \\
\hline Myrmotherula axillaris heteroziga & 8 & 1 & $12,5 \%$ & Paruterinidae (P03) \\
\hline Myrmotherula brachyura & 2 & 0 & & \\
\hline Myrmotherula iheringi heteroptera & 1 & 0 & & \\
\hline Myrmotherula longipennis garbei & 3 & 0 & & \\
\hline Myrmotherula longipennis ochrogyna & 1 & 0 & & \\
\hline Myrmotherula longipennis paraensis & 5 & 0 & & \\
\hline Myrmotherula menetriesii omissa & 1 & 0 & & \\
\hline Myrmotherula menetriesii menetriesii & 4 & 1 & $25 \%$ & Metadilepididae (M05) \\
\hline Myrmotherula sclateri & 3 & 1 & $33,3 \%$ & Metadilepididae (M06) \\
\hline Neoctantes niger & 1 & 0 & & \\
\hline Oneillornis salvini & 16 & 3 & $18,8 \%$ & Dilepididae (D08; D09); Hymenolepididae (H17) \\
\hline Phlegopsis borbae & 2 & 2 & $100 \%$ & Hymenolepididae (H18; H19); Metadilepididae (M07) \\
\hline Phlegopsis erythroptera ustulata & 3 & 2 & $66,6 \%$ & Dilepididae (D10); Metadilepididae (M08) \\
\hline Phlegopsis nigromaculata bowmani & 9 & 3 & $33,3 \%$ & Dilepididae (D11) \\
\hline Phlegopsis nigromaculata paraensis & 13 & 4 & $30,8 \%$ & Dilepididae (D12); Hymenolepididae (H2; H21); Metadilepididae (M09) \\
\hline Pygiptila stellaris stellaris & 6 & 0 & & \\
\hline Pyriglena leuconota interposita & 9 & 3 & $33,3 \%$ & Hymenolepididae (H22; H23); Metadilepididae (M10); não identificado (NI04) \\
\hline Pyriglena leuconota similis & 6 & 6 & $100 \%$ & Dilepididae (D13); Hymenolepididae (H24; H25); Metadilepididae (M11) \\
\hline Rhegmatorhina gymnops & 5 & 4 & $80 \%$ & Hymenolepididae (H26) \\
\hline Rhegmatorhina hoffmannsi & 7 & 3 & $42,9 \%$ & Dilepididae (D14); Hymenolepididae (H27); Metadilepididae (M12) \\
\hline Rhegmatorhina melanosticta purusiana & 1 & 1 & $100 \%$ & Dilepididae (D15; D16); Hymenolepididae (H28); Metadilepididae (M13) \\
\hline Sciaphylax hemimelaena & 19 & 3 & $15,8 \%$ & Dilepididae (D17; D18) \\
\hline Sciaphylax pallens & 2 & 2 & $100 \%$ & Dilepididae (D19); Hymenolepididae (H29); não identificado (NI05) \\
\hline Sclateria naevia toddi & 1 & 1 & $100 \%$ & Hymenolepididae (H30) \\
\hline Sclateria naevia argentata & 2 & 0 & & \\
\hline Taraba major borbae & 2 & 1 & $50 \%$ & Metadilepididae (M14) \\
\hline Taraba major melanurus & 1 & 0 & & \\
\hline
\end{tabular}




\begin{tabular}{lcccc}
\hline Espécie & $\begin{array}{c}\mathbf{n} \\
\text { amostral }\end{array}$ & $\begin{array}{c}\mathbf{n} \\
\text { infestação }\end{array}$ & Prevalência Cestódeos \\
\hline Taraba major semifasciatus & 1 & 0 & & \\
Thamnomanes ardesiacus ardesiacus & 16 & 3 & $18,8 \%$ & Hymenolepididae (H31); Paruterinidae (P04) \\
Thamnomanes caesius hoffmannsi & 13 & 0 & & \\
Thamnomanes caesius persimilis & 17 & 2 & $11,8 \%$ & Hymenolepididae (H32) \\
Thamnomanes saturninus saturninus & 9 & 3 & $33,3 \%$ & Paruterinidae (P05); Metadilepididae (M15); não identificado (NI06) \\
Thamnophilus aethiops atriceps & 1 & 0 & & \\
Thamnophilus aethiops injunctus & 2 & 0 & & \\
Thamnophilus aethiops punctuliger & 7 & 2 & \multirow{2}{*}{ 28,6\% } & Hymenolepididae (H33); Metadilepididae (M16) \\
Thamnophilus amazonicus obscurus & 1 & 0 & & \\
Thamnophilus doliatus difficilis & 2 & 0 & & \\
Thamnophilus doliatus radiatus & 2 & 0 & & \\
Thamnophilus murinus canipennis & 4 & 1 & $25 \%$ & Paruterinidae (P06) \\
Thamnophilus palliatus palliatus & 1 & 0 & & \\
Thamnophilus palliatus puncticeps & 2 & 0 & & \\
Thamnophilus schistaceus schistaceus & 6 & 0 & & \\
Thamnophilus stictocephalus stictocephalus & 1 & 0 & & \\
Willisornis poecilinotus griseiventris & 27 & 4 & 14,8\% & Dilepididae (D20; D21) \\
Willisornis vidua vidua & 30 & 0 & &
\end{tabular}


02

A

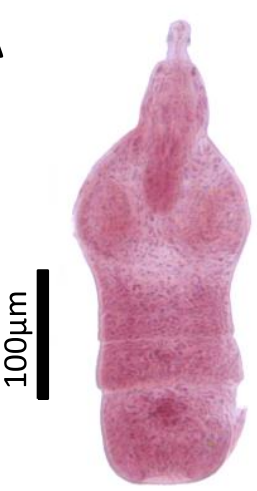

04

B

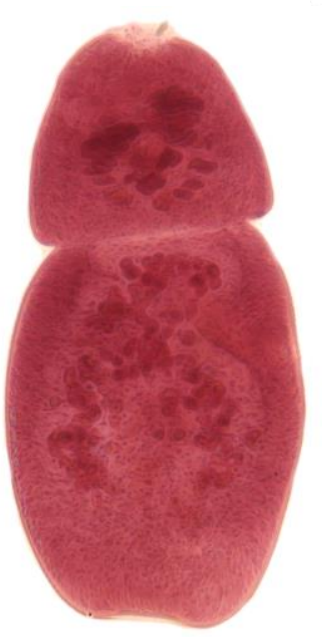

03
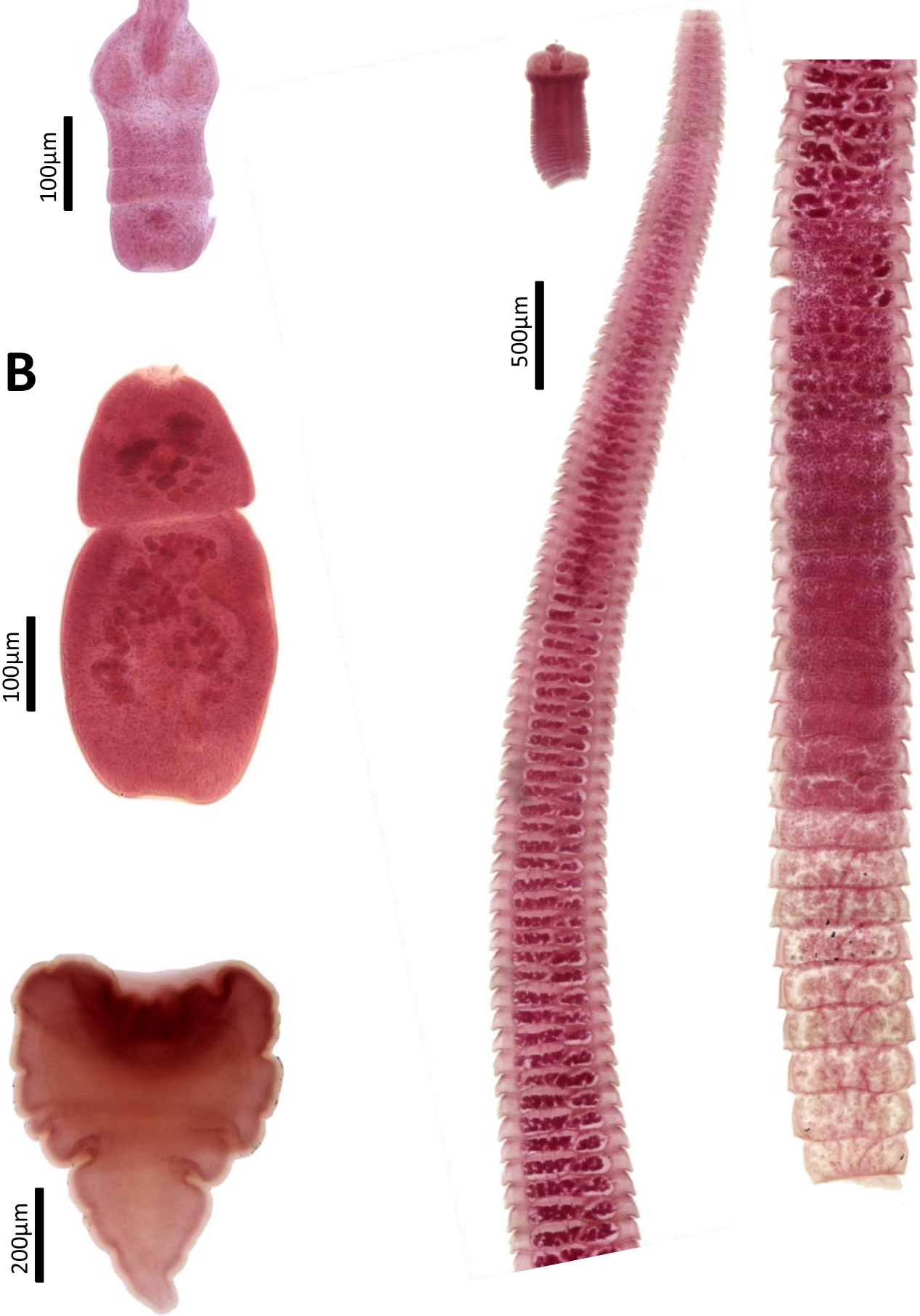

\section{ANEXO D}

Figura 02. Dilepididae (D01). A: Espécime completo, imaturo. B: Proglótides finais, madura e pré grávida. Parasita de Cercomacroides nigrecens ochrogyna (Altamira, PA).

Figura 03. Não identificado (NI01). Espécime em estágio larval. Parasita de Cercomacroides serva hypomelaena (Porto Velho, RO).

Figura 04. Hymenolepididae (H01). Espécime completo. Parasita de Epinecrophylla amazonica (Porto Velho, RO). 


\section{5}

\section{6}
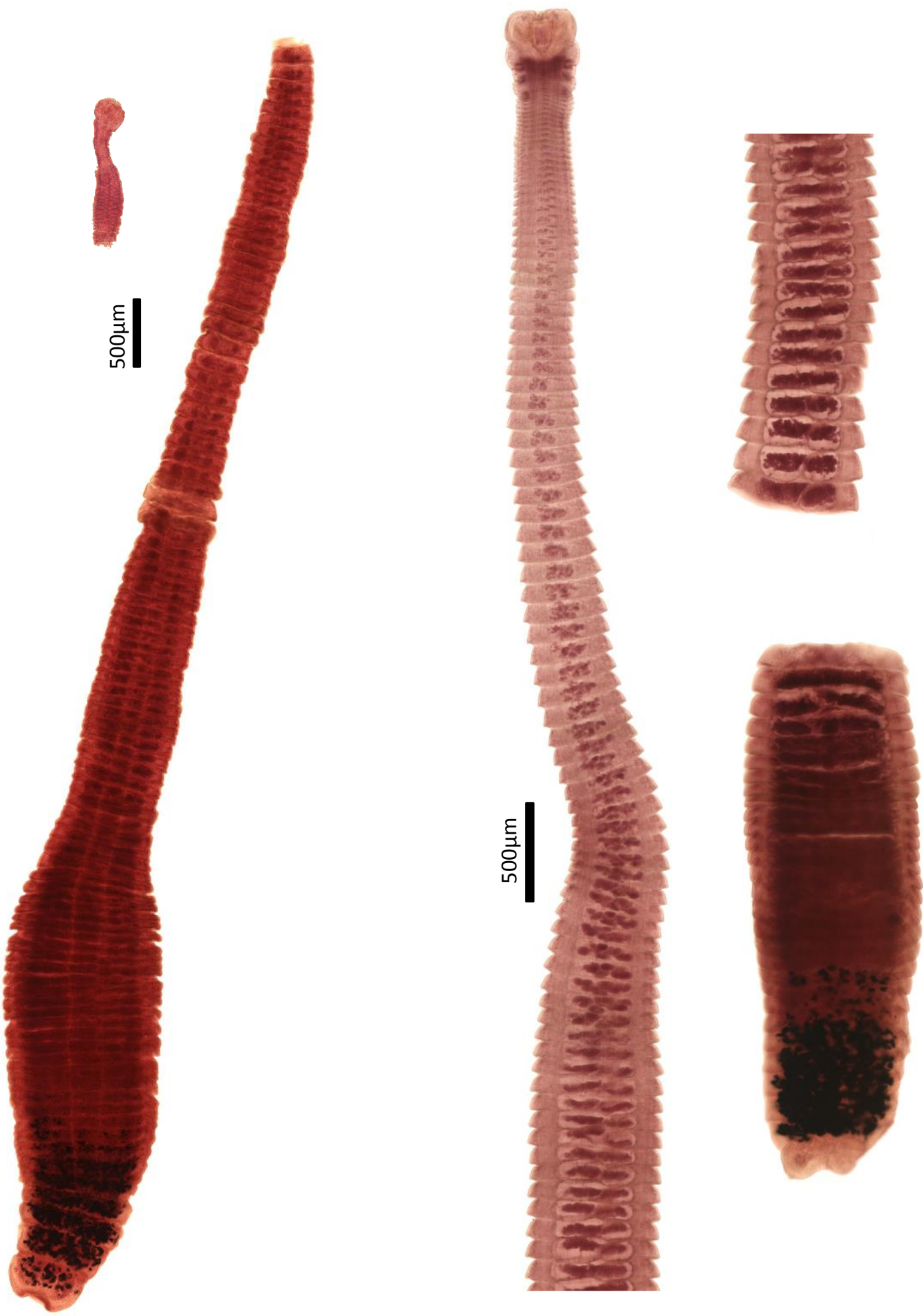

ANEXO D (continuação)

Figura 05. Hymenolepididae (H02). Espécime incompleto. Parasita de Epinecrophylla amazonica (Porto Velho, RO).

Figura 06. Hymenolepididae (H04). Espécime completo. Parasita de Epinecrophylla dentei (Machadinho d'Oeste, RO). 

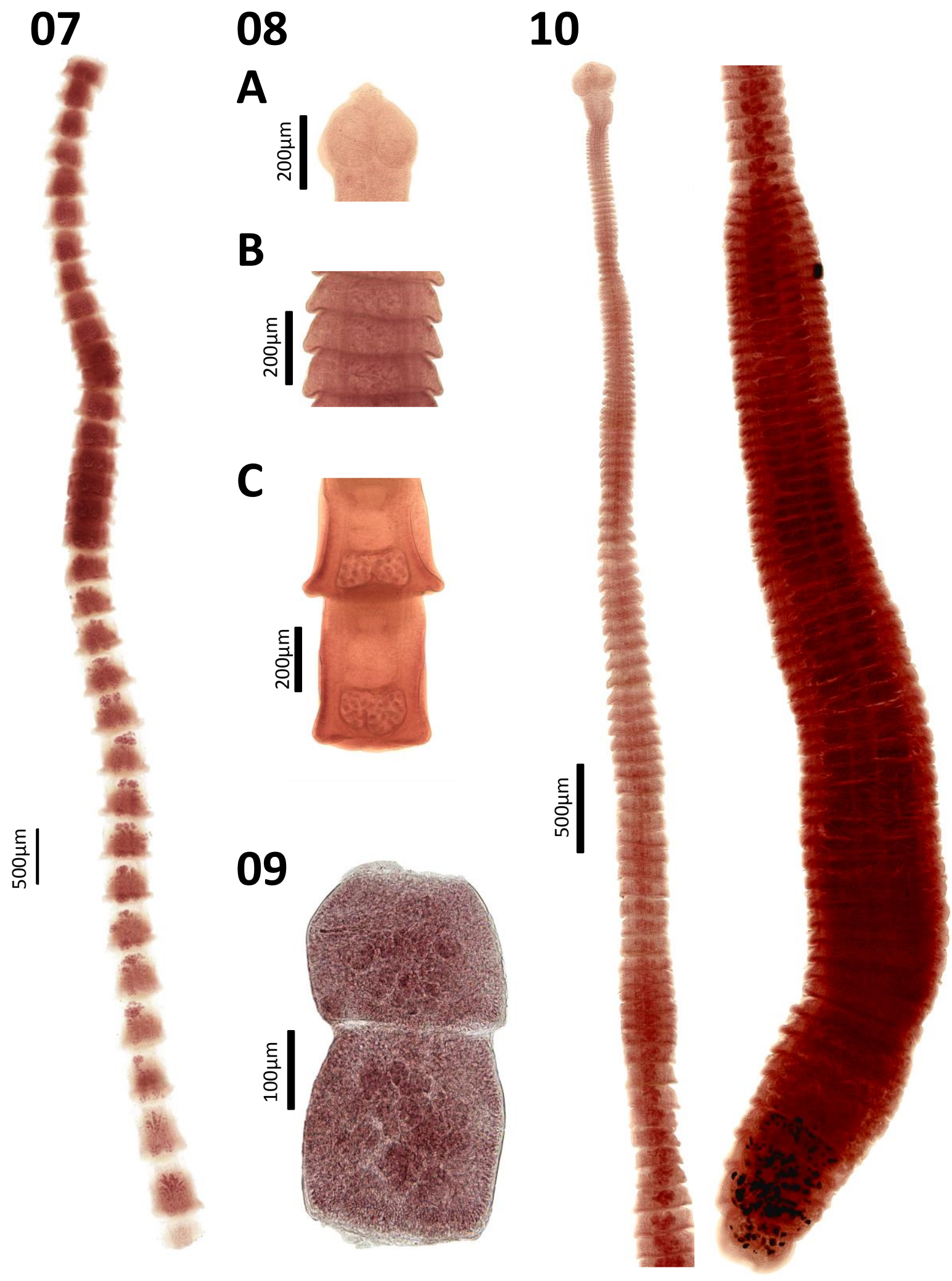

Figura 07. Não identificado (NI02). Espécime incompleto. Parasita de Epinecrophylla dentei (Machadinho d'Oeste, RO).

Figura 08. Paruterinidae (P01). A: Escólex. B: Proglótides maduras. C. Proglótides finais pós grávidas. Parasita de Epinecrophylla leucophtalma leucophtalma (Porto Velho, RO).

Figura 09. Dilepididae (D02). Espécime incompleto. Parasita de Hafferia fortis fortis (Porto Velho, RO). Figura 10. Himenolepididae (H05). Espécime completo. Parasita de Hafferia fortis fortis (Porto Velho, RO). 

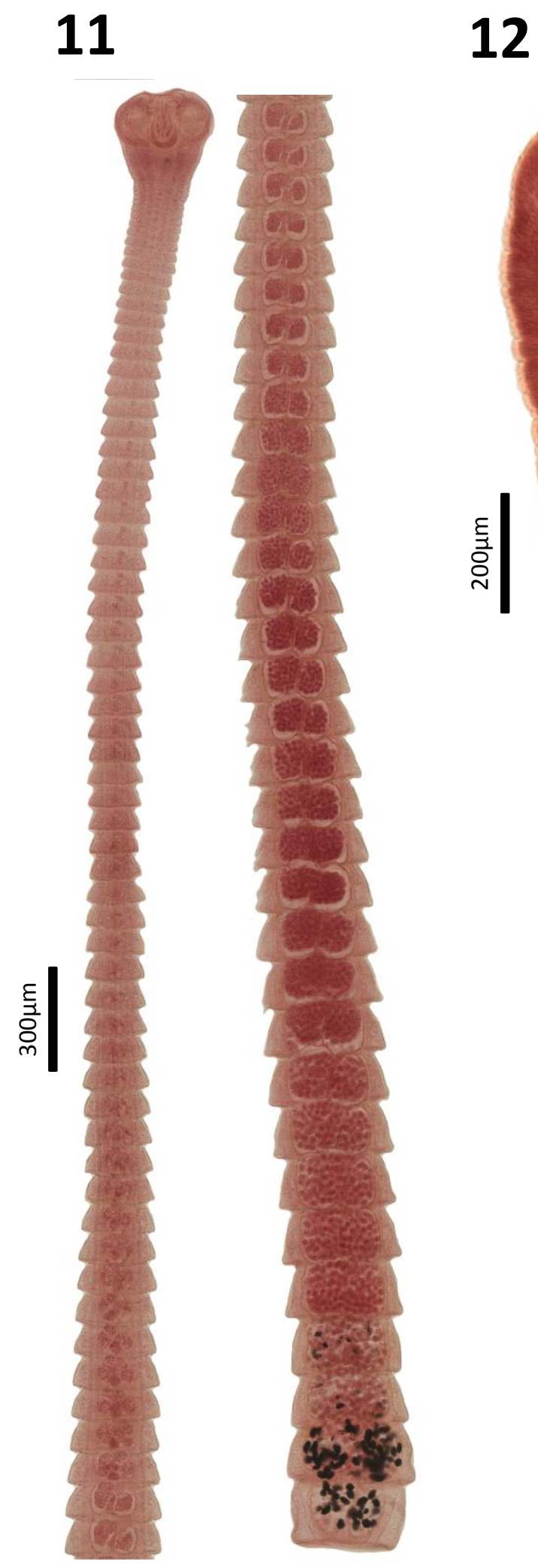

13
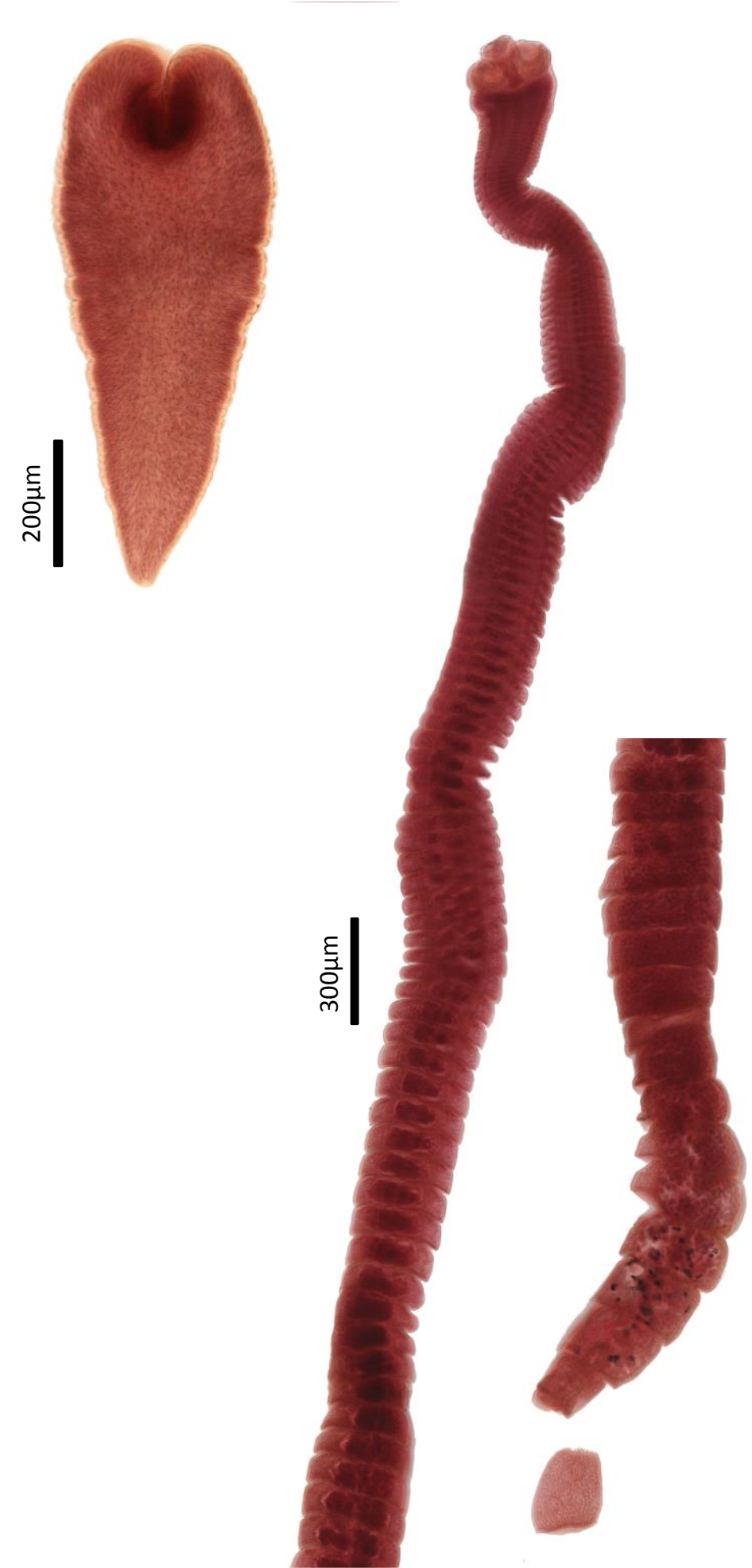

ANEXO D (continuação)

Figura 11. Hymenolepididae (H06). Espécime completo. Parasita de Hypocnemis peruviana (Porto Velho, RO).

Figura 12. Não identificado (NIO3). Espécime em estágio larval. Parasita de Hypocnemis rondoni (Machadinho d'Oeste, RO).

Figura 13. Hymenolepididae (H07). Espécime completo. Parasita de Isleria hauxwelli hauxwelli (Porto Velho, $\mathrm{RO})$. 

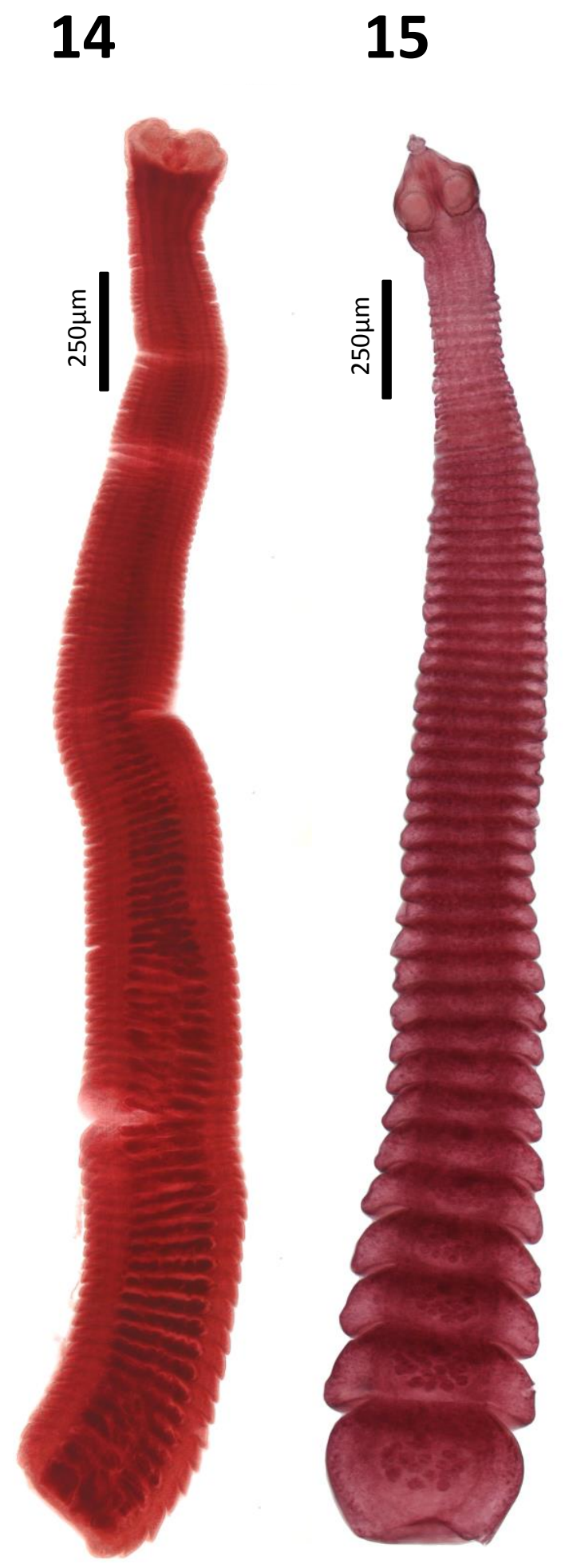

\section{6}

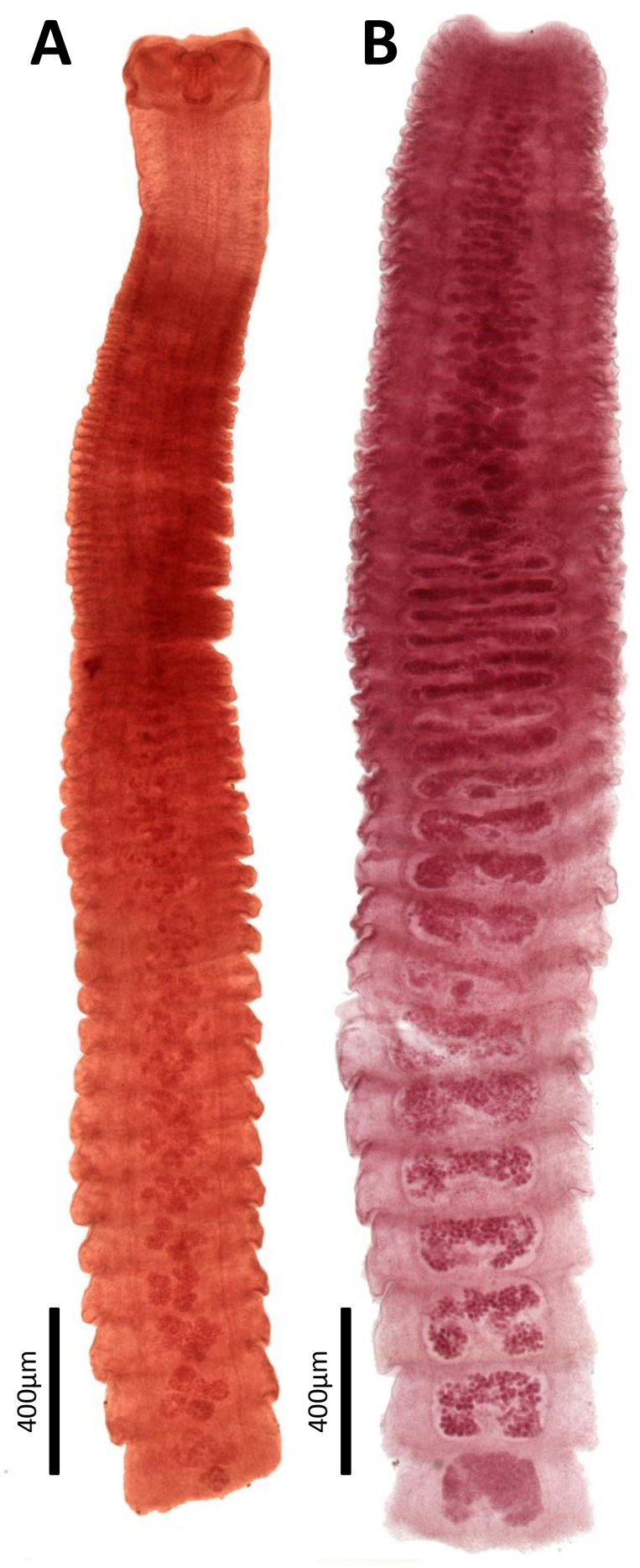

\section{ANEXO D (continuação)}

Figura 14. Hymenolepididae (H08). Espécime completo. Parasita de Isleria hauxwelli hellmayri (Santana do Araguaia, PA).

Figura 15. Dilepididae (D04). Espécime completo. Parasita de Megastictus margaritaus (Porto Velho, RO). Figura 16. Hymenolepididae (H09). A. Espécime incompleto. B. Estróbilo. Parasita de Megastictus margaritaus (Porto Velho, RO). 
17

18

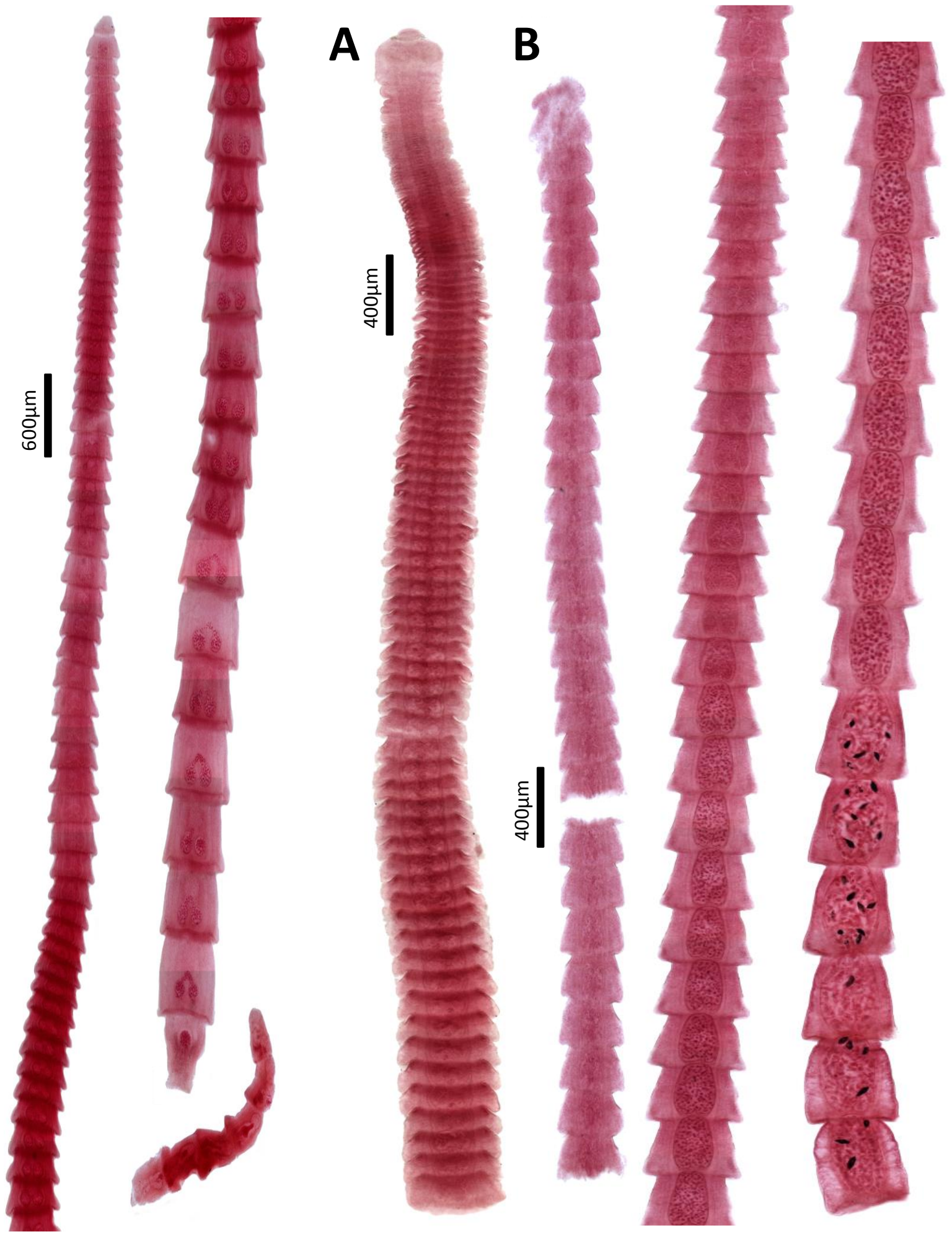

ANEXO D (continuação)

Figura 17.Paruterinidiae (P02). Espécime incompleto. Parasita de Megastictus margaritatus (Porto Velho, RO).

Figura 18. Metadilepididae (M01). A. Espécime incompleto. B. Estróbilo. Parasita de Megastictus margaritaus (Porto Velho, RO). 
19

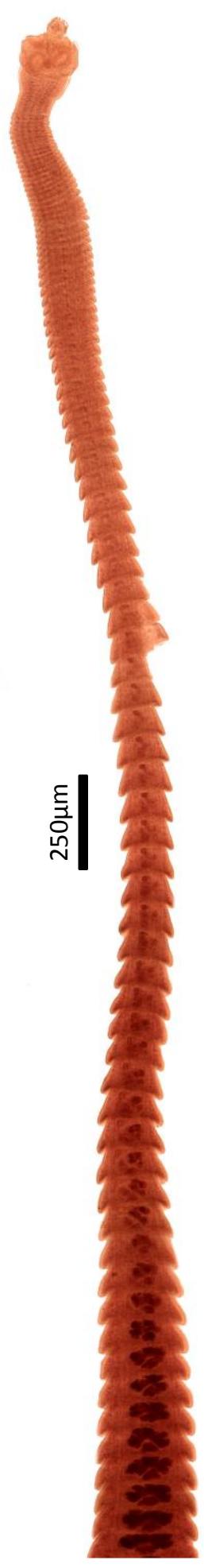

20

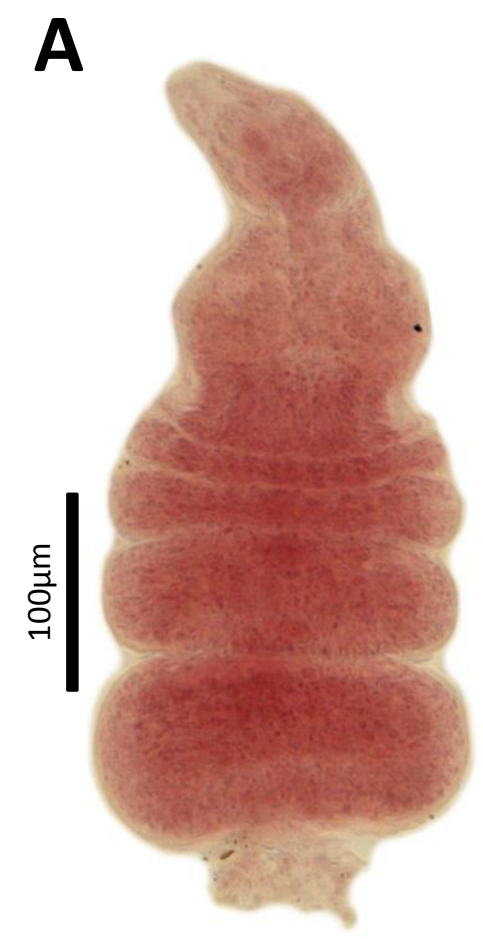

B

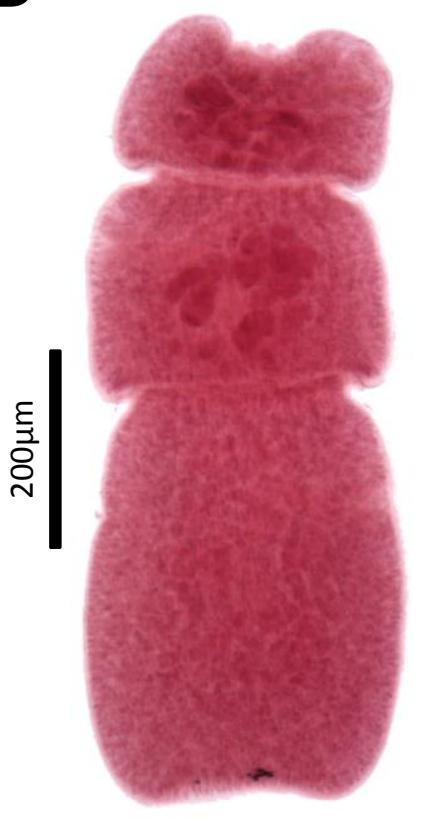

ANEXO D (continuação)

Figura 19. Hymenolepididae (H10). Espécime completo. Parasita de Microrhopias quixensis bicolor (Porto Velho, RO).

Figura 20. Dilepididae (D05). A. Espécime incompleto. B. Estróbilo. Parasita de Myrmelastes humaythae (Porto Velho, RO). 

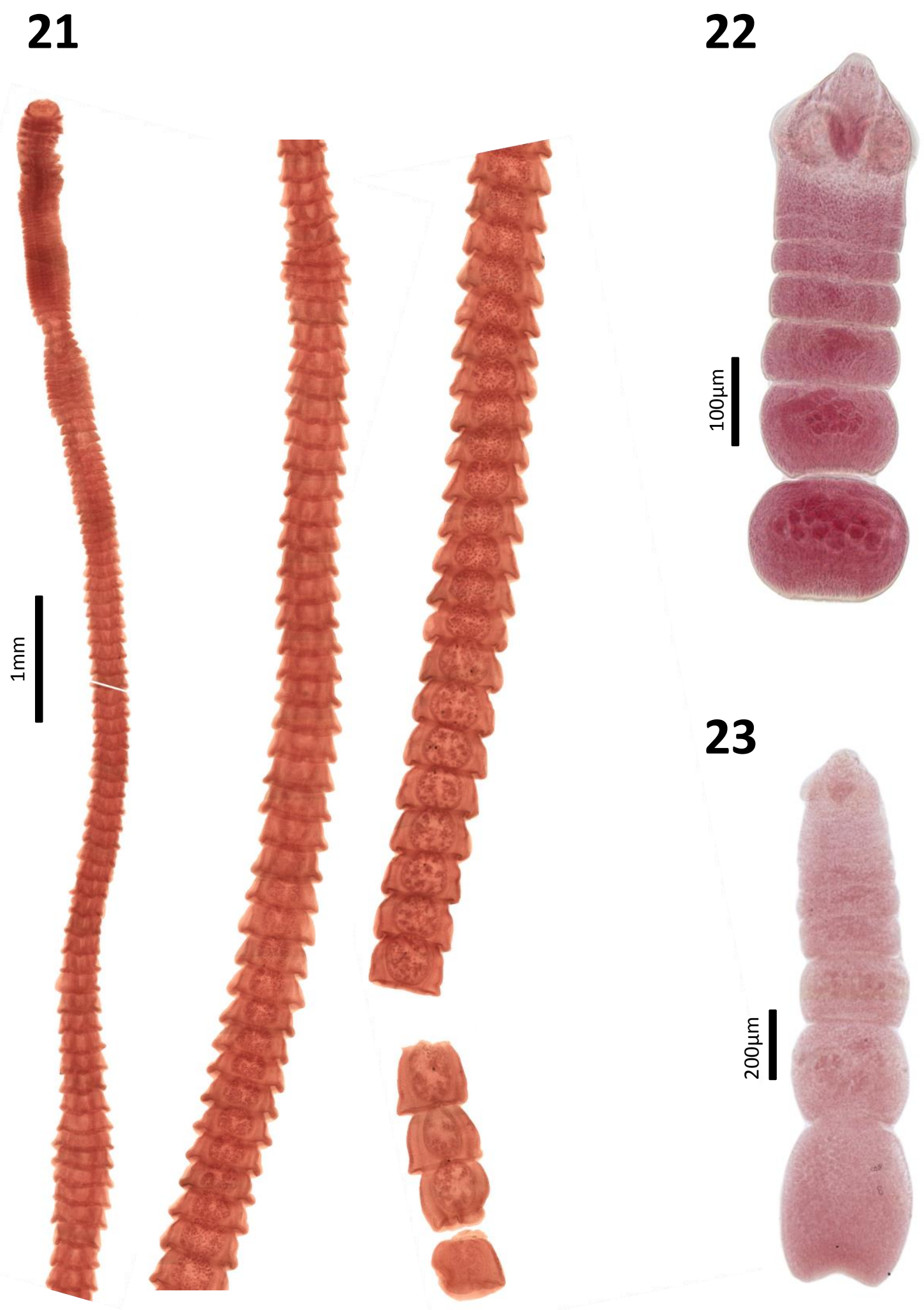

\section{ANEXO D (continuação)}

Figura 21. Metadilepididae (M02). Espécime completo. Parasita de Myrmoborus leucophrys leucophrys (Altamira, PA).

Figura 22. Dilepididae (D06). Espécime completo. Parasita de Myrmoborus myotherinus ochrolaema (Altamira, PA).

Figura 23. Dilepididae (D07). Espécime completo. Parasita de Myrmoborus myotherinus ochrolaema (Santana do Araguaia, PA). 


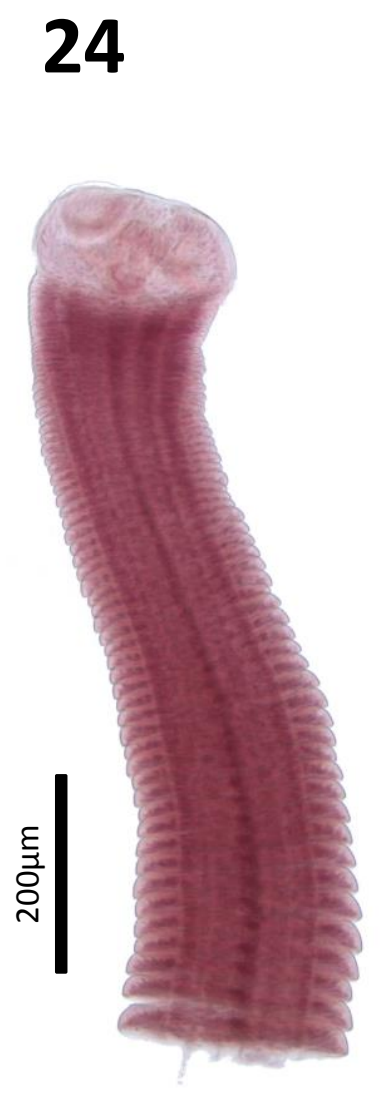

25
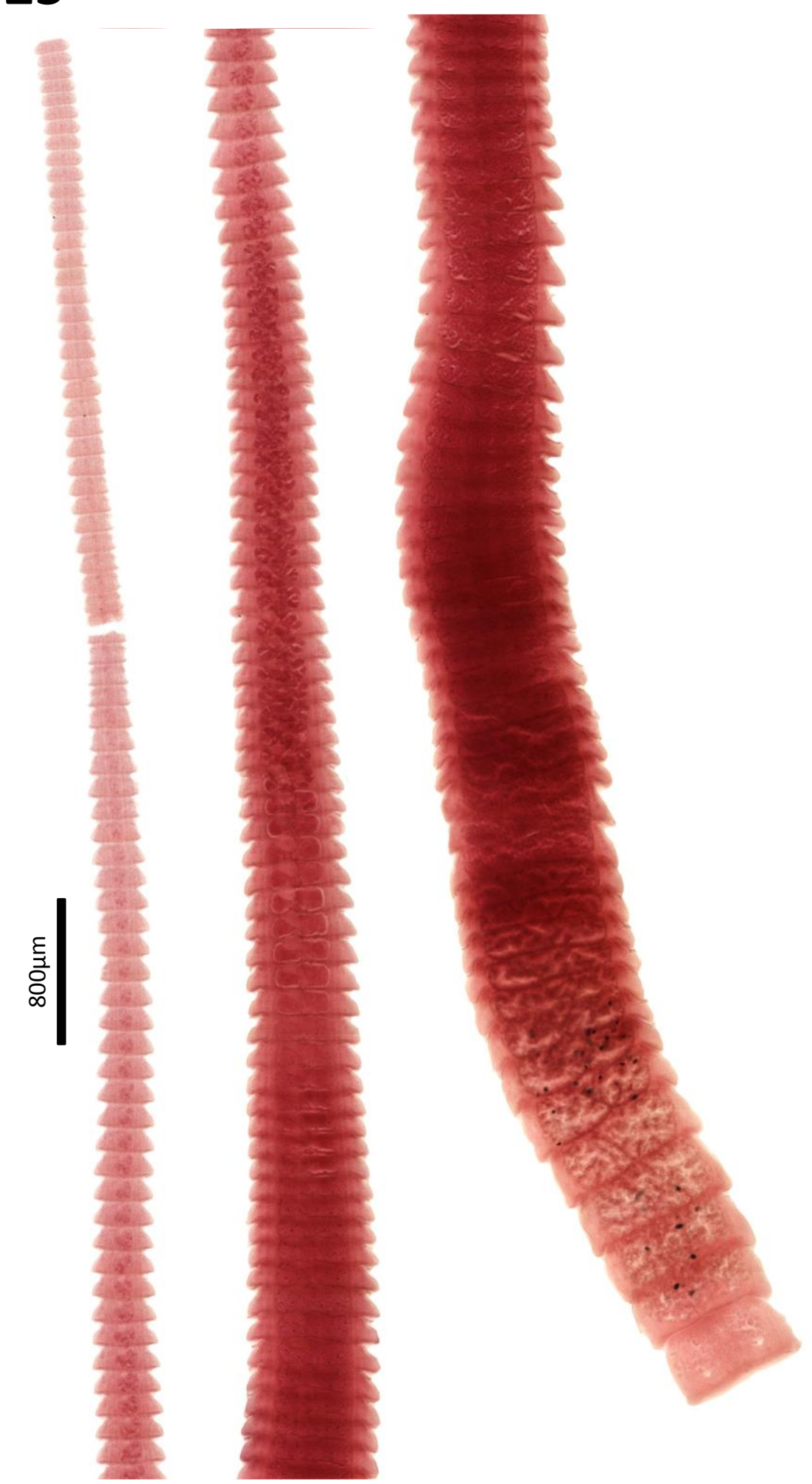

\section{ANEXO D (continuação)}

Figura 24. Hymenolepididae (H11). Espécime incompleto. Parasita de Myrmoborus myotherinus ochrolaema (Altamira, PA).

Figura 25. Hymenolepididae (H12). Espécime completo. Parasita de Myrmoborus myotherinus ochrolaema (Santana do Araguaia, PA). 


\section{6}

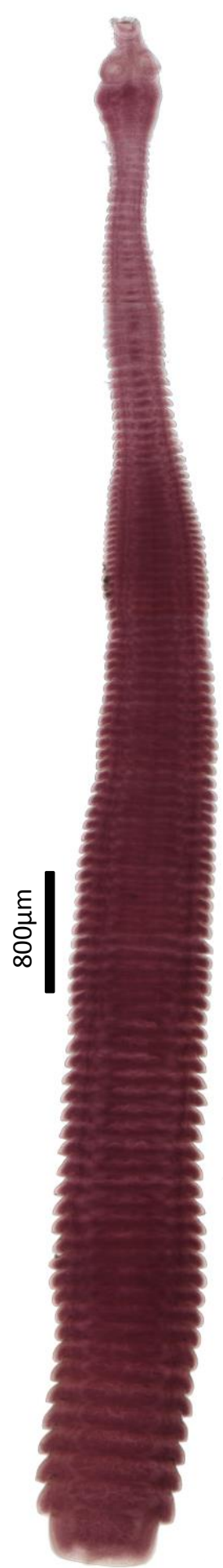

27

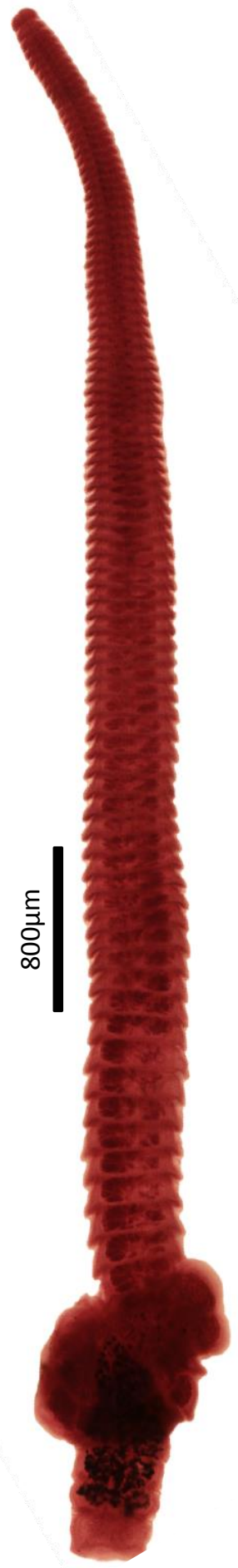

28

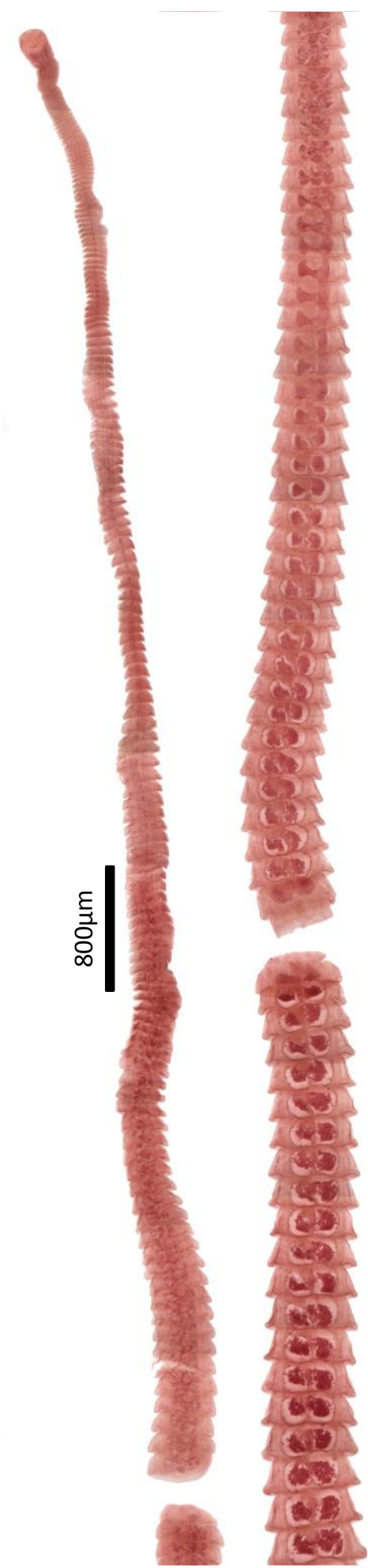

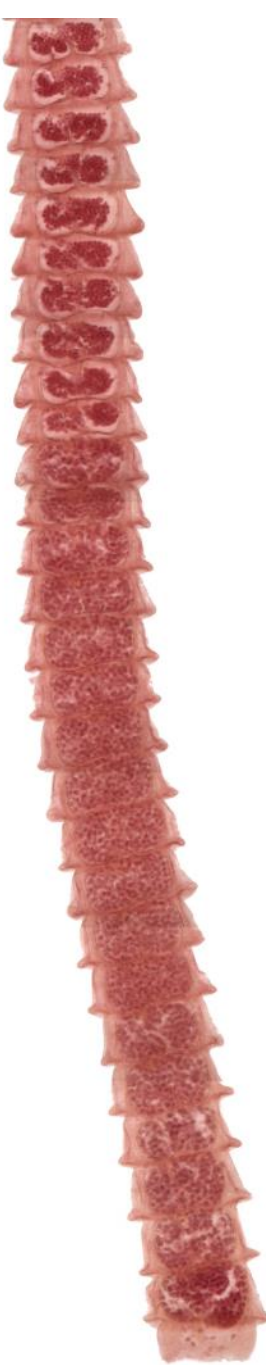

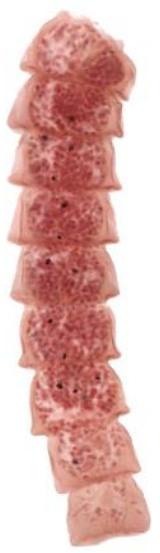

ANEXO D (continuação)

Figura 26. Metadilepididae (M03). Espécime completo. Parasita de Myrmoborus myotherinus ochrolaema (Altamira, PA).

Figura 27. Hymenolepididae (H13). Espécime completo. Parasita de Myrmoborus myotherinus proximus (Porto Velho, RO).

Figura 28. Hymenolepididae (H14). Espécime completo. Parasita de Myrmophylax athrotorax (Porto Velho, $\mathrm{RO})$. 

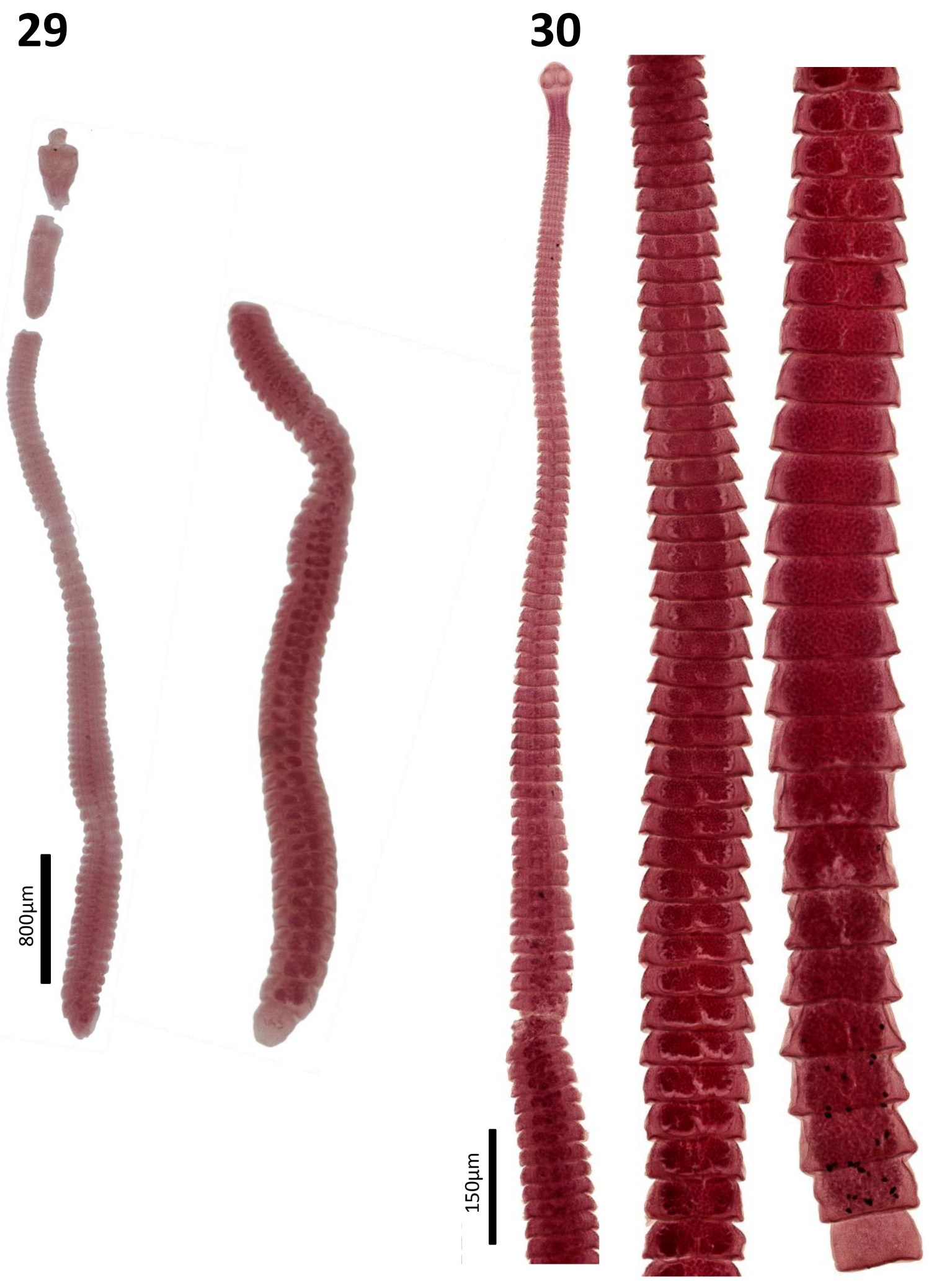

ANEXO D (continuação)

Figura 29. Hymenolepididae (H15). Espécime completo. Parasita de Myrmophylax athrotorax (Porto Velho, RO).

Figura 30. Hymenolepididae (H16). Espécime completo. Parasita de Myrmophylax athrotorax (Santana do Araguaia, PA). 
31

32
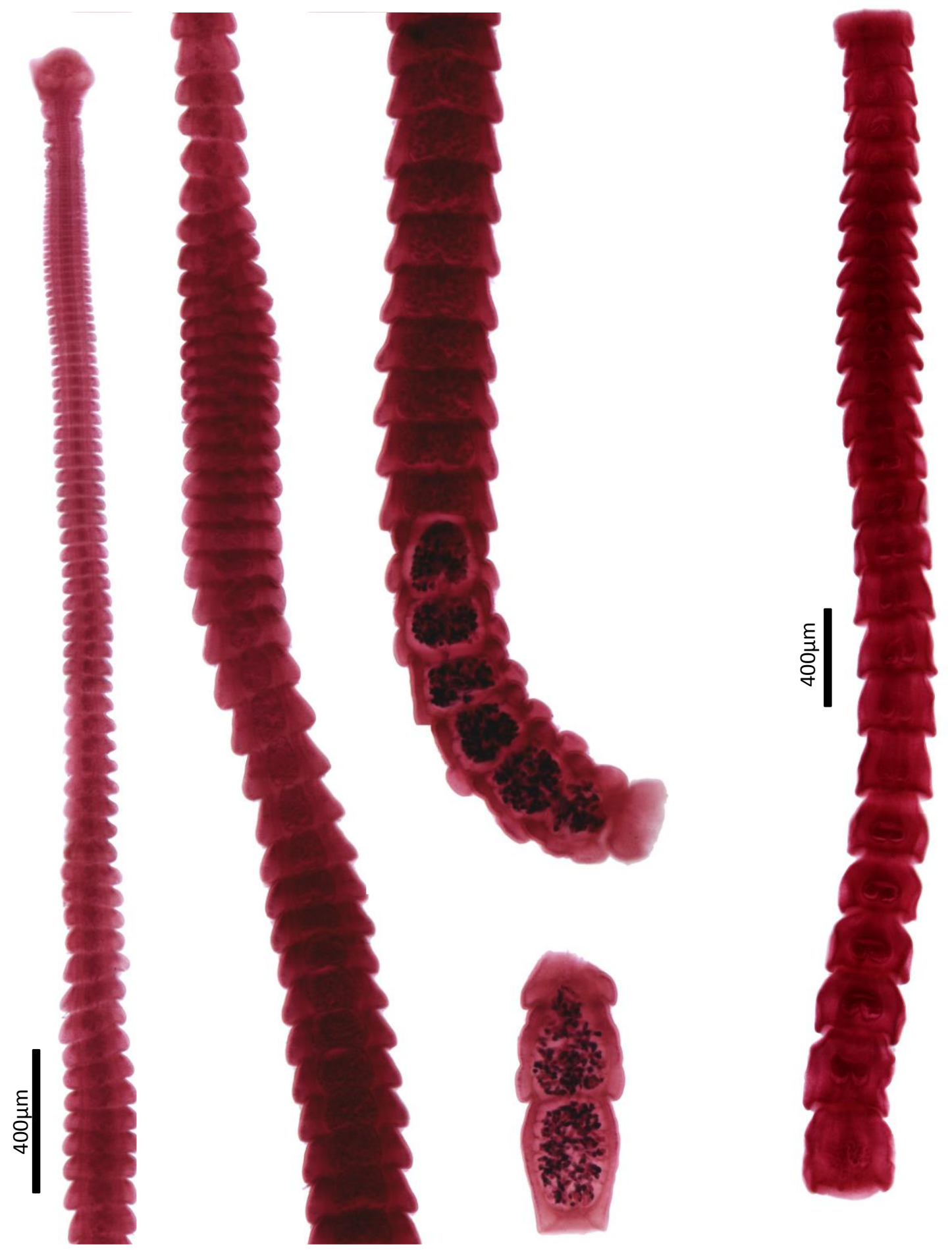

ANEXO D (continuação)

Figura 31. Metadilepididae (M04). Espécime completo. Parasita de Myrmotherula axillaris axillaris (Porto Velho, RO).

Figura 32. Paruterinidae (P03). Espécime incompleto. Parasita de Myrmotherula axillaris heterozyga (Porto Velho, RO). 
33
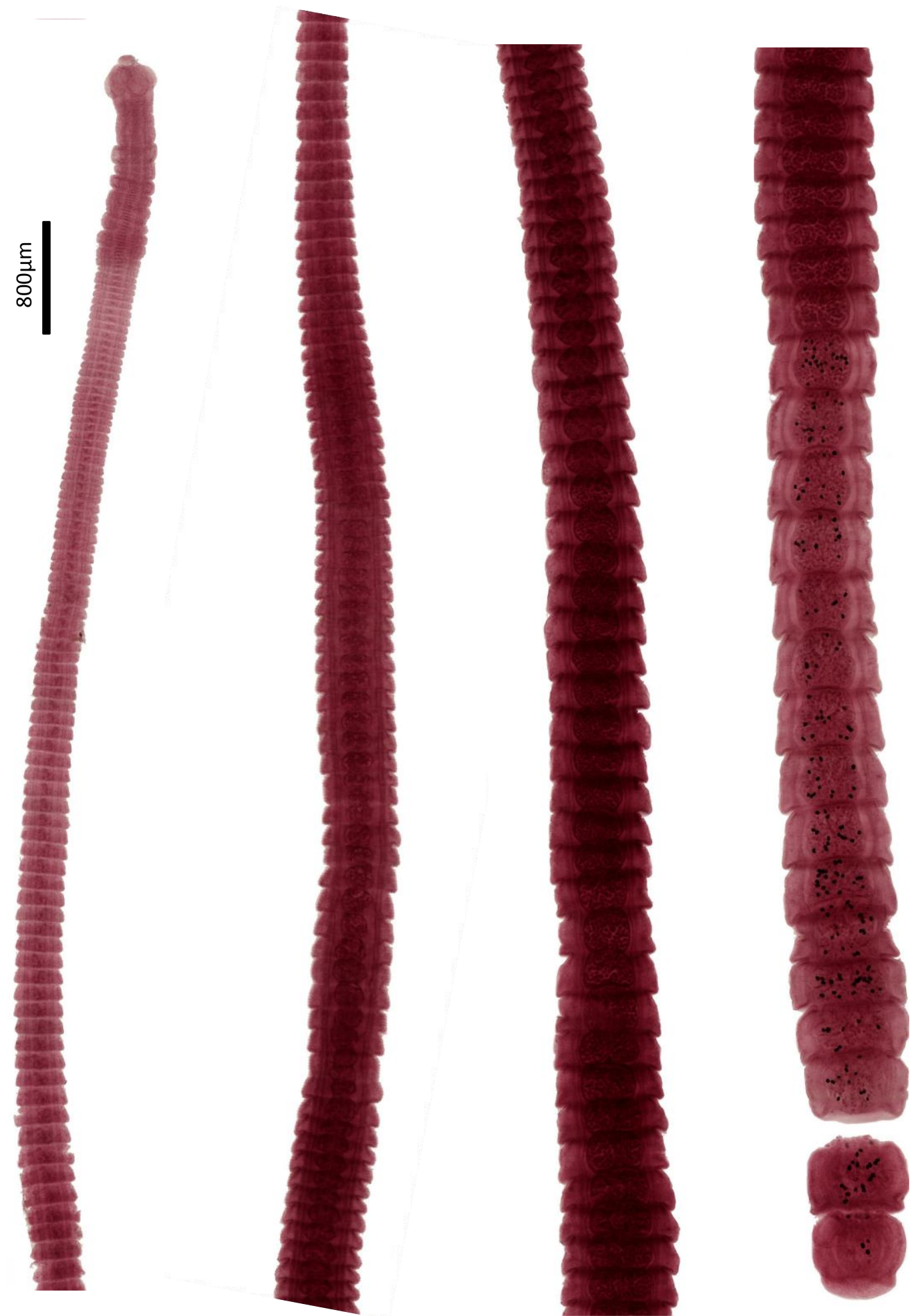

ANEXO D (continuação)

Figura 33. Metadilepididae (M05). Espécime completo. Parasita de Myrmotherula menetriesii menetriesii (Porto Velho, RO). 
34

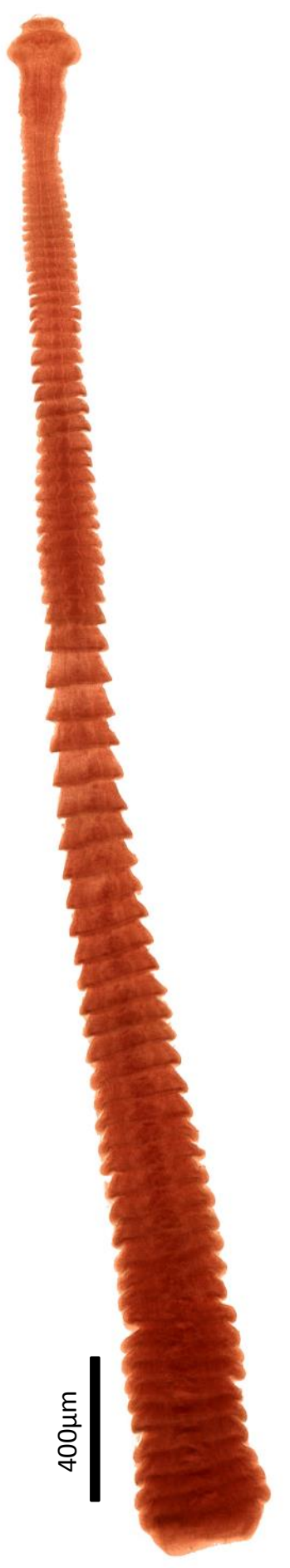

35

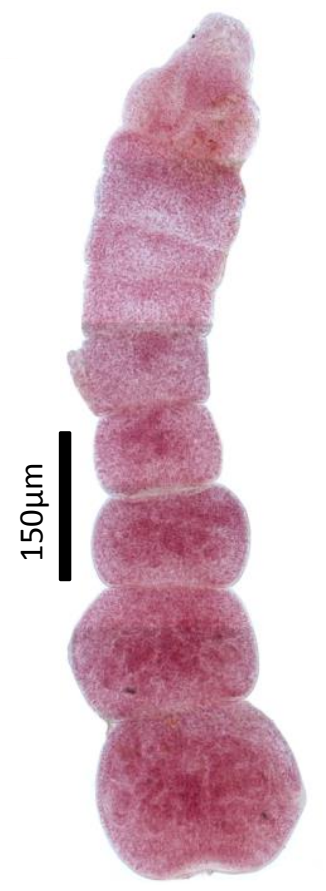

36

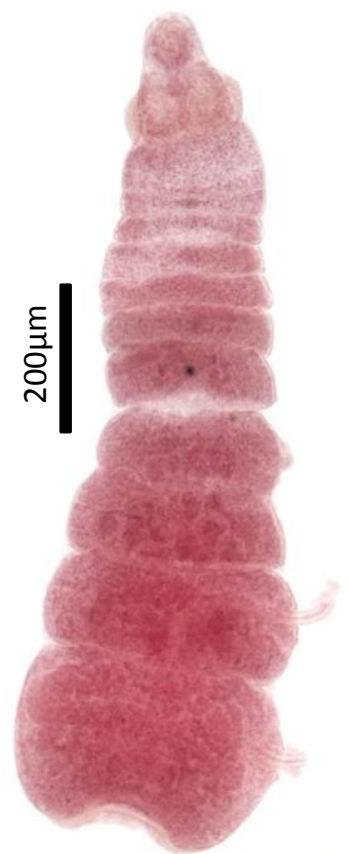

37

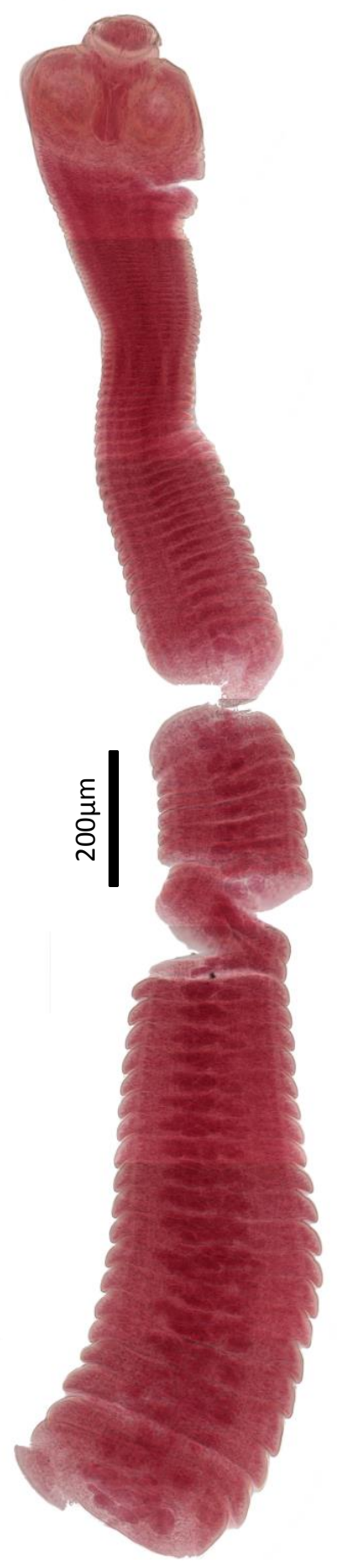

\section{ANEXO D (continuação)}

Figura 34. Metadilepididae (M06). Espécime incompleto. Parasita de Myrmotherula sclateri (Porto Velho, $\mathrm{RO})$.

Figura 35. Dilepididae (D08). Espécime completo. Parasita de Oneillornis salvini (Porto Velho, RO). Figura 36. Dilepididae (D09). Espécime completo. Parasita de Oneillornis salvini (Porto Velho, RO). Figura 37. Hymenolepididae (H17). Espécime incompleto. Parasita de Oneillornis salvini (Porto Velho, RO). 
38

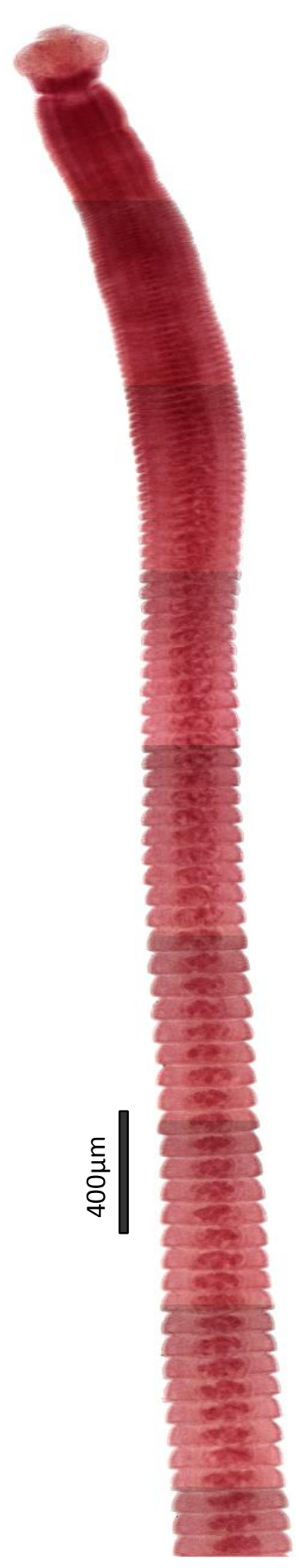

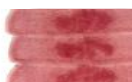

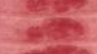

ats

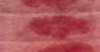

$\operatorname{lig}_{x}$

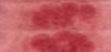

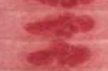

$x^{2}$

(etses

(2)

sise

$\left(\frac{902}{253}\right.$

$4=\frac{495}{435}$

$\div$

9.
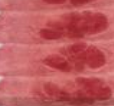

C.3.
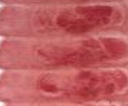

$(x+3)$

(a)
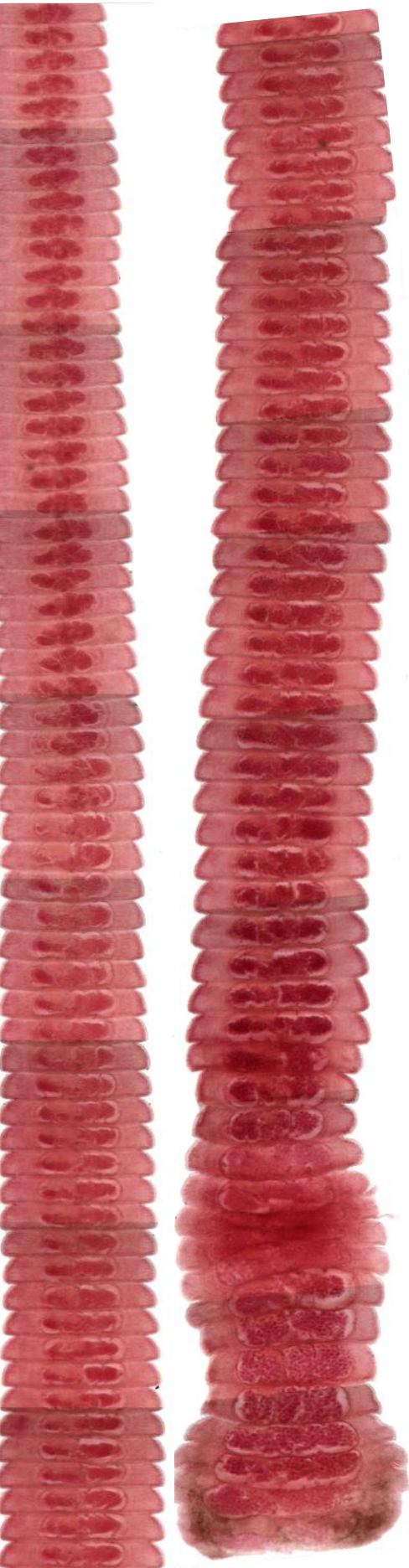

39

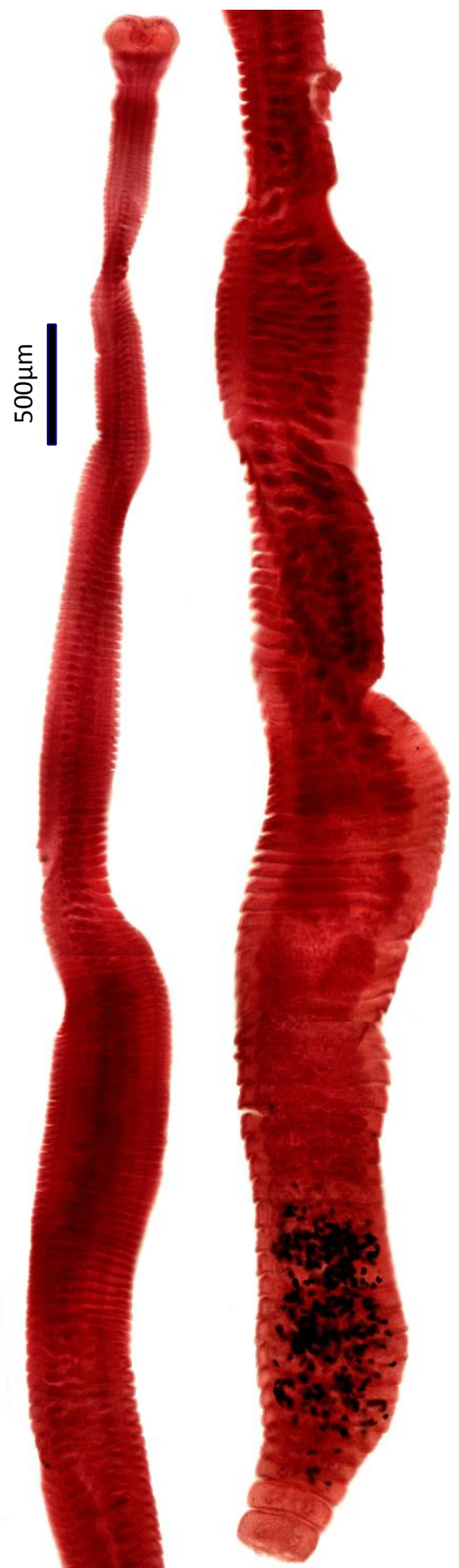

ANEXO D (continuação)

Figura 38. Hymenolepididae (H18). Espécime completo. Parasita de Phlegopsis borbae (Machadinho d'Oeste, RO).

Figura 39. Hymenolepididae (H19). Espécime incompleto. Parasita de Phlegopsis borbae (Machadinho d'Oeste, RO). 
40

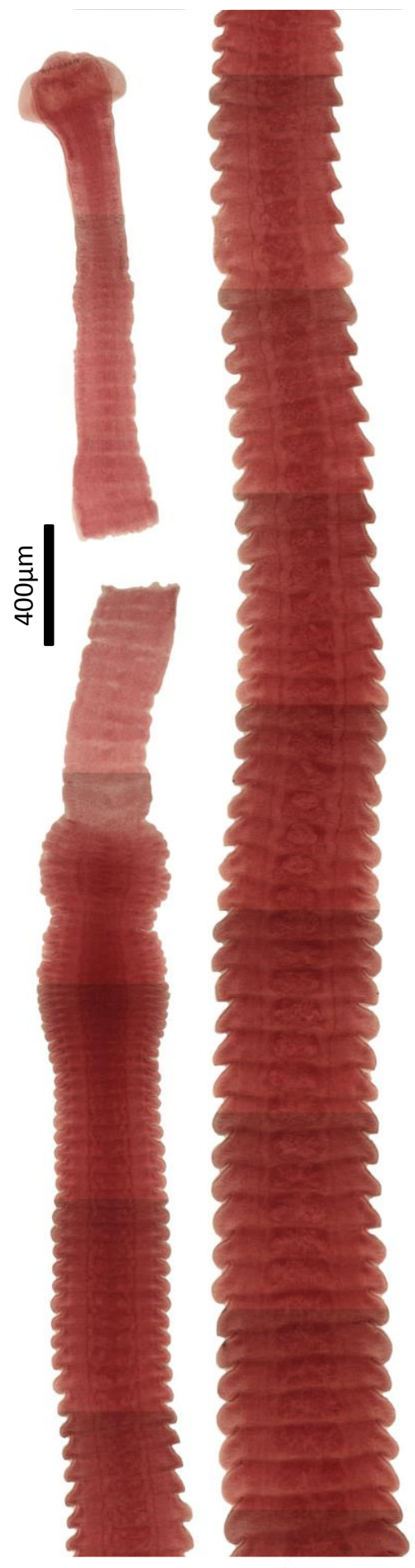

41
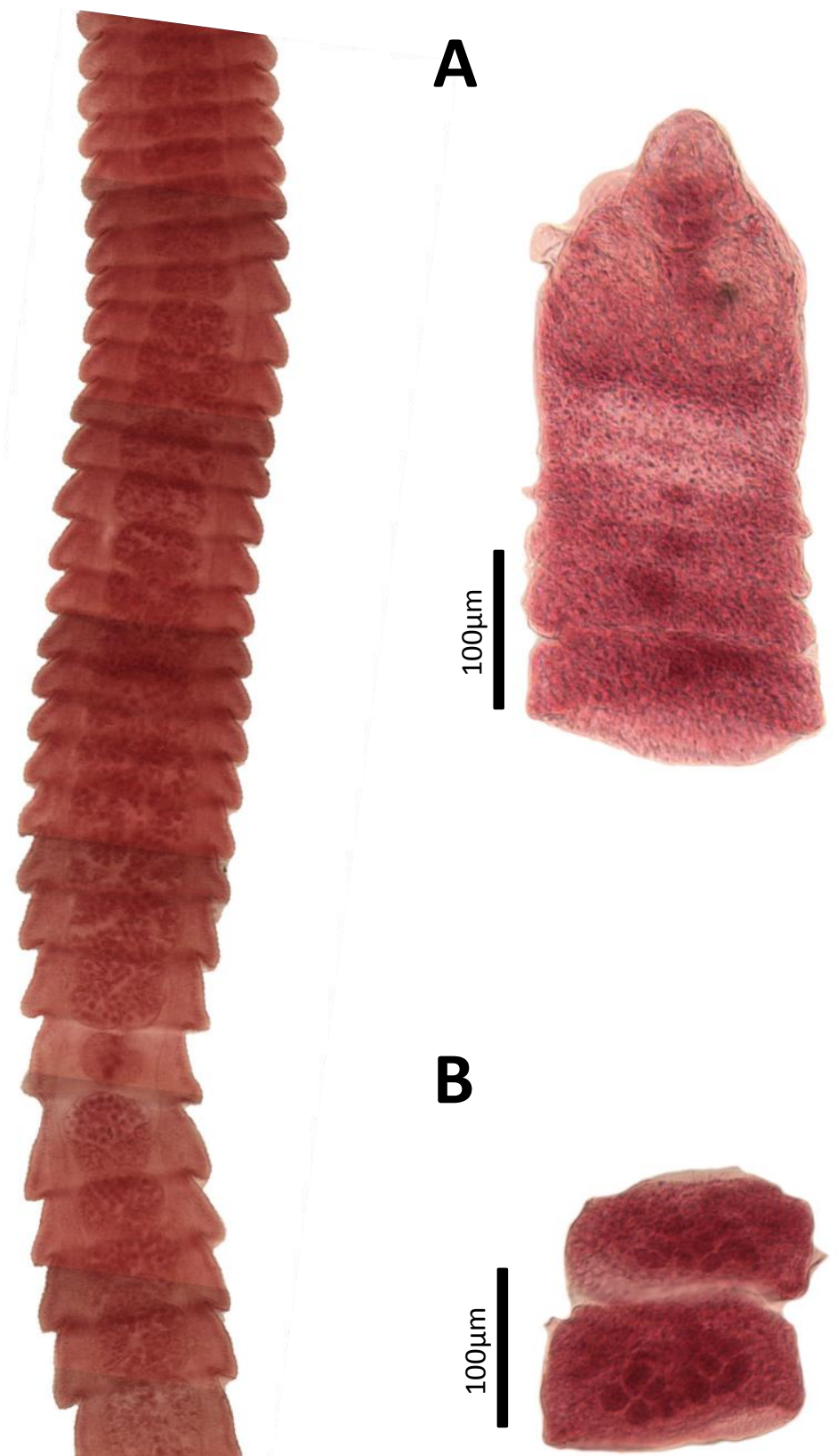

\section{ANEXO D (continuação)}

Figura 40. Metadilepididae (M07). Espécime completo. Parasita de Phlegopsis borbae (Machadinho d'Oeste, RO).

Figura 41. Dilepididae (D10). A. Espécime incompleto. B. Estróbilo. Parasita de Phlegopsis erythroptera ustulata (Porto Velho, RO). 
42

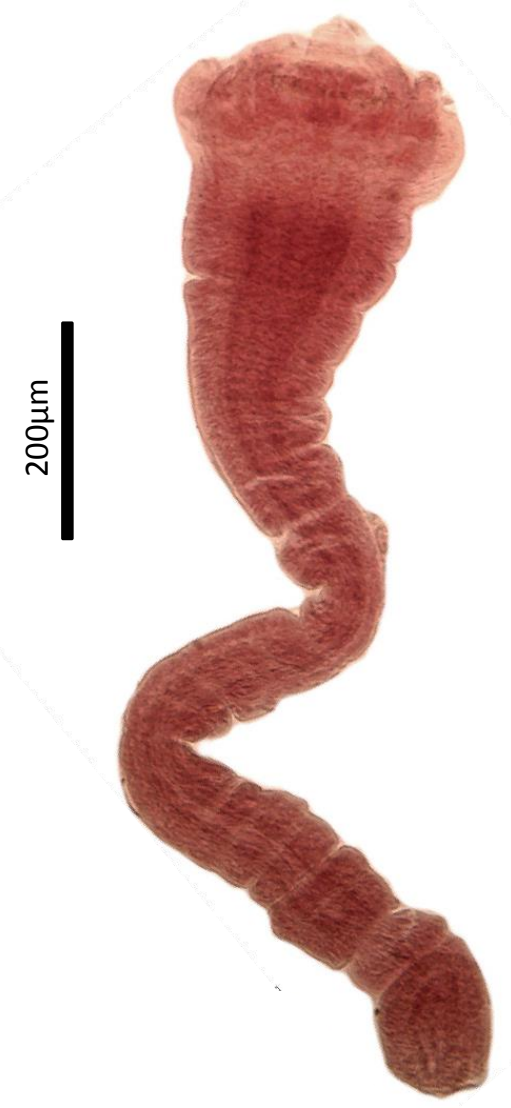

\section{4}

A

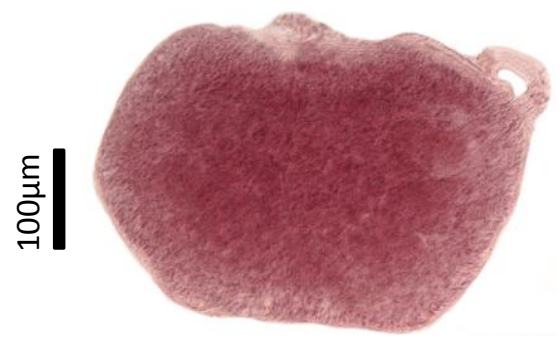

43

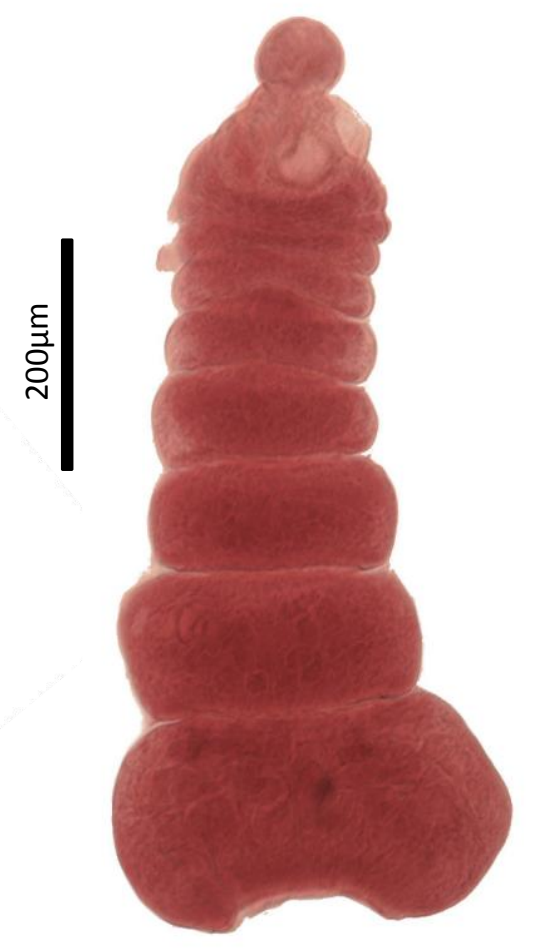

B

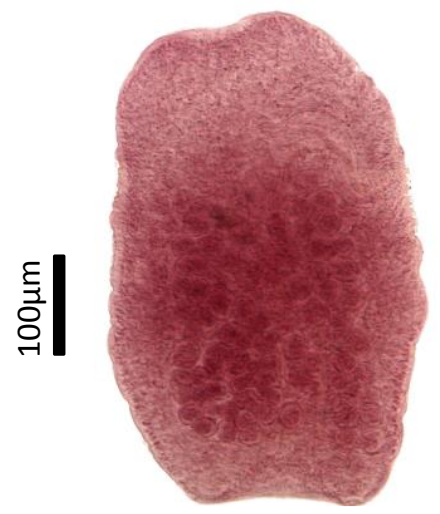

ANEXO D (continuação)

Figura 42. Metadilepididae (M08). Espécime incompleto imaturo. Parasita de Phlegopsis erythroptera ustulata (Porto Velho, RO).

Figura 43. Dilepididae (D11). Espécime completo. Parasita de Phlegopsis nigromaculata bowmani (Altamira, PA)

Figura 44. Dilepididae (D12).A. Proglótide pré grávida. B. Proglótide grávida. Parasita de Phlegopsis nigromaculata paraensis (Santana do Araguaia, PA). 


\section{5}

46
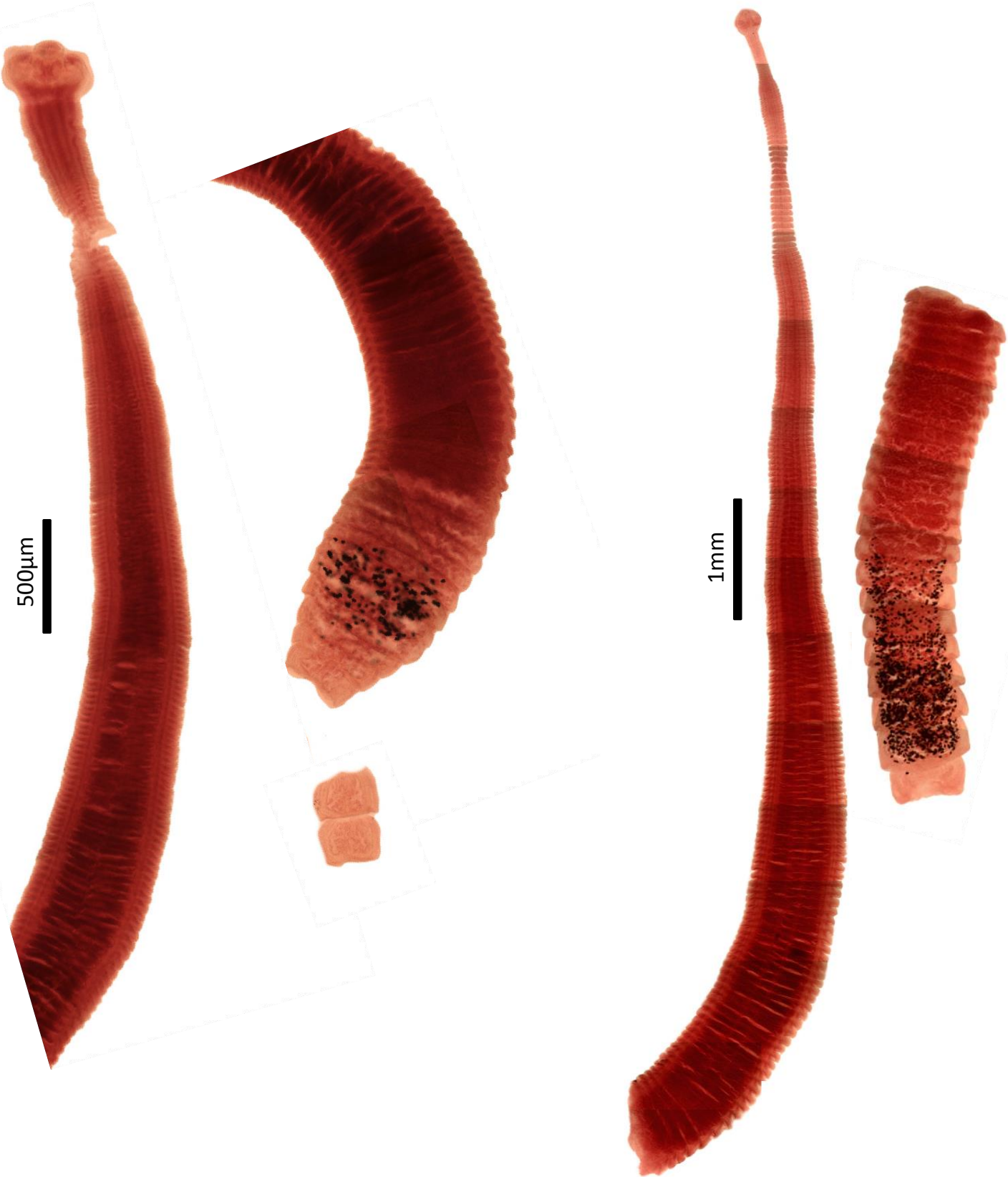

ANEXO D (continuação)

Figura 45. Hymenolepididae (H20). Espécime completo. Parasita de Phlegopsis nigromaculata paraensis (Santana do Araguaia, PA).

Figura 46. Hymenolepididae (H21). Espécime completo. Parasita de Phlegopsis nigromaculata paraensis (Santana do Araguaia, PA). 
47

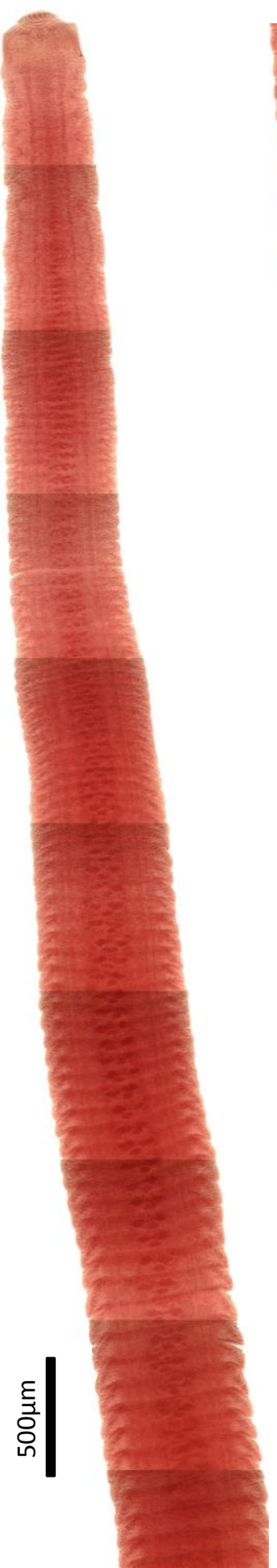

48

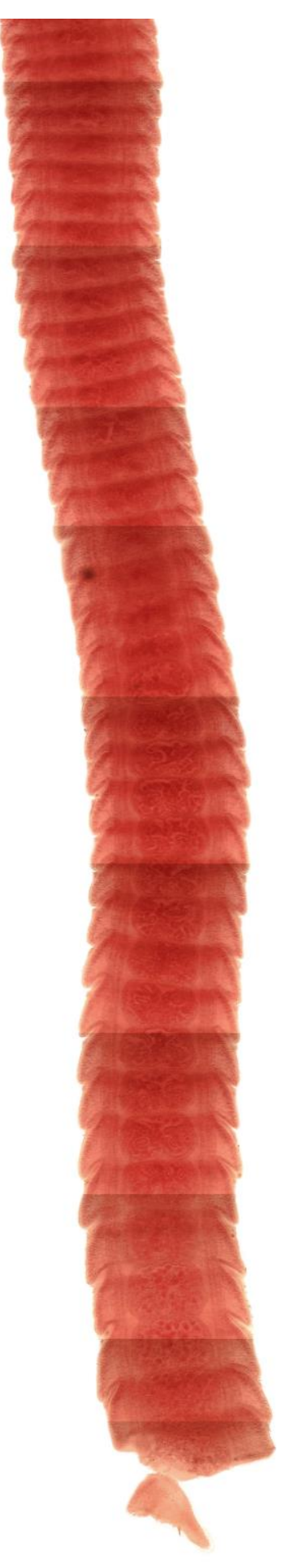

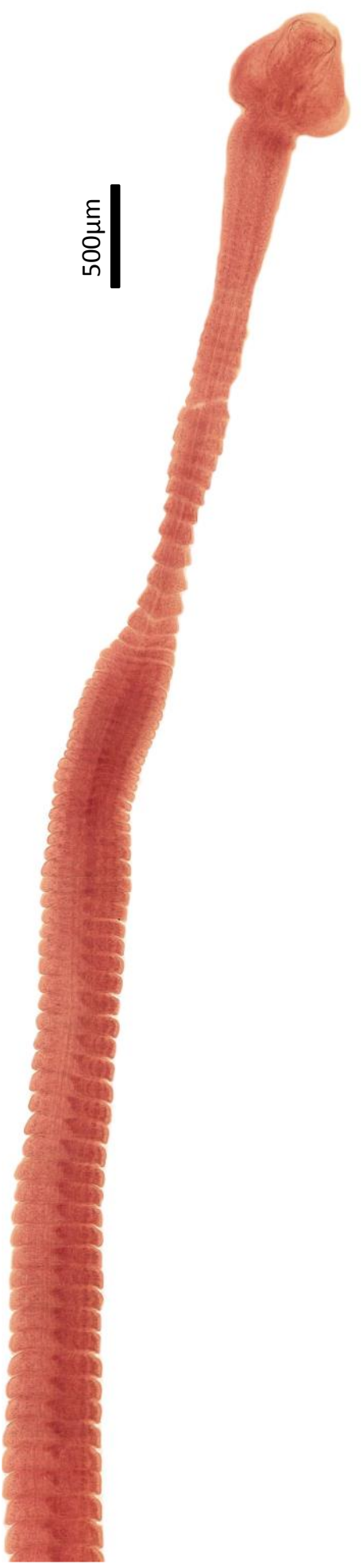

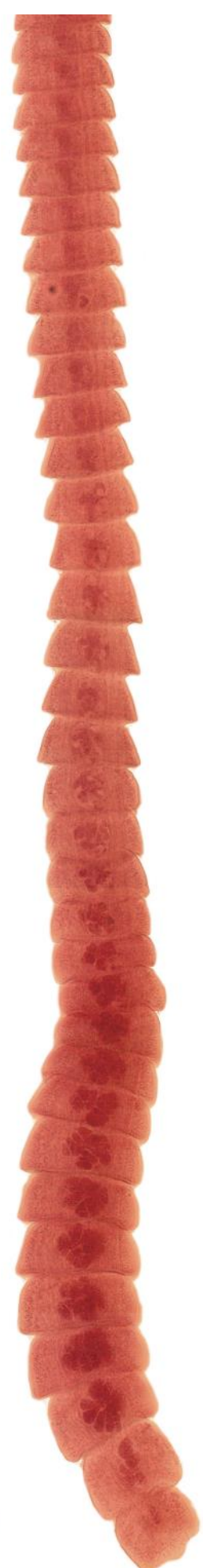

ANEXO D (continuação)

Figura 47. Metadilepididae (M09). Espécime incompleto. Parasita de Phlegopsis nigromaculata paraensis (Santana do Araguaia, PA).

Figura 48. Hymenolepididae (H22). Espécime completo. Parasita de Pyriglena leuconota interposita (Santana do Araguaia, PA). 
49

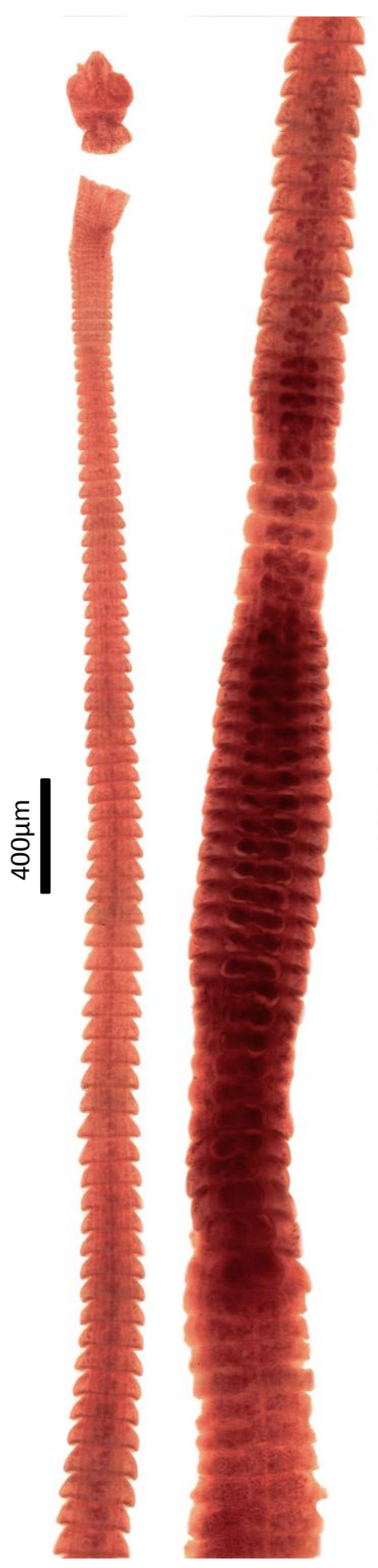

50

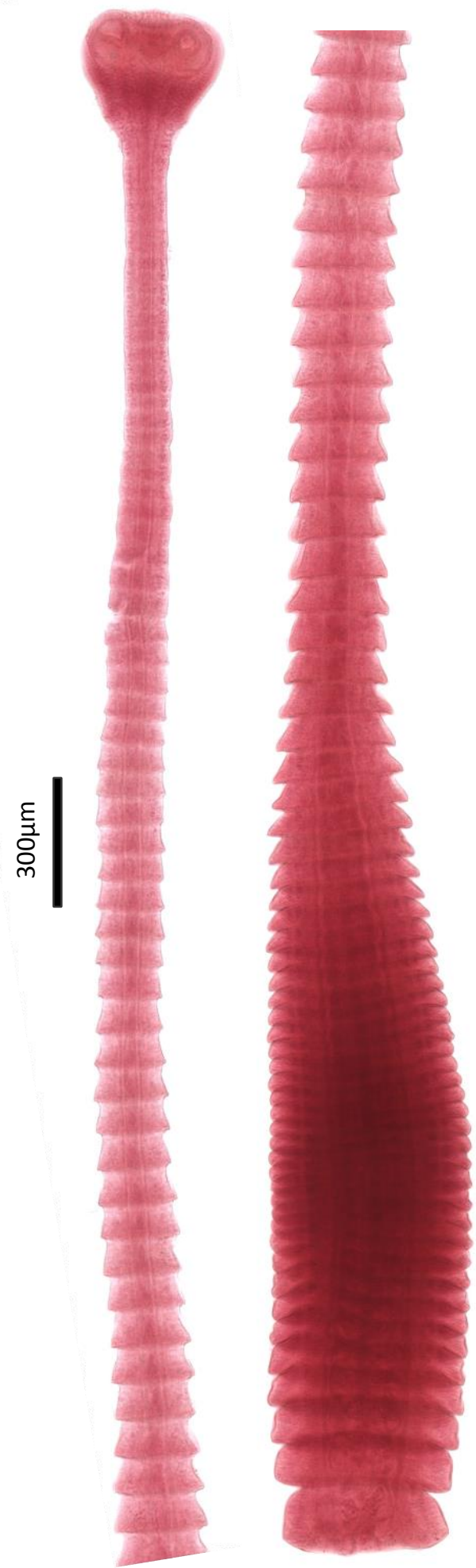

ANEXO D (continuação)

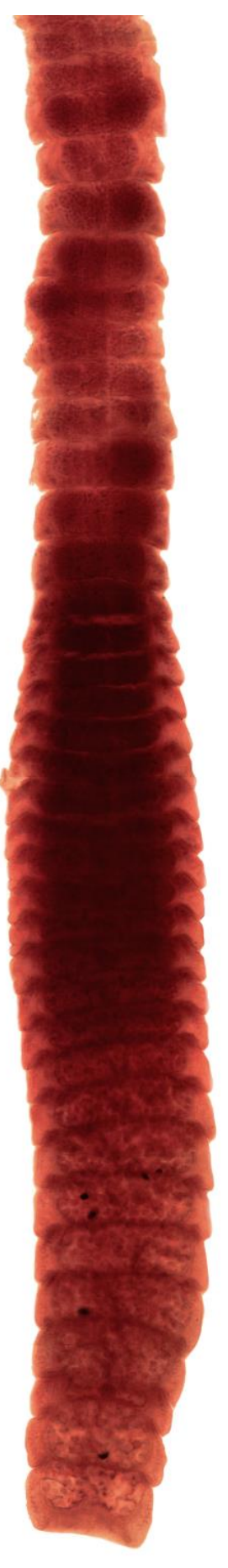

Figura 49. Hymenolepididae (H23). Espécime completo. Parasita de Pyriglena leuconota interposita (Santana do Araguaia, PA).

Figura 50. Metadilepididae (M10). Espécime incompleto. Parasita de Pyriglena leuconota interposita (Santana do Araguaia, PA). 
51

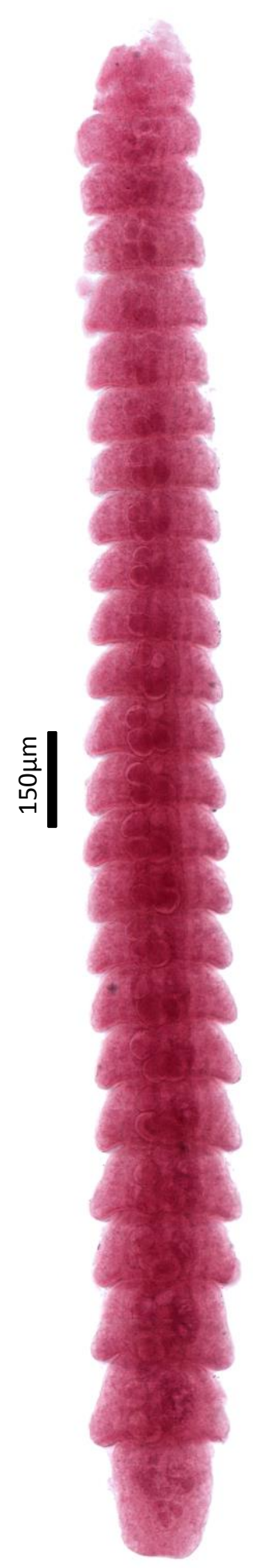

52

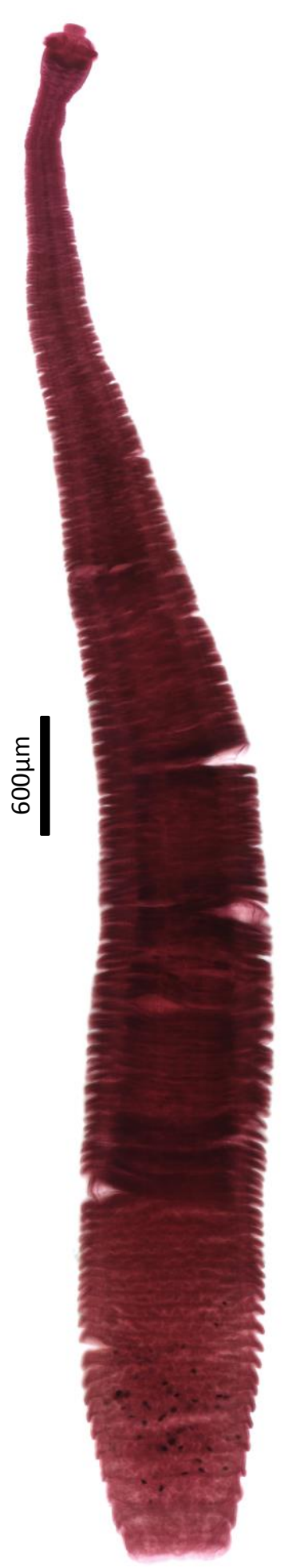

53

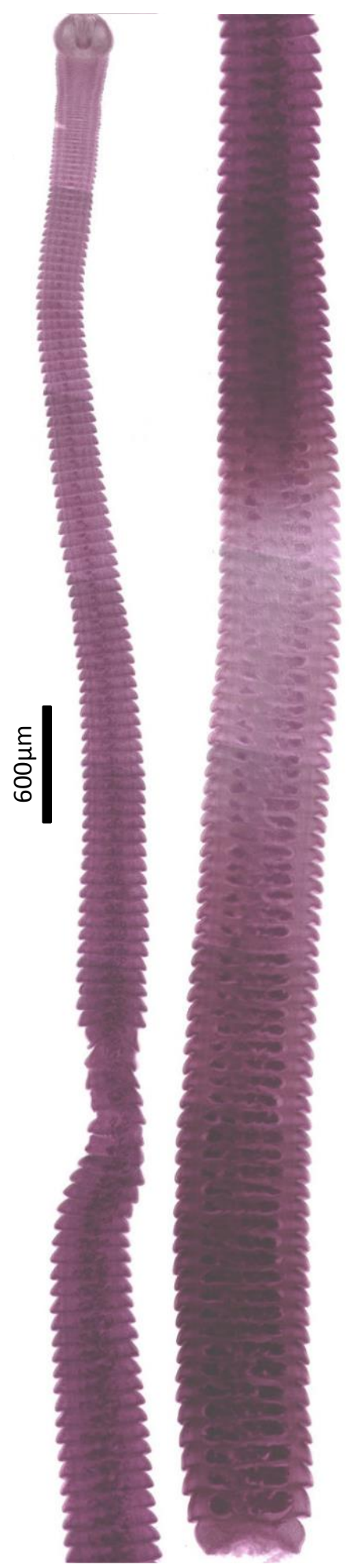

ANEXO D (continuação)

Figura 51. Não identificado (NI04). Espécime incompleto. Parasita de Pyriglena leuconota interposita (Santana do Araguaia, PA).

Figura 52. Hymenolepididae (H24). Espécime incompleto. Parasita de Pyriglena leuconota similis (Altamira, PA).

Figura 53. Hymenolepididae (H25). Espécime incompleto. Parasita de Pyriglena leuconota similis (Altamira, PA). 


\section{4}

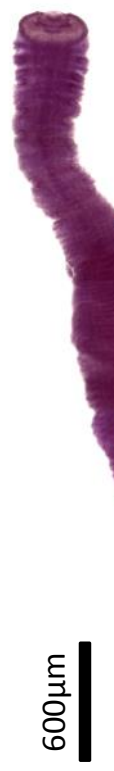

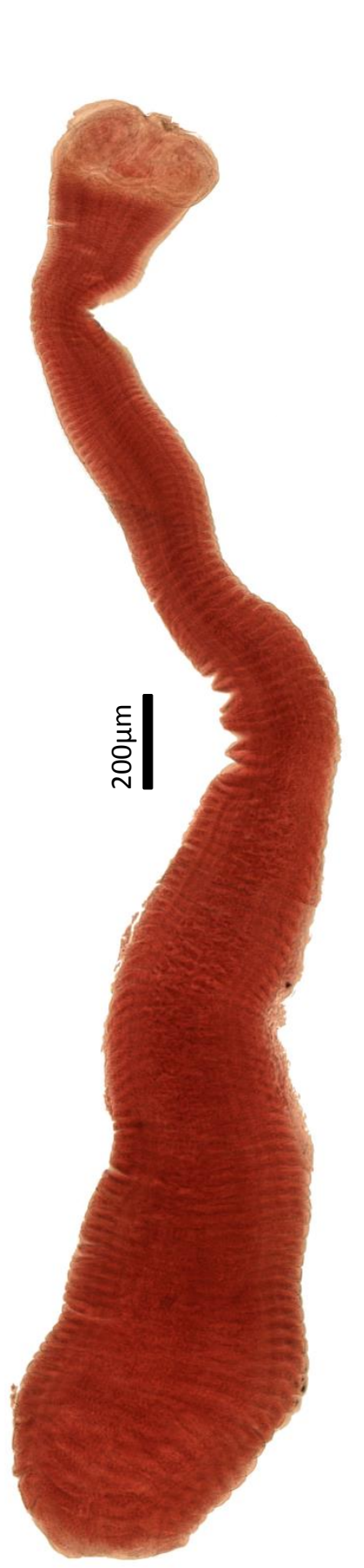

55
56

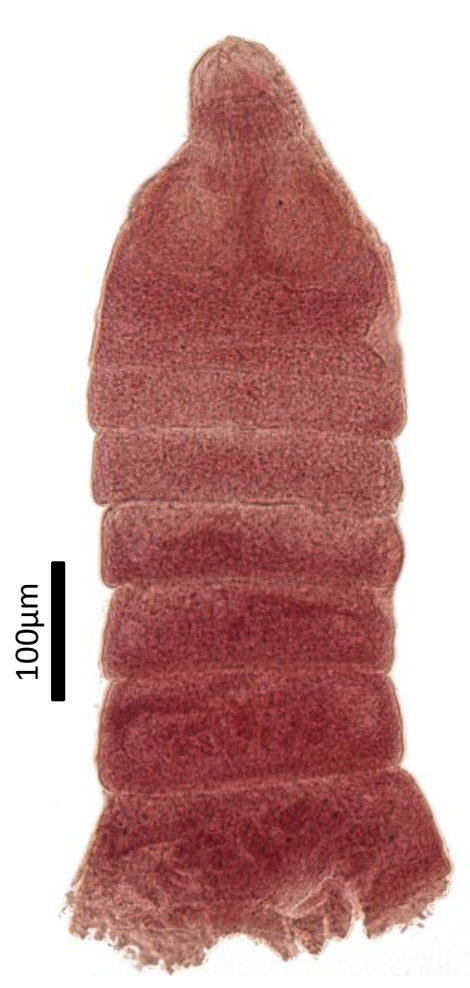

\section{ANEXO D (continuação)}

Figura 54. Metadilepididae (M11). Espécime incompleto. Parasita de Pyriglena leuconota similis (Altamira, PA).

Figura 55. Hymenolepididae (H26). Espécime incompleto. Parasita de Rhegmatorhina gymnops (Altamira, PA).

Figura 56. Dilepididae (D14). Espécime incompleto. Parasita de Rhegmatorhina hoffmannsi (Machadinho d'Oeste). 
57

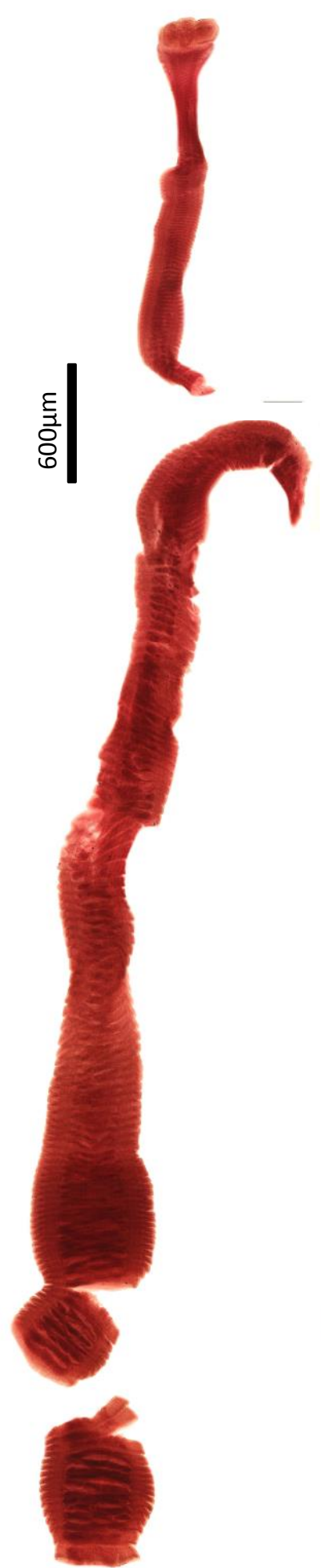

58

A

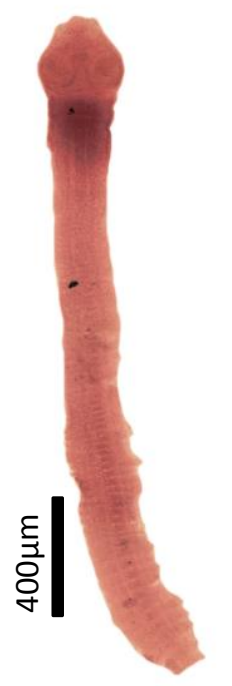

B
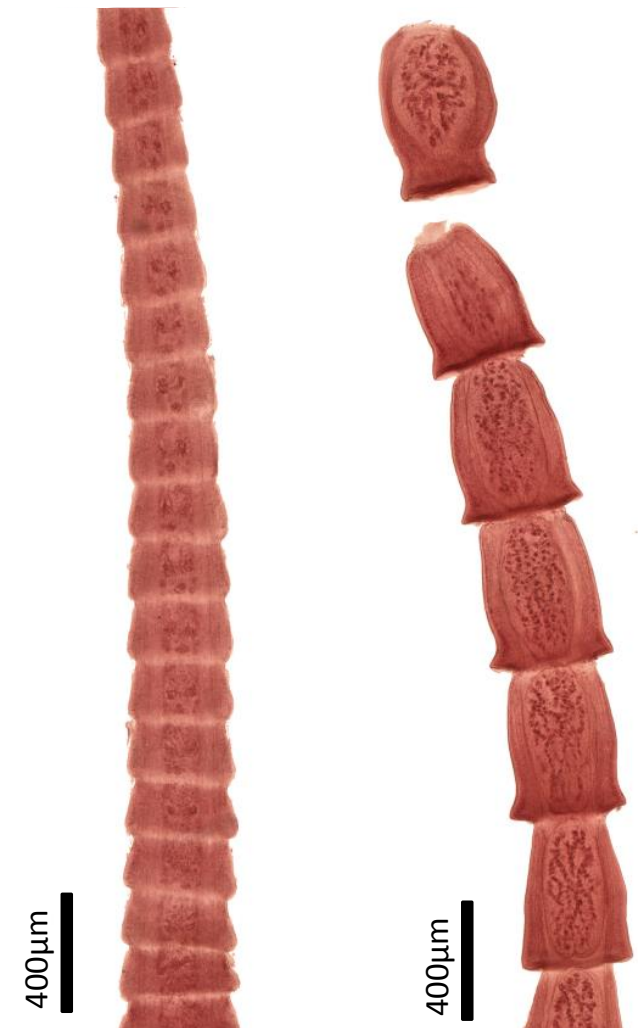

통
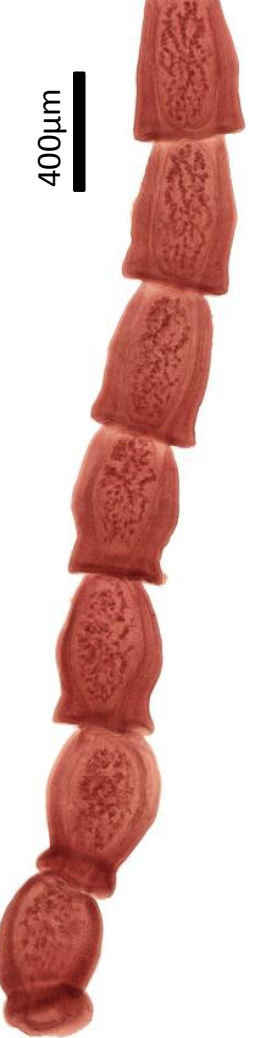

ANEXO D (continuação)

Figura 57. Hymenolepididae (H27). Espécime incompleto. Parasita de Rhegmatorhina hoffmannsi (Machadinho d'Oeste).

Figura 58. Metadilepididae (M12). Segmentos de um espécime completo. A. Escólex e segmento estrobilar imaturo. B. Segmento estrobilar maduro e pré grávido. C. Segmento estrobilar grávido. Parasita de Rhegmatorhina hoffmannsi (Machadinho d'Oeste). 
59

A

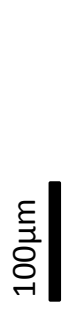

60

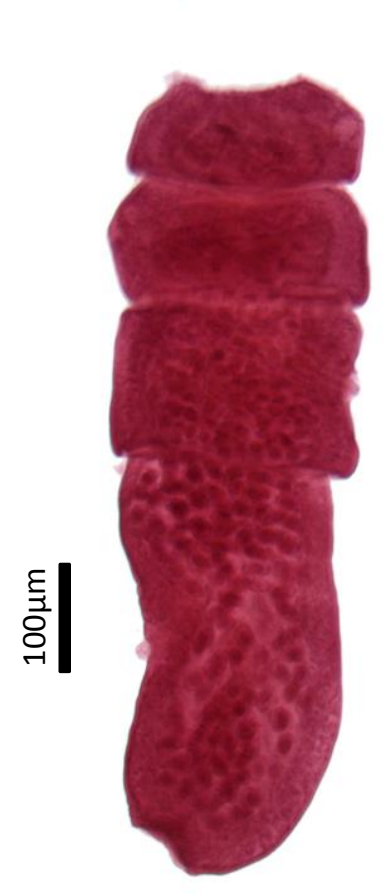

B

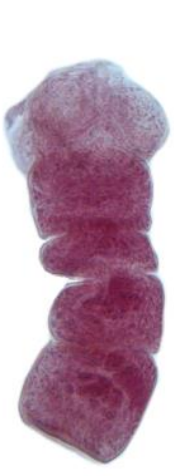

61
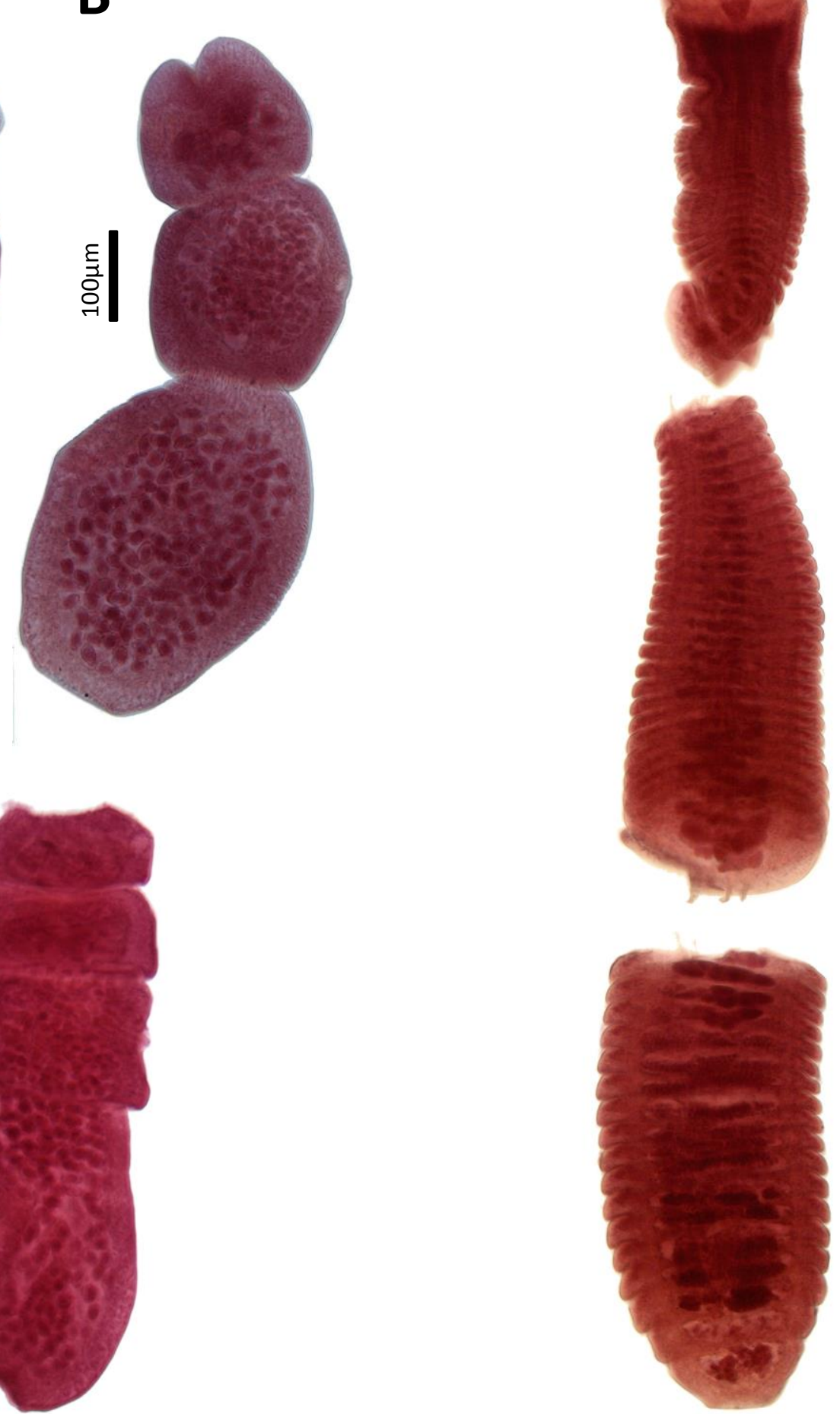

\section{ANEXO D (continuação)}

Figura 59. Dilepididae (D15). A. Escólex. B. Estróbilo. Parasita de Rhegmatorhina melanosticta purusiana (Porto Velho, RO).

Figura 60. Dilepididae (D16). Espécime incompleto. Parasita de Rhegmatorhina melanosticta purusiana (Porto Velho, RO).

Figura 61. Hymenolepididae (H28). Espécime completo. Parasita de Rhegmatorhina melanosticta purusiana (Porto Velho, RO). 
62

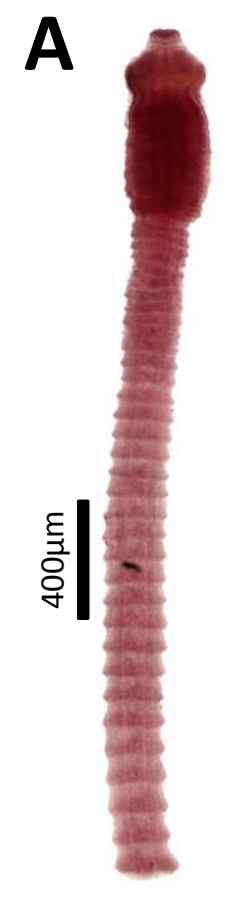

64
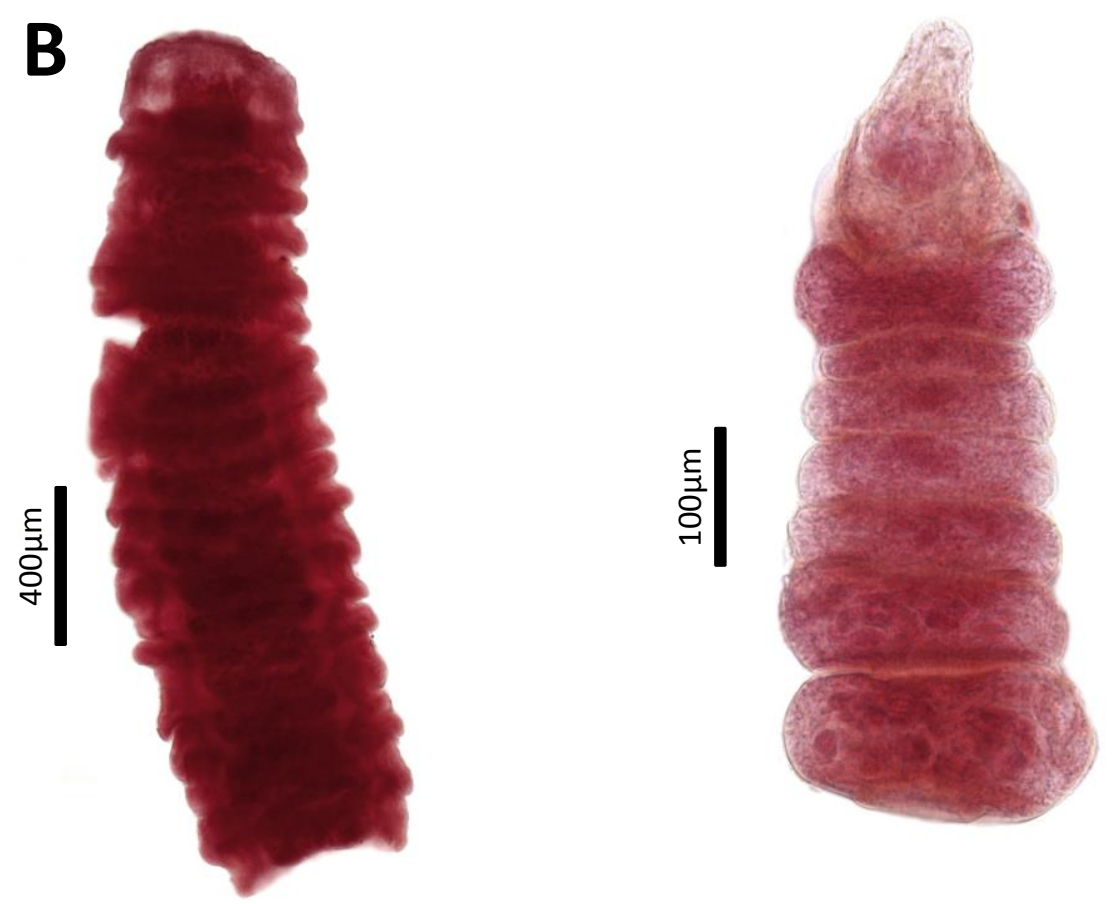

65

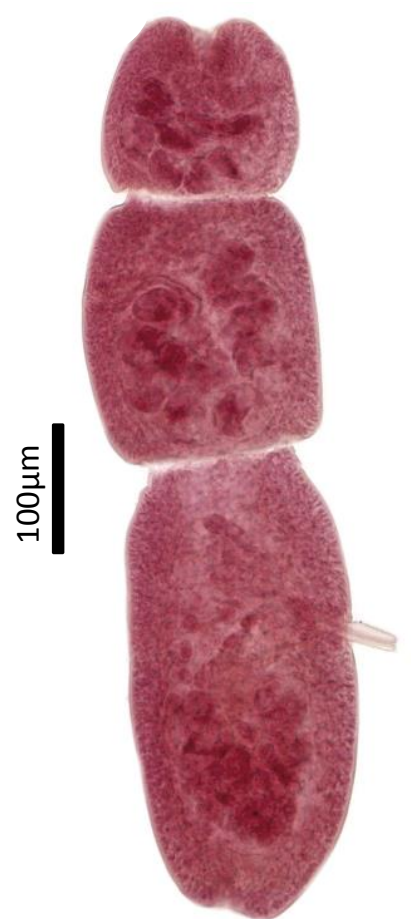

ANEXO D (continuação)

Figura 62. Metadilepididae (M13). Espécime incompleto A. Escólex. B. Estróbilo. Parasita de Rhegmatorhina melanosticta purusiana (Porto Velho, RO).

Figura 63. Dilepididae (D17). Espécime completo. Parasita de Sciaphylax hemimelaena (Porto Velho, RO).

Figura 64. Dilepididae (D18). Espécime completo. Parasita de Sciaphylax hemimelaena (Porto Velho, RO).

Figura 65. Dilepididae (D19). Espécime completo. Parasita de Sciaphylax pallens (Porto Velho, RO). 
66

$\mathbf{A}$

67

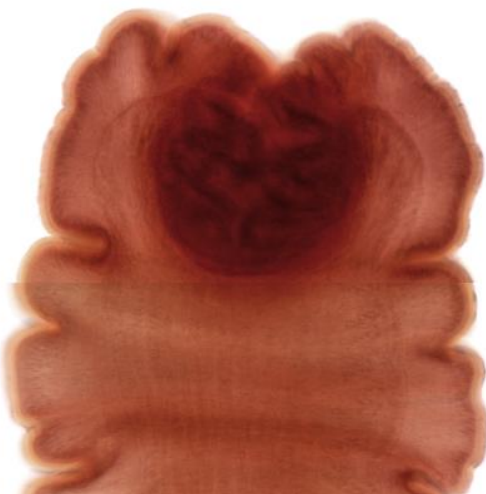

|

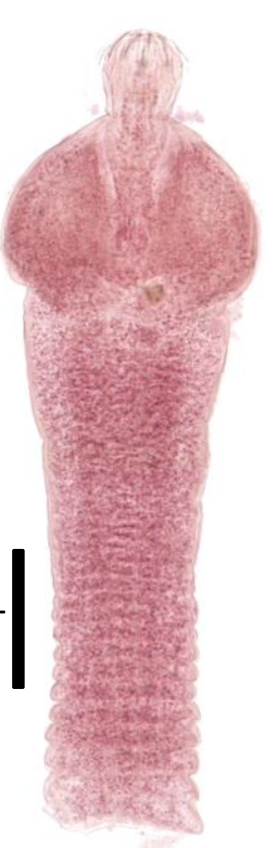

B

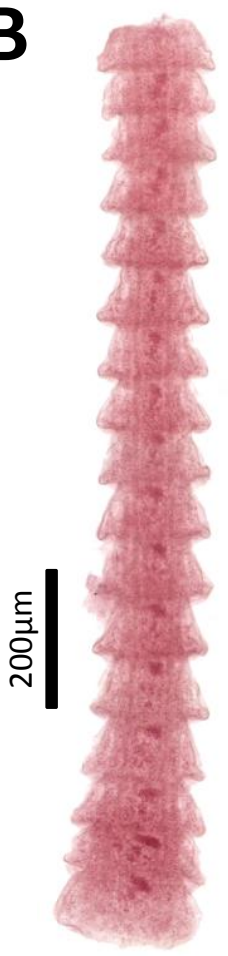

68
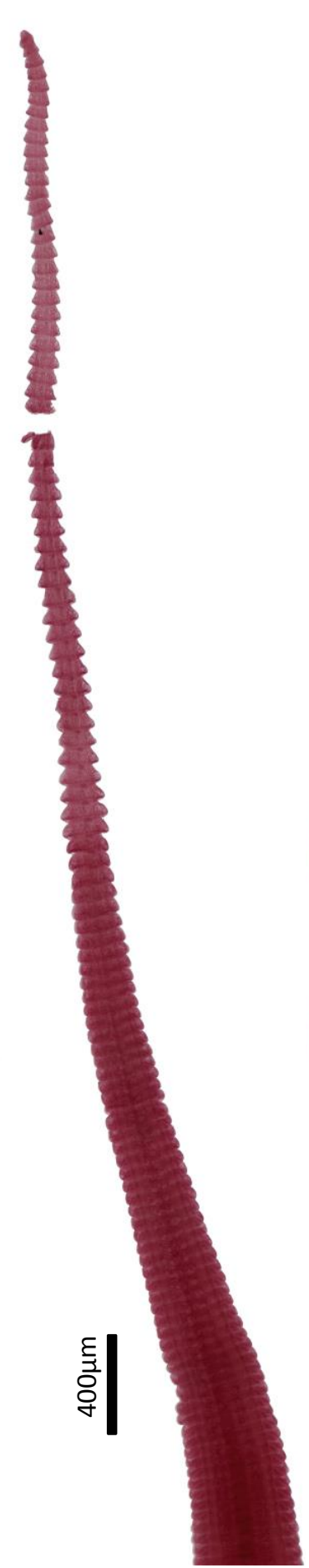

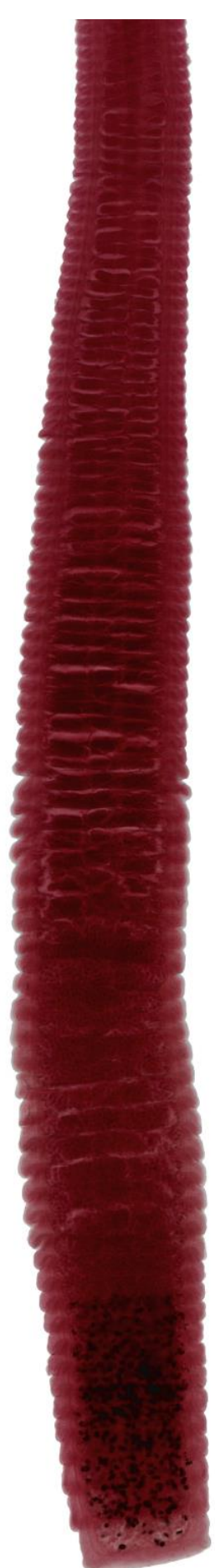

ANEXO D (continuação)

Figura 66. Hymenolepididae (H29). Espécime incompleto A. Escólex. B. Estróbilo. Parasita de Sciaphylax pallens (Machadinho d'Oeste, RO).

Figura 67. Não identificado (NI05). Espécime em estágio larval. Parasita de Sciaphylax pallens (Machadinho d'Oeste, RO).

Figura 68. Hymenolepididae (H30). Espécime completo. Parasita de Sclateria naevia toddi (Altamira, PA). 
69

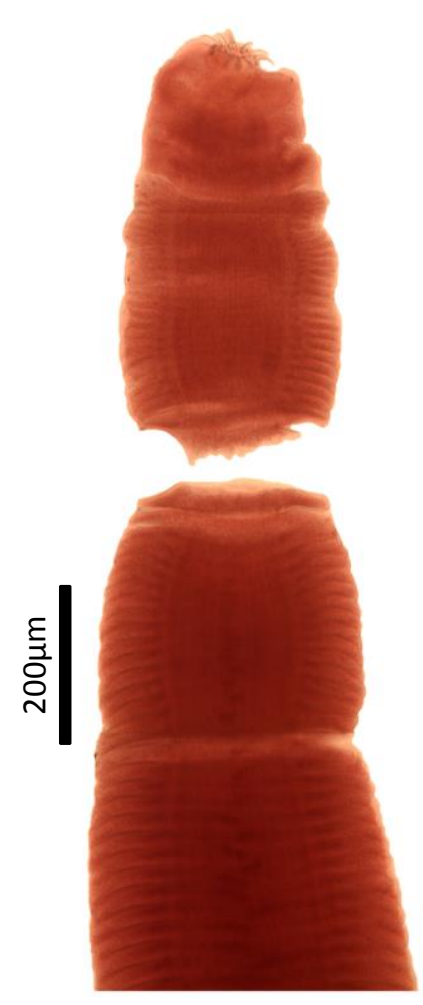

70

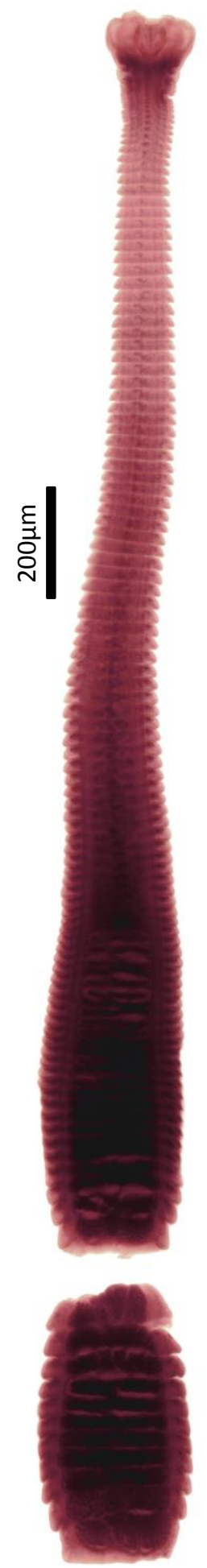

71

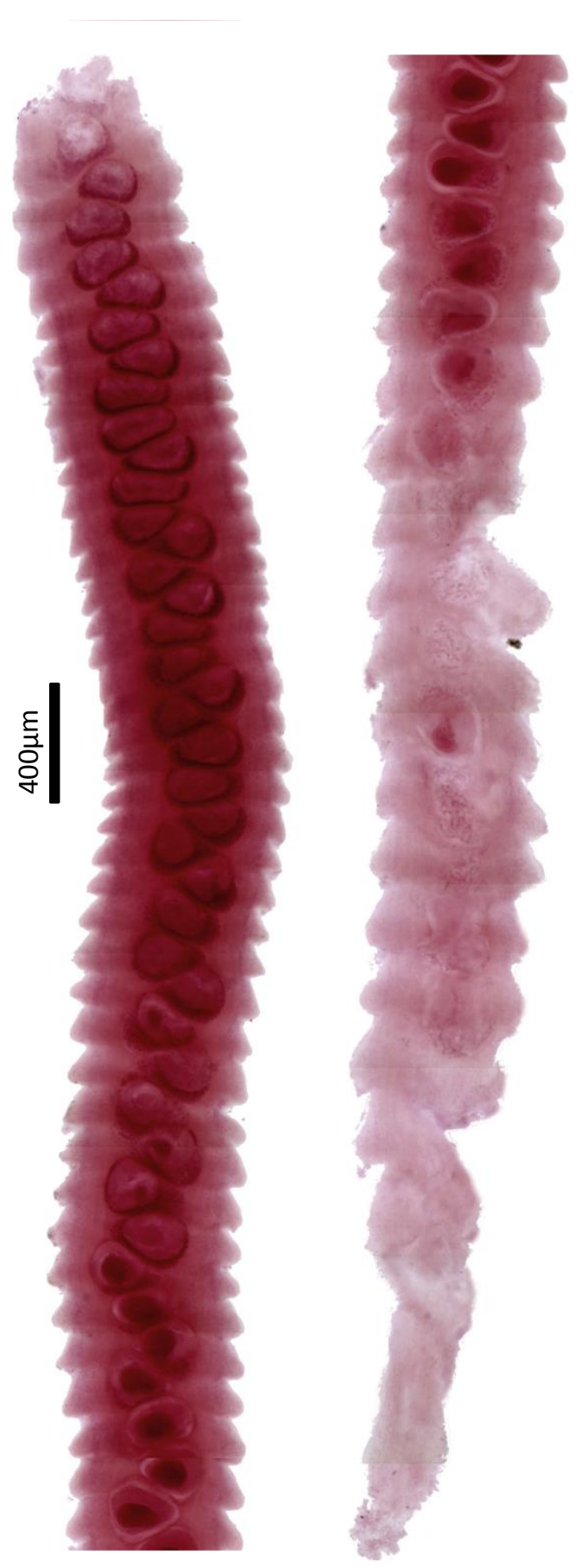

\section{ANEXO D (continuação)}

Figura 69. Metadilepididae (M14). Espécime incompleto. Parasita de Taraba major borbae (Porto Velho, RO).

Figura 70. Hymenolepididae (H31). Espécime completo. Parasita de Thamnomanes ardesiacus ardesiacus (Porto Velho, RO).

Figura 71. Paruterinidae (P04). Espécime incompleto. Parasita de Thamnomanes ardesiacus ardesiacus (Porto Velho, RO). 
72

73
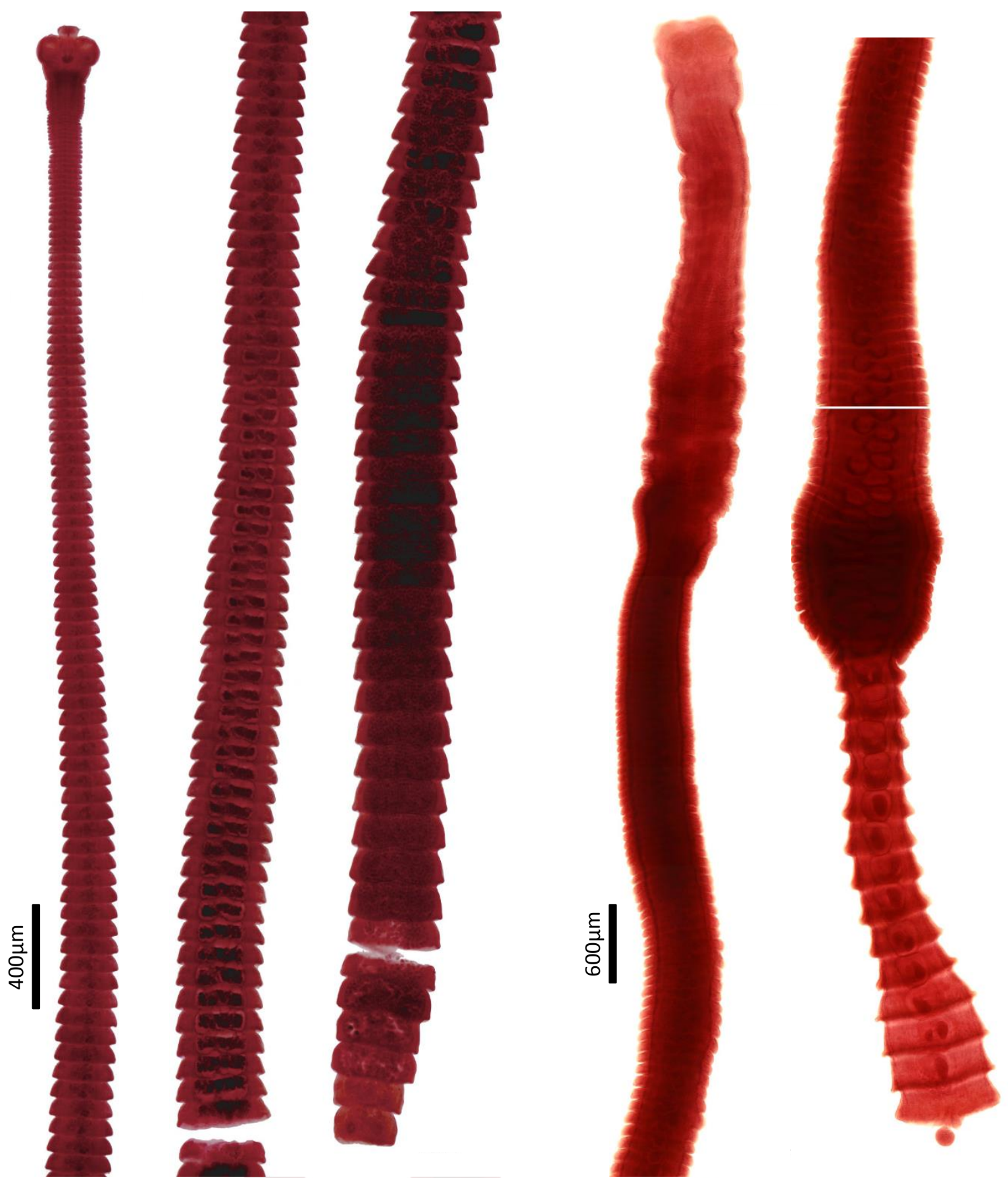

ANEXO D (continuação)

Figura 72. Hymenolepididae (H32). Espécime completo. Parasita de Thamnomanes caesius persimilis (Porto Velho, RO).

Figura 73. Paruterinidae (P05). Espécime incompleto. Parasita de Thamnomanes saturninus saturninus (Porto Velho, RO). 


\section{4}

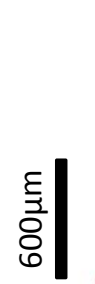

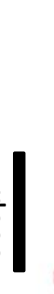
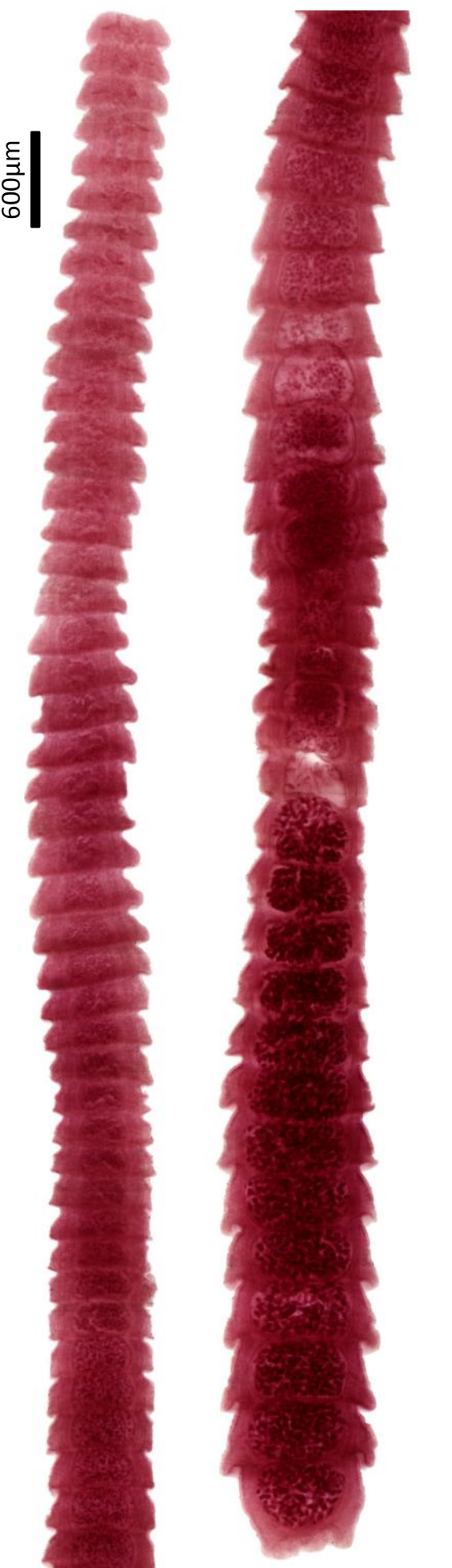

ANEXO D (continuação)

Figura 74. Metadilepididae (M15). Espécime incompleto. Parasita de Thamnomanes saturninus saturninus (Porto Velho, RO).

Figura 75. Não identificado (NI06). Espécime em estágio larval. Parasita de Thamnomanes saturninus saturninus (Machadinho d'Oeste, RO).

Figura 76. Hymenolepididae (H33). Espécime incompleto. Parasita de Thamnophilus aethiops punctuliger (Machadinho d'Oeste, RO).

\section{5}
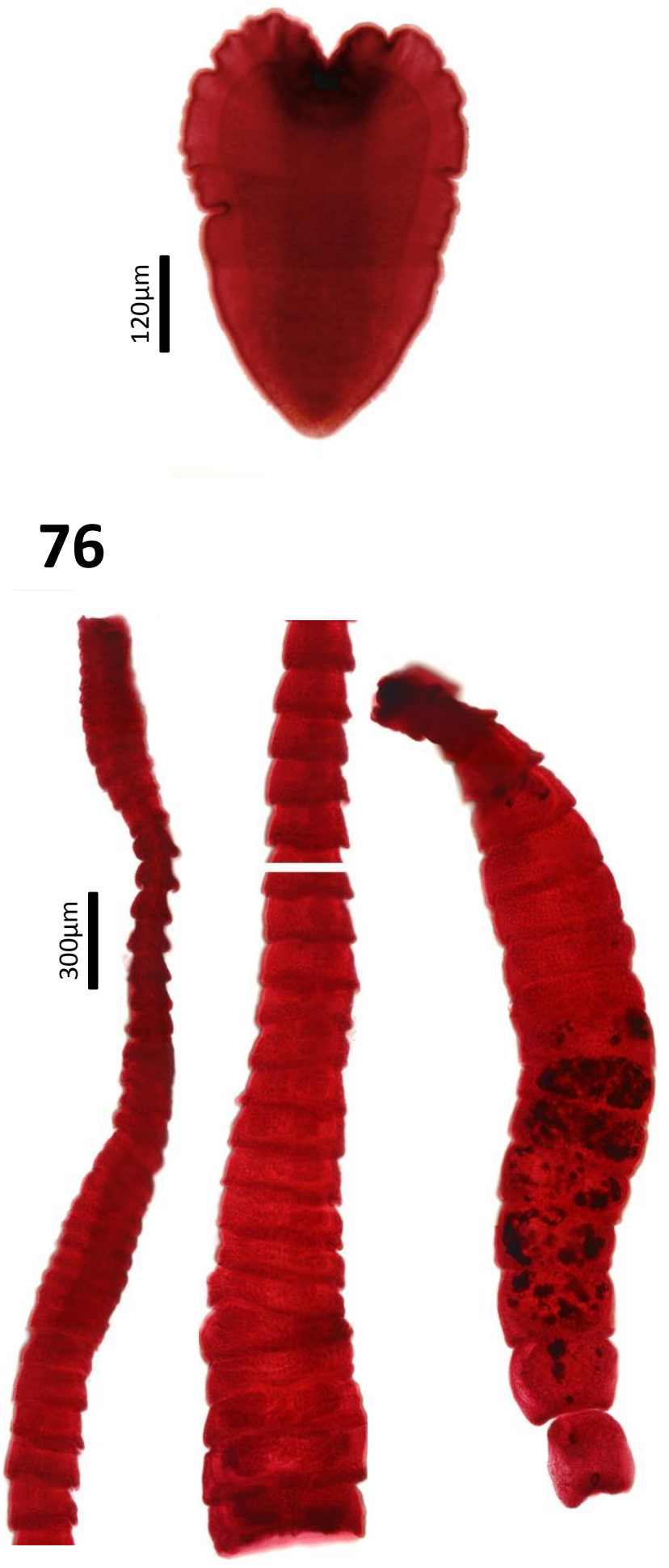


\section{7}

78
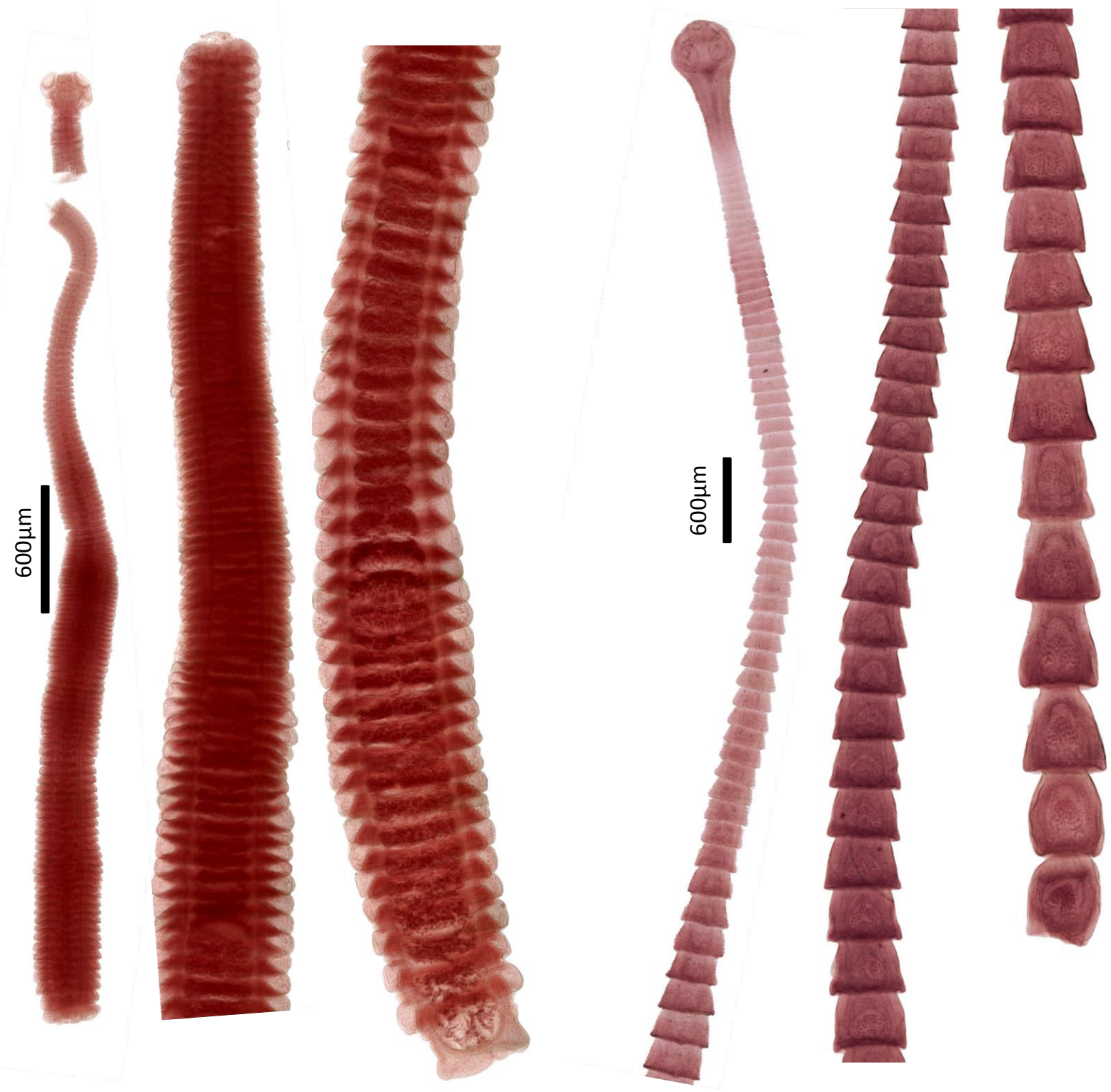

ANEXO D (continuação)

Figura 77. Metadilepididae (M16). Espécime completo. Parasita de Thamnophilus aethiops punctuliger (Porto Velho, RO).

Figura 78. Paruterinidae (P06). Espécime completo. Parasita de Thamnophilus murinus canipennis (Porto Velho, RO). 
79

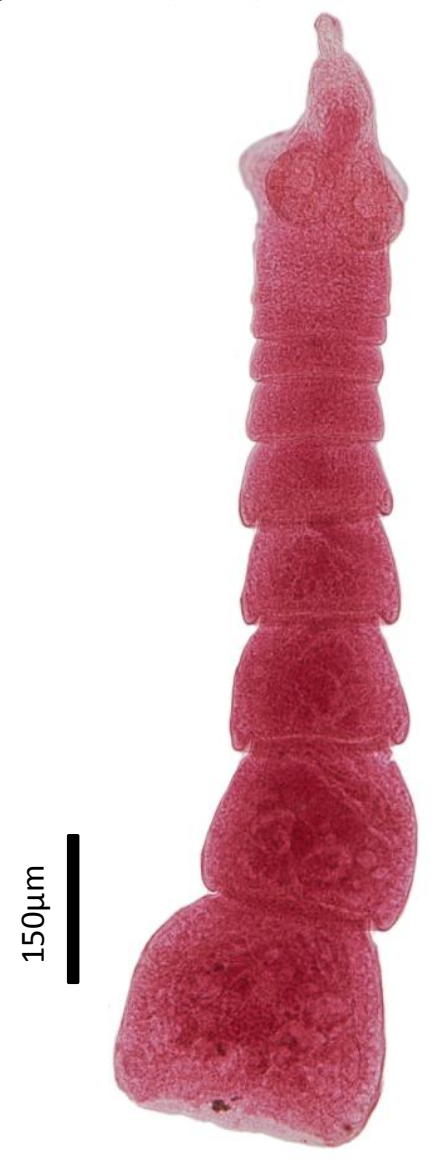

80

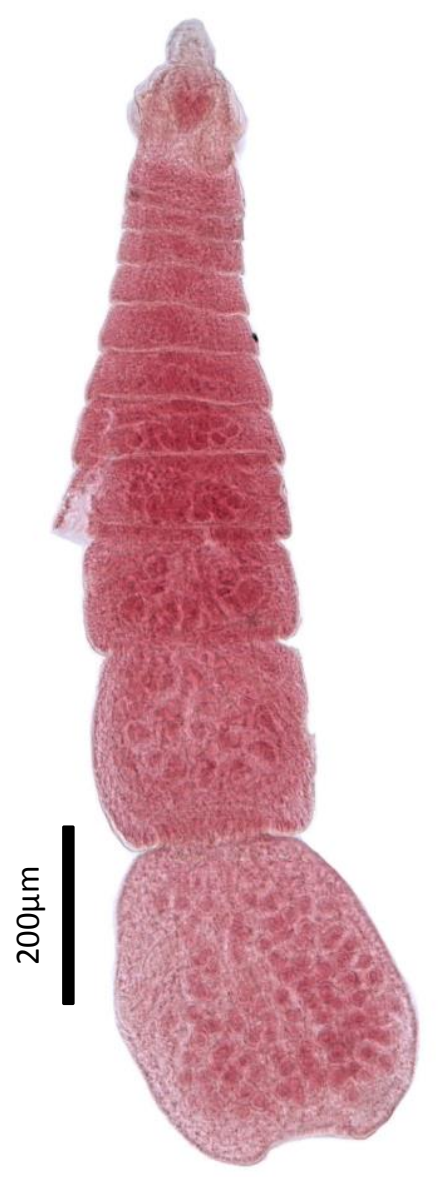

ANEXO D (continuação)

Figura 79. Dilepididae (D20). Espécime completo. Parasita de Willisornis poecilinotis griseiventris (Porto Velho, RO).

Figura 80. Dilepididae (D21). Espécime completo. Parasita de Willisornis poecilinotis griseiventris (Porto Velho, RO). 
ANEXO D (continuação)

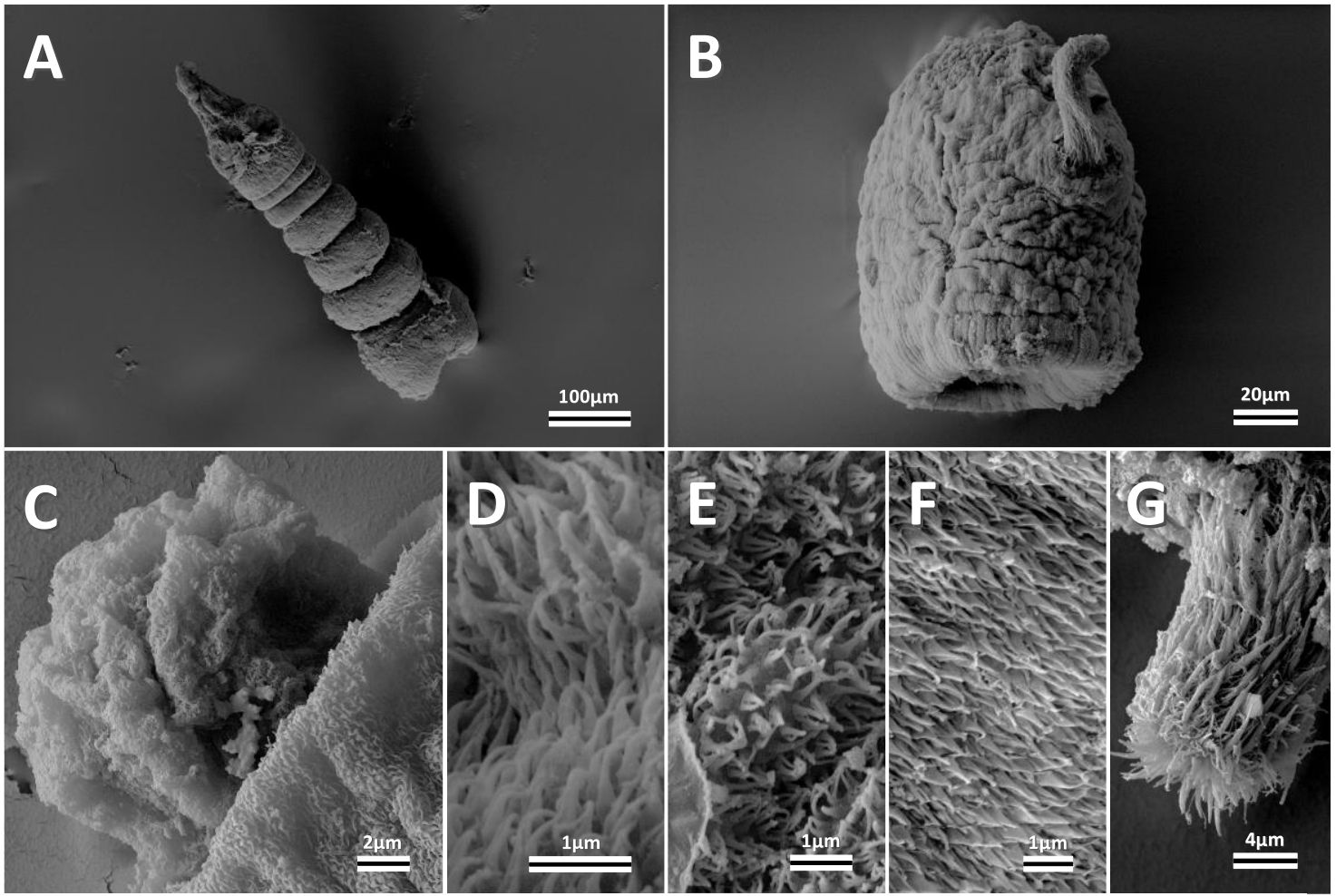

Figura 81. Dilepididae (D03). Microscopia eletrônica de varredura. A: Espécime completo. B: Proglótide terminal com cirro evertido. C: Rostelo parcialmente evertido e região apical. D: Região periférica do botrídeo. E: Região central do botrídeo. F: Superfície da proglótide após região de crescimento. G: Cirro.

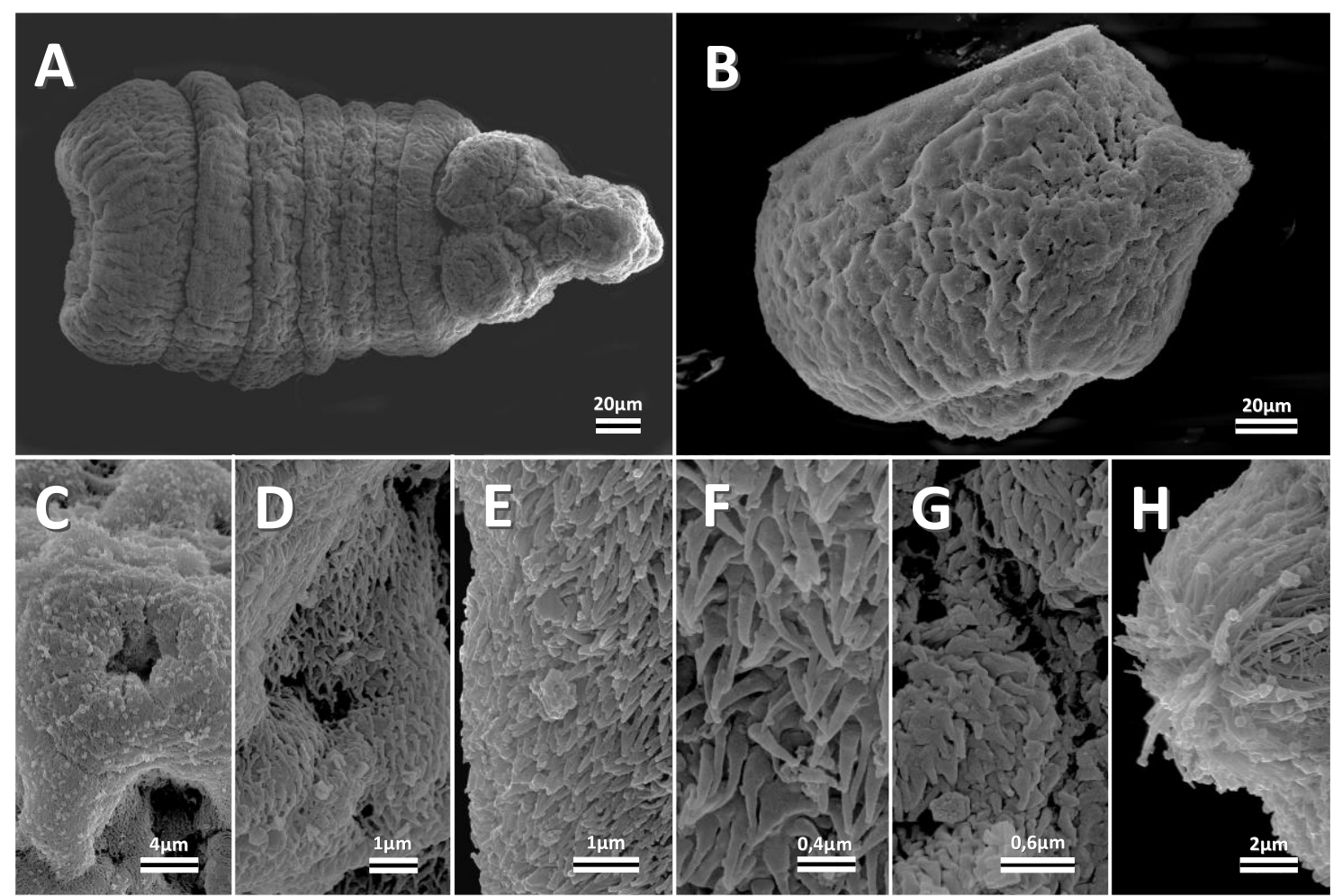

Figura 82. Dilepididae (D09). Microscopia eletrônica de varredura. A: Espécime completo. B: Proglótide terminal com cirro evertido. C: Região apical. D: Região apical. E: Região periférica do botrídeo. F: Região central do botrídeo. G: Superfície da proglótide. H: Cirro. 
ANEXO D (continuação)

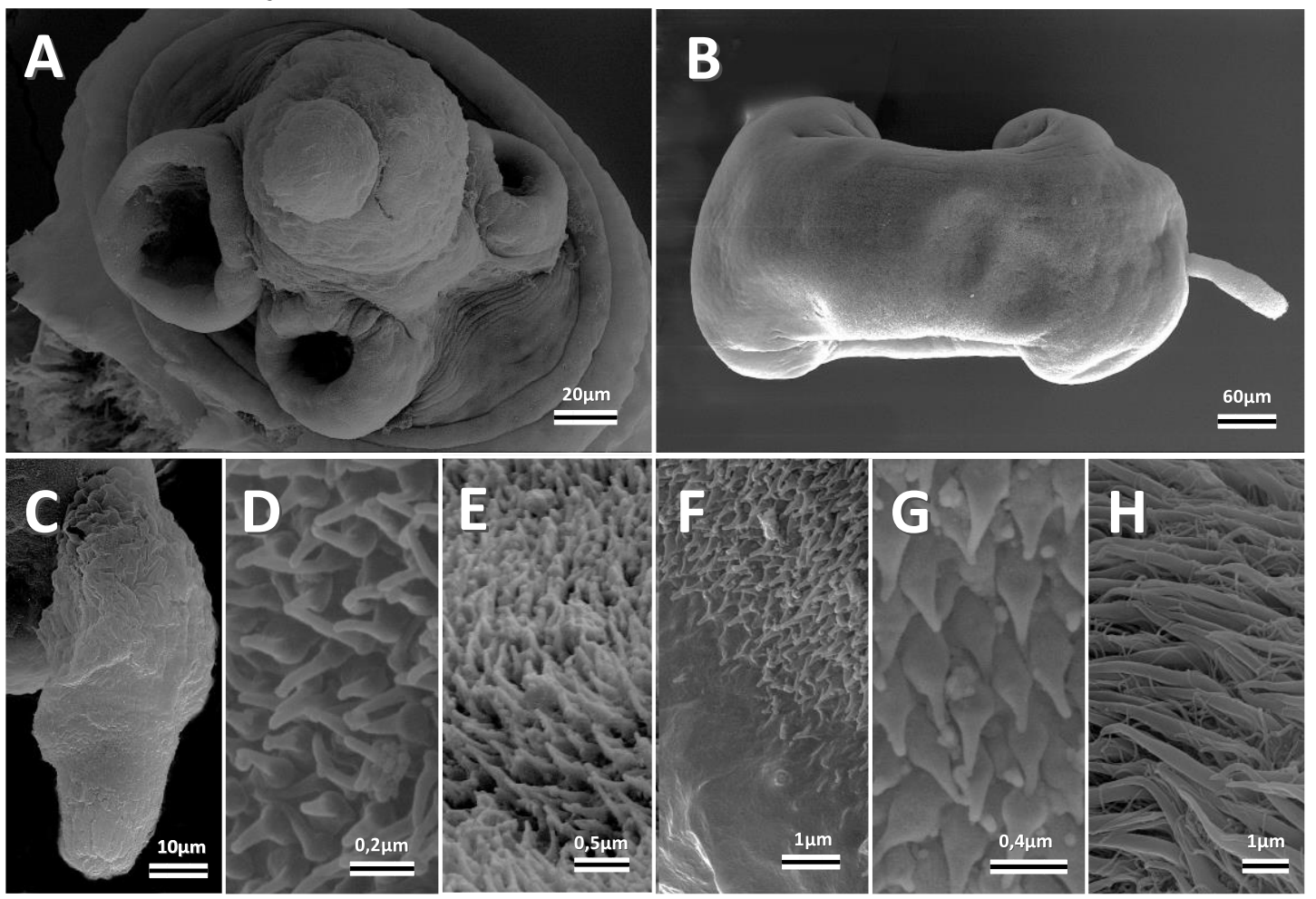

Figura 83. Dilepididae (D11). Microscopia eletrônica de varredura. A: Escólex B: Proglótide com cirro evertido. C: Região apical. D: Região periférica do botrídeo. E: Região entre botrídeos. F: Região de crescimento. G: Superfície da proglótide. H: Superfície do cirro.

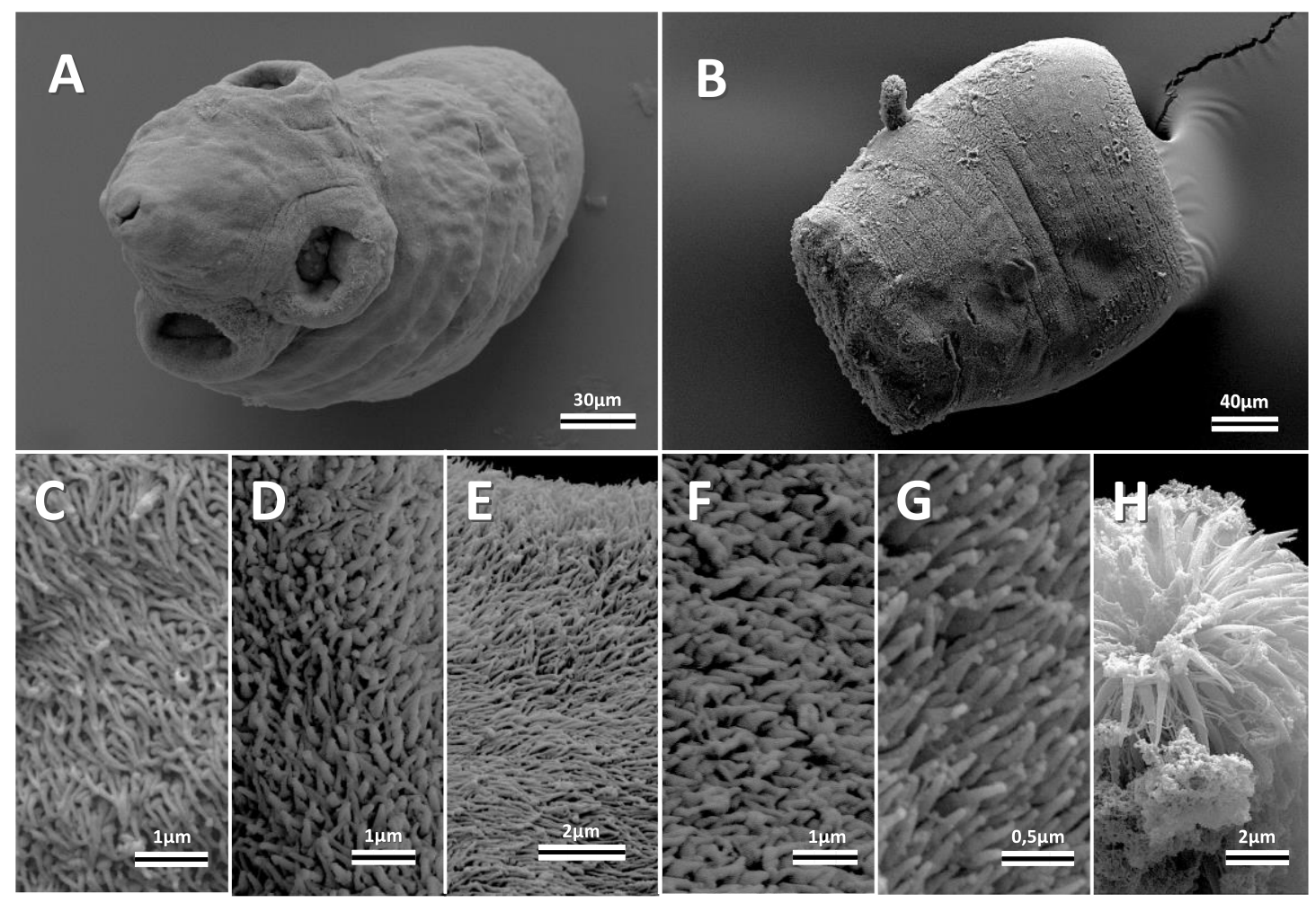

Figura 84. Dilepididae (D17). Microscopia eletrônica de varredura. A: Escólex. B: Proglótide destacada com cirro evertido. C: Região apical. D: Região periférica do botrídeo. E: Região central do botrídeo. F: Região de crescimento. G:Superfície da proglótide. H: Região distal do cirro. 
ANEXO D (continuação)

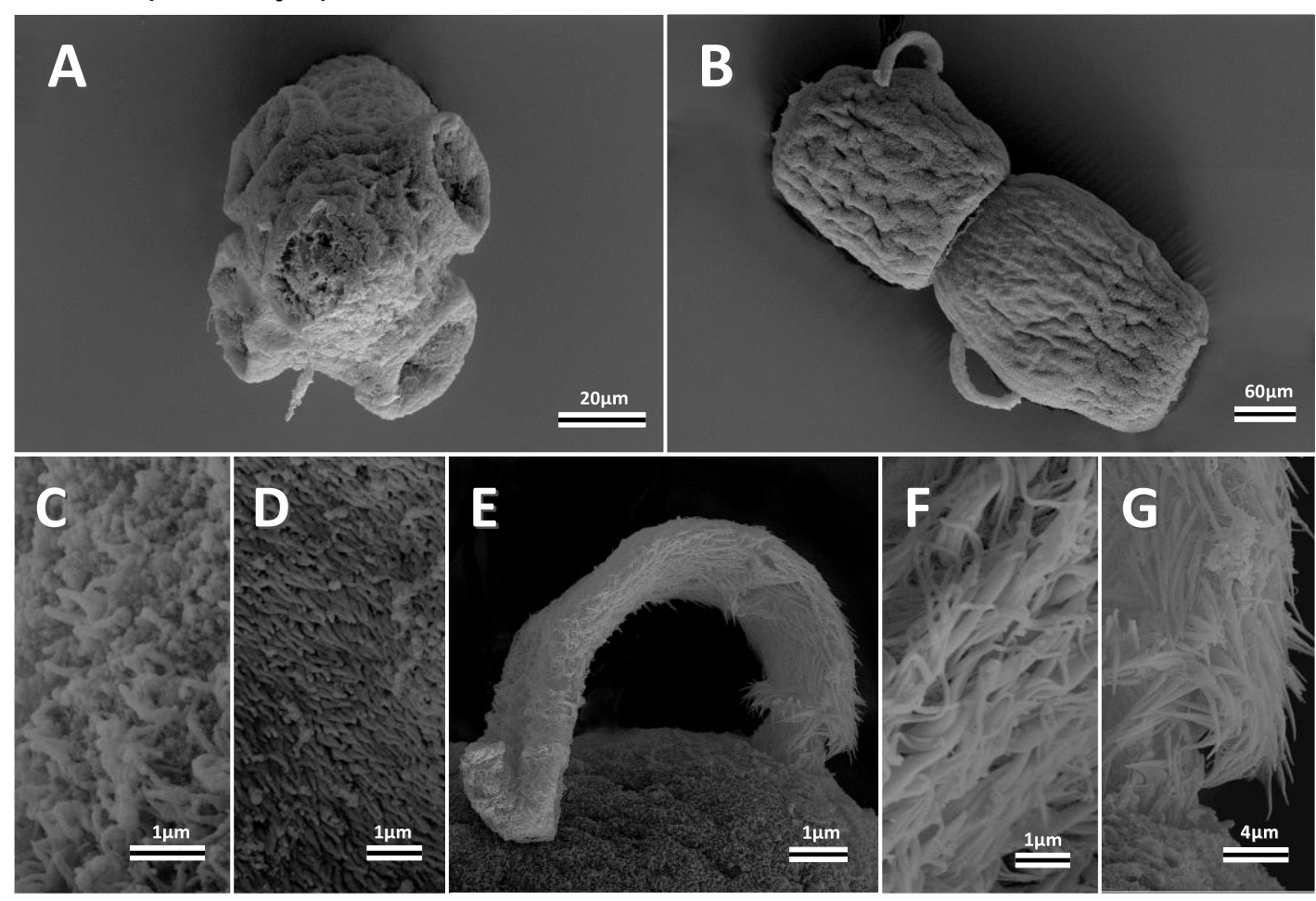

Figura 85. Dilepididae (D20). Microscopia eletrônica de varredura. A: Escólex. B: Proglótides terminais com cirro evertido. C: Região periférica do botrídeo. D: Superfície da proglótide. E: Cirro. F: Região distal do cirro. G: Região proximal do cirro. 


\begin{tabular}{|c|c|c|c|c|c|c|c|c|c|}
\hline & \multirow{2}{*}{\multicolumn{3}{|c|}{$\begin{array}{l}\text { Região apical } \\
\text { Espinitríquias gladiadas }\end{array}$}} & \multirow{2}{*}{\multicolumn{3}{|c|}{$\begin{array}{l}\text { Botrídeo - região periférica } \\
\text { Espinitríquias gladiadas }\end{array}$}} & \multirow{2}{*}{\multicolumn{3}{|c|}{$\begin{array}{l}\text { Botrídeo - região intermediária entre botrídeos } \\
\text { Espinitríquias gladiadas }\end{array}$}} \\
\hline & & & & & & & & & \\
\hline & Comprimento & Largura & Densidade & Comprimento & Largura & Densidade & Comprimento & Largura & Densidade \\
\hline \multirow[t]{2}{*}{ H. peruviana } & $0,53-0,60$ & $0,19-0,22$ & $7-11$ & $0,64-0,72$ & $0,23-0,29$ & $10-13$ & indisponível & indisponível & indisponível \\
\hline & $(0,56 \pm 0,04, n=5)$ & $(0,21 \pm 0,01, n=5)$ & $(8,8 \pm 1,48, n=5)$ & $(0,67 \pm 0,04, n=4)$ & $(0,25 \pm 0,03, n=4)$ & $(10,8 \pm 1,64, n=5)$ & & & \\
\hline \multirow[t]{2}{*}{ O. salvini } & $0,50-0,61$ & $0,18-0,21$ & $9-12$ & indisponível & indisponível & $14-18$ & indisponível & indisponível & indisponível \\
\hline & $(0,55 \pm 0,05, n=4)$ & $(0,2 \pm 0,01, n=4)$ & $(10,2 \pm 1,3, n=5)$ & & & $(16,2 \pm 1,64, n=5)$ & & & \\
\hline \multirow[t]{2}{*}{ P. nigromaculatc } & aindisponível & indisponível & indisponível & $0,57-0,64$ & $0,17-0,18$ & $25-34$ & $0,46-0,50$ & $0,18-0,19$ & $13-21$ \\
\hline & & & & $(0,61 \pm 0,05, n=2)$ & $(0,18 \pm 0,01, n=2)$ & $(28,3 \pm 4,93, n=3)$ & $(0,48 \pm 0,03, n=2)$ & $(0,19 \pm 0,01, n=2)$ & $(17 \pm 5,66, n=2)$ \\
\hline \multirow[t]{2}{*}{ S.hemimelaena } & $0,45-0,56$ & $0,19-0,23$ & $9-12$ & $0,44-0,51$ & $0,16-0,20$ & $6-9$ & indisponível & indisponível & indisponível \\
\hline & $(0,51 \pm 0,06, n=3)$ & $(0,21 \pm 0,02, n=3)$ & $(10,5 \pm 1,29, n=4)$ & $(0,48 \pm 0,03, n=5)$ & $(0,17 \pm 0,02, n=5)$ & $(7,8 \pm 1,3, n=5)$ & & & \\
\hline \multirow[t]{2}{*}{ W. poecilinotus } & indisponível & indisponível & indisponível & $0,57-0,60$ & $0,19-0,24$ & $6-7$ & indisponível & indisponível & indisponível \\
\hline & & & & $(0,59 \pm 0,02, n=2)$ & $(0,22 \pm 0,04, n=2)$ & $(6,5 \pm 0,71, n=2)$ & & & \\
\hline
\end{tabular}

\begin{tabular}{|c|c|c|c|c|c|c|c|c|c|}
\hline & \multicolumn{3}{|c|}{$\begin{array}{l}\text { Botrídeo - região central } \\
\text { Espinitríquias gladiadas }\end{array}$} & \multicolumn{3}{|c|}{$\begin{array}{l}\text { Botrídeo - região central } \\
\text { Espinitríquias bifurcadas }\end{array}$} & \multicolumn{3}{|c|}{$\begin{array}{l}\text { Botrídeo - região central } \\
\text { Espinitríquias colunares }\end{array}$} \\
\hline & Comprimento & Largura & Densidade & Comprimento & Largura & Densidade & Comprimento & Largura & Densidade \\
\hline \multirow[t]{2}{*}{ H. peruviana } & 0,82 & 0,2 & $1-2$ & 0,52 & $0,27-0,32$ & $4-5$ & $\mathrm{n} / \mathrm{a}$ & $\mathrm{n} / \mathrm{a}$ & $\mathrm{n} / \mathrm{a}$ \\
\hline & $(n=1)$ & $(n=1)$ & $(1,33 \pm 0,58, n=3)$ & $(n=1)$ & $(0,3 \pm 0,04, n=2)$ & $(4,33 \pm 0,58, n=3)$ & & & \\
\hline \multirow[t]{2}{*}{ O. salvini } & $0,55-0,58$ & $0,17-0,18$ & $5-8$ & $\mathrm{n} / \mathrm{a}$ & $\mathrm{n} / \mathrm{a}$ & $\mathrm{n} / \mathrm{a}$ & $0,48-0,63$ & 0,09 & 3-5 \\
\hline & $(0,56 \pm 0,01, n=4$ & $(0,18 \pm 0,01, n=4)$ & $(6,5 \pm 1,29, n=4)$ & & & & $(0,56 \pm 0,11, n=2)$ & $(0,09, n=2)$ & $(4,25 \pm 0,96, n=4)$ \\
\hline \multicolumn{2}{|c|}{ P. nigromaculata indisponível } & indisponível & indisponível & $\mathrm{n} / \mathrm{a}$ & $\mathrm{n} / \mathrm{a}$ & $\mathrm{n} / \mathrm{a}$ & $\mathrm{n} / \mathrm{a}$ & $\mathrm{n} / \mathrm{a}$ & $\mathrm{n} / \mathrm{a}$ \\
\hline \multirow{2}{*}{ S.hemimelaena } & 0,63 & 0,15 & $14-16$ & $\mathrm{n} / \mathrm{a}$ & $\mathrm{n} / \mathrm{a}$ & $\mathrm{n} / \mathrm{a}$ & $\mathrm{n} / \mathrm{a}$ & $\mathrm{n} / \mathrm{a}$ & $\mathrm{n} / \mathrm{a}$ \\
\hline & $(n=1)$ & $(n=1)$ & $(15,4 \pm 0,89, n=5)$ & & & & & & \\
\hline W. poecilinotus & indisponível & indisponível & indisponível & $\mathrm{n} / \mathrm{a}$ & $\mathrm{n} / \mathrm{a}$ & $\mathrm{n} / \mathrm{a}$ & $\mathrm{n} / \mathrm{a}$ & $\mathrm{n} / \mathrm{a}$ & $\mathrm{n} / \mathrm{a}$ \\
\hline
\end{tabular}

n/a: não aplicável 


\begin{tabular}{|c|c|c|c|c|c|c|c|c|c|}
\hline & \multicolumn{2}{|c|}{$\begin{array}{l}\text { Região de crescimento } \\
\text { Espinitríquias gladiadas }\end{array}$} & \multirow[b]{2}{*}{ Densidade } & \multicolumn{3}{|c|}{$\begin{array}{l}\text { Superfície da proglótide } \\
\text { Espinitríquias gladiadas }\end{array}$} & \multicolumn{3}{|c|}{$\begin{array}{l}\text { Cirro distal } \\
\text { Espinitríquias coniformes }\end{array}$} \\
\hline & Comprimento & Largura & & Comprimento & Largura & Densidade & Comprimento & Largura & Densidade \\
\hline \multirow[t]{2}{*}{ H. peruviana } & indisponível & indisponível & indisponível & $0,80-0,84$ & $0,32-0,40$ & $9-11$ & $1,75-1,85$ & $0,16-0,17$ & $2-3$ \\
\hline & & & & $(0,82 \pm 0,02, n=4)$ & $(0,37 \pm 0,03, n=4)$ & $(9,6 \pm 0,89, n=5)$ & $(1,8 \pm 0,07, n=2)$ & $(0,17 \pm 0,01, n=2)$ & $(2,4 \pm 0,55, n=5)$ \\
\hline \multirow[t]{2}{*}{ O. salvini } & indisponível & indisponível & indisponível & indisponível & indisponível & $18-22$ & indisponível & indisponível & indisponível \\
\hline & & & & & & $(20,5 \pm 2,08, n=3)$ & & & \\
\hline \multirow[t]{2}{*}{ P. nigromaculata } & indisponível & indisponível & indisponível & $0,58-0,63$ & $0,21-0,29$ & $9-12$ & indisponível & 0,39 & indisponível \\
\hline & & & & $(0,60 \pm 0,02, n=5)$ & $(0,24 \pm 0,03, n=5)$ & $10 \pm 1,22, n=5)$ & & $(n=1)$ & \\
\hline \multirow[t]{2}{*}{ S.hemimelaena } & indisponível & indisponível & $25-34$ & $0,51-0,54$ & 0,18 & $25-31$ & indisponível & 0,37 & indisponível \\
\hline & & & $(28,3 \pm 4,27, n=4)$ & $(0,53 \pm 0,02, n=2)$ & $(0,18, n=2)$ & $(28,7 \pm 3,21, n=3)$ & & $(n=1)$ & \\
\hline \multirow[t]{2}{*}{ W. poecilinotus } & indisponível & indisponível & indisponível & $0,41-0,48$ & $0,15-0,18$ & $11-14$ & 4,02 & 0,41 & indisponível \\
\hline & & & & $(0,45 \pm 0,04, n=3)$ & $(0,17 \pm 0,02, n=3)$ & $(12,8 \pm 1,1, n=5)$ & $(n=1)$ & $(n=1)$ & \\
\hline
\end{tabular}

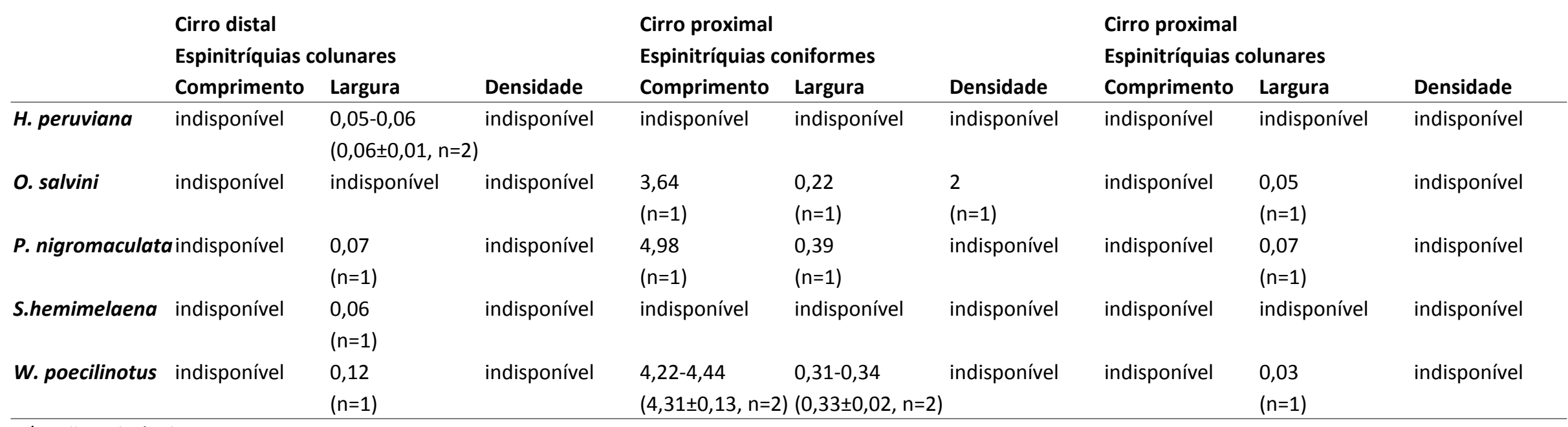

n/a: não aplicável 


\section{Porto Velho $(\mathrm{RO})$}

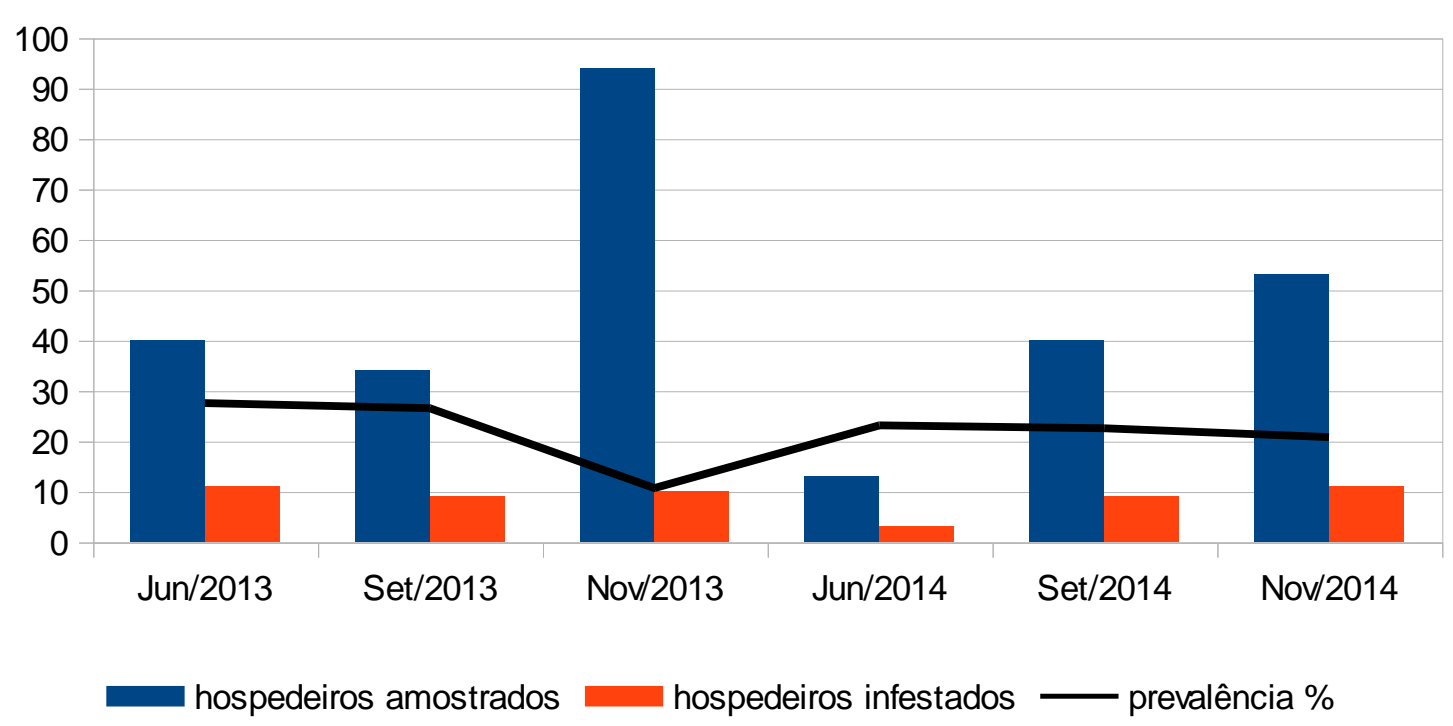

ANEXO F. Gráfico 1. Quantidade de espécimes de tamnofilídeos analisados em busca de cestódeos (hospedeiros analisados) e quantidade de espécimes de tamnofilídeos infestado por cestódeos (hospedeiros infestados), com prevalência média observada em cada amostragem. Região de Porto Velho (RO).

\section{Santana do Araguaia (PA)}

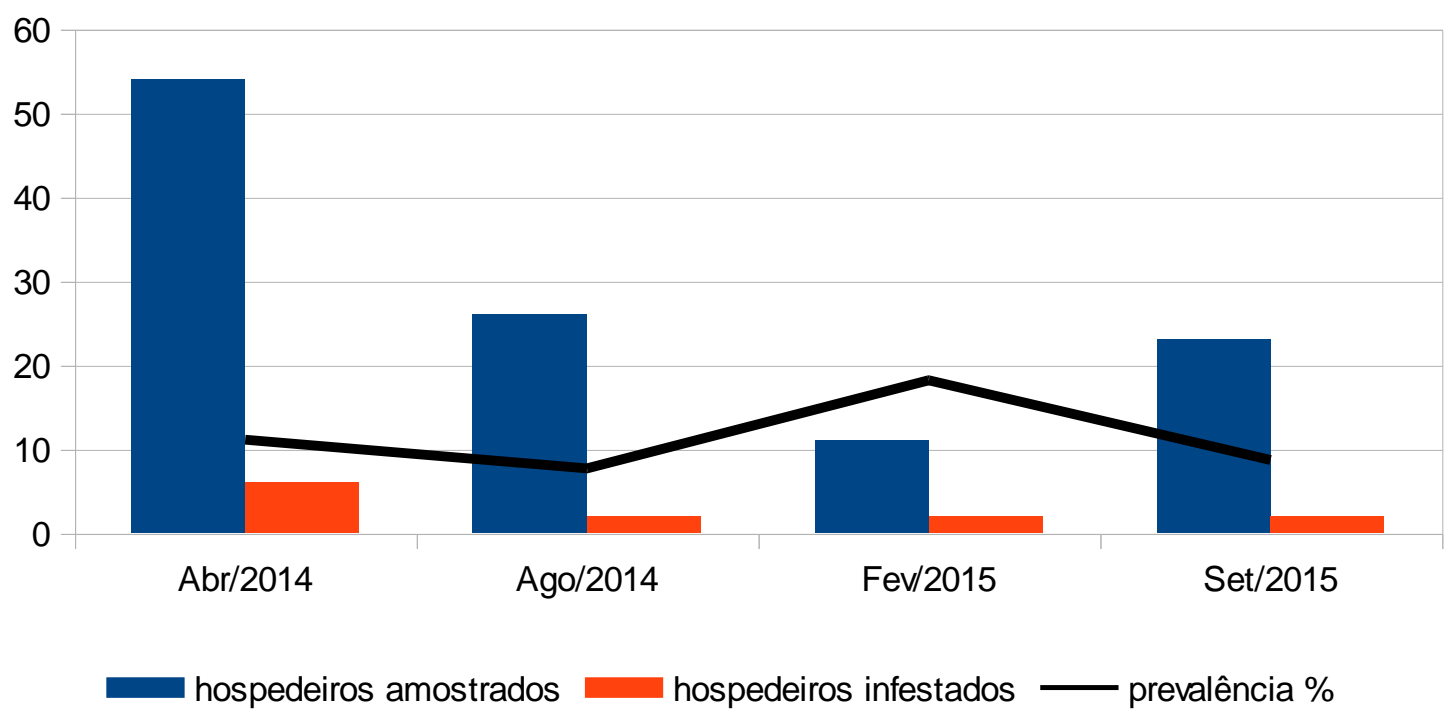

ANEXO F. Gráfico 2. Quantidade de espécimes de tamnofilídeos analisados em busca de cestódeos (hospedeiros analisados) e quantidade de espécimes de tamnofilídeos infestado por cestódeos (hospedeiros infestados), com prevalência média observada em cada amostragem. Região de Santana do Araguaia (PA). 